\title{
Um Processo para Modelagem e Aplicação de Técnicas Computacionais para Deteç̧ão de Fraudes em Transações Eletrônicas
}

Gabriel Preti Santiago

\author{
DisSERTAÇÃO APRESENTADA \\ $\mathrm{AO}$ \\ Instituto de Matemática e Estatística \\ DA \\ Universidade DE SÃo PaUlo \\ PARA \\ OBTENÇÃo DO TÍtulo \\ DE \\ Mestre em CiênCIAS \\ Programa: Ciência da Computação \\ Orientador: Prof. Dr. Roberto Hirata Jr.
}




\section{Um Processo para Modelagem e Aplicação de Técnicas Computacionais para Detecção de Fraudes em Transações Eletrônicas}

Esta versão da dissertação contém as correções e alterações sugeridas pela Comissão Julgadora durante a defesa da versão original do trabalho, realizada em 08/05/2014. Uma cópia da versão original está disponível no

Instituto de Matemática e Estatística da Universidade de São Paulo.

Comissão Julgadora:

- Prof. Dr. Roberto Hirata Jr. (orientador) - IME-USP

- Prof. Dr. Alair Pereira do Lago - IME-USP

- Prof. Dr. Andre Carlos Ponce de Leon Ferreira de Carvalho - ICMC-USP 


\section{Agradecimentos}

Ao meu orientador, Prof. Dr. Roberto Hirata Jr., pela confiança depositada em mim ao me aceitar como orientando, mesmo ciente que eu precisaria dividir meu tempo entre os esforços acadêmicos e meu trabalho. Seus conselhos e orientações, sempre diretos e assertivos, foram fundamentais para o desenvolvimento dessa pesquisa.

Ao Prof. Dr. Adriano Cesar Machado Pereira, que me acompanhou neste trabalho desde o início, e cuja orientação foi fundamental em diversos momentos. Ao Prof. Dr. Alair Pereira do Lago, que me abriu as portas de entrada do IME-USP, e que certamente foi um dos maiores responsáveis pelo início desse trabalho. Ao Rafael Plana Maranzato, que foi quem primeiro me ouviu sobre minha intenção de iniciar o mestrado e teve a iniciativa de me apresentar ao Prof. Dr. Alair Pereira do Lago, o qual gentilmente me aceitou como orientando.

Não poderia deixar de agradecer a Profa. Dra. Tânia Fátima Calvi Tait, com a qual tive a oportunidade de trabalhar em programas de iniciação científica por três anos, durante minha graduação na Universidade Estadual de Maringá. Na época nossas pesquisas eram relacionadas à assuntos bastante distintos em relação aos que me interesso atualmente, mas foi ela uma das maiores responsáveis por despertar em mim o interesse pelo mundo acadêmico. Gostaria também de agradecer postumamente ao Prof. Dr. Sérgio Roberto da Silva, que foi meu primeiro orientador em projetos de iniciação científica, ainda no ano de 2001, quando estava no meu primeiro ano de graduação.

Sou muito grato ao UOL pelo incentivo para a realização desse trabalho, tanto pela compreensão e paciência em todos os momentos em que precisei me ausentar para poder cumprir meus compromissos com a USP, mas principalmente pela disponibilização dos dados e da infra-estrutura que foram absolutamente essenciais para o desenvolvimento dessa pesquisa. Admiro muito o incentivo oferecido pelo UOL, a mim e a vários outros colegas de trabalho, para a participação em trabalhos acadêmicos.

A minha família, que mesmo diante das dificuldades, sempre fez todos os esforços necessários para que eu tivesse a oportunidade de estudar. Tudo o que será apresentado nesse trabalho teve início muitos anos atrás, quando com muito sacrifício minha família me deu todas as condições necessárias para ingresso e conclusão da minha graduação em Ciência da Computação pela Universidade Estadual de Maringá.

Por fim, aos meus amigos e familiares que, em várias ocasiões, tiveram convites negados por eu não conseguir me fazer presente, sempre muito atarefado com minhas obrigações profissionais e acadêmicas. 


\section{Resumo}

Nos últimos anos, tem-se observado um aumento significativo no volume de transações financeiras realizadas pela Internet. Esse crescimento no volume financeiro, associado à fragilidade inerente à ausência de verificações básicas, possíveis somente em transações do mundo físico, tem atraído a atenção de pessoas com o objetivo de obter vantagens financeiras de forma ilícita.

Devido aos prejuízos causados pelas fraudes, surgiram empresas de pagamento online com o objetivo de tornar as transações de compra e venda na Internet mais seguras. Essas empresas atuam como um intermediário das transações e assumem os riscos associados, mostrando-se ser esse um negócio de alto risco. Dado o alto volume de transações com as quais essas empresas precisam lidar, torna-se clara a necessidade de métodos computacionais para detecção de transações fraudulentas, visto que a utilização estrita de verificações manuais é inviável para lidar com tal volume de transações. Essa tarefa de análise e identificação de transações fraudulentas pode ser vista como um problema computacional de classificação, sendo então aplicáveis técnicas de classificação, aprendizado computacional e mineração de dados.

Porém, dada a complexidade do problema, a aplicação de técnicas computacionais só é possível após um profundo entendimento do problema e a definição de uma modelagem eficiente associada a um processo consistente e abrangente, capaz de lidar com todas as etapas necessárias para a análise eficiente de uma transação. Face a isso, o presente trabalho propõe uma abordagem abrangente para tratar o problema da fraude nesse novo mercado de intermediação de pagamentos online, utilizando como base um processo já muito bem estabelecido na indústria. Abordaremos mais especificamente uma das fases desse processo, que se refere justamente a utilização de ferramentas computacionais para a detecção das fraudes, e apresentaremos um sub-processo que envolve a utilização de várias ferramentas para o tratamento do ponto de vista computacional do problema de detecção de fraudes. Para a validação dos resultados da proposta, utilizaremos uma enorme quantidade de dados reais disponibilizados por uma grande empresa do setor de intermediação de pagamentos online que colaborou com nossa pesquisa.

Palavras-chave: cartão de crédito, aprendizado computacional, fraude, mineração de dados, intermediadores de pagamento online. 


\section{Abstract}

In recent years, there has been a significant increase in the volume of electronic transactions in the Web. This growth in trading volume, associated with the risks caused by the absence of basic checks, possible only in transactions of the physical world, has attracted the attention of people with the intention of taking advantage to obtain illicit financial benefits.

Due to the injuries caused by fraud, online payment service companies emerged, with the goal of making Web transactions safer. These companies act as an intermediary between buyers and sellers, assuming all the risks, and so it is clear that it is a high-risk business. Given the high volume of transactions with which these companies must deal, it is clear the need for computational methods for detecting fraudulent transactions, as the strict use of manual checks is infeasible to handle such a volume. The task of analysis and identification of fraudulent transactions can be seen as a classification problem, and so classification, data mining and machine learning techniques can be applied to it.

However, given the complexity of the problem, the application of computational techniques is only possible after a thorough understanding of the problem and the definition of an efficient model, associated with a consistent and comprehensive process which would be able to handle all the steps needed to analyze a transaction in an efficient way. Given this scenario, this work proposes a comprehensive approach to address the problem of fraud in this new business of online payment intermediation, using as basis a process already established in the industry. We will discuss more specifically one of the phases of this process, which refers to the use of computational tools to detect frauds, and we will present a sub-process using several tools to deal with the problem from a computational point of view. To validate our results, we will use a huge amount of real data provided by an important company of the online payment industry, which cooperated with our research.

Keywords: credit card, machine learning, fraud, data mining, online payment services. 


\section{Sumário}

Lista de Figuras $\quad$ xiii

Lista de Tabelas $\quad$ xix

1 Introdução $\quad 1$

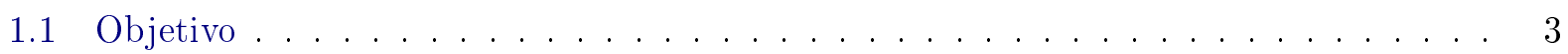

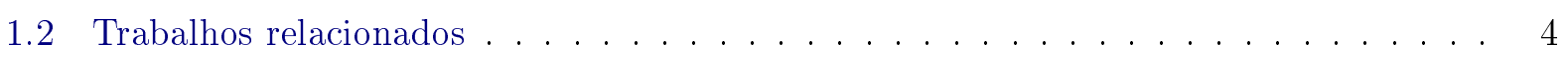

1.3 Organização da dissertação . . . . . . . . . . . . . . . . 5

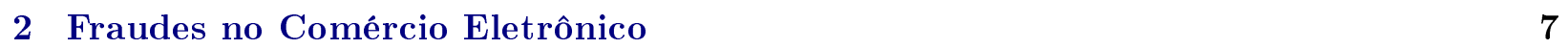

2.1 Funcionamento do Cartão de Crédito . . . . . . . . . . . . . . . . 7

2.2 Fraudes em Transações com Cartão de Crédito . . . . . . . . . . . . . . . 8

2.3 Impacto das Fraudes de Cartão de Crédito . . . . . . . . . . . . . . . . . 9

2.3.1 Impacto das Fraudes para o Titular do Cartão . . . . . . . . . . . . . . 9

2.3.2 Impacto das Fraudes para os Comerciantes . . . . . . . . . . . . . . 9

2.3.3 Impacto das Fraudes nas Instituições Financeiras (Emissor/Adquirente) $\ldots . .9$

2.4 Intermediadores de Pagamentos Online . . . . . . . . . . . . . . . . . . 10

2.5 O processo de Gerenciamento de Fraude . . . . . . . . . . . . . . . . . . . . 12

2.5.1 Triagem Automatizada . . . . . . . . . . . . . . . . . 13

2.5 .2 Revisão Manual . . . . . . . . . . . . . . . . . . . . . . . . . . . . . . 14

2.5.3 Situação do Pedido (Aceitar/Rejeitar) . . . . . . . . . . . . . . . 14

2.5.4 Gerenciamento de Disputas . . . . . . . . . . . . . . . . . . 14

2.6 Considerações Finais . . . . . . . . . . . . . . . . . . . . . . . 15

3 Técnicas Computacionais para a Detecção de Fraude com Cartão de Crédito 17

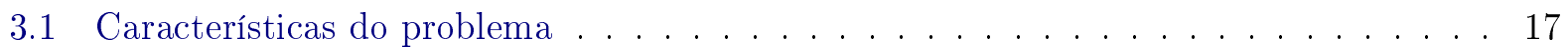

3.1.1 Desbalanceamento . . . . . . . . . . . . . . . . . . 17

3.1 .2 Ruído . . . . . . . . . . . . . . . . . . . . . 18

3.1.3 Evolução das Fraudes . . . . . . . . . . . . . . . . . . . . . . . . 18

3.2 Tipos de Técnicas Computacionais Aplicados ao Problema de Detecção de Fraude . . 19

3.2 .1 Aprendizado Supervisionado . . . . . . . . . . . . . . . . . . . . 19

3.2 .2 Aprendizado Semi-Supervisionado . . . . . . . . . . . . . . . . 20

3.2.3 Classificadores Híbridos ． . . . . . . . . . . . . . . . . . . . . 20

3.2 .4 Métricas para Avaliação de Classificadores . . . . . . . . . . . . . . . . . . 21

3.3 Support Vector Machines . . . . . . . . . . . . . . . . . . . . . . . 21 
3.4 Considerações Finais . . . . . . . . . . . . . . . . . . . . 23

4 Descrição e Análises Preliminares dos Dados $\quad 25$

4.1 Identificação da Fraude . . . . . . . . . . . . . . . . . . . . . . 25

4.2 Preparação do Conjunto de Dados . . . . . . . . . . . . . . . . . . 26

4.3 Descrição dos atributos . . . . . . . . . . . . . . . . . . . 27

4.4 Avaliando a Recorrência do Uso do Sistema . . . . . . . . . . . . . . . . . . 28

4.5 Considerações Finais . . . . . . . . . . . . . . . . . . . . . . . . 32

5 Uma Abordagem para a Modelagem do Problema Baseada nas Entidades Envolvidas na Transação $\quad 33$

5.1 Processo para a Deteç̧ão Automática de Fraudes . . . . . . . . . . . . . . . . . . 33

5.1 .1 Prevenção à Fraude . . . . . . . . . . . . . . . . . . . . . . . 33

5.1 .2 Validação da Transação com o Adquirente . . . . . . . . . . . . . . . . . . . 34

5.1.3 Consultas a Sistemas Externos . . . . . . . . . . . . . . . . . . . 34

5.1 .4 Regras de Alta Precedência . . . . . . . . . . . . . . . . . . 34

5.1 .5 Modelagem do Problema . . . . . . . . . . . . . . . . . . . 35

5.1 .6 Comparação com Fraudes Anteriores . . . . . . . . . . . . . . . . 36

5.1 .7 Comparação com Transações Legítimas Anteriores . . . . . . . . . . . . . . 37

5.2 Análise de uma Transação . . . . . . . . . . . . . . . . . . . . . . 37

5.2.1 Transações Legítimas, Transações Fraudulentas e Transações Não efetivadas . 38

5.2 .2 Histórico da Entidade . . . . . . . . . . . . . . . . . . . . 38

$5.2 .3 \quad$ Score do Atributo . . . . . . . . . . . . . . . . . . . . 38

5.2.4 Comportamento Diferenciado da Entidade Vendedor . . . . . . . . . . . . 39

5.2 .5 Scores da Transação . . . . . . . . . . . . . . . . . . . . . . . 39

5.2 .6 Peso das entidades . . . . . . . . . . . . . . . . . . . . . 39

5.3 Classificação da Transação . . . . . . . . . . . . . . . . . . . . . . . . . . . . 39

5.3 .1 Peso geral da transação . . . . . . . . . . . . . . . . . . . . 40

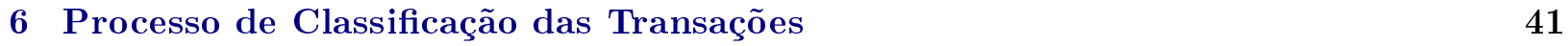

6.1 Separação das Transações por Peso Geral . . . . . . . . . . . . . . . . . . . . 41

6.2 Execução da Classificação . . . . . . . . . . . . . . . . . . . . . . . . . 44

6.2.1 Tratando a Demora no Reconhecimento do Chargeback . . . . . . . . . . . 45

6.3 Tratando o Desbalanceamento Entre as Classes . . . . . . . . . . . . . . . . . 45

6.4 Eficiência Econômica . . . . . . . . . . . . . . . . . . . . . . . . . . . . 49

6.5 Considerações Finais . . . . . . . . . . . . . . . . . . . 58

7 Resultados da Classificação para Cada Subconjunto de Transação $\quad 59$

7.1 Resultados da Classificação das Transações . . . . . . . . . . . . . . . . . . . 59

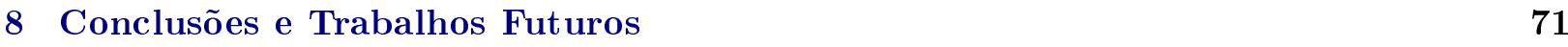

A Resultados da Classificação para Todos os Níveis de Balanceamento $\quad 73$

A.1 Balanceamento $1 x 1 \ldots \ldots \ldots \ldots \ldots \ldots \ldots$

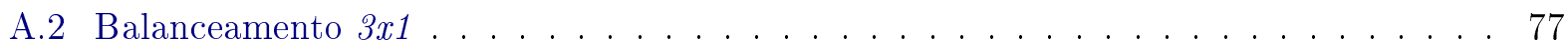


A.3 Balanceamento $4 x 1 \ldots \ldots \ldots \ldots \ldots \ldots \ldots \ldots \ldots$

A.4 Balanceamento $5 x 1 \ldots \ldots \ldots \ldots \ldots \ldots \ldots \ldots$

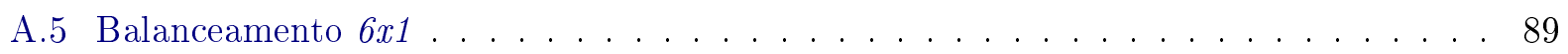

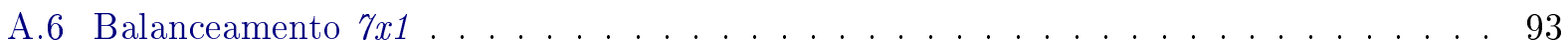

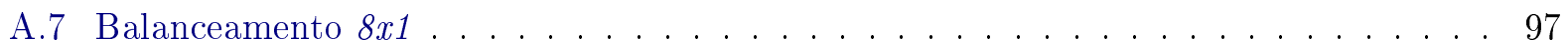

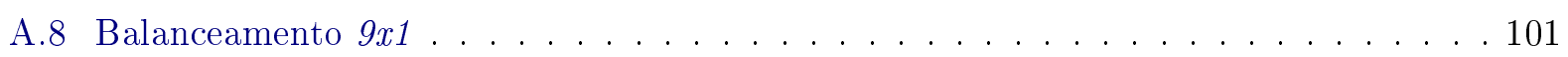

$\begin{array}{ll}\text { Referências Bibliográficas } & 107\end{array}$ 


\section{Lista de Figuras}

1.1 Crescimento anual do e-commerce no Brasil. Fonte: http://www.e-commerce.org.br/

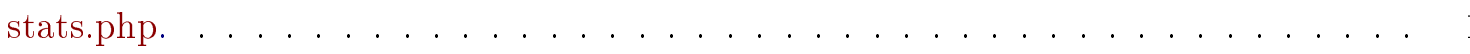

1.2 Evolução da quantidade de artigos publicados relacionados a fraudes em cartão de

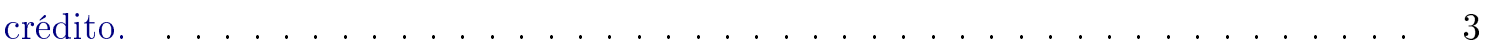

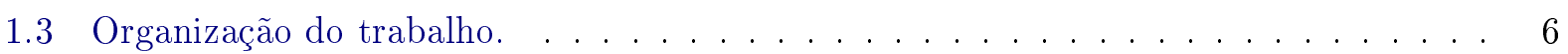

2.1 Sistema de autorização de uma transação. Fonte: Gadi et al. (2010) . . . . . . . . 8

2.2 Página inicial do intermediador de pagamentos online PagSeguro. . . . . . . . . . 10

2.3 Página para informação dos dados bancários para pagamento no intermediador de pagamentos online PagSeguro. . . . . . . . . . . . . . . . 11

2.4 Página para o gerenciamento das transações do comprador no intermediador de pagamentos online PagSeguro. . . . . . . . . . . . . . . . . . . . 12

2.5 Processo de gestão de fraude. Adaptado de CyberSource (2011) . . . . . . . . . . . . 13

3.1 Hiperplano de separação ótimo com margem máxima. Fonte: http://docs.opencv.org/ 22

3.2 Mapeamento das características para espaços com dimensões maiores; (a) Conjunto de dados não-linear; (b) Fronteira não-linear no espaço original; (c) Fronteira linear no novo espaço. Fonte: Lorena e Carvalho (2007) . . . . . . . . . . . . . . 22

4.1 Risco por nível de recorrência da utilização do cartão de crédito. . . . . . . . . . . 29

4.2 Risco por nível de recorrência do comprador. . . . . . . . . . . . . . . . 30

4.3 Risco por nível de recorrência do portador. . . . . . . . . . . . . . . . 30

4.4 Risco por nível de recorrência do vendedor. . . . . . . . . . . . . . . . . 31

4.5 Comparação do nível médio de recorrência de cada entidade. . . . . . . . . . . . . . . 32

5.1 Visão do relacionamento entre as entidades e a transação. . . . . . . . . . . . . . 35

5.2 Visão do relacionamento transação, entidades e histórico. . . . . . . . . . . . . 36

5.3 Visão geral do processo de detecção e prevenção à fraudes. . . . . . . . . . . . . . 37

5.4 Visão do período considerado para análise do histórico das entidades da transação. . 38

5.5 Visão do processo completo de cálculo de scores e classificação. . . . . . . . . . . . 40

6.1 Comparativo da quantidade de transações por mês para cada um dos subconjuntos de transações. . . . . . . . . . . . . . . . . . . . . . . 4 42

6.2 Percentual de chargebacks por mês para cada um dos subconjuntos de transações. . . 43

6.3 Distribuição dos chargebacks entre os subconjuntos de transações. . . . . . . . . . . . . 44 
6.4 Percentual de chargebacks detectados por mês para cada nível de balanceamento da amostra de treinamento. . . . . . . . . . . . . . . . . . . . . . . 46

6.5 Percentual de falsos alarmes por mês para cada nível de balanceamento da amostra de treinamento. . . . . . . . . . . . . . . . . . . . . . . . . 48

6.6 Eficiência econômica para os diferentes níveis de balanceamento artificial da amostra de treinamento. . . . . . . . . . . . . . . . . . . . . . . . . 51

6.7 Eficiência econômica considerando somente os melhores níveis de balanceamento. $\quad$. . 52

6.8 Eficiência econômica considerando que toda transação não aprovada pela empresa é fraude. . . . . . . . . . . . . . . . . . . . . . . . . 53

6.9 Eficiência econômica somente para os melhores níveis de balanceamento e considerando que toda transação não aprovada pela empresa é fraude. . . . . . . . . . . . . 54

6.10 Eficiência econômica considerando que toda transação não aprovada pela empresa é legítima. . . . . . . . . . . . . . . . . . . . . . . . . 55

6.11 Eficiência econômica somente para os melhores níveis de balanceamento e considerando que toda transação não aprovada pela empresa é legítima. . . . . . . . . . . 56

6.12 Eficiência econômica considerando uma estimativa da taxa de transações não aprovadas que realmente são fraudes. . . . . . . . . . . . . . . . . . . . . 57

7.1 Taxa de detecção de chargebacks por mês para cada subconjunto utilizando um balanceamento 2x1 na amostra de treinamento do classificador. . . . . . . . . . . . . . 60

7.2 Percentual de chargebacks detectados por mês para cada subconjunto utilizando um balanceamento $10 x 1$ na amostra de treinamento do classificador. . . . . . . . . . . 61

7.3 Taxa de detecção de chargebacks por mês para cada subconjunto utilizando um balanceamento 2x1 na amostra de treinamento do classificador. Os resultados para cada subconjunto são incrementais para que se perceba a evolução dos resultados em relação ao peso geral da transação. . . . . . . . . . . . . . . . . . . . . . . . .

7.4 Taxa de detecção de chargebacks por mês para cada subconjunto utilizando um balanceamento $10 x 1$ na amostra de treinamento do classificador. Os resultados para cada subconjunto são incrementais para que se perceba a evolução dos resultados em relação ao peso geral da transação. . . . . . . . . . . . . . . . . . . . . . . . . . .

7.5 Taxa de transações legítimas classificadas como fraude para cada subconjunto utilizando balanceamento $2 x 1$ na amostra de treinamento do classificador.

7.6 Taxa de transações legítimas classificadas como fraude para cada subconjunto utilizando balanceamento $10 x 1$ na amostra de treinamento do classificador.

7.7 Taxa de transações legítimas classificadas como fraude para cada subconjunto utilizando balanceamento $2 x 1$ na amostra de treinamento do classificador. Os resultados para cada subconjunto são incrementais para que se perceba a evolução dos resultados em relação ao peso geral da transação. . . . . . . . . . . . . . . . . . . . . . . . .

7.8 Taxa de transações legítimas classificadas como fraude para cada subconjunto utilizando balanceamento $10 x 1$ na amostra de treinamento do classificador. Os resultados para cada subconjunto são incrementais para que se perceba a evolução dos resultados em relação ao peso geral da transação. . . . . . . . . . . . . . . . . . . . . 
7.9 Percentual de transações não aprovadas pela empresa classificadas como fraude pelo classificador, utilizando balanceamento $2 x 1$ na amostra de treino. Os resultados para cada subconjunto são incrementais para que se perceba a evolução dos resultados em relação ao peso geral da transação. . . . . . . . . . . . . . . . . . . 69

7.10 Percentual de transações não aprovadas pela empresa classificadas como fraude pelo classificador, utilizando balanceamento $10 x 1$ na amostra de treino. Os resultados para cada subconjunto são incrementais para que se perceba a evolução dos resultados em relação ao peso geral da transação. . . . . . . . . . . . . . . . . . . . . . 70

A.1 Taxa de detecção de chargebacks por mês para cada subconjunto utilizando um balanceamento $1 x 1$ na amostra de treinamento do classificador. . . . . . . . . . . 74

A.2 Taxa de detecção de chargebacks por mês para cada subconjunto utilizando um balanceamento $1 x 1$ na amostra de treinamento do classificador. Os resultados para cada subconjunto são incrementais para que se perceba a evolução dos resultados em relação ao peso geral da transação. . . . . . . . . . . . . . . . . . . 75

A.3 Taxa de transações legítimas classificadas como fraude para cada subconjunto utilizando balanceamento $1 x 1$ na amostra de treinamento do classificador. . . . . . . . 76

A.4 Taxa de transações legítimas classificadas como fraude para cada subconjunto utilizando balanceamento $1 x 1$ na amostra de treinamento do classificador. Os resultados para cada subconjunto são incrementais para que se perceba a evolução dos resultados em relação ao peso geral da transação. . . . . . . . . . . . . . . . . . 77

A.5 Taxa de detecção de chargebacks por mês para cada subconjunto utilizando um balanceamento $3 x 1$ na amostra de treinamento do classificador. . . . . . . . . 78

A.6 Taxa de detecção de chargebacks por mês para cada subconjunto utilizando um balanceamento $3 x 1$ na amostra de treinamento do classificador. Os resultados para cada subconjunto são incrementais para que se perceba a evolução dos resultados em relação ao peso geral da transação. . . . . . . . . . . . . . . . . . . . . . 79

A.7 Taxa de transações legítimas classificadas como fraude para cada subconjunto utilizando balanceamento $3 x 1$ na amostra de treinamento do classificador. . . . . . . . . 80

A.8 Taxa de transações legítimas classificadas como fraude para cada subconjunto utilizando balanceamento $3 x 1$ na amostra de treinamento do classificador. Os resultados para cada subconjunto são incrementais para que se perceba a evolução dos resultados em relação ao peso geral da transação. . . . . . . . . . . . . . . . . 81

A.9 Taxa de deteç̧ão de chargebacks por mês para cada subconjunto utilizando um balanceamento $4 x 1$ na amostra de treinamento do classificador. . . . . . . . . . . 82

A.10 Taxa de detecção de chargebacks por mês para cada subconjunto utilizando um balanceamento $4 x 1$ na amostra de treinamento do classificador. Os resultados para cada subconjunto são incrementais para que se perceba a evolução dos resultados em relação ao peso geral da transação. . . . . . . . . . . . . . . . . 83

A.11 Taxa de transações legítimas classificadas como fraude para cada subconjunto utilizando balanceamento $4 x 1$ na amostra de treinamento do classificador. . . . . . . . 8 
A.12 Taxa de transações legítimas classificadas como fraude para cada subconjunto utilizando balanceamento $4 x 1$ na amostra de treinamento do classificador. Os resultados para cada subconjunto são incrementais para que se perceba a evolução dos resultados em relação ao peso geral da transação. . . . . . . . . . . . . . . . . . . 85

A.13 Taxa de detecção de chargebacks por mês para cada subconjunto utilizando um balanceamento $5 x 1$ na amostra de treinamento do classificador. . . . . . . . . . . 86

A.14 Taxa de detecção de chargebacks por mês para cada subconjunto utilizando um balanceamento $5 x 1$ na amostra de treinamento do classificador. Os resultados para cada subconjunto são incrementais para que se perceba a evolução dos resultados em relação ao peso geral da transação. . . . . . . . . . . . . . . . . . . 87

A.15 Taxa de transações legítimas classificadas como fraude para cada subconjunto utilizando balanceamento $5 x 1$ na amostra de treinamento do classificador. . . . . . . . 88

A.16 Taxa de transações legítimas classificadas como fraude para cada subconjunto utilizando balanceamento $5 x 1$ na amostra de treinamento do classificador. Os resultados para cada subconjunto são incrementais para que se perceba a evolução dos resultados em relação ao peso geral da transação. . . . . . . . . . . . . . . . . . . . .

A.17 Taxa de detecção de chargebacks por mês para cada subconjunto utilizando um balanceamento $6 x 1$ na amostra de treinamento do classificador. . . . . . . . . . . 90

A.18 Taxa de detecção de chargebacks por mês para cada subconjunto utilizando um balanceamento $6 x 1$ na amostra de treinamento do classificador. Os resultados para cada subconjunto são incrementais para que se perceba a evolução dos resultados em relação ao peso geral da transação. . . . . . . . . . . . . . . . . . . . . 91

A.19 Taxa de transações legítimas classificadas como fraude para cada subconjunto utilizando balanceamento $6 x 1$ na amostra de treinamento do classificador. . . . . . . . 92

A.20 Taxa de transações legítimas classificadas como fraude para cada subconjunto utilizando balanceamento $6 x 1$ na amostra de treinamento do classificador. Os resultados para cada subconjunto são incrementais para que se perceba a evolução dos resultados em relação ao peso geral da transação. . . . . . . . . . . . . . . . . . . . . 93

A.21 Taxa de detecção de chargebacks por mês para cada subconjunto utilizando um balanceamento $7 x 1$ na amostra de treinamento do classificador. . . . . . . . . . . 94

A.22 Taxa de detecção de chargebacks por mês para cada subconjunto utilizando um balanceamento $7 x 1$ na amostra de treinamento do classificador. Os resultados para cada subconjunto são incrementais para que se perceba a evolução dos resultados em relação ao peso geral da transação. . . . . . . . . . . . . . . . . . . 95

A.23 Taxa de transações legítimas classificadas como fraude para cada subconjunto utilizando balanceamento $7 x 1$ na amostra de treinamento do classificador. . . . . . . . 96

A.24 Taxa de transações legítimas classificadas como fraude para cada subconjunto utilizando balanceamento $7 x 1$ na amostra de treinamento do classificador. Os resultados para cada subconjunto são incrementais para que se perceba a evolução dos resultados em relação ao peso geral da transação. . . . . . . . . . . . . . . . . . . . 9 97

A.25 Taxa de detecção de chargebacks por mês para cada subconjunto utilizando um balanceamento $8 x 1$ na amostra de treinamento do classificador. . . . . . . . . . . 98 
A.26 Taxa de deteç̧ão de chargebacks por mês para cada subconjunto utilizando um balanceamento $8 x 1$ na amostra de treinamento do classificador. Os resultados para cada subconjunto são incrementais para que se perceba a evolução dos resultados em relação ao peso geral da transação. . . . . . . . . . . . . . . . . . . . . . . 99

A.27 Taxa de transações legítimas classificadas como fraude para cada subconjunto utilizando balanceamento $8 x 1$ na amostra de treinamento do classificador. . . . . . . . 100

A.28 Taxa de transações legítimas classificadas como fraude para cada subconjunto utilizando balanceamento $8 x 1$ na amostra de treinamento do classificador. Os resultados para cada subconjunto são incrementais para que se perceba a evolução dos resultados em relação ao peso geral da transação. . . . . . . . . . . . . . . . . . . . . . . . . 101

A.29 Taxa de detecção de chargebacks por mês para cada subconjunto utilizando um balanceamento $9 x 1$ na amostra de treinamento do classificador. . . . . . . . . . . . . 102

A.30 Taxa de detecção de chargebacks por mês para cada subconjunto utilizando um balanceamento $9 x 1$ na amostra de treinamento do classificador. Os resultados para cada subconjunto são incrementais para que se perceba a evolução dos resultados em relação ao peso geral da transação. . . . . . . . . . . . . . . . . . . . . . 103

A.31 Taxa de transações legítimas classificadas como fraude para cada subconjunto utilizando balanceamento $9 x 1$ na amostra de treinamento do classificador. . . . . . . . . 104

A.32 Taxa de transações legítimas classificadas como fraude para cada subconjunto utilizando balanceamento $9 x 1$ na amostra de treinamento do classificador. Os resultados para cada subconjunto são incrementais para que se perceba a evolução dos resultados em relação ao peso geral da transação. . . . . . . . . . . . . . . . . . . . 105 


\section{Lista de Tabelas}

1.1 Organização das referências bibliográficas. . . . . . . . . . . . . . . . 4

1.2 Organização das referências bibliográficas. . . . . . . . . . . . . . . 5

6.1 Percentual de chargebacks detectados por mês para cada nível de balanceamento da amostra de treinamento. Os dados estão no formato média/desvio padrão. . . . . . . 46

6.2 Percentual de chargebacks detectados por mês para cada nível de balanceamento da amostra de treinamento. Os dados estão no formato média/desvio padrão. . . . . . . 47

6.3 Percentual de falsos alarmes por mês para cada nível de balanceamento da amostra de treinamento. Os dados estão no formato média/desvio padrão. . . . . . . . . . 48

6.4 Percentual de falsos alarmes por mês para cada nível de balanceamento da amostra de treinamento. Os dados estão no formato média/desvio padrão. . . . . . . . . . . 49

6.5 Eficiência econômica considerando uma estimativa da taxa de transações não aprovadas que realmente são fraudes. Os resultados estão no formato média/desvio padrão. 57

6.6 Eficiência econômica considerando uma estimativa da taxa de transações não aprovadas que realmente são fraudes. Os resultados estão no formato média/desvio padrão. 58

7.1 Percentual de chargebacks detectados por mês para cada subconjunto utilizando um balanceamento $2 \mathrm{x} 1$ na amostra de treinamento do classificador, com o respectivo desvio padrão. Os dados estão no formato média/desvio padrão. . . . . . . . . . . . 60

7.2 Percentual de chargebacks detectados por mês para cada subconjunto utilizando um balanceamento $2 x 1$ na amostra de treinamento do classificador, com o respectivo desvio padrão. Os dados estão no formato média/desvio padrão. . . . . . . . . . . . . 61

7.3 Percentual de chargebacks detectados por mês para cada subconjunto utilizando um balanceamento $10 x 1$ na amostra de treinamento do classificador, com o respectivo desvio padrão. Os dados estão no formato média/desvio padrão. . . . . . . . . . . . 62

7.4 Percentual de chargebacks detectados por mês para cada subconjunto utilizando um balanceamento $10 x 1$ na amostra de treinamento do classificador, com o respectivo desvio padrão. Os dados estão no formato média/desvio padrão. . . . . . . . . . . . 62

7.5 Taxa de transações legítimas classificadas como fraude para cada subconjunto utilizando balanceamento $2 x 1$ na amostra de treinamento do classificador. Os dados estão no formato média/desvio padrão. . . . . . . . . . . . . . . 65

7.6 Taxa de transações legítimas classificadas como fraude para cada subconjunto utilizando balanceamento $2 x 1$ na amostra de treinamento do classificador. Os dados estão no formato média/desvio padrão. . . . . . . . . . . . . . . . . . 65 
7.7 Taxa de transações legítimas classificadas como fraude para cada subconjunto utilizando balanceamento $10 x 1$ na amostra de treinamento do classificador. Os dados estão no formato média/desvio padrão. . . . . . . . . . . . . . . . 66

7.8 Taxa de transações legítimas classificadas como fraude para cada subconjunto utilizando balanceamento $10 x 1$ na amostra de treinamento do classificador. Os dados estão no formato média /desvio padrão. . . . . . . . . . . . . . . . . . 67 


\section{Capítulo 1}

\section{Introdução}

Nos últimos anos tem-se observado um aumento crescente no volume de transações eletrônicas realizadas via $W e b$. Isso se deve principalmente ao crescimento expressivo que vem sendo observado no e-commerce desde a última década. Pesquisas indicam que o faturamento total do e-commerce no Brasil em 2012 foi de $\mathrm{R} \$ 22,5$ bilhões, um aumento de $20 \%$ em relação ao faturamento de 2011 (http: //www.e-commerce.org.br/stats.php). A Figura 1.1 mostra o crescimento anual do e-commerce no Brasil desde 2001.

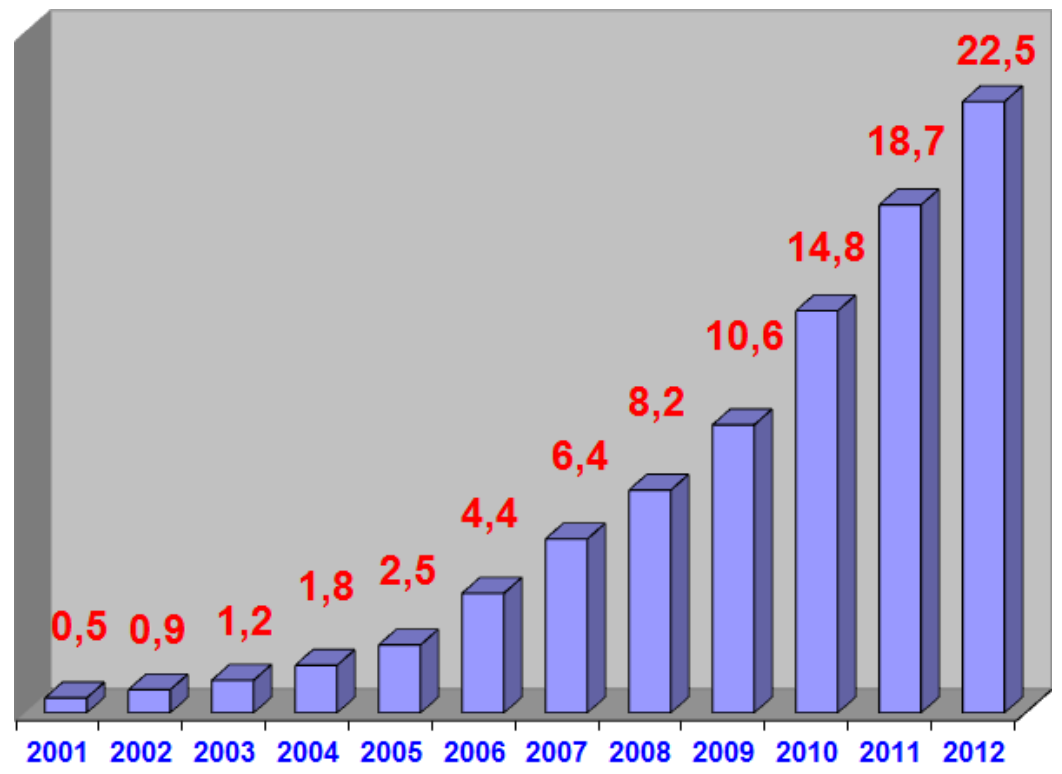

Figura 1.1: Crescimento anual do e-commerce no Brasil. Fonte: http://www.e-commerce.org.br/stats.php.

Esse crescimento do e-commerce traz consigo uma crescente utilização de cartões de crédito como meio de pagamento para transações online. Segundo Júnior et al. (2012), a popularidade do cartão de crédito no e-commerce, o grande volume financeiro transacionado e o tráfego de informações pessoais sigilosas, como CPF e número de cartão de crédito, têm atraído a atenção de indivíduos com a intenção de aproveitar-se desse cenário para a obtenção de vantagens financeiras de forma ilícita. Some-se a isso o fato de que nas transações eletrônicas realizadas pela $W e b$ não são possíveis a realização de algumas verificações usuais do mundo físico, como por exemplo a verificação da assinatura do usuário, a análise visual do comportamento suposto do comprador, a identificação visual com fotografia, etc. O que se tem como resultado é um ambiente com uma alta incidência de fraudes, gerando prejuízos bilionários. Segundo Delamaire et al. (2009), com a rápida expansão do e-commerce, foi na Web que metade de todas as fraudes com cartão de crédito foram cometidas. Segundo CyberSource (2013), as perdas devido a fraudes no e-commerce atingiram uma média de 0,9\% da receita total das empresas da América do Norte em 2012, o que representa um prejuízo total de $\$ 3,5$ bilhões e um incremento de $\$ 100$ milhões em relação a 2011. 
Frente a esse cenário de forte crescimento, surgiram recentemente na Web os chamados intermediadores de pagamento online, que são empresas que buscam fornecer soluções para pagamentos com o objetivo de tornar as transações de compra e venda no e-commerce mais seguras. Essas empresas facilitam muito o recebimento de pagamentos via $W e b$, principalmente para pequenos sites de e-commerce, os quais em geral costumam ter dificuldades em negociar diretamente com instituições financeiras para o recebimento de pagamentos com cartão de crédito. Porém, se por um lado os intermediadores de pagamento online democratizaram o acesso a recebimento de pagamentos via cartão de crédito na $W e b$, por outro lado eles abriram um novo e gigantesco campo de oportunidade para a ação de fraudadores.

De acordo com Chan e Stolfo (1998), quando as instituições financeiras perdem dinheiro devido às fraudes com cartão de crédito, os usuários (tanto os portadores de cartão de crédito como os comerciantes que recebem pagamentos via cartão) pagam parcialmente (possivelmente integralmente) por essa perda através de taxas e tarifas maiores e redução de benefícios. Assim, é do interesse tanto dos usuários como dos bancos a redução do uso ilícitos dos cartões.

Dado o cenário descrito, fica clara a necessidade de estratégias eficientes para prevenção e detecção de fraudes em transações via Web. Porém, o combate a fraude apresenta muitos desafios, e talvez o maior deles seja o grande volume de dados associados, uma vez que o volume de transações é imenso. Segundo CyberSource (2011), o número de compradores online em 2010 foi de 23 milhões, um aumento de $35 \%$ em relação ao ano anterior, ou seja, temos um número grande de compradores seguindo uma forte tendência de crescimento. Ainda segundo CyberSource (2011), $64 \%$ das transações realizadas nesse período foram feitas com cartão de crédito. Frente a esse volume imenso de transações, torna-se inviável economicamente a análise manual de cada transação a fim de decidir de forma rápida se ela é fraude ou não. Além disso, a análise estritamente manual não é capaz de identificar certos tipos de fraude que só poderiam ser capturadas através de análises automatizadas correlacionando várias fontes de dados. Fica claro então a necessidade da aplicação de teorias e técnicas computacionais para a elaboração de ferramentas que ajudem a desenvolver um combate eficiente às fraudes, a um custo viável economicamente.

Essa tarefa de análise e identificação de transações fraudulentas pode ser vista como um problema computacional de classificação, sendo então aplicáveis técnicas de classificação, aprendizado computacional e mineração de dados. De acordo com Kumar et al. (2006), mineração de dados consiste de um conjunto de técnicas organizadas para analisar grandes quantidades de dados com o objetivo de descobrir padrões úteis que poderiam, de outra forma, permanecer ignorados - uma definição claramente aplicável ao cenário de detecção de fraude. Mas, dada a complexidade do problema, a aplicação de técnicas computacionais só é possível após um profundo entendimento do problema e a definição de modelagem eficiente associada a um processo consistente e abrangente, capaz de lidar com todas as etapas necessárias para a análise eficiente de uma transação.

Apesar disso, o desenvolvimento acadêmico dessa área têm sido seriamente impactado de forma negativa pela severa limitação no compartilhamento de dados. Dados reais necessários para o desenvolvimento de pesquisas em geral possuem informações sensíveis de usuários, o que dificulta sua liberação por parte das empresas que possuem esses dados. Além disso, muitas vezes os resultados das pesquisas desenvolvidos na indústria ou em parceria com esta não são abertos ao público (Bhattacharyya et al., 2011). A Figura 1.3 mostra a quantidade de artigos publicados relacionados a fraudes em cartão de crédito desde o ano 2000. Os dados foram obtidos através de uma busca na ferramenta Google Scholar (http://scholar.google.com.br/) por artigos contendo os termos "credit card fraud" no título. Fica evidente que somente a partir de 2008 houve um ligeiro aumento na quantidade de publicações, mas ainda assim continuamos encontrando um cenário bastante modesto em termos de quantidade de publicações. 


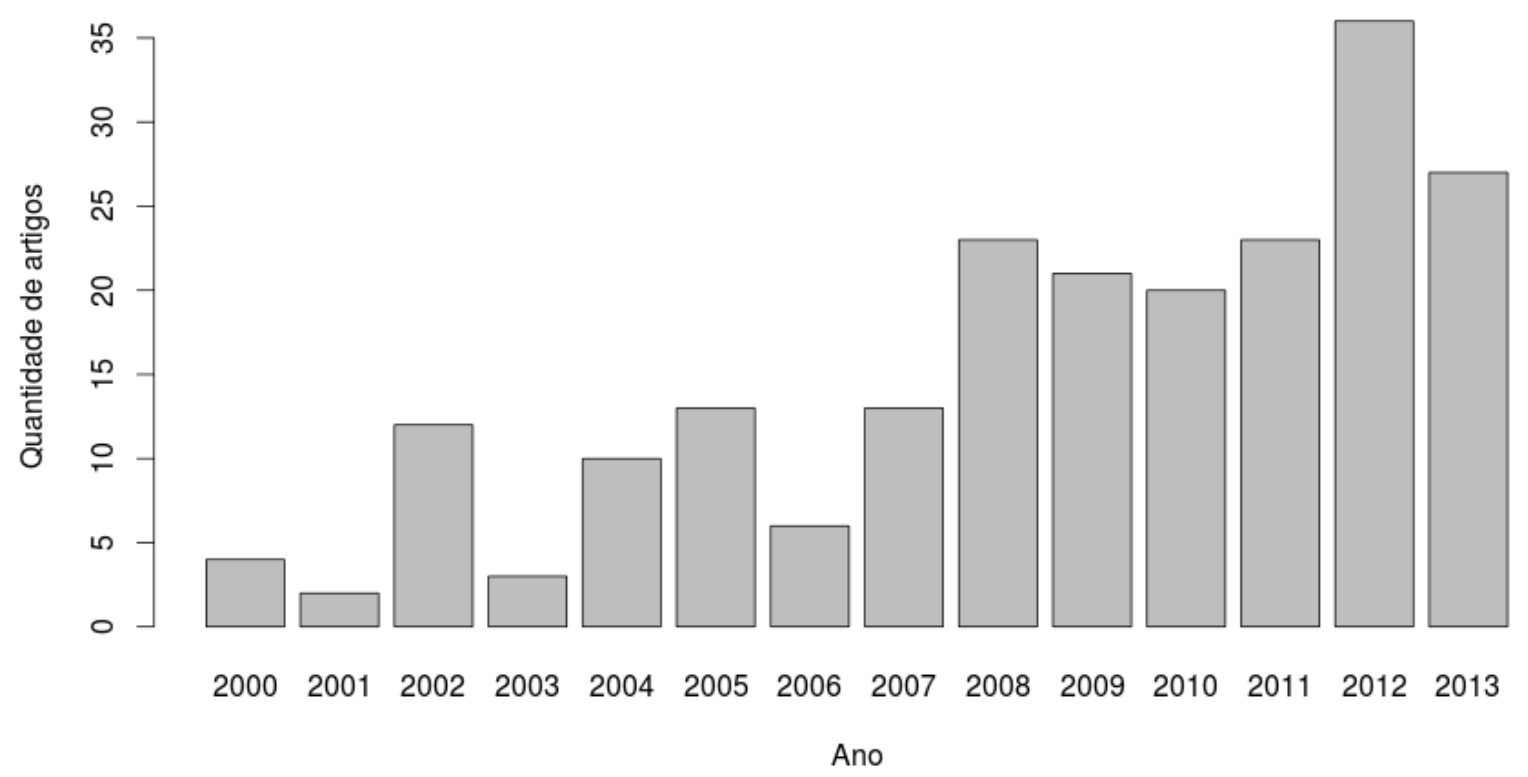

Figura 1.2: Evolução da quantidade de artigos publicados relacionados a fraudes em cartão de crédito.

Esse trabalho propõe uma abordagem abrangente para tratar o problema da fraude nos intermediadores de pagamento online, utilizando como base um processo já muito bem estabelecido na indústria. Abordaremos mais especificamente uma das fases desse processo, que se refere justamente a utilização de ferramentas computacionais para a detecção das fraudes, e apresentaremos um sub-processo que envolve a utilização de várias ferramentas para o tratamento do ponto de vista computacional do problema de detecção de fraudes. Para avaliação dos resultados da proposta, utilizaremos uma enorme quantidade de dados reais disponibilizados por uma grande empresa do setor de intermediação de pagamentos online brasileiro que colaborou com nossa pesquisa.

\subsection{Objetivo}

É comum, entre as empresas que trabalham com o recebimento de pagamentos com cartão de crédito, a utilização de um processo de detecção e gestão de fraudes já bem estabelecido na indústria e que será descrito na Seção 2.5. O principal objetivo dessa pesquisa é desenvolver um sub-processo eficiente que se encaixe nesse processo. O sub-processo proposto envolve a utilização de diferentes tipos de ferramentas em diferentes etapas, assim como uma modelagem eficiente do problema baseada nas principais entidades envolvidas na realização de uma transação. Definida a modelagem, utilizaremos técnicas de aprendizado computacional para classificar uma transação como fraudulenta ou legítima. Podemos enumerar os seguintes objetivos específicos deste trabalho:

1. Definição de um processo de análise automatizada de transações eletrônicas no contexto das empresas de intermediação de pagamentos online;

2. Aplicar uma das etapas do processo proposto, definindo para isso uma modelagem eficiente do problema que permita a aplicação de técnicas de aprendizado computacional para a classificação das transações como fraudulentas ou legítimas; e

3. Validar o modelo proposto em um cenário real. No caso, utilizaremos um conjunto de dados disponibilizado por um grande intermediador de pagamentos online brasileiro. 


\subsection{Trabalhos relacionados}

Durante o trabalho de revisão bibliográfica que fizemos para a execução dessa pesquisa, encontramos vários temas pertinentes que são recorrentes em diferentes trabalhos relacionados ao assunto. Dada a limitação na quantidade de trabalhos publicados relacionados, nessa seção apresentamos uma organização sintetizada de alguns temas recorrentes que consideramos bastante pertinentes e os respectivos trabalhos nos quais são abordados. O resultado está nas Tabelas 1.1 e 1.2.

\begin{tabular}{|c|c|}
\hline Assunto & Referências \\
\hline Detecção de fraude e e-commerce & $\begin{array}{lr}\text { Bhatla et al. } \quad \text { (2003); } & \text { Caldeira et al. } \\
\text { (2012a,b); } \quad \text { Chan } \text { et al. } & \text { (1999); } \\
\text { Delamaire et al. } \quad(2009) ; & \text { Júnior et al. } \\
\text { (2012); } \quad \text { Raj e Portie } & (2011) ; \\
\text { Whitrow et al. (2008) } & \end{array}$ \\
\hline Tipos de fraude & $\begin{array}{lll} & & \\
\text { Bhatla et al. } & \text { (2003); Bhattacharyya } \text { et al. } \\
\text { (2011); } \quad \text { Bolton e Hand } & \text { (2001); } \\
\text { Ganji e Mannem ; Jha et al. } & (2012) ; \\
\text { Phua et al. } \quad(2010) ; \quad \text { Simic } & (2005) ; \\
\text { Travaille et al. (2011) } & \end{array}$ \\
\hline $\begin{array}{l}\text { Aplicação de técnicas de aprendizado } \\
\text { computacional a detecção de fraude }\end{array}$ & $\begin{array}{lll}\text { Caldeira et al. } & \text { (2012a,b); } \\
\text { Duman e Ozcelik (2011); Gadi } & \text { (2008); } \\
\text { Ganji e Mannem ; Hejazi e Singh } & \text { (2012); } \\
\text { Jha et al. (2012); Lee e Shamoun } & \text { (2013); } \\
\text { Mishra et al. (2013); Ngai et al. } & \text { (2011); } \\
\text { Phua et al. (2010); Sahin et al. } & \text { (2013); } \\
\text { Wong et al. (2012) }\end{array}$ \\
\hline $\begin{array}{l}\text { Análise exploratória, manipulação e agregação } \\
\text { de dados }\end{array}$ & $\begin{array}{lr}\text { Bhattacharyya } \text { et al. } & \text { (2011); } \\
\text { Caldeira et al. } \quad(2012 \mathrm{a}, \mathrm{b}) ; & \text { Chiu e Tsai } \\
\text { (2004); Gadi } \text { et al. } & \text { (2010); } \\
\text { Guyon e Elisseeff (2003); Júnior et al. } \\
\text { (2012); Whitrow et al. (2008) }\end{array}$ \\
\hline Desbalanceamento & $\begin{array}{l}\text { Bhattacharyya et al. } \\
\text { Chan e Stolfo (1998); Chan et al. (1999); } \\
\text { Delamaire et al. (2009); Duman e Ozcelik } \\
\text { (2011); Gadi et al. (2010); Jha et al. } \\
\text { (2012); Sahin et al. (2013); Weiss (2004) }\end{array}$ \\
\hline Ruído & $\begin{array}{ll}\text { Bhattacharyya et al. } & \text { (2011); } \\
\text { Delamaire et al. (2009); Weiss } & \text { (2004); } \\
\text { Wheeler e Aitken (2000) } & \end{array}$ \\
\hline Análise de alterações em fluxos de dados & $\begin{array}{l}\text { Bifet e Gavaldà (2006); Ferdousi e Maeda } \\
\text { (2006); Kifer et al. } \\
\text { Sebastião e Gama (2009) }\end{array}$ \\
\hline
\end{tabular}

Tabela 1.1: Organização das referências bibliográficas. 


\begin{tabular}{|c|c|}
\hline Assunto & Referências \\
\hline Característica evolutiva das fraudes & $\begin{array}{l}\text { Bolton e Hand (2001); Chan e Stolfo } \\
\text { (1998); Chan et al. } \quad \text { (1999); } \\
\text { Delamaire et al. (2009); Panigrahi et al. } \\
\text { (2009); Phua et al. (2010); Simic (2005) }\end{array}$ \\
\hline Aprendizado supervisionado & $\begin{array}{l}\text { Bhatla et al. (2003); Bhattacharyya et al. } \\
\text { (2011); Delamaire et al. (2009); } \\
\text { Gadi et al. (2010); Hodge e Austin } \\
\text { (2004); Jha et al. (2012); Júnior et al. } \\
\text { (2012); Kou et al. (2004); Ngai et al. } \\
\text { (2011); Phua et al. (2010); Raj e Portie } \\
\text { (2011) }\end{array}$ \\
\hline Aprendizado semi-supervisionado & $\begin{array}{l}\text { Bhattacharyya et al. } \\
\text { Bolton e Hand (2001); Delamaire et al. } \\
\text { (2009); Duman e Ozcelik (2011); } \\
\text { Ganji e Mannem ; Guyon e Elisseeff } \\
\text { (2003); Hodge e Austin (2004); Jha et al. } \\
\text { (2012); Kou et al. (2004); Lee Shamoun } \\
\text { (2013); Mishra et al. (2013); Ngai et al. } \\
\text { (2011); Panigrahi et al. (2009); } \\
\text { Phua et al. (2010); Whitrow et al. } \\
\text { (2008) }\end{array}$ \\
\hline Combinação de classificadores & $\begin{array}{l}\text { Chan e Stolfo (1998); Chan et al. (1999); } \\
\text { Hodge e Austin (2004); Júnior et al. } \\
\text { (2012); Phua et al. (2010) }\end{array}$ \\
\hline Avaliação de classificadores & $\begin{array}{l}\text { Bhatla et al. (2003); Bhattacharyya et al. } \\
\text { (2011); Caldeira et al. (2012a,b); } \\
\text { Chan e Stolfo (1998); Chan et al. (1999); } \\
\text { Delamaire et al. (2009); Duman e Ozcelik } \\
\text { (2011); Júnior et al. (2012); Ngai et al. } \\
\text { (2011); Phua et al. (2010); Sahin et al. } \\
\text { (2013); Weiss (2004); Whitrow et al. } \\
\text { (2008) }\end{array}$ \\
\hline $\begin{array}{l}\text { Seleção de características (redução de } \\
\text { dimensionalidade) }\end{array}$ & $\begin{array}{l}\text { Guyon e Elisseeff (2003); Molina et al. } \\
\text { (2002) }\end{array}$ \\
\hline
\end{tabular}

Tabela 1.2: Organização das referências bibliográficas.

Adicionalmente, vale citar também os trabalhos de Maranzato et al. (2010a,b), que abordam o problema das fraudes em um cenário diferente mas também bastante ligado ao comércio eletrônico: o de reputação de usuários em sites de leilão online.

\subsection{Organização da dissertação}

O restante desse trabalho é organizado da seguinte forma: no Capítulo 2 é apresentada uma visão geral do mercado de comércio eletrônico, mostrando o funcionamento do mercado de processamento de cartões de crédito, uma discussão sobre a incidência de fraudes sobre esse mercado e os impactos gerados pelas fraudes na cadeia de processamento do cartão. Apresentamos nesse mesmo capítulo os intermediadores de pagamento online, e o finalizamos com uma descrição de um processo de gerenciamento de fraudes bastante utilizado pela indústria. No Capítulo 3 apresentamos uma visão do problema do ponto de vista computacional, com uma breve descrição dos desafios encontrados 
e uma visão um pouco mais detalhada de uma técnica computacional que será bastante utilizada na parte experimental do trabalho. No Capítulo 4 começamos a parte prática, onde descrevemos o conjunto de dados que estamos utilizando e fazemos algumas análises iniciais para compreender melhor os dados. No Capítulo 5 apresentamos uma proposta de um sub-processo para análise de transações fraudulentas, composto de uma modelagem do problema baseada em quatro principais entidades envolvidas no processo de realização de uma transação. No Capítulo 6 descrevemos o processo de classificação de uma transação, baseado na modelagem descrita no Capítulo 5 . No Capítulo 7 apresentamos os resultados finais obtidos com os experimentos realizados e, por fim, no Capítulo 8, apresentamos as conclusões. A Figura 1.3 mostra uma visão geral da organização do trabalho.

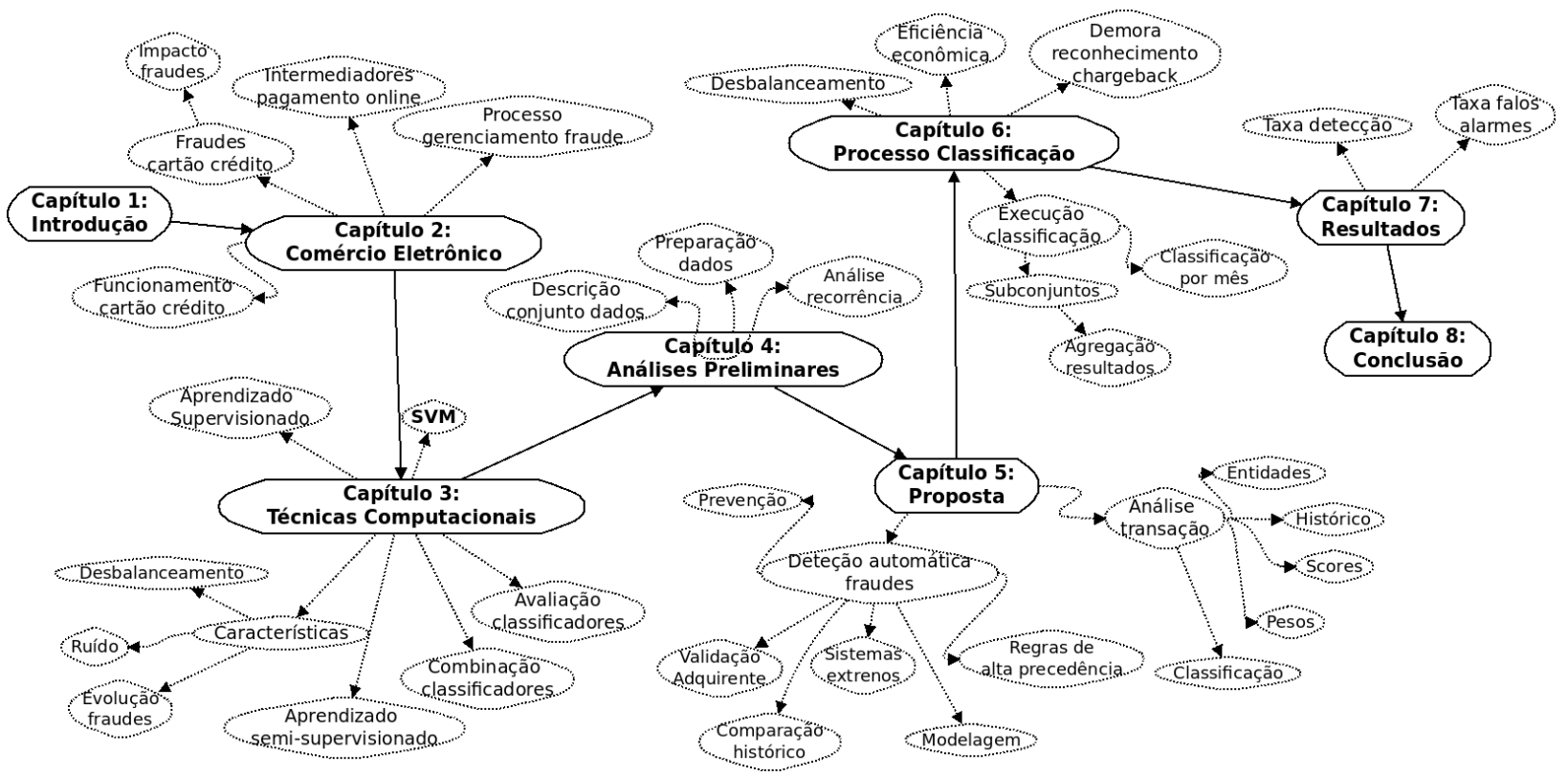

Figura 1.3: Organização do trabalho. 


\section{Capítulo 2}

\section{Fraudes no Comércio Eletrônico}

As fraudes com cartão de crédito no comércio eletrônico causam mundialmente, a cada ano, prejuízos financeiros da ordem de bilhões de dólares. Logo, fica claro a necessidade de métodos de combate à fraude nesse contexto. Porém, para combater a fraude é necessário um entendimento completo do funcionamento do processamento dos cartões de crédito no contexto do comércio eletrônico. Esse capítulo procura descrever o funcionamento da cadeia de processamento de cartão de crédito, os impactos das fraudes em cada ponto dessa cadeia e o mercado emergente dos intermediadores de pagamento online.

\subsection{Funcionamento do Cartão de Crédito}

O cartão de crédito é utilizado atualmente como meio de pagamento tanto para transações eletrônicas via $W e b$ como para transações no mundo físico. O dono do cartão recebe mensalmente, em um endereço informado, sua fatura para pagamento, contendo a discriminação de todas as suas transações realizadas.

As transações com cartões de crédito são operações complexas e possuem cinco partes envolvidas em todo o processo: o portador, o estabelecimento, o adquirente, a bandeira e o emissor. Todas essas partes interagem para a autorização e execução de uma transação quando um portador executa uma compra em um estabelecimento comercial. Cada uma delas é detalhada a seguir:

1. Portador: pode ser uma pessoa ou uma empresa e tem como objetivo fazer pagamentos através do cartão de crédito, seja para a aquisição de bens ou para a contratação de serviços.

2. Estabelecimento: empresa que deseja receber pagamentos de seus clientes por meio do cartão de crédito.

3. Adquirente: empresa que faz a comunicação entre o estabelecimento e a bandeira. São responsáveis pelo aluguel e manutenção dos equipamentos utilizados pelos estabelecimentos. As maiores adquirentes no Brasil são Redecard e Cielo.

4. Bandeira: responsável pela comunicação entre o adquirente e o emissor do cartão de crédito. As maiores bandeiras no Brasil são Visa e MasterCard.

5. Emissor: instituições financeiras, em geral bancos, que emitem e administram o cartão de crédito. Também são chamadas de administradoras do cartão.

Para a realização da transação, os dados do cartão são inseridos pelo portador em um equipamento eletrônico disponível no estabelecimento comercial ou informados no site do vendedor na Web. O equipamento eletrônico ou o site $W e b$ comunica-se com o adquirente, que envia a transação para a bandeira e que por sua vez a envia para o emissor. O emissor decide se a transação será aprovada ou não e envia a decisão de volta para a bandeira, que a envia para o adquirente, o qual repassa para o estabelecimento que por sua vez a repassa para o portador. (Gadi et al., 2010; Júnior et al., 2012) 


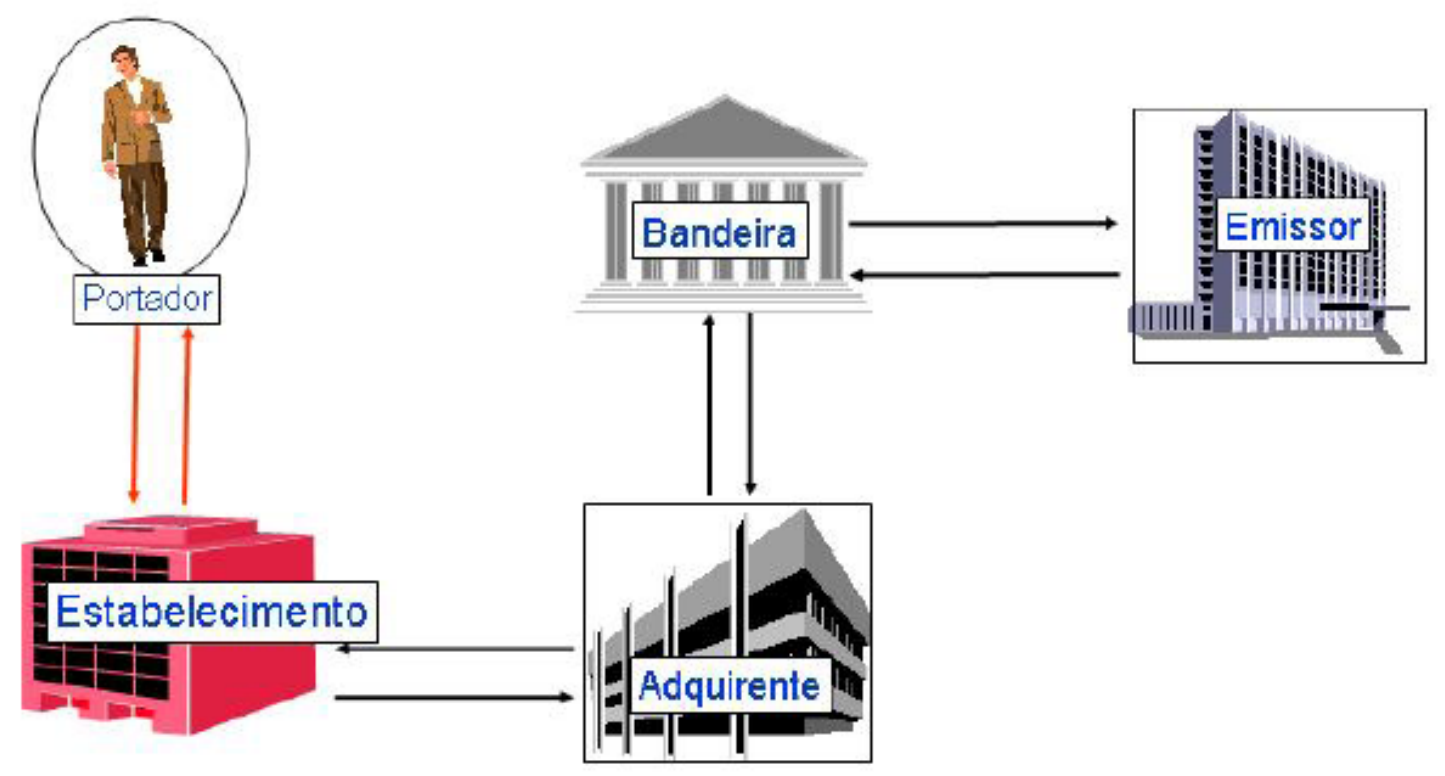

Figura 2.1: Sistema de autorização de uma transação. Fonte: Gadi et al. (2010)

\subsection{Fraudes em Transações com Cartão de Crédito}

Em termos simples, uma fraude de cartão de crédito acontece quando um indivíduo usa o cartão de crédito de outro indivíduo por motivos pessoais, enquanto o proprietário do cartão e o emissor do cartão não estão cientes do fato. Além disso, o indivíduo que utiliza o cartão não tem nenhuma conexão com seu titular ou emitente e não tem intenção nem de entrar em contato com o proprietário do cartão ou fazer reembolsos das compras feitas. (Bhatla et al., 2003)

Existem várias formas pelas quais fraudadores podem executar uma fraude de cartão de crédito. Segundo Bhatla et al. (2003), fraudes podem podem ser classificadas em três categorias: fraudes relacionadas ao cartão de crédito, fraudes relacionadas ao comerciante e fraudes de Internet. Já Travaille et al. (2011) divide as fraudes em duas categorias: as do tipo "rouba-se muito somente uma vez" e as do tipo "rouba-se pouco constantemente". Phua et al. (2010) diz que o fraudador possui três perfis básicos: o ocasional, o criminoso e o crime organizado, sendo os dois últimos os que apresentam maior risco para as instituições. Outras classificações de fraude e fraudadores são apresentadas por Bhattacharyya et al. (2011); Bolton e Hand (2001); Delamaire et al. (2009). Júnior et al. (2012) apresenta uma descrição mais detalhada de como as fraudes de cartão de crédito são cometidas.

Sempre que um portador legítimo do cartão de crédito contesta uma cobrança, a instituição financeira emissora do cartão vai enviar uma ordem de inversão de crédito, ou chargeback, ao comerciante, revertendo o crédito da transação em favor do consumidor. O chargeback ${ }^{1}$ é um dos maiores temores dos comerciantes, principalmente os de lojas virtuais, e muitas vezes podem causar o seu fechamento. O chargeback pode acontecer por dois motivos: não reconhecimento da compra por parte do titular do cartão ou a transação não obedece às regulamentações previstas nos contratos, termos, aditivos e manuais editados pelas administradoras. Resumindo, o lojista vende e depois descobre que o valor da venda não será creditado porque a compra foi considerada inválida. Se o valor já tiver sido creditado, ele será imediatamente estornado ou lançado a débito. (Júnior et al., 2012)

Ao contrário da crença popular, os comerciantes sofrem muito mais com o risco de fraude

\footnotetext{
${ }^{1}$ Daqui em diante, usaremos o termo chargeback.
} 
de cartão de crédito do que os portadores de cartão. Enquanto os consumidores podem enfrentar problemas para tentar obter a reversão de uma cobrança fraudulenta, os comerciantes podem perder o custo do produto vendido, pagam taxas de chargeback e ainda sofrem o risco de ter sua conta de comerciante fechada (Bhatla et al., 2003). Ainda segundo Bhatla et al. (2003), comerciantes são a parte mais afetada nas fraudes com cartão de crédito, particularmente nas transações não presenciais, já que nesses casos eles têm que aceitar a responsabilidade integral pela perda gerada pela fraude.

Tem sido cada vez mais frequente a utilização de cartão de crédito em transações não presenciais pela Web. Devido a impossibilidade de verificações possíveis somente no meio físico, esse tipo de transação apresenta um risco maior para o comerciante. Posto isso, a Internet tem se tornado um ambiente extremamente atraente para quem deseja cometer fraude. Segundo Bhatla et al. (2003), a taxa em que a fraude ocorre na Internet é de doze a quinze vezes maior do que no mundo físico.

\subsection{Impacto das Fraudes de Cartão de Crédito}

A atividade fraudulenta afeta praticamente todos os envolvidos na cadeia de processamento da transação de cartão de crédito, alguns mais serveramente e outros menos. Bhatla et al. (2003) e Júnior et al. (2012) fazem uma análise desses impactos que descreveremos a seguir.

\subsubsection{Impacto das Fraudes para o Titular do Cartão}

Os titulares do cartão são a parte menos afetada com as fraudes em transações de cartão de crédito. As legislações vigentes nos países em geral protegem o consumidor das transações fraudulentas, principalmente para as transações não presenciais feitas pela Web. Os próprios bancos em geral possuem políticas de proteção ao consumidor em casos de fraude que cobrem a maior parte das perdas do cliente, repassando a maior parte desses custos para os outros envolvidos na cadeia de processamento.

\subsubsection{Impacto das Fraudes para os Comerciantes}

Os comerciantes são a parte mais afetada com as fraudes, principalmente nas transações não presenciais. Sempre que um titular comprovadamente legítimo contestar uma transação da sua fatura, o banco emissor do cartão repassará essa cobrança ao adquirente que por sua vez a enviará para o comerciante, revertendo o crédito da transação. Esse processo de contestação da transação por parte do titular com o consequente repasse ao comerciante é chamado de chargeback.

A menos que o comerciante consiga comprovar a não legitimidade ou não idoneidade do titular do cartão através de um processo de contestação de chargeback (o que em geral é extremamente difícil para transações não presenciais), ele terá que absorver por completo o custo da transação em questão. Além disso, grandes adquirentes do mercado têm adotado políticas rígidas que penalizam os comerciantes que geram muitos chargebacks, impondo-lhes uma taxa adicional para cada chargeback. Em casos extremos, o contrato do comerciante para aceitar cartões de crédito pode ser encerrado.

\subsubsection{Impacto das Fraudes nas Instituições Financeiras (Emissor/Adquirente)}

Não é comum, mas as vezes é possível que o emissor ou o adquirente assumam os custos da fraude, integral ou parcialmente, dependendo do tipo de contrato estabelecido entre as partes. Mesmos nos casos em que essas instituições não arcam com os custos da fraude, existe o custo administrativo indireto que recai sobre elas, como por exemplo a mão de obra necessária para enviar as cobranças para o comerciante. 


\subsection{Intermediadores de Pagamentos Online}

Devido aos prejuízos causados pelas fraudes, surgiram na Internet empresas que buscam fornecer soluções para pagamentos online com o objetivo de tornar as transações de compra e venda mais seguras. Como exemplo desse tipo de empresa podemos citar o PayPal [http://www.paypal.com] e o PagSeguro [http://www.pagseguro.uol.com.br]. A primeira é uma empresa norte-americana líder mundial nesse segmento, enquanto que a segunda é uma empresa brasileira que lidera o segmento de intermediação de pagamentos online no Brasil.

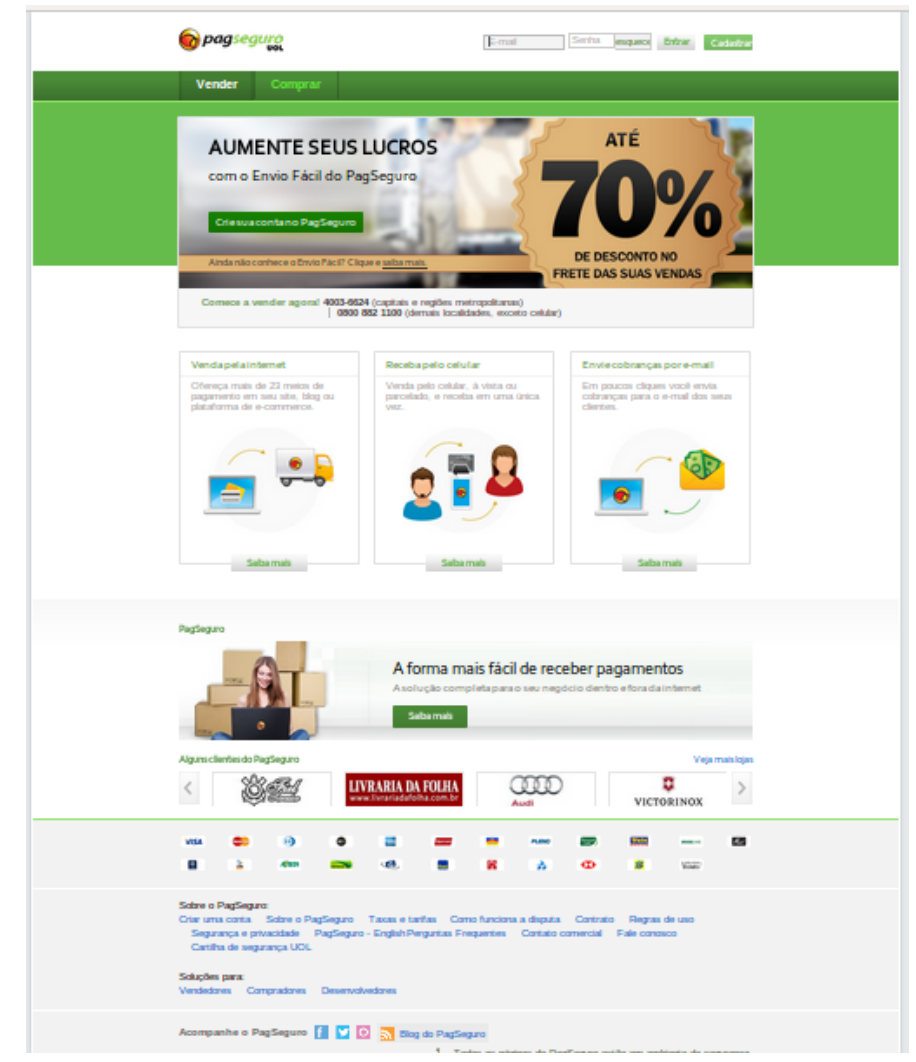

Figura 2.2: Página inicial do intermediador de pagamentos online PagSeguro.

Por ser um mercado relativamente novo quando comparado ao mercado de cartões de crédito, o modelo de negócio dessas empresas ainda não está completamente definido e vem sofrendo evoluções ao longo do tempo. Atualmente, a forma mais correta de situar essas empresas na cadeia de processamento do cartão de crédito descrita na Seção 2.1 é entre o estabelecimento comercial e o adquirente: ou seja, o comerciante (em geral, um site Web) repassa as informações da transação para o intermediador de pagamentos online, que por sua vez repassa ao adquirente, de onde a transação segue o fluxo normal na cadeia.

O intermediador de pagamentos online não possui nenhum controle sobre o conteúdo das informações transacionadas: ele somente recebe os valores associados aos dados de pagamento juntamente com uma breve descrição do produto transacionado que é fornecida pelo comerciante. O intermediador não se responsabiliza pela entrega ou qualidade do produto ou serviço transacionado, ele é responsável somente pela intermediação financeira. É comum essas empresas oferecerem garantias de entrega ou devolução de dinheiro aos compradores, mas esse é um risco assumido pelos intermediadores que não possuem controle sobre o conteúdo dos produtos ou serviços transacionados.

A Figura 2.3 mostra a página do intermediador de pagamentos online PagSeguro na qual o comprador insere os dados bancários para pagamento. Percebe-se que são oferecidos outros meios de pagamentos além de cartão de crédito, o que é muito comum em todas as empresas desse setor. Porém, as transações pagas com cartões de crédito são as que costumam receber mais atenção dessas empresas em relação à ocorrência de fraudes. 


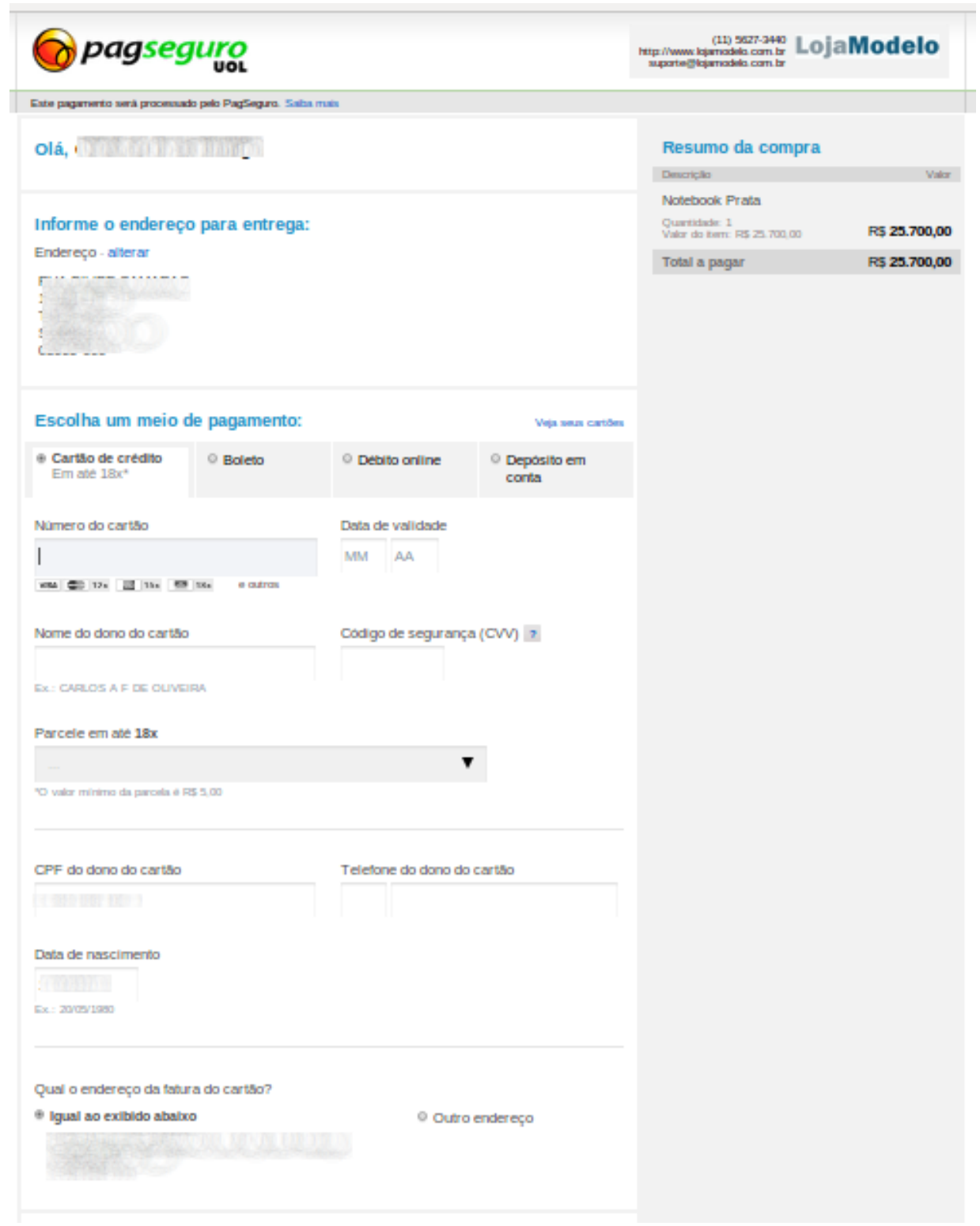

Figura 2.3: Página para informação dos dados bancários para pagamento no intermediador de pagamentos online PagSeguro.

O comerciante que deseja aceitar pagamentos através do intermediador de pagamentos online precisa fazer um cadastro no site da empresa. Após o cadastro, o comerciante tem a opção de aceitar ou não o recebimento de pagamentos através de cartão de crédito. Caso ele opte por não aceitar, somente as demais opções de meios de pagamento ficam disponíveis para os seus compradores. Por outro lado, caso ele opte pelo recebimento de pagamentos através de cartão de crédito, ela irá passar por uma análise mais cuidadosa de uma equipe de investigadores do intermediador de pagamentos online.

O comerciante obrigatoriamente precisa fazer um cadastro no intermediador de pagamentos online, já o comprador não tem essa necessidade - ele tem a opção de somente informar um endereço de e-mail para o recebimento das notificações que o intermediador irá lhe enviar e os dados bancários necessários para o pagamento. Caso ele opte por fazer o cadastro, ele precisará informar seu endereço de e-mail e sua senha no intermediador, e terá a sua disposição no site do intermediador de pagamentos uma área para o gerenciamento das suas transações. A Figura 2.4 mostra a página do intermediador de pagamentos online PagSeguro onde o usuário comprador pode fazer esse gerenciamento. 


\section{(6) pagseguro}

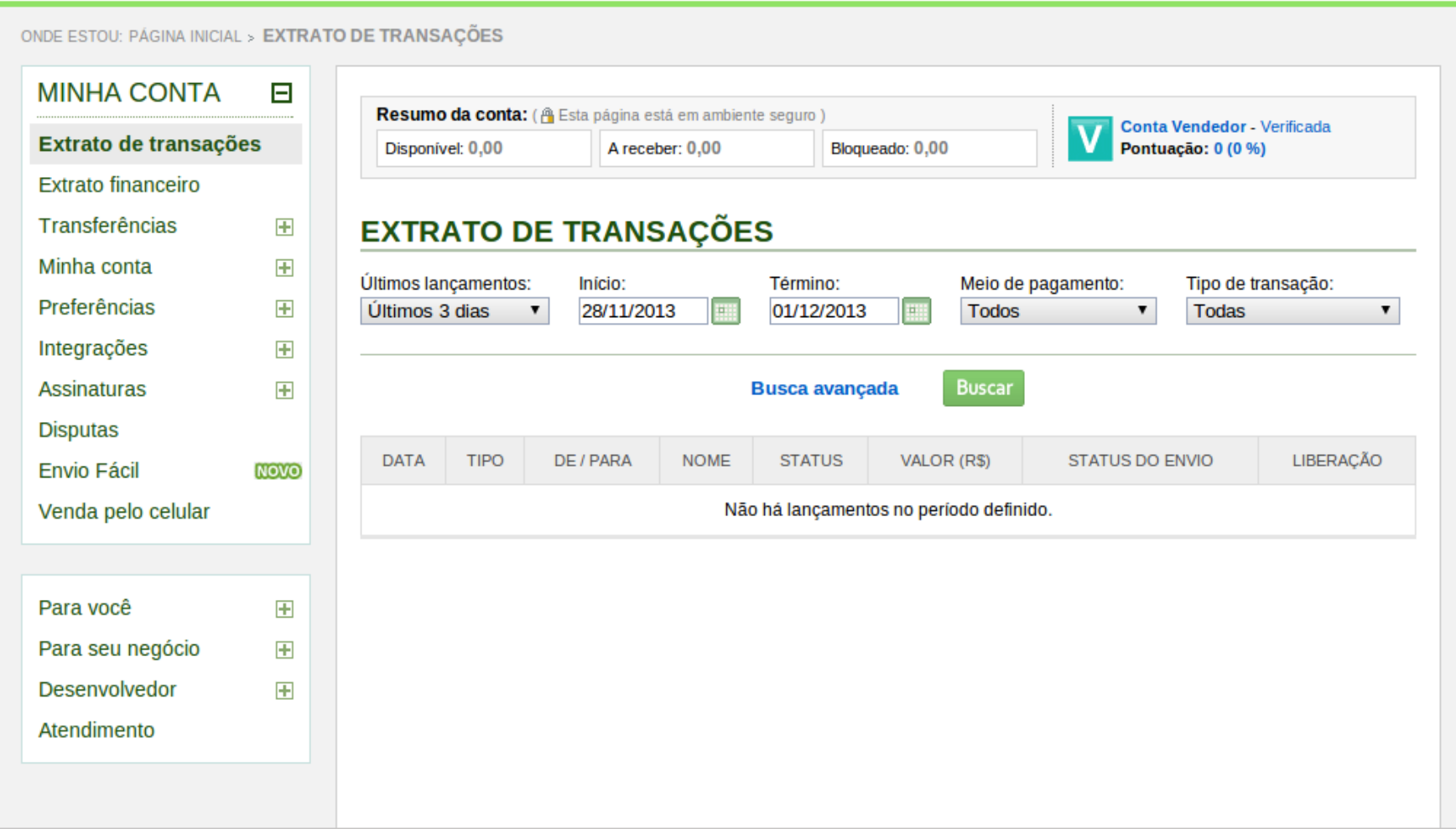

Figura 2.4: Página para o gerenciamento das transações do comprador no intermediador de pagamentos online PagSeguro.

Os intermediadores de pagamento online em geral assumem todo o risco associado nas transações, garantindo que tanto a compra quanto a venda serão realizadas com sucesso. Caso contrário, o cliente ou o vendedor serão reembolsados, ou seja, os intermediadores assumem o prejuízo no caso da ocorrência de chargebacks. Pode-se perceber que tanto o comprador quanto o vendedor transferem todo o risco da transação para essas empresas, o que faz com que esse seja um serviço de altíssimo risco. Dessa forma, investimento em tecnologias para detecção de fraudes são de extrema importância para essas empresas. (Júnior et al., 2012)

\subsection{O processo de Gerenciamento de Fraude}

Vimos que a Web é um ambiente particularmente propício para a prática de fraudes em transações eletrônicas e que os comerciantes são a parte mais afetada pelas fraudes. Posto isso, a gestão da fraude constitui um desafio importante para os comerciantes, principalmente para os intermediadores de pagamento online, que agregam o risco de vários comerciantes. Segundo Bhatla et al. (2003), a defasagem média entre a data da transação e a identificação do chargeback pode ser superior a setenta e dois dias, o que significa que os fraudadores podem gerar danos significativos durante vários dias antes mesmo que a fraude seja sequer percebida, o que reforça a necessidade de um processo de gestão de fraude.

A Figura 2.5 mostra o processo de gestão de fraude que é bastante utilizado pelas empresas de comércio eletrônico e intermediadores de pagamento online. De forma geral, o processo inicia quando o portador do cartão realiza um pedido, o qual é analisado por ferramentas de triagem automática, que por sua vez sinalizam se a transação deve ser aprovada, rejeitada ou encaminhada para revisão manual. Os pedidos encaminhados para revisão manual são avaliados por uma equipe 
de especialistas, aprovando-os ou rejeitando-os. Por fim, temos a etapa de gerenciamento das fraudes identificadas. A seguir descrevemos cada etapa do processo.

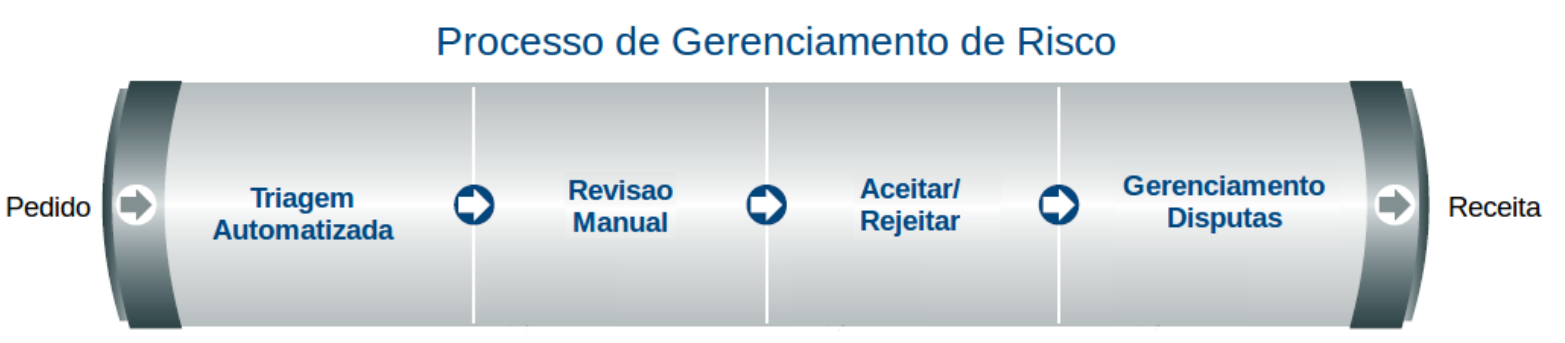

Figura 2.5: Processo de gestão de fraude. Adaptado de CyberSource (2011).

\subsubsection{Triagem Automatizada}

Tecnologias de detecção de fraudes permitem aos comerciantes e intermediadores de pagamento online realizarem triagens sofisticadas e automatizadas sobre grandes volumes de pedidos a fim de identificar possíveis transações suspeitas de fraude. Em geral, várias ferramentas são utilizadas nessa etapa, e segundo Júnior et al. (2012), uma única ferramenta não é capaz de eliminar por si só a fraude, mas as várias ferramentas utilizadas em conjunto fornecem um valor incremental em termos de capacidade de deteç̧ão. Essas ferramentas podem ser utilizadas para cancelar automaticamente eventuais suspeitas de fraude ou para sinalizar transações que devem passar por uma revisão manual. A seguir são apresentadas algumas ferramentas comuns de triagem automática.

\section{Sistema de Regras}

Sistemas de regras consistem da existência de vários critérios do tipo "se ... então" que são aplicados às transações. Esses critérios, ou regras, são projetados para identificar tipos específicos de transações consideradas de alto risco e são criadas a partir do conhecimento de uma equipe de especialistas em fraude sobre o que caracteriza uma transação fraudulenta ou de alto risco. Em geral, a eficácia de um sistema baseado em regras tende a aumentar com o passar do tempo, uma vez que o conhecimento da equipe de especialistas tende a evoluir e mais regras são adicionadas ao sistema. Esses sistemas possuem a vantagem de serem bastante flexíveis e com resultados facilmente compreensíveis por seus projetistas. Porém, para garantir um certo grau de flexibilidade, é importante a existência de ferramentas que possibilitem um gerenciamento eficiente do sistema de regras.

\section{Ferramentas de Pontuação de Risco}

Ferramentas de pontuação de risco são baseadas em modelos estatísticos projetados para fazer a separação das transações fraudulentas das transações legítimas, com base em uma série de indicadores gerados a partir das informações de cada transação. Em geral, essas ferramentas geram uma pontuação (muitas vezes chamadas de score) que indica a probabilidade de uma transação ser fraude. Uma grande vantagem dessas ferramentas é a representação em um único número do risco total da transação: tal característica permite a priorização das transações de acordo com sua pontuação de risco, sendo então enviadas para revisão manual de acordo com a capacidade da equipe disponível.

\section{Listas Positivas/Negativas}

Listas positivas e negativas são um tipo de banco de dados utilizado para identificar transações sabidamente de alto risco ou sabidamente legítimas respectivamente. Por exemplo, um sistema de gerenciamento de fraude pode manter uma lista com o número de todos os cartões que tiveram uma 
alta incidência de chargebacks recentemente e utilizar isso como uma lista negativa, sinalizando todas as transações desses cartões como sendo de alto risco. Essas listas não precisam ser necessariamente baseadas no cartão de crédito, podem existir listas baseadas em IPs, endereços de e-mail, CPFs, etc.

\section{Geolocalização por IP}

Ferramentas de geolocalização por IP tentam identificar a localização geográfica do dispositivo de origem da transação e consistem de uma informação adicional a ser comparada com outras informações fornecidas pelo usuário e com as regras de aceitação do sistema. Porém, é importante notar que esse dispositivo tem algumas limitações:

- Em alguns casos, apenas o endereço de um provedor de serviços de Internet é devolvido, e não o do usuário;

- Os fraudadores podem utilizar formas para esconder seu verdadeiro endereço IP através da utilização de proxy servers ou manipulação das requisições http no caso de sistemas Web.

\subsubsection{Revisão Manual}

Transações sinalizadas como sendo de alto risco na fase de triagem automatizada podem ser reprovados imediatamente ou enviadas para revisão manual. Durante a revisão manual, informações adicionais são recolhidas para determinar se as transações devem ser aprovadas ou rejeitadas. Na maioria dos casos, uma "investigação" consistirá de uma breve análise das transações recentes dos usuários envolvidos, seguindo de uma ligação telefônica a fim de confirmar que a transação foi de fato realizada pelo verdadeiro portador do cartão. Ela também pode requerer ligações para os vendedores envolvidos, ou um trabalho ainda mais extensivo dependendo do tamanho da perda em potencial, ou seja, do valor da transação. Porém, dado que a fraude é uma ocorrência rara quando comparada à quantidade total de transações legítimas, haverá uma preponderância de falsos alarmes, sendo então importante manter o custo da investigação baixo, principalmente quando a perda em potencial for baixa (Whitrow et al., 2008). Dado o custo envolvido no processo, se o valor da transação for baixo o suficiente a ponto de ser menor que o custo da revisão manual, pode até mesmo não ser viável realizar a análise da transação, mesmo que ela tenha um alto indício de fraude. (Bhatla et al., 2003; Chan e Stolfo, 1998; Chan et al., 1999)

Segundo Júnior et al. (2012), aumentar a produtividade da equipe de revisão manual mantendo o quantitativo de pessoal representa um desafio significativo para o crescimento do lucro. Isso porque o número total de pedidos que devem ser revistos tende a aumentar na mesma proporção do aumento total das vendas, mesmo quando um percentual estável de transações são enviadas para análise manual.

\subsubsection{Situação do Pedido (Aceitar/Rejeitar)}

As fases anteriores do processo resultarão na aceitação ou rejeição da transação, e é importante um gerenciamento cuidadoso da taxa de aprovação e de rejeição das transações. Um percentual alto de transações manualmente revistas e, em última análise aprovadas, evidencia a necessidade de melhorar os sistemas de triagem automática com a consequente redução da necessidade de revisão manual.

\subsubsection{Gerenciamento de Disputas}

Infelizmente alguns pedidos aprovados pela triagem automática ou pela revisão manual serão posteriormente descobertos como sendo fraudulentos e irão gerar chargebacks. Os comerciantes ou os intermediadores de pagamento online irão tentar reaver o valor da transação através do processo de contestação de chargeback. Esse processo não é fácil e possui custos associados, logo é importante fazer um gerenciamento de quais transações passarão por esse processo, assim como organizar as 
informações necessárias para realizar a contestação. Muitos estabelecimentos têm adotado ferramentas automatizadas para fazer esse gerenciamento. Segundo CyberSource (2011), 63\% dos grandes comerciantes utilizam ferramentas para essa gestão e o tempo médio para lidar com as disputas é de 1,8 horas. Ainda segundo CyberSource (2011), os comerciantes ganham em média $41 \%$ das contestações.

\subsection{Considerações Finais}

Este capítulo apresentou uma visão geral sobre o mercado de cartões de crédito e a incidência de fraudes nesse mercado. Iniciamos com uma visão geral do funcionamento da cadeia de processamento de cartão de crédito. Em seguida, discutimos a ocorrência de fraudes nas transações com cartão de crédito e os impactos para cada um dos envolvidos na cadeia de processamento. Vimos que a consequência imediata da fraude é o chargeback. Além disso, vimos também que, ao contrário da crença popular, os comerciantes são a parte mais afetadas pela fraude. Após isso apresentamos os intermediadores de pagamento online, um mercado relativamente novo com um modelo de negócio de alto risco, no qual tecnologias para detecção de fraude são extremamente importantes. Por fim, dados os riscos envolvidos e o potencial prejuízo causado pelas fraudes no comércio eletrônico, mostramos a importância de um processo bem estabelecido para gestão de risco. Esse processo envolve a utilização de ferramentas automatizadas e a revisão manual de parte das transações por especialistas em detecção de fraude. Esse processo de gestão tem por objetivo tratar o problema da fraude de uma forma eficiente economicamente e tem sido cada vez mais utilizados por comerciantes ligados ao comércio eletrônico e intermediadores de pagamento online. 


\section{Capítulo 3}

\section{Técnicas Computacionais para a Deteç̧ão de Fraude com Cartão de Crédito}

Para evitar o problema da fraude nas transações eletrônicas, faz-se necessário algum mecanismo de verificação de cada transação a fim de tentar classificar a transação como fraude ou não fraude. Analisar cada transação manualmente não é uma estratégia viável do ponto de vista econômico, visto que em muitos casos o lucro que seria obtido com uma transação é menor do que o custo do processo de análise manual. Além disso, é muito difícil classificar com certeza absoluta a legitimidade de qualquer transação, assim a opção com o melhor custo benefício é levantar possíveis evidências de fraude a partir dos dados disponíveis (Phua et al., 2010).

Segundo Duman e Ozcelik (2011), detecção de fraude tem sido visto na comunidade acadêmica como um problema de mineração de dados onde o objetivo é classificar corretamente as transações como legítimas ou fraudulentas. Segundo Ngai et al. (2011), vários algoritmos de mineração de dados têm sido aplicados ao problema, incluindo Árvores de Decisão, Regressão Logística, Redes Neurais Artificiais, Nä̈ve Bayes, Support Vector Machines, entre outros. Ainda segundo Ngai et al. (2011), mineração de dados desenvolve um papel importante em detecção de fraude, visto que é frequentemente aplicado para extrair e descobrir informações por trás de grandes quantidades de dados. Phua et al. (2010) diz que detecção de fraude tem se tornado uma das aplicações mais bem estabelecidas de mineração de dados, tanto na indústria como no setor público.

Este capítulo pretende dar uma visão das características do problema de detecção de fraude do ponto de vista de mineração de dados. Iniciamos descrevendo algumas dessas características e por fim descrevemos a técnica de classificação Support Vector Machines que será bastante utilizada na parte experimental desse trabalho.

\subsection{Características do problema}

Nesta seção descreveremos as principais características do problema de detecção de fraudes sob o ponto de vista das técnicas computacionais.

\subsubsection{Desbalanceamento}

Uma característica inerente ao problema de detecção de fraudes em transações eletrônicas é o grande desbalanceamento dos dados, já que a quantidade de transações fraudulentas é muito menor que a de transações legítimas (Bhattacharyya et al., 2011; Delamaire et al., 2009). Um classificador poderia obter uma assertividade grande se simplesmente classificasse todas as transações como legítimas (Chan et al., 1999). Esse desbalanceamento entre as duas classes faz da detecção de fraude um problema desafiador (Duman e Ozcelik, 2011). Weiss (2004) explica em detalhes os problemas trazidos pelo desbalanceamento dos dados. 
Existem várias técnicas propostas na literatura para lidar com o problema do desbalanceamento. A mais frequente é a utilização de técnicas de amostragem (Bhattacharyya et al., 2011; Chan e Stolfo, 1998; Chan et al., 1999; Delamaire et al., 2009; Weiss, 2004). A ideia básica dessa abordagem é dividir o conjunto de treinamento do classificador em vários subconjuntos menores, utilizando em cada um deles um percentual grande das transações fraudulentas (eventualmente 100\%) e um percentual pequeno das transações legítimas, de forma que se obtenha vários subconjuntos menos desbalanceados que o problema original a serem utilizados para treinar o classificador.

Weiss (2004) também propõe a geração de classificadores com regras que saibam classificar somente as transações fraudulentas. Outra abordagem proposta no mesmo trabalho é uma segmentação cuidadosa dos dados, de forma a gerar regiões com dados menos desbalanceados mas também regiões com dados mais desbalanceados ainda que o problema original. $\mathrm{O}$ autor argumenta que em algumas situações isso pode ser aceitável. Chan et al. (1999) propõe um pré-processamento dos dados de forma a remover as transações que são muito facilmente classificadas como legítimas, o que diminuiria a quantidade de transações legítimas a ser apresentada ao classificador, atenuando o problema do desbalanceamento. Por fim, Chan et al. (1999) diz que o problema do desbalanceamento ainda não foi largamente estudado devido ao fato de que muitos conjuntos de dados utilizados nas pesquisas, por serem conjunto de dados artificiais ou não totalmente reais, não apresentam o mesmo grau de desbalanceamento encontrado na prática.

\subsubsection{Ruído}

Outro problema com o desenvolvimento de classificadores para detecção de fraude em cartões de crédito, principalmente classificadores supervisionados, é a existência de ruído nos dados (Wheeler e Aitken, 2000). Ruído pode surgir, por exemplo, através de transações fraudulentas que não foram detectadas, e portanto erroneamente tratadas como legítimas durante o treinamento do classificador (Bhattacharyya et al., 2011).

Segundo Weiss (2004), ruído nos dados afetará qualquer sistema de mineração de dados, mas traz um prejuízo maior para aqueles que precisam lidar com dados desbalanceados, impactando principalmente as classes mais raras, já que, uma vez que as classes mais raras possuem menos exemplos, ela precisará de menos ruído para impactar o resultado final.

\subsubsection{Evolução das Fraudes}

Outra característica inerente ao problema de detecção de fraudes em cartão de crédito é a variação constante na relação entre transações legítimas e fraudulentas. O volume de ambas as classes irá flutuar independentemente uma da outra; assim, a distribuição das classes irá mudar ao longo do tempo. Vários tipos de fraude podem acontecer ao mesmo tempo, sendo que cada uma delas pode ter uma característica regular, ocasional ou sazonal (Phua et al., 2010).

Não bastasse isso, os fraudadores tendem a evoluir suas técnicas e as fraudes tendem a mudar com o tempo, adaptando-se às reações do sistema. Tão logo os fraudadores percebem que um certo tipo de comportamento fraudulento pode ser detectado, eles irão adaptar suas estratégias e tentar outras (Bolton e Hand, 2001; Phua et al., 2010). Isso coloca para os sistemas de detecção de fraude a necessidade de serem adaptativos e reavaliados constantemente (Delamaire et al., 2009). Logo, visto que os fraudadores aprendem o funcionamento dos sistemas de detecção de fraude e os padrões de fraude evoluem ao longo do tempo, alguns classificadores serão mais relevantes que outros em um dado momento (Chan e Stolfo, 1998; Chan et al., 1999).

Porém, é importante ressaltar que fraudadores novos surgem a todo momento e estes não terão conhecimento dos métodos de detecção de fraude que tiveram sucesso no passado. Isso significa que os padrões de detecção de fraudes previamente aplicados precisam ser aplicados constantemente em conjunto com suas respectivas evoluções (Bolton e Hand, 2001). 


\subsection{Tipos de Técnicas Computacionais Aplicados ao Problema de Detecção de Fraude}

As técnicas de mineração de dados e aprendizado computacional aplicadas à detecção de fraude são divididas em duas grandes categorias na literatura: supervisionadas e semi-supervisionadas. Nos métodos supervisionados, modelos são estimados baseados em amostras de transações legítimas e fraudulentas, a fim de se classificar novas transações em uma dessas duas classes. Nos métodos semisupervisionados, outliers são identificados como potenciais casos de fraude. Ambos os métodos tentam estimar a probabilidade de fraude em uma dada transação (Bhattacharyya et al., 2011). Essa probabilidade em geral é chamada de score, ou risco da transação.

\subsubsection{Aprendizado Supervisionado}

Métodos supervisionados examinam transações previamente classificadas a fim de determinar futuras transações fraudulentas. Logo, métodos supervisionados precisam de identificação precisa de transações fraudulentas em dados históricos e só podem ser utilizados para detectar tipos de fraude que já ocorreram previamente. Vários métodos supervisionados são encontrados na literatura como sendo aplicáveis ao problema de detecção de fraude em cartão de crédito. Os mais comumente vistos são Redes Neurais, Support Vector Machines, Redes Bayesianas, Árvores de Decisão e Regressão Logística.

Regressão Logística é um método que gera um score numérico para cada transação analisada baseado em modelos estatísticos gerados a partir das características da transação. Quanto maior o score gerado, maior a probabilidade de fraude na transação. Métodos de geração de score estão entre as ferramentas mais efetivas; sua principal vantagem é uma avaliação completa da análise de uma transação, que é capturada a partir de um único número, o qual indica o grau de suspeita de fraude presente na transação (Bhatla et al., 2003).

Redes Neurais são uma extensão das técnicas de geração de score. Elas são baseadas no conhecimento estatístico contido no histórico de transações, em particular no histórico de transações fraudulentas. Tais modelos são treinados utilizando exemplos de transações legítimas e fraudulentas e são capazes de correlacionar e ponderar vários indicadores à ocorrência da fraude. Uma grande vantagem das Redes Neurais é que seus modelos são capazes de aprender a partir de transações anteriores, e portanto seus resultados tendem a melhorar com o passar do tempo (Bhatla et al. , 2003).

Support Vector Machines são capazes de gerar bons resultados a partir de dados não muito balanceados. Porém, uma desvantagem de Support Vector Machines é que eles são computacionalmente complexos (Hodge e Austin, 2004).

Métodos supervisionados necessitam de dados de treinamento previamente classificados a fim de gerar um modelo a ser utilizado para classificação de transações. Para isso, são utilizados conjuntos de dados para desenvolvimento do modelo, a partir dos quais são extraídos subconjuntos de amostras a serem utilizadas para geração, teste e avaliação do modelo. Existem na literatura algumas técnicas para a geração desses subconjuntos, como por exemplo Hold-out, K-Fold Cross Validation e Threeway data splits.

Hold-out consiste na divisão do conjunto de dados em dois subconjuntos disjuntos: o subconjunto utilizado para treinamento do classificador e o subconjunto utilizado para validação, sendo que o subconjunto de treinamento é tipicamente maior que o subconjunto de validação (uma divisão comum é o subconjunto de treinamento conter dois terços do conjunto total e o subconjunto de validação conter um terço). K-Fold Cross Validation consiste na divisão do conjunto de dados em $N$ subconjuntos disjuntos de tamanho igual a $k$, onde $N-1$ subconjuntos são utilizados para geração do modelo, ou treinamento, do classificador, e o subconjunto restante é utilizado para validação do modelo. Three-way data splits consiste da divisão do conjunto de dados em três subconjuntos disjuntos: o subconjunto de treinamento, o de validação e o de teste; neste cenário os subconjuntos de treinamento e de validação são utilizados iterativamente para a geração de vários modelos, avaliando-se diferentes arquiteturas de classificadores e, ao obter-se uma configuração satisfatória, 
utiliza-se o subconjunto de teste para uma avaliação final do modelo (Gutierrez-Osuna ; Hirata , 2011; Nguyen, 2008).

Existem algumas críticas encontradas na literatura à utilização de dados de treinamento préclassificados para a aplicação de métodos supervisionados (Phua et al., 2010):

- A classificação dos dados de treinamento pode estar incorreta;

- Pode ser custoso obter tais dados;

- Na maioria das vezes, pessoas precisam analisar manualmente cada transação. Isso demanda tempo, além de expor dados muitas vezes sensíveis dos usuários.

\subsubsection{Aprendizado Semi-Supervisionado}

Métodos semi-supervisionados buscam por aquelas transações que indicam um comportamento atípico: modela-se uma distribuição base do que seria um comportamento típico e então procuramse observações que demonstrem certo grau de discrepância em relação aquele comportamento. O método de aprendizado semi-supervisionado mais popular utiliza técnicas de clustering e detecção de outliers. Primeiro aplica-se técnicas de clustering sobre os dados pré-existentes para modelar os agrupamentos naturais (ou clusters), e a cada transação nova aplica-se técnicas de detecção de outliers sobre essa transação em relação aos clusters pré-definidos. No contexto de detecção de fraude, um outlier global é uma transação com um alto grau de discrepância em relação à todo o conjunto de transações (por exemplo, uma transação de milhares de reais em um conjunto onde todas as transações estão na casa das dezenas de reais). Já um outlier local é uma transação que se diferencia somente em relação a um subconjuntos dos dados, em geral, clusters locais.

Detecção de outliers locais é útil em situações onde o conjunto de dados é heterogêneo, sendo que esse costuma ser o caso dos sistemas de detecção de fraude em cartão de crédito. Se conseguirmos encontrar o padrão de gasto de um determinado usuário, este será representado como um cluster local e uma transação desse usuário com certo grau de discrepância em relação à esse padrão é considerado um outlier local (mas não necessariamente um outlier global) (Bolton e Hand, 2001).

Uma das grandes diferenças dos métodos semi-supervisionados em relação aos supervisionados é que, enquanto estes últimos tentam identificar a probabilidade de uma transação ser fraudulenta pela semelhança com fraudes já identificadas previamente, os métodos semi-supervisionados indicam o grau de anomalia de uma dada transação em relação a um padrão pré-estabelecido. Ou seja, métodos semi-supervisionados assumem que um comportamento inesperado é uma suspeita de fraude. Uma das vantagens dos métodos semi-supervisionados é que ele é capaz de detectar tipos de fraude que ainda não foram cometidos previamente, sendo portanto mais adaptativos.

Conforme dito na Seção 3.2.1, existem algumas críticas aos métodos supervisionados relacionadas principalmente à dificuldade em se obter dados pré-classificados. Nesses casos, faz-se necessário uma solução que não é baseada somente no comportamento dos fraudadores, mas também no comportamento dos compradores legítimos. A maioria dos compradores possui um comportamento típico na utilização de seus cartões e não costuma mudar seus hábitos com frequência. Logo, o comportamento típico de cada comprador pode ser modelado e qualquer transação feita a partir daquele comprador pode ser comparada com esse comportamento. Se ela se desviar desse padrão, temos uma suspeita de fraude (Duman e Ozcelik, 2011).

\subsubsection{Classificadores Híbridos}

Frequentemente, algoritmos supervisionados populares são combinados ou aplicados sequencialmente a fim de se obter melhores resultados (Phua et al., 2010). Esse processo é conhecido como combinação de classificadores, ou hibridização (Hodge e Austin, 2004), é usado para contornar as restrições e o viés de um algoritmo de classificação, e explorar as vantagens de múltiplas abordagens.

Ao utilizar vários classificadores ao mesmo tempo, inicialmente teremos várias saídas, sendo portanto necessário combinar essas várias saídas e gerar um resultado único. Uma maneira de 
combinar saídas é por meio de um mecanismo de votação. Porém, tal mecanismo só faz sentido se os classificadores envolvidos executam com uma performance semelhante. A classificação ficaria errada se, por exemplo, dois de três classificadores utilizados fizerem previsões incorretas. Logo, ao invés disso, uma das técnicas utilizadas é o Stacking, que introduz o conceito de aprendizado de alto nível, o qual substitui o processo de votação. Stacking tenta aprender quais dos classificadores são confiáveis, usando algoritmos de aprendizagem para descobrir a melhor forma de combinar a saída dos classificadores base (Júnior et al., 2012).

Combinação de classificadores deve ser feita cuidadosamente. Deve ser o mais simples possível, de modo a diminuir redundância, já que módulos, ou classificadores supérfluos desperdiçam recursos, aumentam a complexidade e o tempo de processamento. Identificar a melhor combinação de classificadores é um problema combinatorial (Hodge e Austin, 2004).

\subsubsection{Métricas para Avaliação de Classificadores}

Muitas medidas de avaliação de performance foram definidas para sistemas de classificação. Dentre elas temos taxa de cobertura, taxa de acertos e área sob a curva $R O C$ (Duman e Ozcelik, 2011). Para os sistemas de classificação de fraude, em cartão de crédito em específico, uma métrica bastante utilizada é a taxa mensal de chargeback (Bhatla et al., 2003). Porém, para o problema em questão, a melhor solução não necessariamente é aquela que detecta muitas fraudes, mas sim aquela que detecta fraudes possivelmente em quantidade menor, mas com um prejuízo em potencial maior (Duman e Ozcelik, 2011).

Cada transação tem um valor financeiro específico e portanto possui um prejuízo em potencial diferente. Assim, o custo de falha na detecção de uma fraude varia para cada transação (Chan et al., 1999). Além disso, conforme vimos na Seção 2.5, quando uma transação é identificada como suspeita, uma análise individual deve ser realizada por uma equipe de especialistas, o que implica em custos. Uma solução de gerenciamento de risco eficiente é aquela que minimiza o custo total da fraude, o que inclui as perdas financeiras devido às fraudes assim como o custo do sistema de detecção de fraude. Para minimizar o custo total da fraude, um balanço ótimo precisa ser alcançado entre a redução do número de fraudes e o custo do processo de análise manual (Bhatla et al., 2003). Além disso, quando uma transação é identificada como suspeita e necessita de uma revisão manual de especialistas, isso gera um atraso na efetivação da transação, gerando para o cliente uma visão de mal serviço prestado. Esse tipo de custo é extremamente difícil de ser mensurado.

\subsection{Support Vector Machines}

Support Vector Machines são uma peça importante na parte experimental deste trabalho que será descrita nos capítulos 6 e 7 e portanto vamos apresentar aqui uma breve visão conceitual sobre essa técnica.

Máquina de Vetores de Suporte ( $S V M$, do inglês Support Vector Machine) é uma técnica de aprendizado computacional bastante citada na literatura que vem recebendo crescente atenção da comunidade acadêmica. É baseada na teoria de aprendizado estatístico (Vapnik, 1995) e pode ser aplicada tanto a problemas de classificação como a problemas de regressão (Vapnik et al., 1997). O conceito primário de Support Vector Machines foi proposto por Vapnik (1995) como uma técnica de classificação binária.

$S V M$ é baseado na seleção de um hiperplano de separação ótima entre as classes no espaço de características. O hiperplano é definido de modo que a distância entre ele e o exemplo mais próximo de cada uma das classes seja máxima. Esses exemplos são chamados de vetores de suporte e a distância entre esses vetores de classes diferentes é chamada de margem do classificador. Segundo Kumar et al. (2006), um classificador com um limite de decisão com margem máxima tem o efeito de minimizar erros de generalização. A Figura 3.1 ilustra a ideia de um hiperplano de separação entre as classes com margem máxima para um problema onde o espaço de características possui 2 dimensões. 


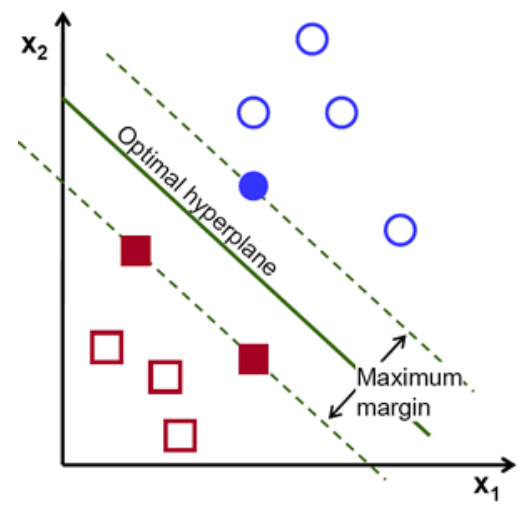

Figura 3.1: Hiperplano de separação ótimo com margem máxima. Fonte: http://docs.opencv.org/

Percebe-se que a descrição apresentada acima é aplicável somente para os casos em que as classes são linearmente separáveis. Para os casos em que as classes não são linearmente separáveis, o espaço de características original é mapeado em um espaço com dimensões muito maiores. Esse processo resulta em um conjunto de dados linearmente separável que pode ser tratado por um separador linear no novo espaço de características. A Figura 3.2 ilustra essa ideia.

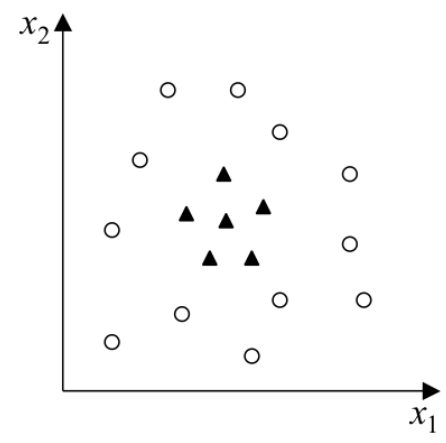

(a)

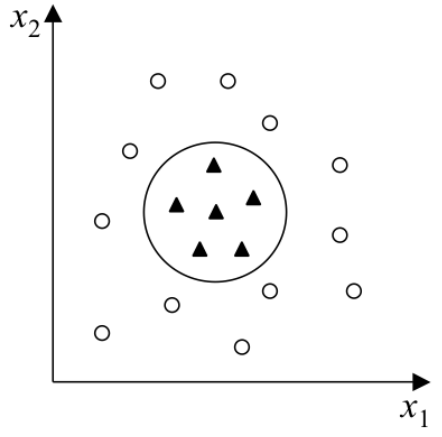

(b)

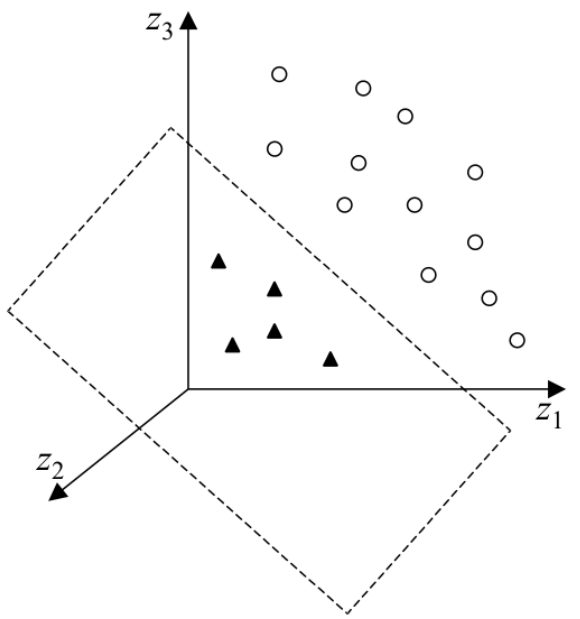

(c)

Figura 3.2: Mapeamento das características para espaços com dimensões maiores; (a) Conjunto de dados não-linear; (b) Fronteira não-linear no espaço original; (c) Fronteira linear no novo espaço. Fonte: Lorena e Carvalho (2007)

A projeção dos dados do espaço de características original no novo espaço de dimensões maiores é feita através de funções chamadas de kernel. Essas funções podem ser, por exemplo, polinomiais, gaussianas (em geral chamadas de radiais), quadráticas dentre outras. A escolha do tipo da função kernel depende do problema em questão pois ela depende do que se pretende modelar. Um kernel polinomial por exemplo permite a modelagem de conjunções de características até a ordem polinomial selecionada. Kernels radiais permitem a seleção de círculos (ou hiper-esferas) enquanto um kernel linear permite somente a seleção de hiperplanos (Singh et al., 2012).

De acordo com Burges (1998), a performance de SVM é igual ou significativamente maior quando comparado a outras técnicas computacionais na maioria dos casos. Uma das vantagens de SVMs quando comparada a outras técnicas tradicionais de classificação é sua robustez diante de dados de grande dimensão (Burges (1998); Lorena e Carvalho (2007)), sobre os quais outras técnicas, como Redes Neurais, tendem a gerar modelos super ou sub-ajustados. Essa é uma característica 
muito importante para o problema de detecção de fraude que estamos tratando, pois conforme veremos no Capítulo 5, estamos utilizando um conjunto grande de atributos a ser passado para o classificador. Outra característica importante de $S V M s$ é que devido a convexidade do problema de otimização formulado em seu treinamento, o modelo gerado possui um único mínimo global, diferente de Redes Neurais por exemplo, onde a existência de vários mínimos locais leva a problemas de generalização do modelo gerado a partir dos dados de treinamento (Lorena e Carvalho (2007); Singh et al. (2012)). Essa também é uma característica de grande importância para o problema de detecção de fraude na forma como iremos tratá-lo no Capítulo 5, uma vez que apesar de ser razoável assumir que o comportamento dos usuários envolvidos no sistema tende a manter um padrão semelhante ao longo do tempo, ele certamente sofrerá algumas variações, o que faz com que uma boa capacidade de adaptação às variações do modelo seja uma característica importante para a técnica de aprendizado computacional utilizada. Segundo Singh et al. (2012), SVM possui um interpretação geométrica simples, e sua complexidade computacional não depende da dimensionalidade do espaço de característica do problemas, o que o torna adequado para problemas cujo modelo possui um grande número de dimensões.

Hejazi e Singh (2012) e Burges (1998) dizem que pela sua natureza, SVMs são intrinsecamente classificadores binários. Apesar de existirem estratégias através das quais $S V M$ pode ser adaptado para problemas com mais de duas classes, essa é uma limitação que não nos afeta pelo fato do nosso problema ser naturalmente binário (o objetivo é classificar em uma de duas classes: fraude ou nãofraude). Do ponto de vista prático, uma das maiores limitações de $S V M$ é a sua alta complexidade algorítmica e extensiva necessidade de memória computacional. Segundo Cao (2003) e Hand et al. (2006), a complexidade computacional para o treinamento de SVMs escala aproximadamente entre quadrática e cúbica na quantidade de exemplos de treinamento.

Uma descrição de $S V M$ com uma fundamentação matemática mais completa pode ser encontrada em Lorena e Carvalho (2007), Hejazi e Singh (2012) e Burges (1998)

\subsection{Considerações Finais}

Este Capítulo apresentou uma visão geral do problema de detecção de fraude em cartões de crédito do ponto de vista das técnicas computacionais de mineração de dados. Descrevemos algumas características do problema e os tipos de classificadores aplicáveis. Vimos também que um bom classificador não é necessariamente aquele que detecta muitas fraudes, mas sim aquele que detecta os maiores prejuízos em potencial. Por fim, descrevemos a técnica Support Vector Machine que será utilizada nos experimentos descritos em capítulos posteriores deste trabalho. 
24 TÉCNICAS COMPUTACIONAIS PARA A DETECÇÃO DE FRAUDE COM CARTÃO DE CRÉDITß.4 


\section{Capítulo 4}

\section{Descrição e Análises Preliminares dos Dados}

Neste capítulo descrevemos todo o processo de preparação inicial e extração do conjunto de dados a ser utilizado nos experimentos, assim como os resultados de algumas análises iniciais mais simples sobre o conjunto de dados.

Neste trabalho estamos contando com a colaboração de uma importante empresa do mercado de intermediação de pagamentos online brasileiro. Temos a disposição uma enorme quantidade de dados reais da referida empresa para a realização da nossa pesquisa. Conforme dito no Capítulo 1, um dos desafios na pesquisa para métodos de detecção de fraudes em cartões de crédito é a dificuldade na obtenção de dados reais para pesquisas. Tais dados só existem com instituições financeiras e mais recentemente com intermediadores de pagamento online, e invariavelmente possuem informações confidenciais a respeito dos clientes dessas empresas, o que justifica o cuidado na disponibilização dessas informações. Os dados que nos foram disponibilizados passaram por um processo de sanitização, no qual todas as informações consideradas sensíveis foram mascaradas, de forma que ao final do processo não era possível mais ter conhecimento sobre a informação original, mas a diferenciação entre os dados era mantida. Além disso, assinamos um acordo de não divulgação das informações (non-disclosure agreement), motivo pelo qual omitiremos algumas informações sensíveis ao negócio nos resultados que serão apresentados.

\subsection{Identificação da Fraude}

Conforme dito no Capítulo 2, a consequência imediata da fraude é o chargeback: toda fraude que for identificada pelo usuário lesado irá resultar em um chargeback, cujo prejuízo será assumido integralmente pelo intermediador de pagamentos online. Por outro lado, nem todo chargeback é consequência de uma fraude. Podemos enumerar três principais motivos para a ocorrência de um chargeback nas transações realizadas através de um intermediador de pagamentos online:

1. Uma fraude cuja origem está no comprador da transação. Esses casos incluem, por exemplo, situações em que o comprador inicia a transação já com a intenção ilícita de solicitar um chargeback posterior, ou casos em que dados de um comprador idôneo são utilizados, sem o seu consentimento, por outro indivíduo para realizar a transação;

2. Uma fraude cuja origem está no vendedor da transação. Aqui incluímos, por exemplo, situações em que o vendedor intencionalmente entrega um produto diferente, ou com uma qualidade inferior, em relação ao produto originalmente transacionado, gerando no comprador uma insatisfação que pode resultar em um chargeback; e

3. Uma situação de desacordo comercial entre o comprador e o vendedor, sem que houvesse uma má intenção original de qualquer uma das partes, porém sem uma resolução amigável. 
Das três situações enumeradas, somente duas estão relacionadas a fraude, porém é fundamental notar que todas as três resultarão no mesmo prejuízo para o intermediador de pagamentos online: a absorção completa do prejuízo gerado pelo chargeback. Logo, podemos afirmar com segurança que, seja qual for a origem do chargeback, ele é igualmente nocivo para o intermediador de pagamentos, e portanto, do ponto de vista prático, o principal objetivo dessas empresas ao fazer investimentos em tecnologias para detecção de fraudes é evitar os prejuízos gerados pelos chargebacks, independente de qual seja a sua origem.

Por outro lado, é de conhecimento de especialistas da área que a grande maioria dos chargebacks são causados por fraudes, seja ela do vendedor ou do comprador. Para os casos de descordo comercial, as empresas do setor de intermediação de pagamentos online costumam oferecer ferramentas que fazem a mediação da situação entre o vendedor e o comprador, com o intuito de facilitar a resolução da situação de forma amigável, o que gera um redução significativa na quantidade de chargebacks consequentes de desacordos comerciais.

Nos dados que nos foram disponibilizados, não temos uma indicação clara da ocorrência ou não de fraude em uma transação, mas temos a identificação da ocorrência ou não de chargeback. Porém, não há a indicação do motivo do chargeback, de forma que não conseguimos identificar qual das três situações previamente enumeradas é a sua causa. Face a essa situação, ao conhecimento de que a grande maioria dos chargebacks são decorrentes de fraude e finalmente pelo fato de o prejuízo gerado ser o mesmo independente da origem do chargeback, daqui em diante nós vamos tratar todos os chargebacks da nossa base de dados como fraude, com o entendimento de que isso não irá gerar um prejuízo significativo para as análises, e tampouco irá distanciar nossas análises de uma situação real. Assim, sempre que falarmos de um chargeback, estamos falando de uma fraude. De forma análoga, sempre que falarmos de uma transação legítima, estamos falando de uma transação para a qual não ocorreu um chargeback.

\subsection{Preparação do Conjunto de Dados}

Estamos trabalhando com uma quantidade muito grande de dados e devido a isso é importante fazer uma preparação cuidadosa de forma a simplificar dentro do possível etapas posteriores de análise. Os dados que nos foram disponibilizados estão em um banco de dados relacional contendo várias tabelas, cada uma das quais podendo ou não possuir informações relevantes para o problema. Assim, a primeira etapa do processo consistiu em selecionar somente as tabelas que possuem informações relacionadas a transações e/ou usuários. Feita essa primeira seleção, o próximo passo foi fazer uma análise mais minuciosa do conjunto de tabelas selecionado e selecionar somente as colunas relevantes de cada uma delas.

Essa fase inicial de seleção representou uma redução significativa no volume de dados, porém ainda estamos com um modelo relacional fragmentado em várias tabelas. O próximo passo foi montar uma consulta $S Q L$ que agrupa em uma única linha todas as informações que estão espalhadas em várias tabelas. A principal dificuldade nessa etapa foi em conseguir elaborar uma consulta capaz de agrupar todos os dados necessários respeitando as regras de negócio representadas nos dados armazenados. Um exemplo desse tipo de regra que pode facilmente gerar registros duplicados de transações no resultado da consulta é o fato do comprador poder tentar fazer o pagamento com mais de um cartão de crédito: é possível que o usuário utilize, em uma primeira tentativa, um cartão cujo limite de crédito seja insuficiente para o valor da transação. Nesse caso, poderá ser oferecida imediatamente ao usuário a possibilidade de ele utilizar outro cartão de crédito (ou até mesmo outra forma de pagamento), porém ambas as tentativas de pagamento ficarão registradas, sendo que somente a tentativa que foi efetiva interessa para as nossas análise. Dada a imensa quantidade de dados que estamos tratando, qualquer erro nesse processo que afete somente conjuntos menores de transações pode passar facilmente despercebido e gerar ruídos em etapas posteriores do processo. Posto isso, tomamos o cuidado de constantemente verificar a quantidade de registros retornados por esse processo e compará-los com a quantidade de registros esperada.

Finalizada a consulta $S Q L$ responsável por agrupar todas as informações, criamos uma nova 
tabela em um banco de dados intermediário para armazenar os resultados dessa consulta. Cada linha dessa tabela representa um registro retornado pela consulta, com exatamente os mesmos atributos. Isso foi feito para facilitar a manipulação dos resultados e a geração de arquivos no formato $C S V$ (comma-separated values) menores e mais adequados para a importação em ferramentas de análise estatística. Nesse trabalho estamos utilizando o software $R$ [http://www.r-project.org] para tais análises.

Ao final desse processo, obtivemos um conjunto de dados com todas as transações disponíveis no período de $01 / 01 / 2011$ a $31 / 05 / 2012$, o que equivale a dezenas de milhões de transações com um percentual muito pequeno de fraudes, caracterizando um altíssimo nível de desbalanceamento. Conforme já dito, uma fraude equivale a um chargeback por parte do dono do cartão de crédito, e este não ocorre imediatamente após a concretização da transação. Bhatla et al. (2003) diz que, em média, ele ocorre cerca de um ou dois meses após a efetivação da transação, que é o tempo para o usuário receber a transação em sua fatura e realizar a contestação. Porém, verificamos nos dados que temos disponíveis que em alguns casos o chargeback demora mais de seis meses para ser realizado. Devido a isso, é importante analisar um conjunto de dados relativamente antigo para que se tenha certeza de que todas as fraudes ocorridas naquele período já tenham sido identificadas.

\subsection{Descrição dos atributos}

Após entender o processo de extração e preparação do conjunto de dados inicial, descrevemos os atributos que utilizaremos para a realização de experimentos que serão descritos posteriormente. Tomamos o cuidado de selecionar somente atributos que sejam gerais para o modelo de negócio dos intermediadores de pagamento online, ou seja, informações que estariam presentes em qualquer empresa desse setor. Existem outras informações disponíveis no conjunto de dados que preparamos através do processo recém-descrito, mas estas são informações muito específicas da empresa que nos disponibilizou os dados e não seriam necessariamente aplicáveis ao modelo de negócio de outras empresas do setor.

As informações de cada transação que utilizaremos nas nossas análises são as seguintes:

1. Hora: hora do dia em que a transação foi realizada;

2. Código do comprador: código de identificação única do comprador dentro do sistema;

3. CPF do comprador: CPF do comprador da transação;

4. IP do comprador: IP da estação de trabalho do comprador da transação;

5. Código de geolocalização do IP do comprador: código que indica a unidade federativa correspondente aquele $I P$, ou seja, tenta identificar através do $I P$ qual a unidade federativa da qual está sendo feita a transação - essa identificação não é totalmente precisa;

6. Telefone do comprador: telefone informado pelo comprador na transação;

7. CEP do comprador: CEP residencial informado pelo comprador na transação;

8. CEP de entrega: CEP de entrega da mercadoria envolvida na transação;

9. Código de identificação do vendedor: código de identificação única do vendedor dentro do sistema;

10. Categoria do vendedor: todo vendedor precisa se enquadrar em uma das categorias de venda disponíveis no sistema, a qual está associada ao tipo de negócio do vendedor. Cada vendedor está associado a somente uma categoria e, caso ele se encaixe em mais de uma categoria, será associado àquela que mais lhe for adequada;

11. Cartão de crédito: identificador único do cartão de crédito da transação; 
12. CPF do portador do cartão de crédito: CPF do portador ou dono do cartão de crédito;

13. Data de nascimento do portador do cartão de crédito;

14. Idade do portador do cartão de crédito;

15. Bandeira do cartão de crédito;

16. Faixa de valor da transação: definimos previamente faixas de valores fixas e classificamos cada transação em uma dessas faixas, de acordo com o seu valor específico;

17. Meio de pagamento da transação: nosso foco está nas transações cujo meio de pagamento é cartão de crédito, mas também existem transações com outros meios de pagamento na nossa base que são relevantes para a análise histórica;

18. Quantidade de parcelas da transação;

19. Quantidade de produtos da transação; e

20. Quantidade de produtos distintos da transação.

Nem todas as informações anteriores estão presentes em todas as transações. Por exemplo, o CEP de entrega não é uma informação obrigatória, o código de geolocalização pode não ter sido detectado, etc. Além disso, informações relacionadas ao cartão de crédito só existirão se o meio de pagamento da transação for cartão de crédito. Outro ponto importante a ser considerado é que o portador do cartão de crédito e o comprador nem sempre são a mesma pessoa - existem casos de transações legítimas feitas por um determinado usuário utilizando o cartão de crédito de outra pessoa com o consentimento desta última.

Por fim, é importante citar que toda análise de dados prevê uma etapa, conhecida como análise preliminar de dados, onde fazem-se estatísticas simples sobre os dados e, principalmente, algumas visualizações no plano e no espaço, com o objetivo de verificar se há estruturas, ou padrões, nos dados que não deveriam estar la. Essas análises consistem em fixar algum critério e verificar graficamente como se distribuem as transações boas (aquelas que não originaram chargeback) e as transações fraudulentas (aquelas que geraram chargeback) em relação a esse critério. Nesse trabalho realizamos essa etapa para algumas das informações recém-enumeradas, como por exemplo a Hora, a Categoria do vendedor, a Idade do portador do cartão de crédito, a Faixa de valor da transação e a Quantidade de parcelas da transação. Essas análises foram importantes para nos fornecer um entendimento inicial dos dados, além de nos mostrar que algumas dessas características, mesmo que de forma isolada, nos trazem alguma capacidade de discriminação para identificação dos chargebacks.

\subsection{Avaliando a Recorrência do Uso do Sistema}

No Capítulo 5 será apresentada um proposta de modelagem baseada no comportamento de quatro entidades principais envolvidas na realização de uma transação: o comprador, o vendedor, o cartão de crédito e o portador do cartão de crédito. Para essa abordagem que será proposta, é importante ter um entendimento do padrão de utilização do sistema por parte dessas entidades, principalmente no que se refere a variação do risco associado à transação em relação a esse padrão de utilização. Para isso, analisamos a variação do risco em relação ao nível de recorrência de utilização do sistema por parte dessas entidades. O que chamamos de risco aqui é a relação entre a quantidade de chargebacks e a quantidade de transações boas e, o que chamamos de recorrência, é a quantidade de vezes que uma dada entidade (um comprador, por exemplo) utilizou o sistema, ou seja, de quantas transações ela participou. Essas análises foram realizadas em um subconjunto dos dados descritos na Seção 4.2, o qual consiste de todas as transações de cartão de crédito do dia 01/01/2011 ao dia $30 / 06 / 2011$.

As Figuras 4.1, 4.2, 4.3 e 4.4 mostram a variação do risco de acordo com o nível de recorrência de cada uma das entidades citadas. Para a apresentação dos dados nessas figuras, o risco, para 
cada nível de recorrência do eixo $x$, foi divido pelo desvio padrão do conjunto de valores do eixo $y$, de forma que cada valor de risco apresentado a seguir consiste da relação entre a quantidade de transações legítimas e fraudulentas em cada nível de recorrência, divido pelo desvio padrão dessa relação em todos os níveis de recorrência apresentados.

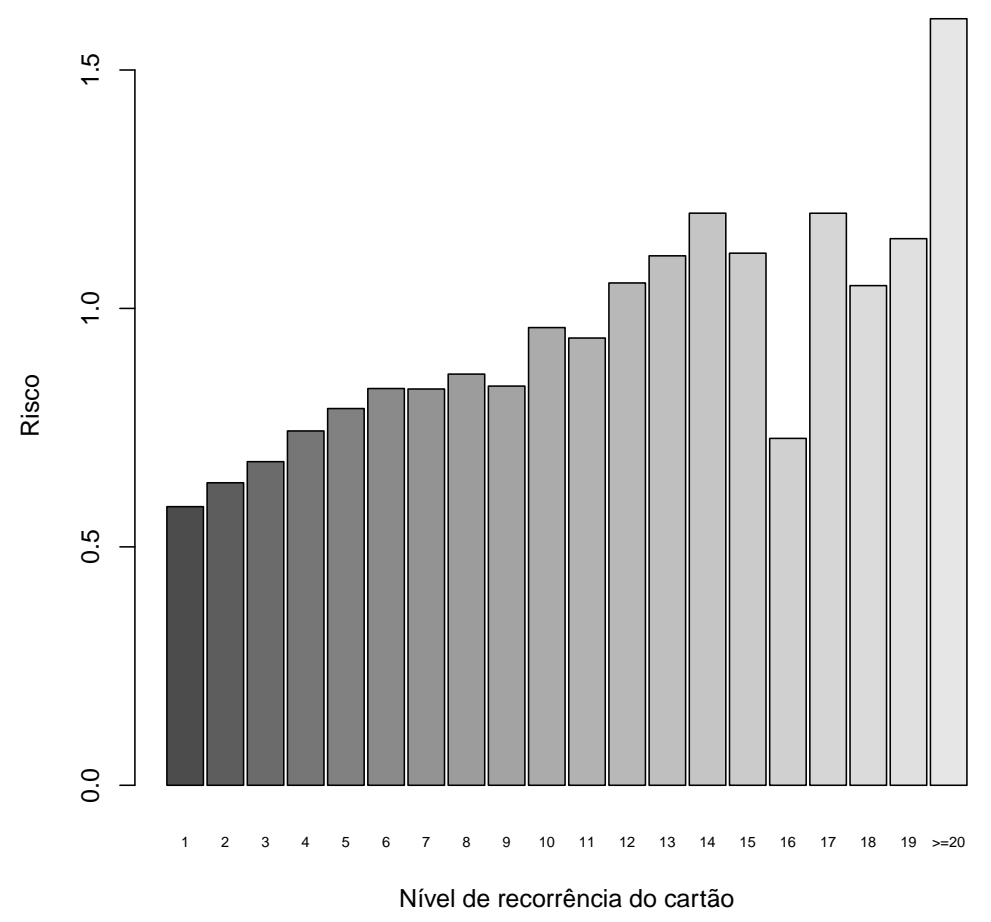

Figura 4.1: Risco por nivel de recorrência da utilização do cartão de crédito. 


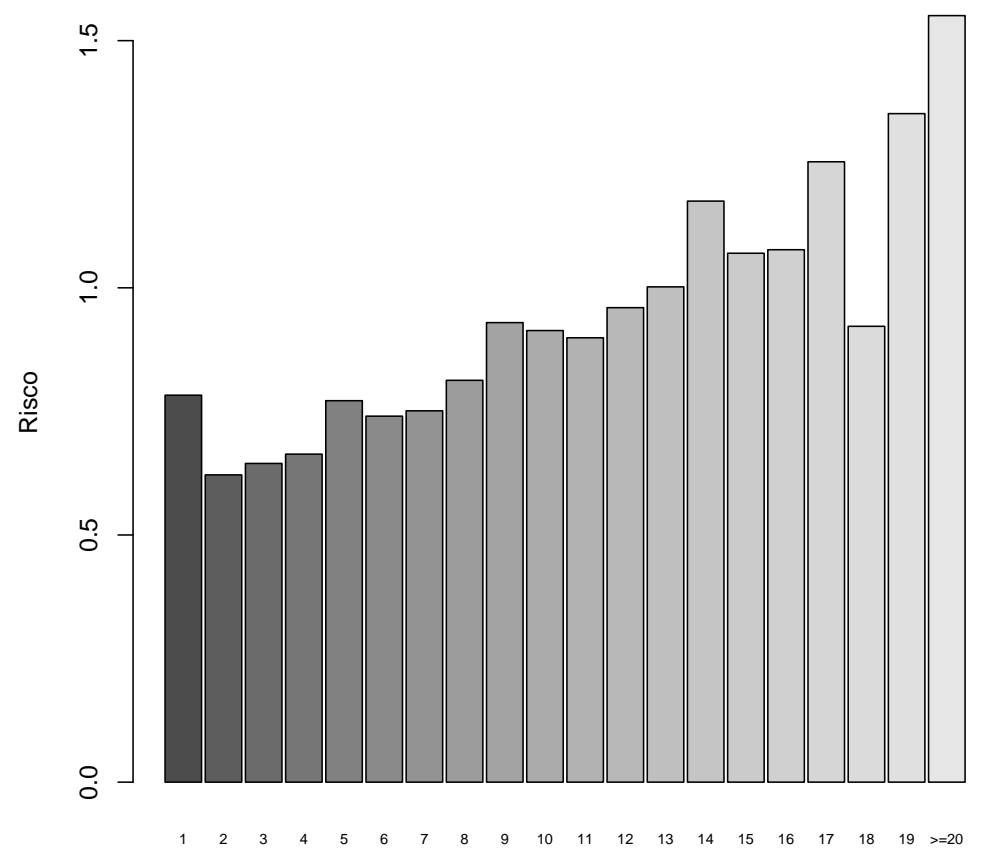

Nível de recorrência do comprador

Figura 4.2: Risco por nivel de recorrência do comprador.

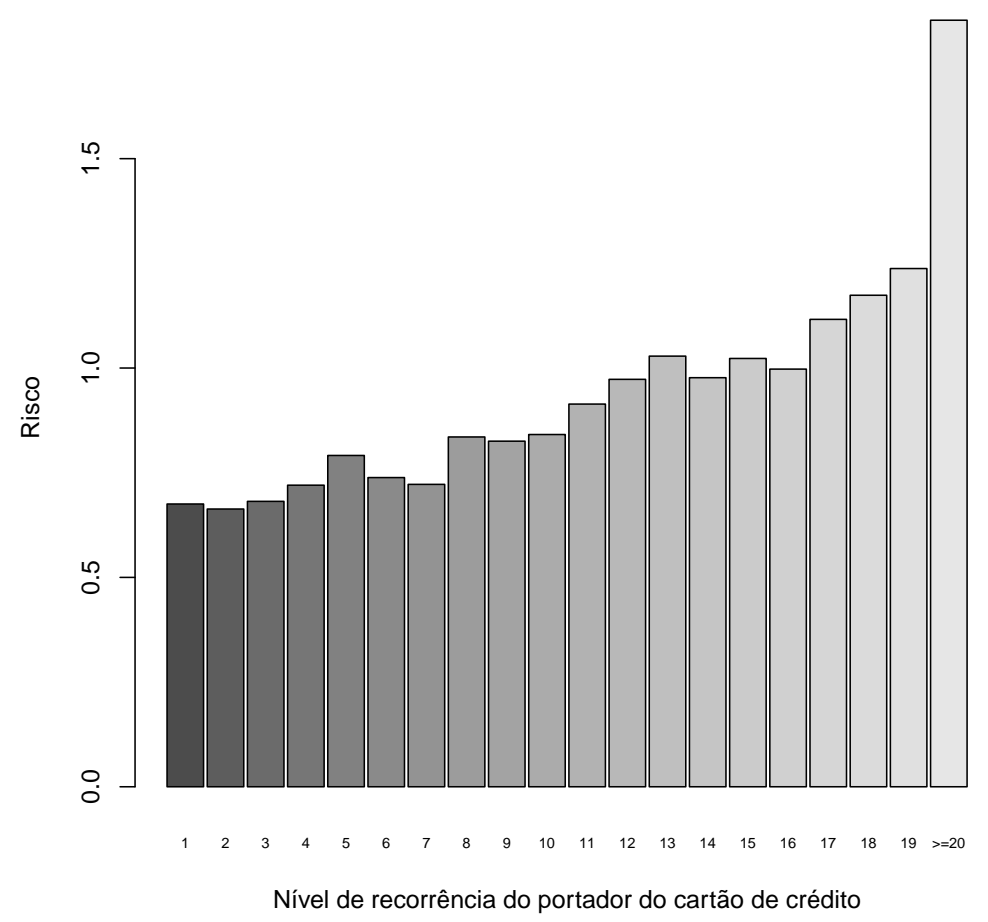

Figura 4.3: Risco por nivel de recorrência do portador. 


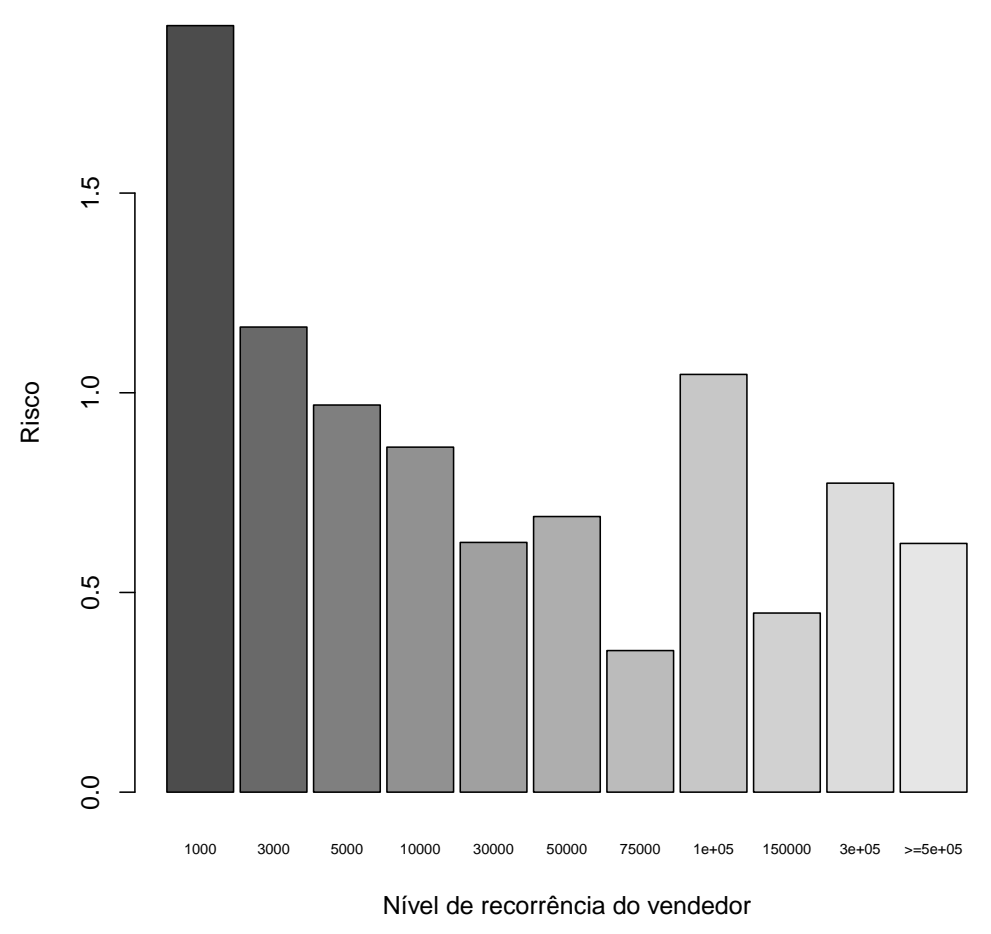

Figura 4.4: Risco por nível de recorrência do vendedor.

O que se percebe nas Figuras 4.1, 4.2, 4.3 e 4.4 é que há uma variação do risco associado às transações em relação ao nível de recorrência. Outro ponto muito importante a ser notado é que, para as figuras 4.1, 4.2 e 4.3, há uma tendência de aumento do risco de acordo com o nível de recorrência do cartão, do comprador e do portador respectivamente, enquanto que para a Figura 4.4 há uma tendência de diminuição do risco de acordo com o aumento da recorrência do vendedor. Além disso, percebe-se que os níveis de recorrência do vendedor são bem maiores do que para o cartão, o comprador e para o portador; esse comportamento fica claro na Figura 4.5, que mostra uma comparação da quantidade média de transações em que cada uma das quatro entidades citadas participa. 


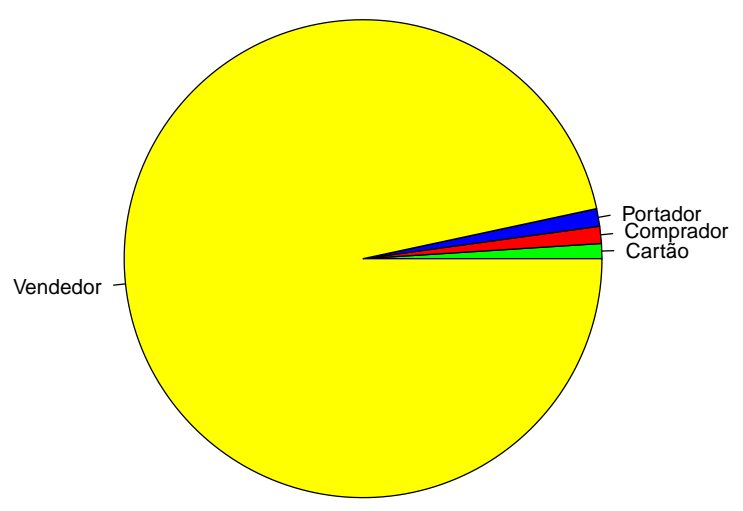

Figura 4.5: Comparação do nível médio de recorrência de cada entidade.

Fica claro pela Figura 4.5 que os vendedores possuem, em média, um nível de recorrência muito maior do que as outras três entidades, ou seja, um mesmo vendedor tende a participar de mais transações do que um único comprador, um único portador ou um único cartão.

\subsection{Considerações Finais}

Neste capítulo descrevemos o processo de extração e preparação do conjunto de dados a ser utilizado nos nossos experimentos. Em seguida, descrevemos as informações presentes em cada transação que serão consideradas nos nossos experimentos descritos posteriormente nos capítulos 6 e 7. Por fim, analisamos o comportamento de quatro entidades envolvidas em uma transação e chegamos a importante conclusão que o vendedor possui um comportamento bem diferenciado em relação às outras três entidades.

Já citamos anteriormente a dificuldade em se obter dados reais para a realização de pesquisas para detecção de fraude em cartões de crédito e o impacto que isso tem na publicação de trabalhos relevantes. Posto isso, o presente trabalho tem muito a contribuir no sentido de estar utilizando dados reais de um grande intermediador de pagamentos online. 


\section{Capítulo 5}

\section{Uma Abordagem para a Modelagem do Problema Baseada nas Entidades Envolvidas na Transação}

Detecção de fraude é um problema extremamente complexo e difícil de ser tratado. Transações fraudulentas estão espalhadas entre uma quantidade muito grande de transações legítimas e, conforme visto no Capítulo 3, são muitos os desafios presentes para detectar essas transações.

Um dos grandes desafios do problema é a sua heterogeneidade. O perfil dos fraudadores é bastante variado, assim como o perfil dos usuários legítimos, o que dificulta muito o estabelecimento de padrões. Vimos na Seção 3.1.3 que os perfis dos usuários podem variar com o tempo, principalmente o perfil dos fraudadores: os fraudadores tendem a aprender como os sistemas de detecção de fraude funcionam e constantemente evoluem o seu comportamento para tentar driblar esses sistemas (Bolton e Hand, 2001; Chan e Stolfo, 1998; Chan et al., 1999; Delamaire et al., 2009; Phua et al. , 2010). Além disso, vimos na Seção 2.5.1 que é muito difícil ter um único sistema ou uma única abordagem capaz de detectar corretamente todos os tipos de fraude.

Dissemos na Seção 2.5 que detecção de fraude é um processo abrangente composto de vários sistemas e interações humanas, o qual envolve desde a utilização de ferramentas de detecção automática de fraudes, passando por revisões manual das transações até a gestão econômica do processo como um todo. Neste capítulo apresentamos uma proposta de um sub-processo a ser aplicado à etapa de triagem automatizada do processo de gerenciamento de fraude apresentado na Seção 2.5.

\subsection{Processo para a Detecção Automática de Fraudes}

Nesta seção descreveremos o que consideramos ser relevante para um processo de detecção automática de fraude no contexto dos intermediadores de pagamento online.

\subsubsection{Prevenção à Fraude}

A primeira barreira contra a fraude é a prevenção. Esta, diferentemente da detecção, tenta evitar que a transação fraudulenta se inicie, ao invés de tentar detectá-la após seu início. Exemplos de ações de prevenção à fraude são:

- Análise do estabelecimento, ou vendedor, ao qual se permitirá o recebimento de pagamentos através de cartões de crédito;

- Análise dos compradores antes de permitir que estes realizem transações com cartões de crédito. Isso não é aplicável ao modelo de negócio dos intermediadores de pagamento online, uma vez que não há nem mesmo a necessidade de um comprador fazer um cadastro no sistema para sua posterior utilização; 
- Bloqueio de usuários com alta incidência de chargebacks;

- É muito comum no mercado de intermediação de pagamentos online que os intermediadores recebam periodicamente dos adquirentes uma lista de números de cartões de crédito, ou uma lista de clientes, que foram identificados como tendo um alto grau de risco, por diversas razões, e que portanto devem ter suas transações bloqueadas;

- Campanhas de conscientização dos usuários quanto ao uso seguro do cartão de crédito, ou do sistema de intermediação de pagamentos online.

Em muitos casos a linha de separação entre detecção e prevenção à fraude é tênue, chegando a ser discutível onde termina o escopo de uma e começa o da outra.

\subsubsection{Validação da Transação com o Adquirente}

Uma característica dos intermediadores de pagamento online é que eles não são os responsáveis pela efetivação das transações junto às instituições financeiras. Como o próprio nome diz, eles somente fazem a intermediação entre os usuários (compradores e vendedores) e os adquirentes, e estes por sua vez é que são as responsáveis por repassar a transação para o restante da cadeia de processamento.

É perfeitamente possível que uma transação aprovada pelo intermediador de pagamentos online seja posteriormente rejeitada pelo adquirente ou qualquer outro membro da cadeia de processamento, uma vez que trata-se de empresas distintas e suas análises são independentes. Além disso, o intermediador de pagamentos online não é o responsável pela administração da operação do cartão de crédito, e portanto não possui informações para algumas validações básicas, como por exemplo se os dados do cartão de crédito informado são válidos ou se o valor da transação está dentro dos limites de utilização de crédito disponíveis para o cartão. Assim, todo um esforço de análise e posterior aprovação de uma transação por parte do intermediador de pagamentos seria totalmente desperdiçado se a transação fosse posteriormente rejeitada por algum outro membro da cadeia de processamento.

Dado o cenário acima, algo passível de ser feito é, antes de iniciar o processo de análise de uma transação de cartão de crédito por parte do intermediador de pagamentos online, verificar com o adquirente se a transação será aprovada. Se o adquirente informar que a transação será rejeitada, a transação pode ser descartada imediatamente pelo intermediador. Caso o adquirente informe que a transação será aprovada, o processo de análise da transação por parte do intermediador de pagamentos online segue normalmente.

\subsubsection{Consultas a Sistemas Externos}

Atualmente existem no mercado algumas empresas que reúnem dados de consumidores, realizam análises de credibilidade dos mesmos e vendem o acesso à essas análises, cobrando uma taxa por essas consultas. Um exemplo desse tipo de empresa é o Serasa (http://www.serasaexperian.com.br/). Uma das etapas relevantes para um processo de detecção de fraude consiste na consulta dos dados do usuário nessas empresas. O resultado da consulta pode ser utilizado nas etapas posteriores do processo e a forma de utilização desses dados pode variar desde a rejeição imediata caso alguma inconsistência seja encontrada até a simples agregação do resultado da consulta à outras informações para análises adicionais.

\subsubsection{Regras de Alta Precedência}

Existe um grupo de transações que se enquadram em um tipo de análise que pode ser considerada mais simples, baseada em regras bem conhecidas por especialistas em fraude e de complexidade relativamente baixa. Essas regras podem variar de um sistema para outro e são muito dependentes do conhecimento da equipe de especialistas que modela o sistema. Exemplos simples desses tipos de regras são: 
- Cartões de crédito ou usuários sabidamente fraudulentos por algum motivo (ou seja, dados cadastrados em listas negativas);

- Cartões de crédito ou usuários sabidamente idôneos por algum motivo (ou seja, dados cadastrados em listas positivas);

- Transações oriundas de estações de trabalho consideradas de alto risco (ex: lan-houses);

- Transações de usuários que cometeram fraudes recentemente.

Essas regras podem ser responsáveis tanto por reprovar como por aprovar diretamente uma transação. Além disso, é importante que esteja disponível para a equipe de especialistas em fraude um sistema ágil de criação e edição de regras, de forma que assim que uma nova situação seja identificada ela seja imediatamente inserida no sistema.

\subsubsection{Modelagem do Problema}

A partir desse ponto do processo começamos a modelar o problema para a aplicação de técnicas de mineração de dados. Descreveremos a seguir o modelo proposto no presente trabalho.

\section{Entidades Envolvidas na Transação}

Podemos fazer uma abstração de modo a enxergar uma transação de cartão de crédito como sendo a interação entre quatro entidades: o comprador, o vendedor, o cartão de crédito utilizado na transação e o portador do respectivo cartão. Daqui em diante, vamos nos referir a essas entidades como Comprador, Vendedor, Cartão e Portador.

Analisando o conjunto de informações relacionadas à transação listado na Seção 4.3, podemos facilmente identificar determinadas informações que são mais diretamente relacionadas a uma ou outra das quatro entidades recém citadas. Por exemplo, é natural fazer uma relação direta da informação "CPF do comprador" com a entidade Comprador. Porém, nossa intenção não é fazer essa associação de cada entidade com as informações que mais lhe são relacionadas. Na abstração aqui sendo feita, é mais correto dizer que cada uma das entidades está relacionada com todas as informações da transação, porém esse conjunto de informações é visto através de uma perspectiva diferente para cada entidade. A Figura 5.1 ilustra essa ideia:

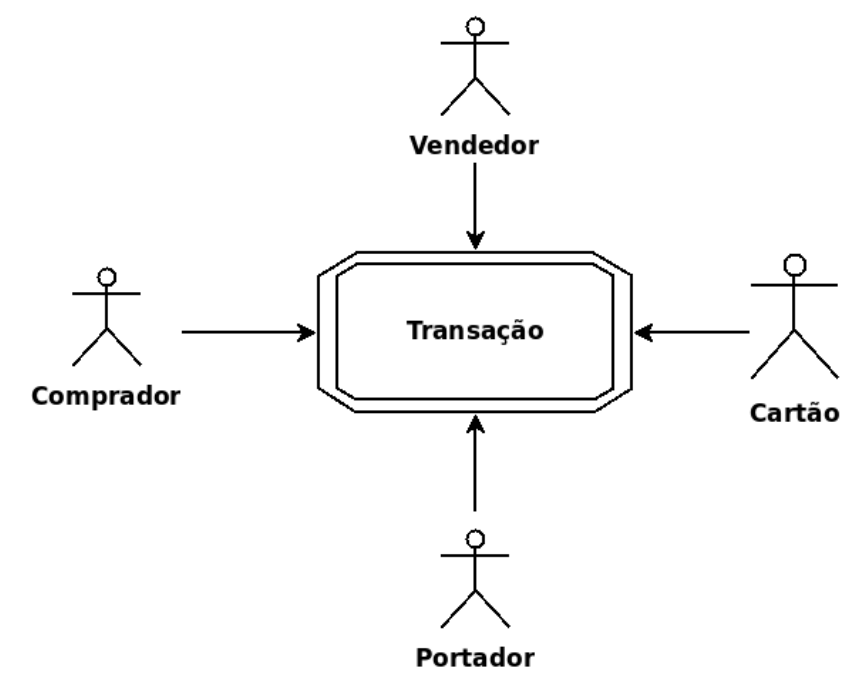

Figura 5.1: Visão do relacionamento entre as entidades e a transação. 


\section{Histórico de Transações das Entidades}

Uma determinada entidade (um determinado comprador, por exemplo) participa de várias transações ao longo do tempo (é razoável supor que um mesmo comprador realize várias transações ao longo do tempo). Vamos considerar que, num dado momento, cada entidade possua um histórico de transações já realizadas anteriormente. Como as entidades de uma transação são independentes entre si, o histórico de cada uma delas será um conjunto de transações que independe do histórico das demais entidades da mesma transação. Pode ser que existam transações comuns no histórico das entidades de uma transação, mas os históricos em si são independentes. Por exemplo, é possível que existam mais de uma transação entre um mesmo comprador e um mesmo vendedor em momentos distintos: assim, em algumas transações o histórico daquele comprador e daquele vendedor terão algumas transações em comum, mas ainda assim consideraremos esses históricos como sendo independentes. A Figura 5.2 ilustra uma transação com suas entidades e respectivos históricos:

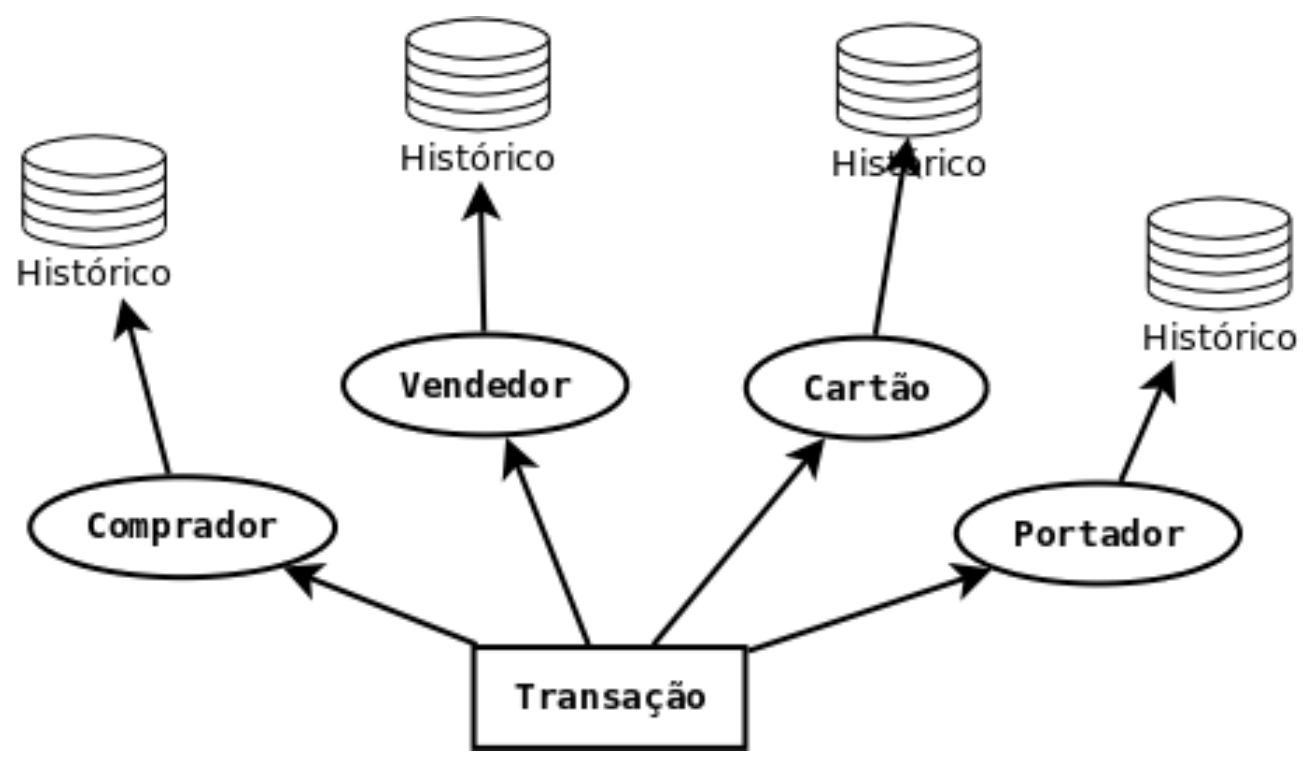

Figura 5.2: Visão do relacionamento transação, entidades e histórico.

\subsubsection{Comparação com Fraudes Anteriores}

Definida a modelagem geral do problema apresentada na Seção 5.1.5, o próximo passo é fazer uma análise do modelo gerado de uma transação comparando-o com outras fraudes já previamente identificadas, verificando assim a semelhança da transação em análise com fraudes que ocorreram previamente. Para isso, é essencial a identificação precisa das fraudes, e essa necessidade representa uma grave problema para os dados que temos disponíveis. Conforme veremos na Seção 5.2.1, existe um conjunto de transações no nosso conjunto de dados que não foi aprovado pelo processo de análise já existente na empresa, porém não temos como saber se essas transações, caso fossem aprovadas, iriam realmente gerar chargebacks. Face a isso, temos três opções disponíveis para tratar esse problema:

1. Assumir que todas as transações não aprovadas iriam de fato gerar chargeback;

2. Assumir que nenhuma das transações que não foram aprovadas iriam gerar chargeback; e

3. Desconsiderar completamente o conjunto de transações não aprovadas;

As duas primeiras opções certamente iriam gerar um nível de ruído muito grande no conjunto de chargebacks e, dado que a existência de ruído afeta principalmente as classes mais raras em sistemas de mineração de dados que precisam lidar com dados desbalanceados (Weiss, 2004), o nível de ruído gerado certamente prejudicaria muito a comparação. A terceira abordagem certamente descartaria 
um conjunto relevante de transações que deveriam ser levadas em consideração nas análises, e portanto também não seria uma estratégia aceitável.

Frente a isso, apesar de a comparação com fraudes anteriores ser uma etapa válida e importante do processo aqui proposto, esse não será o foco principal do presente trabalho e portanto não iremos abordar aqui maneiras de fazer essa comparação.

\subsubsection{Comparação com Transações Legítimas Anteriores}

Por fim, a última etapa do processo proposto consiste em comparar o modelo gerado de uma transação com o histórico de transações legítimas (ou seja, transações que não geraram chargeback) contidas no sistema. O objetivo dessa tarefa é comparar o quão semelhante a transação atual é com outras transações legítimas que ocorreram previamente.

Devido aos motivos apresentados na Seção 5.1.6, temos aqui, ou um problema de ruído gerado ao fazermos alguma suposição sobre a futura geração ou não de chargebacks por parte das transações não aprovadas, ou um problema decorrente do fato de descartarmos um conjunto relevante de transações. Porém, dado que a classe de transações legítimas possui uma quantidade muito maior de exemplos do que a classe de transações fraudulentas, qualquer um desses problemas tem um impacto muito menor nas análises. Face a isso, é nessa etapa do processo que está o foco do presente trabalho e ela será abordada com mais detalhes posteriormente.

A Figura 5.3 fornece uma visão geral do processo recém apresentado.

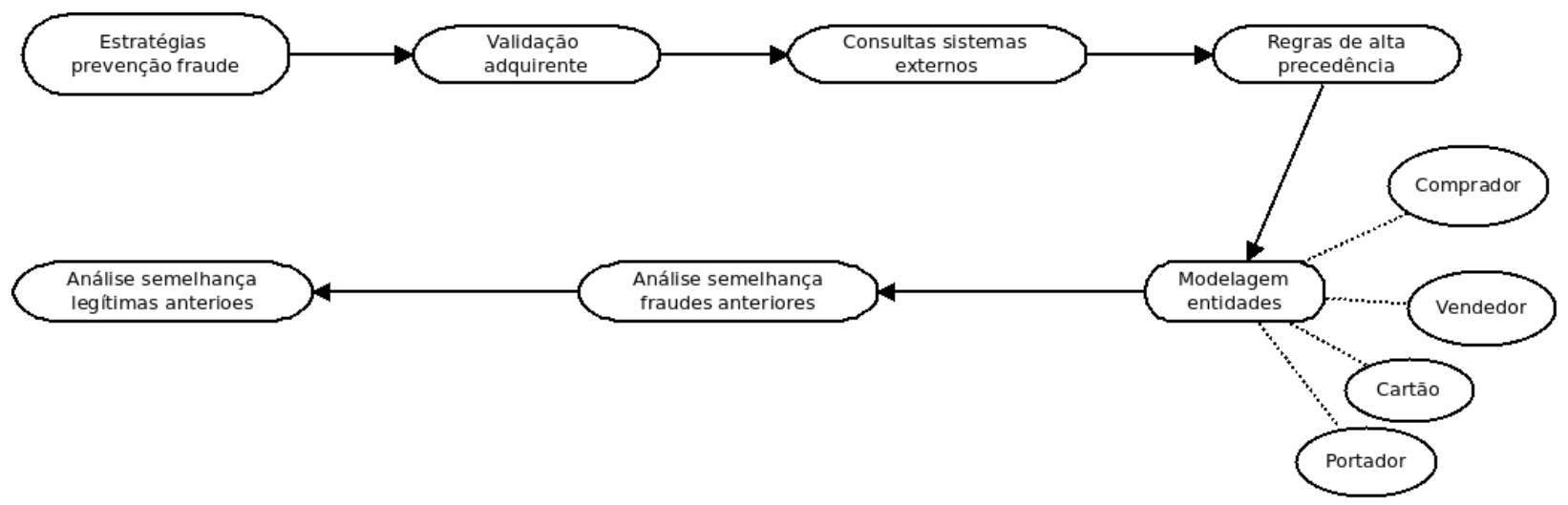

Figura 5.3: Visão geral do processo de detecção e prevenção à fraudes.

\subsection{Análise de uma Transação}

Conforme dito na Seção 5.1.7, apresentamos um processo completo de análise automatizada de uma transação, porém vamos abordar com mais detalhes somente a última etapa do processo apresentado, que é a comparação de uma transação sendo analisada com o histórico de transações legítimas. A seguir, descrevemos essa última etapa do processo.

Sabendo-se que cada entidade participa de várias transações ao longo do tempo, uma suposição razoável de se fazer é que cada uma das entidades tende a manter um padrão de comportamento aproximadamente constante para as suas transações legítimas. Partindo dessa suposição, uma forma de se calcular o risco de uma transação é calculando o grau de discrepância da transação com o histórico de transações legítimas de cada uma das suas entidades. Além disso, como cada uma das entidades são independentes uma da outra, o cálculo desse grau de semelhança deve ser feito de forma independente para cada uma das entidades. Outra suposição razoável é que o grau de confiança desse cálculo de discrepância tende a variar de acordo com o tamanho do histórico da entidade: quanto maior o histórico, mais dados temos para modelar o comportamento da entidade em questão e portanto mais confiável supõe-se que seja o cálculo da discrepância da transação atual com esse comportamento. 


\subsubsection{Transações Legítimas, Transações Fraudulentas e Transações Não efeti- vadas}

Quando uma transação de cartão de crédito é criada, ela primeiramente passa por um processo de análise dentro da empresa. Caso ela seja identificada como uma possível fraude, a transação é negada. Nesse caso, dizemos que a transação foi negada pela empresa e portanto não foi efetivada. É importante notar que uma transação não efetivada não significa necessariamente uma fraude: na verdade, não temos como saber se a transação não efetivada realmente seria uma fraude ou se isso foi simplesmente um erro de análise.

Após a transação ser efetivada é que passa a existir o risco da ocorrência do chargeback, cuja identificação não é imediata. É preciso que o cliente receba a cobrança suspeita em sua fatura de cartão de crédito, identifique uma transação como fraude, entre em contato com a instituição que administra o cartão e esta por sua vez precisa então informar o intermediador de pagamentos online. Este processo todo faz com que a identificação do chargeback ocorra em geral mais de um mês após a efetivação da transação, mas em alguns casos pode demorar muito mais que isso.

\subsubsection{Histórico da Entidade}

Sendo $t$ uma transação sendo analisada, definimos como

$E_{t}=\left\{\right.$ comprador $_{t}$, vendedor $_{t}$, cartao $_{t}$, portador $\left._{t}\right\}$ o conjunto das quatro entidades envolvidas na transação $t$.

Sempre que falamos de histórico de uma entidade, estamos falando do histórico de uma entidade específica em uma transação específica, compreendendo somente transações que ocorreram antes da transação sendo analisada. Um ponto importante a ser definido é o tamanho da janela histórica: estamos fixando um tamanho de noventa dias, visto que, após análises feitas nos dados, percebemos que a grande maioria dos reconhecimentos dos chargebacks ocorrem dentro desse período. Ou seja, sendo $s$ o momento em que uma transação foi realizada, o histórico de uma entidade $e$ em uma transação $t$ compreende todas as transações em que a entidade $e$ esteve envolvida, no período compreendido entre $s-90$ dias e $s$. A Figura 5.4 ilustra essa ideia:

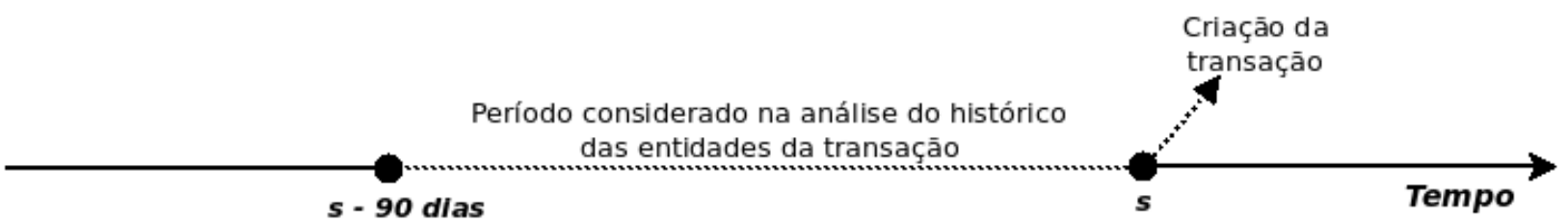

Figura 5.4: Visão do período considerado para análise do histórico das entidades da transação.

Posto isso, vamos definir como $H_{e} t=\left\{t_{1}, \ldots, t_{m}\right\}$ o conjunto contendo todas as transações do histórico de uma entidade $e \in E_{t}$, para uma determinada transação $t$.

\subsubsection{Score do Atributo}

O cálculo do score de um atributo para uma transação $t$ envolve a comparação dele com as informações das transações de $H_{e} t$, resultando numa medida quantitativa. Nossa abordagem para realizar essa comparação consiste em contar quantas vezes o valor do atributo já foi utilizado anteriormente no conjunto $H_{e} t$ para cada uma das entidades $e \in E_{t}$, obtendo-se assim um score específico para cada atributo em cada entidade da transação $t$. Por exemplo, quando um comprador realiza uma transação, caso essa transação seja a primeira efetuada por ele, o score de todos os atributos para a entidade Comprador naquela transação será igual a zero; porém, se ele já tiver feito uma transação anteriormente, com o mesmo vendedor e informando o mesmo CEP de entrega, o score dos atributos vendedor e cep de entrega para a entidade Comprador serão iguais a um naquela transação.

Assim, sendo $X=\left\{x_{1}, \ldots, x_{20}\right\}$ o conjunto dos vinte atributos de uma transação, definidos na Seção 4.3 , e sendo $v_{i}$ o valor de um atributo $x_{i} \in X$ em uma transação $t=\left[v_{1}, \ldots, v_{20}\right]$, a equação 
5.1 nos da o valor do score de um atributo $x_{i}$ para uma entidade $e \in E_{t}$ na transação $t$.

$$
S C a\left(x_{i}, e, t\right)=\operatorname{count}\left(v_{i}, H_{e} t\right)
$$

Na equação 5.1, $\operatorname{count}\left(v_{i}, H_{e} t\right)$ indica a quantidade de vezes que o valor $v_{i}$ aparece para o atributo $x_{i}$ nas transações em $H_{e} t$.

Um ponto importante a ser definido aqui é que, para a equação 5.1 nós consideramos somente as transações efetivadas (Seção 5.2.1) e legítimas de $H_{e} t$. A ideia geral é calcular o quão semelhante uma transação é com transações legítimas anteriores de suas entidades, logo consideramos somente as transações comprovadamente legítimas de $H_{e} t$ na equação 5.1.

\subsubsection{Comportamento Diferenciado da Entidade Vendedor}

Uma característica que observamos na Seção 4.4 em relação às quatro entidades aqui descritas é que a entidade Vendedor possui um comportamento bastante diferenciado em relação às outras três: os vendedores em geral possuem um histórico de transações muito maior que as outras três entidades. Além disso, eles tendem a ter um conjunto mais heterogêneo de transações em seu histórico, o que torna mais difícil a modelagem de comportamento dos vendedores nos mesmos moldes que fazemos com as outras três entidades. Foram realizados alguns experimentos preliminares, semelhantes àqueles que serão descritos nos capítulos 6 e 7, e notou-se que a presença dos scores da entidade Vendedor no processo de classificação gerava um impacto negativo significativo nos resultados. Devido a isso, apesar de considerarmos a entidade Vendedor importante no processo de modelagem aqui sendo descrito, nós não iremos utilizar os scores dos atributos da entidade Vendedor para deteç̧ão de fraude nos experimentos que descreveremos nos capítulos 6 e 7.

\subsubsection{Scores da Transação}

Para uma transação sendo analisada, calculamos a equação 5.1 para cada um dos atributos em cada entidade, obtendo um score $S C a\left(x_{i}, e, t\right)$ para cada atributo em relação a cada uma das entidades. Considerando que não iremos utilizar os scores dos atributos do Vendedor, o vetor $S$ de scores para todos os atributos de uma transação é definido por

$$
\begin{aligned}
S= & {\left[S C a\left(x_{1}, \text { comprador }, t\right), \ldots, S C a\left(x_{20}, \text { comprador }, t\right),\right.} \\
& S C a\left(x_{1}, \text { cartao }, t\right), \ldots, S C a\left(x_{20}, \text { cartao }, t\right), \\
& \left.S C a\left(x_{1}, \text { portador }, t\right), \ldots, S C a\left(x_{20}, \text { portador }, t\right)\right]
\end{aligned}
$$

\subsubsection{Peso das entidades}

Outro conceito importante que será considerado na classificação das transações descrita posteriormente é o de peso de uma entidade em uma transação. Chamamos de $p(e)$ de uma entidade $e \in E_{t}$ para uma transação $t$ o tamanho do histórico de $e$ excluindo as transações que sofreram chargeback. Ou seja, $p(e)$ representa a quantidade de transações que não geraram chargeback no histórico de $e$, o que inclui as transações legítimas e as transações não efetivadas.

\subsection{Classificação da Transação}

Após o cálculo do score, teremos um vetor $S$ de scores definido na Equação 5.2 e o peso do histórico de cada entidade. Essas informações constituem o conjunto completo de atributos que utilizaremos como entrada em um classificador a fim de identificar uma transação como fraude ou não. Antes de serem utilizados no classificador, os valores de todos os atributos passam por uma transformação, de forma que, considerando-se o conjunto de todas as transações, o valor de cada atributo de $S$, assim como o peso de cada entidade, terá média igual a zero e variância igual a um.

A Figura 5.5 ilustra esse processo. 


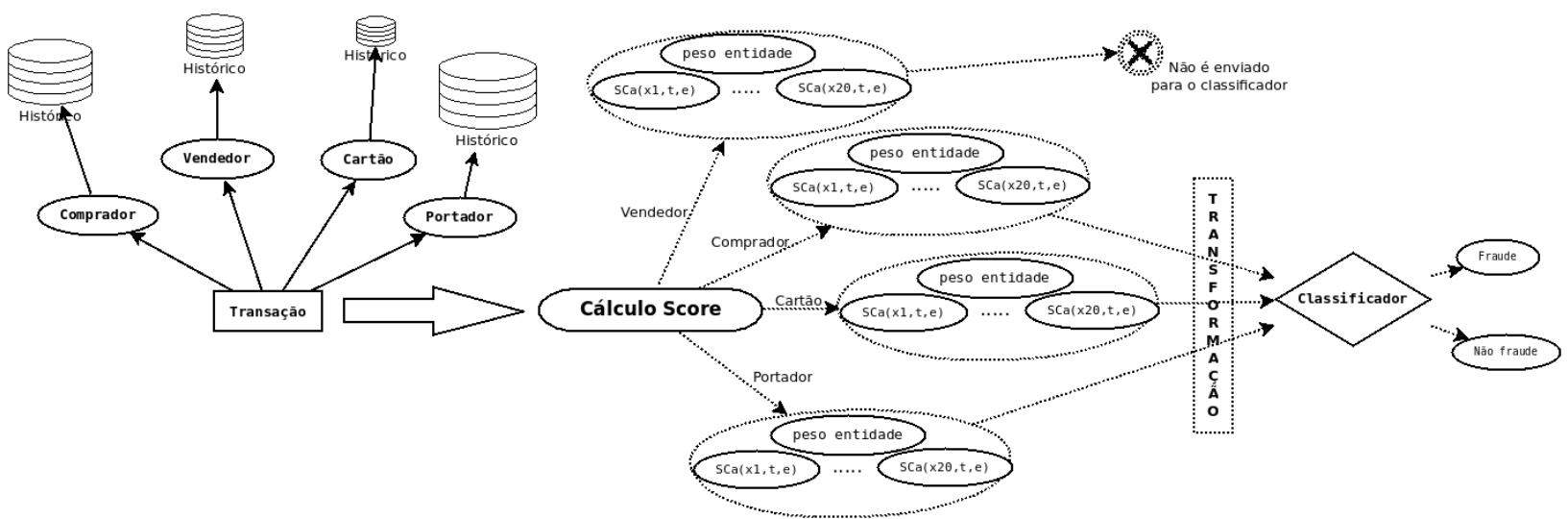

Figura 5.5: Visão do processo completo de cálculo de scores e classificação.

\subsubsection{Peso geral da transação}

Uma suposição que fazemos, e que será verificada posteriormente no Capítulo 7, é que o tamanho do histórico da entidade influencia no grau de confiança dos scores gerados para aquela entidade: quanto maior o histórico, mais significativo supõe-se que sejam os scores calculados. Já descrevemos o conceito de peso de uma entidade na Seção 5.2.6 e vimos que este está diretamente relacionado com o tamanho do histórico da entidade. Um outro conceito importante é o de peso geral da transação: chamamos de peso geral da transação o maior peso dentre as entidades consideradas na tarefa de classificação. Ou seja, sendo $t$ uma transação e suas três entidades consideradas na classificação comprador $_{t}$, cartaot e portador ${ }_{t}$ (lembrando que não vamos considerar o Vendedor), o peso geral $p(t)$ da transação $t$ é definido por:

$$
p(t)=\max \left(p\left(\text { comprador }_{t}\right), p\left(\text { cartao }_{t}\right), p\left(\text { portador }_{t}\right)\right)
$$




\section{Capítulo 6}

\section{Processo de Classificação das Transações}

Após os conceitos apresentados no Capítulo 5, a etapa final do nosso processo consiste em classificar uma transação como fraudulenta ou legítima. Neste capítulo descreveremos em detalhes os procedimentos de preparação para a execução dessa classificação.

\subsection{Separação das Transações por Peso Geral}

Dissemos na Seção 5.3.1 que o tamanho dos históricos das entidades, e por consequência o peso geral da transação, possuem uma grande influência no modelo. Sendo assim, é importante considerar o peso geral da transação nos resultados dos experimentos, e para isso serão gerados subconjuntos de transações com pesos geral específicos, e cada um dos subconjuntos gerados será utilizado para treinar o classificador e executar a tarefa de classificação de forma independente em cada um deles. Essa abordagem é importante para se avaliar o impacto do peso geral nos resultados, mas também é de extrema importância para lidar com uma das principais limitações da técnica de classificação $S V M$, que será utilizada nos experimentos: sua complexidade computacional. Conforme visto na Seção 4.2, estamos trabalhando com uma quantidade muito grande de dados, e vimos também na Seção 3.3 que a complexidade computacional para geração de modelo do $S V M$ escala aproximadamente entre quadrática e cúbica de acordo com a quantidade de exemplos de treinamento (Cao, 2003; Hand et al., 2006). Logo, apesar do SVM apresentar características que se mostram interessantes para o nosso problema, é fundamental tratarmos sua limitação em termos de complexidade computacional. Ao gerar várias amostras de treinamento menores, o problema original é quebrado em várias partes menores que podem ser tratadas em um tempo muito menor e também podem ser executadas paralelamente.

Posto isso, são definidos nove subconjuntos, sendo eles:

1. Subconjunto 1: transações com peso geral igual a um;

2. Subconjunto 2: transações com peso geral igual a dois;

3. Subconjunto 3: transações com peso geral igual a três;

4. Subconjunto 4: transações com peso geral igual a quatro;

5. Subconjunto 5: transações com peso geral maior ou igual a cinco e menor que dez;

6. Subconjunto 6: transações com peso geral maior ou igual a dez e menor que quinze;

7. Subconjunto \%: transações com peso geral maior ou igual a quinze e menor que vinte;

8. Subconjunto 8: transações com peso geral maior ou igual a vinte e menor que trinta; e

9. Subconjunto 9: transações com peso geral maior ou igual trinta; 
Podemos ver que os subconjuntos são todos excludentes. Além disso, vale observar que, como o modelo aqui proposto é essencialmente baseado no histórico de transações das entidades envolvidas, é importante selecionarmos os limites dos intervalos dos subconjuntos de modo a termos somente transações com informações relevantes para o modelo, ou seja, transações que possuem peso geral maior que zero, o que implica em algumas de suas entidades ter pelo menos uma transação em seu histórico. Os limites foram definidos de modo que transações com peso geral igual a zero não estão presentes em nenhum dos subconjuntos, e portanto elas não serão consideradas nos nossos experimentos, visto que não possuem nenhuma informação relevante a ser passada para o classificador. Nesse ponto vale ressaltar que a proposta apresentada no Capítulo 5, e que pode ser visualizada de forma mais ampla na Figura 5.3, envolve todo um processo que é composto de mais de uma etapa para deteç̧ão de fraude. Estamos aplicando aqui somente a última etapa do processo e estamos nesse momento dizendo que essa etapa não é adequada para tratar as transações com peso geral igual a zero, porém tais transações podem ser tratadas em outras etapas. Detecção de fraude é um problema extremamente complexo e heterogêneo, e portanto é muito difícil tratá-lo de forma completa com um único sistema.

Analisemos agora como as transações que serão consideradas estão distribuídas em relação aos subconjuntos definidos. A Figura 6.1 mostra um comparativo da quantidade de transações por mês para cada um dos subconjuntos.

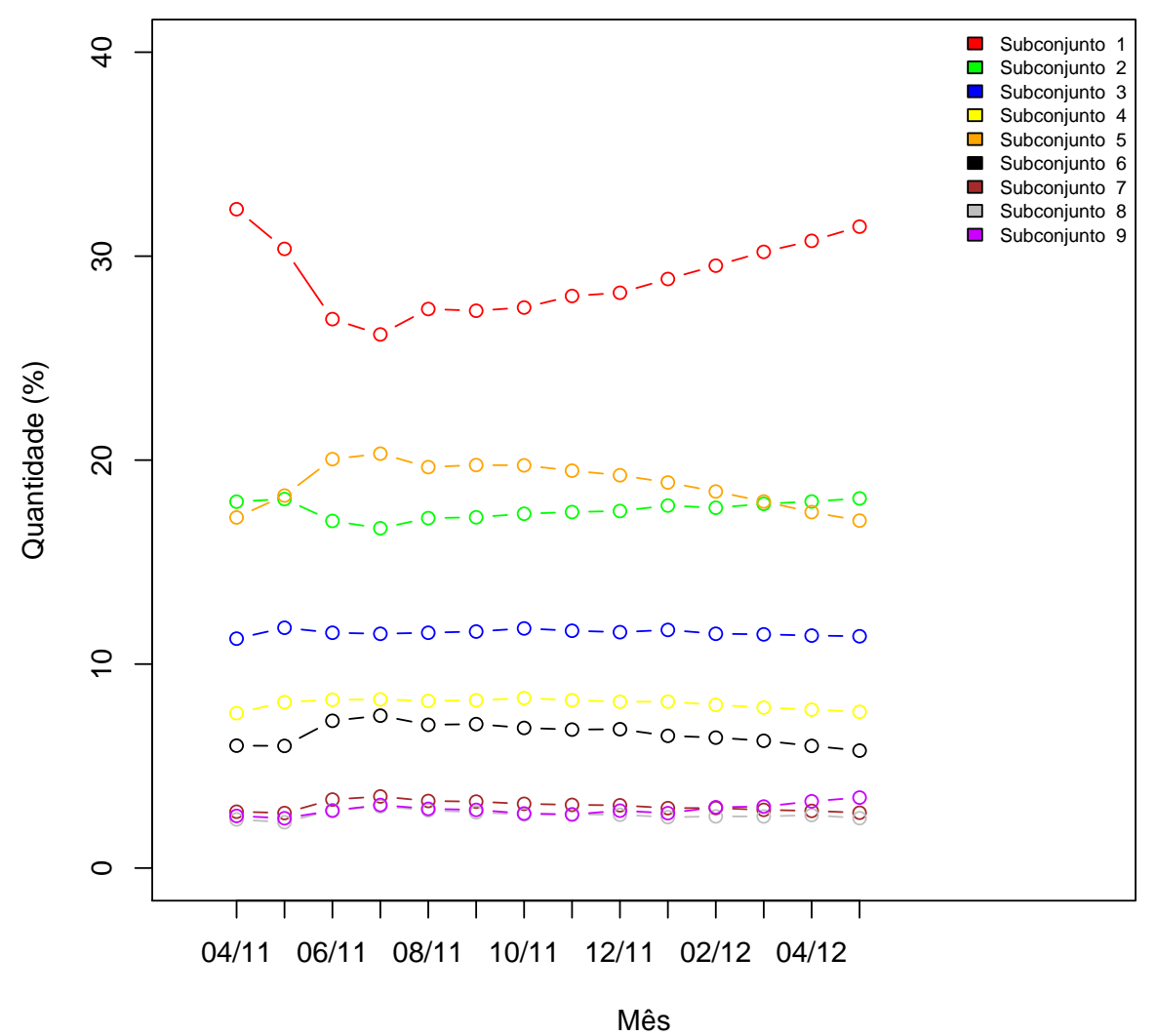

Figura 6.1: Comparativo da quantidade de transações por mês para cada um dos subconjuntos de transações.

Vemos pela Figura 6.1 que o Subconjunto 1 representa entre $30 \%$ e $35 \%$ das transações e o Subconjunto 9 é o que possui menos transações. A Figura 6.2 mostra o percentual de chargebacks por mês dentro de cada um dos subconjuntos de transações. 


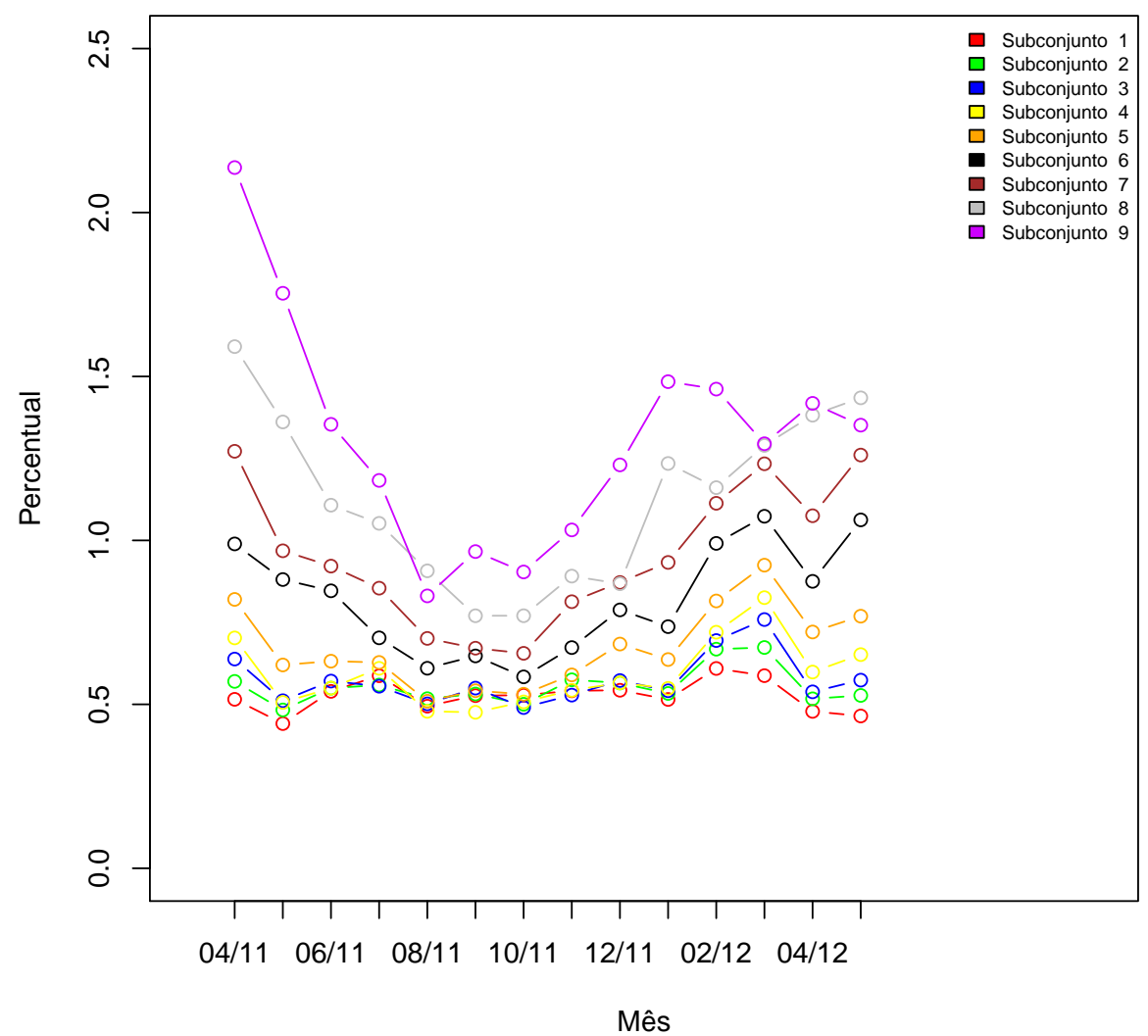

Figura 6.2: Percentual de chargebacks por mês para cada um dos subconjuntos de transações.

A Figura 6.2 mostra que apesar de o Subconjunto 9 ser o que possui menos transações, a incidência de chargeback nele é maior: entre $1 \%$ e $2 \%$ de suas transações são chargebacks, aproximadamente. Já o Subconjunto 1, apesar de ser o que possui mais transações, é o que possui uma incidência de chargebacks menor em média.

A Figura 6.3 mostra como o universo completo de chargebacks está distribuído entre os nove subconjuntos. 


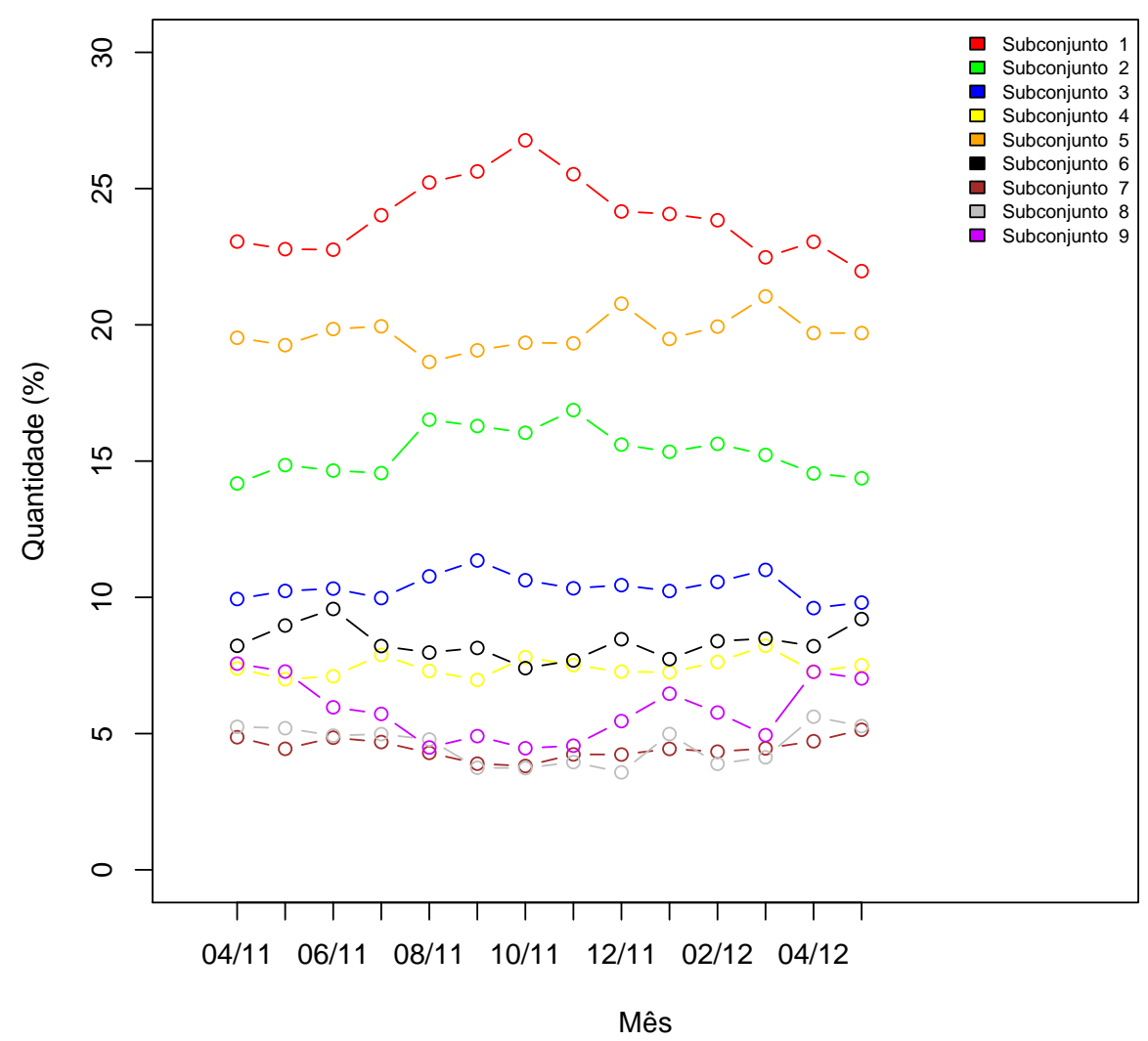

Figura 6.3: Distribuição dos chargebacks entre os subconjuntos de transações.

Percebe-se pela Figura 6.3 que a maior parte do total de chargebacks (entre $20 \%$ e $25 \%$ ) está no Subconjunto 1. Aqui é importante notar que, apesar de termos visto na Figura 6.2 que o Subconjunto 1 é o que possui uma menor incidência de chargebacks, vimos também na Figura 6.1 que ele é o que possui a maior parte das transações, o que justifica uma maior quantidade de chargebacks mesmo com uma incidência percentual menor.

\subsection{Execução da Classificação}

Executamos experimentos separados para cada mês do período que estamos avaliando (Janeiro de 2011 a Maio de 2012), ou seja, para cada mês temos uma amostra de treinamento e de teste diferentes, sendo que a amostra de treino consiste das transações de cartão de crédito do terceiro mês anterior a este, e a amostra de teste consiste das transações deste mês. Por exemplo, quando vamos analisar o mês de Abril de 2011, nossa amostra de treino consiste das transações de Janeiro de 2011 e o teste das transações de cartão de crédito do mesmo mês de Abril. Para o mês de Maio de 2011 teremos a amostra de treino consistindo das transações de Fevereiro de 2011 e a amostra de teste do respectivo mês de Maio, e assim por diante. Devido a isso, o primeiro mês a ser analisado será o mês de Abril de 2011. Outro ponto importante é que na preparação das amostras de treinamento selecionamos somente transações de cartão de crédito que realmente foram efetivadas para a classe de transações legítimas, ou seja, somente transações que temos certeza que não geraram e nem gerariam chargeback (visto que para as transações não efetivadas não podemos ter essa certeza). Uma diferenciação detalhada entre transações legítimas e transações não-efetivadas pode ser vista na Seção 5.2.1.

Para a tarefa de classificação estamos utilizando um classificador SVM com kernel radial. Outras 
técnicas de classificação, como Redes Neurais, Árvores de Decisão e Redes Bayesianas também foram avaliadas, porém não notamos alterações siginificativas nos resultados. Geramos um modelo separado para cada um dos subconjuntos citados, ou seja, treinamos o classificador e executamos a tarefa de classificação de forma isolada em cada subconjunto. Após executar a classificação para todos os subconjuntos, consolidamos os resultados somando a quantidade de acertos e de erros de cada subconjunto de forma a termos uma única métrica para todo o processo de classificação envolvendo todos os subconjuntos.

\subsubsection{Tratando a Demora no Reconhecimento do Chargeback}

Conforme descrito na Seção 5.2.1, o reconhecimento do chargeback não é imediato. Porém, para os nossos experimentos, tomamos o cuidado de selecionar uma amostra de dados antiga o suficiente, de forma que todos os chargebacks que ocorreram na amostra já haviam sido identificados, o que nos permitiria mascarar esse problema. Por outro lado, para um sistema real, esse é um problema que precisa ser considerado, uma vez que ao analisar uma transação que acabou de ser realizada, existe uma grande possibilidade de que alguns chargebacks presente nos históricos de suas entidades ainda não tenham sido reconhecidos por serem muito recentes. Podemos dizer que os chargebacks que ainda não foram identificados são um tipo de ruído nos dados, uma vez que eles fazem com que transações que deveriam ser tratadas como fraude, sejam, na verdade, consideradas legítimas.

Para tentar reproduzir uma situação mais próxima da realidade, introduzimos propositalmente esse ruído que seria encontrado em um sistema executando em tempo real. Na equação 5.1, comparamos os atributos de uma transação sendo analisada com transações efetivadas e legítimas anteriores a esta, ou seja, idealmente, estaríamos ignorando todas as transações que geraram chargeback. Porém, já vimos que isso nem sempre é possível na prática devido à demora no reconhecimento do chargeback, e portanto, para reproduzir uma situação mais próxima da realidade, ao percorrer as transações do histórico das entidades da transação em análise, quando encontramos um chargeback, ao invés de imediatamente descartar a transação para o cálculo do score, nós primeiro analisamos a data em que o chargeback daquela transação foi reconhecido. Se ele foi reconhecido em uma data posterior à data da transação sendo analisada, nós ignoramos o fato daquela transação ter originado um chargeback e a consideramos como uma transação legítima. Dessa forma, estamos introduzindo propositalmente um ruído no cálculo dos scores dos atributos, com a intenção de gerar um cenário o mais próximo possível ao que seria encontrado em um sistema executando em tempo real: houve um chargeback no histórico de alguma entidade da transação sendo analisada e que portanto deveria ser ignorado no cálculo, mas no momento da análise nós ainda não havíamos reconhecido aquele chargeback.

\subsection{Tratando o Desbalanceamento Entre as Classes}

Conforme já dito na Seção 4.2, temos um nível altíssimo de desbalanceamento entre as duas classes consideradas (fraude e legítimas), o que nos traz sérios problemas na geração do modelo a partir de uma amostra de treinamento. Para lidar com essa situação, fazemos uma amenização artificial nesse desbalanceamento nas amostras de treinamento do classificador: selecionamos todos os chargebacks disponíveis para compor a amostra de treino e selecionamos aleatoriamente entre as transações legítimas um múltiplo $x$ dessa quantidade de chargebacks. Com isso, são geradas artificialmente amostras de treino com um nível controlado de desbalanceamento. Um ponto importante a ser definido é o valor desse múltiplo $x$. Fizemos experimentos variando $x$ entre um e dez, ou seja, geramos amostras com dez níveis diferentes de desbalanceamento e chamamos cada uma dessas amostras de $i \times 1$, para $i \in 1 . .10$.

Executamos o procedimento de classificação descrito na Seção 6.2 variando o nível de balanceamento na amostra de treinamento, a fim de avaliar o impacto dessa variação na taxa de detecção de chargebacks e de gerações de falsos alarmes. É importante notar que estamos introduzindo um componente aleatório na geração da amostra de treinamento, visto que as transações legítimas são 
selecionadas de forma aleatória. Devido a isso, os experimentos foram executados dez vezes e os valores apresentados a seguir representam a média aritmética simples de todas as execuções.

A Figura 6.4 mostra o percentual de chargebacks detectados por mês para cada um dos níveis de balanceamento apresentados previamente.

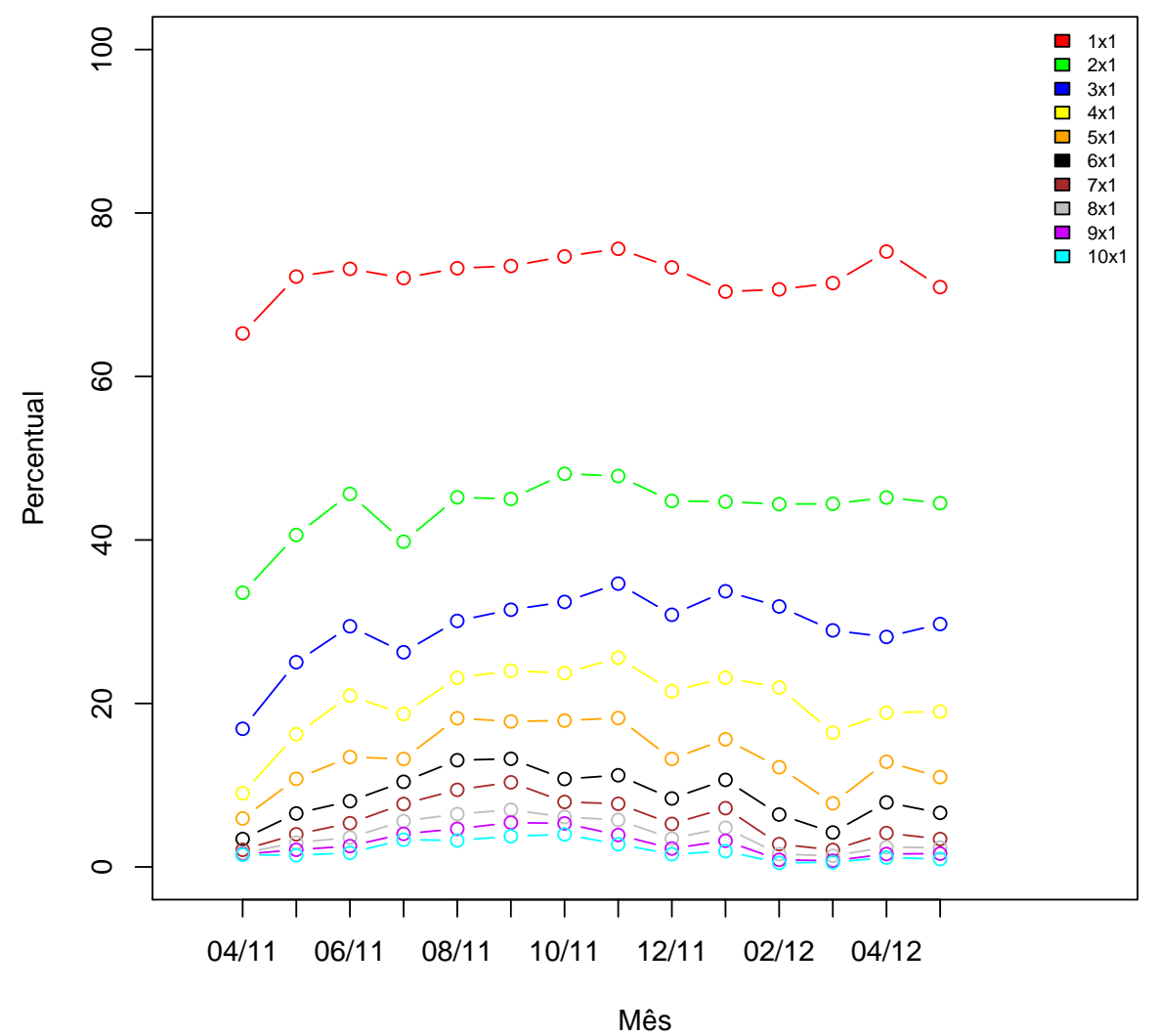

Figura 6.4: Percentual de chargebacks detectados por mês para cada nível de balanceamento da amostra de treinamento.

Os resultados da Figura 6.4 também são apresentados nas Tabelas 6.1 e 6.2, nas quais também mostramos o desvio padrão ao lado de cada um dos valores médios:

\begin{tabular}{|c|c|c|c|c|c|c|c|}
\hline Balanceamento & $04 / 11$ & $05 / 11$ & $06 / 11$ & $07 / 11$ & $08 / 11$ & $09 / 11$ & $10 / 11$ \\
\hline $1 \times 1$ & $65,3 / 3,2$ & $72,2 / 2,1$ & $73,2 / 1,9$ & $72 / 1,8$ & $73,2 / 1,8$ & $73,5 / 2,9$ & $74,7 / 2,1$ \\
$2 \times 1$ & $33,5 / 3,1$ & $40,6 / 3,2$ & $45,6 / 2,4$ & $39,8 / 3,9$ & $45,2 / 3,4$ & $45 / 2,6$ & $48,1 / 4,7$ \\
$3 \times 1$ & $16,9 / 2,7$ & $25 / 3,2$ & $29,4 / 2,4$ & $26,3 / 1,9$ & $30,1 / 2,9$ & $31,5 / 2,5$ & $32,4 / 2,2$ \\
$4 \times 1$ & $9 / 2,6$ & $16,2 / 2$ & $21 / 2 \mathrm{v} 4$ & $18,7 / 2,4$ & $23,1 / 2$ & $24 / 2,8$ & $23,7 / 2,3$ \\
$5 \times 1$ & $5,9 / 1,7$ & $10,8 / 3$ & $13 \mathrm{v} 4 / 3,3$ & $13,2 / 1,5$ & $18,2 / 2,4$ & $17,8 / 2,4$ & $17,9 / 3,2$ \\
$6 \times 1$ & $3,4 / 1,4$ & $6,5 / 2,3$ & $8 / 1,9$ & $10,4 / 1,6$ & $13,1 / 3,3$ & $13,2 / 1,9$ & $10,8 / 2,7$ \\
$7 \times 1$ & $2,1 / 0,9$ & $4 / 1,4$ & $5,4 / 1,4$ & $7,7 / 1,5$ & $9,4 / 2,9$ & $10,4 / 1,8$ & $8 / 1,9$ \\
$8 \times 1$ & $1,7 / 0,3$ & $3 / 1,2$ & $3,6 / 1,1$ & $5,6 / 1,2$ & $6,5 / 1,8$ & $7 / 1,9$ & $6,1 / 1,4$ \\
$9 \times 1$ & $1,6 / 0,1$ & $2,1 / 1$ & $2,6 / 0,7$ & $4 / 1,1$ & $4,7 / 1,3$ & $5,4 / 1,4$ & $5,3 / 1$ \\
$10 \times 1$ & $1,5 / 0,1$ & $1,4 / 0,8$ & $1,7 / 0,8$ & $3,3 / 0,5$ & $3,2 / 1$ & $3,8 / 1,2$ & $4 / 0,9$ \\
\hline
\end{tabular}

Tabela 6.1: Percentual de chargebacks detectados por mês para cada nível de balanceamento da amostra de treinamento. Os dados estão no formato média/desvio padrão. 


\begin{tabular}{|c|c|c|c|c|c|c|c|}
\hline Balanceamento & $11 / 11$ & $12 / 11$ & $01 / 12$ & $02 / 12$ & $03 / 12$ & $04 / 12$ & $05 / 12$ \\
\hline $1 \times 1$ & $75,6 / 1,6$ & $73,3 / 2$ & $70,4 / 2,1$ & $70,7 / 2$ & $71,4 / 2,1$ & $75,3 / 2$ & $70,9 / 2,3$ \\
$2 \times 1$ & $47,8 / 3,5$ & $44,8 / 2,6$ & $44,7 / 2$ & $44,4 / 2,3$ & $44,4 / 2,1$ & $45,2 / 2,5$ & $44,5 / 3$ \\
$3 \times 1$ & $34,7 / 2,1$ & $30,9 / 2,6$ & $33,7 / 2,2$ & $31,9 / 1,8$ & $28,9 / 4,7$ & $28,1 / 3,1$ & $29,7 / 3$ \\
$4 \times 1$ & $25,6 / 2,6$ & $21,5 / 2,9$ & $23,1 / 2,7$ & $21,9 / 2,7$ & $16,4 / 3,8$ & $18,9 / 1,8$ & $19 / 2,8$ \\
$5 \times 1$ & $18,2 / 3,6$ & $13,2 / 3$ & $15,6 / 2,9$ & $12,2 / 2,8$ & $7,8 / 2,3$ & $12,9 / 2,6$ & $11 / 2,8$ \\
$6 \times 1$ & $11,2 / 2,5$ & $8,4 / 2,1$ & $10,7 / 2,2$ & $6,4 / 2,3$ & $4,2 / 2$ & $7,9 / 2,5$ & $6,6 / 2,2$ \\
$7 \times 1$ & $7,7 / 2,2$ & $5,3 / 1,5$ & $7.2 / 2$ & $2,8 / 1,2$ & $2,1 / 0,9$ & $4,1 / 1,7$ & $3,4 / 1,3$ \\
$8 \times 1$ & $5,8 / 2,1$ & $3,5 / 1,1$ & $4,8 / 1,4$ & $1,6 / 0,9$ & $1,4 / 0,7$ & $2,4 / 0,7$ & $2,4 / 0,9$ \\
$9 \times 1$ & $3,9 / 1,4$ & $2,3 / 1$ & $3,2 / 1,1$ & $0,9 / 0,6$ & $0,8 / 0,4$ & $1,6 / 0,7$ & $1,6 / 0,7$ \\
$10 \times 1$ & $2,8 / 1$ & $1,6 / 0,9$ & $1,9 / 0,7$ & $0,5 / 0,5$ & $0,6 / 0,3$ & $1,1 / 0,6$ & $1 / 0,7$ \\
\hline
\end{tabular}

Tabela 6.2: Percentual de chargebacks detectados por mês para cada nível de balanceamento da amostra de treinamento. Os dados estão no formato média/desvio padrão.

Percebe-se pela Figura 6.4 e pelas Tabelas 6.1 e 6.2 que a maior taxa de detecção de chargebacks é obtida com o nível de desbalanceamento $1 \mathrm{x} 1$, e a taxa diminui à medida que se aumenta a quantidade de transações legítimas à amostra, chegando ao menor valor para o nível 10x1. Isso sugere que, quanto maior é a proporção de chargebacks em relação às transações legítimas na amostra de treinamento do classificador, maior é a taxa de deteç̧ão de chargebacks do modelo gerado.

Avaliemos agora o impacto da variação no nível de desbalanceamento da amostra de treinamento na taxa de falsos alarmes, ou seja, transações legítimas identificadas como fraude pelo classificador. A Figura 6.5 mostra o percentual de falsos alarmes por mês para cada um dos níveis de balanceamento apresentados previamente. 


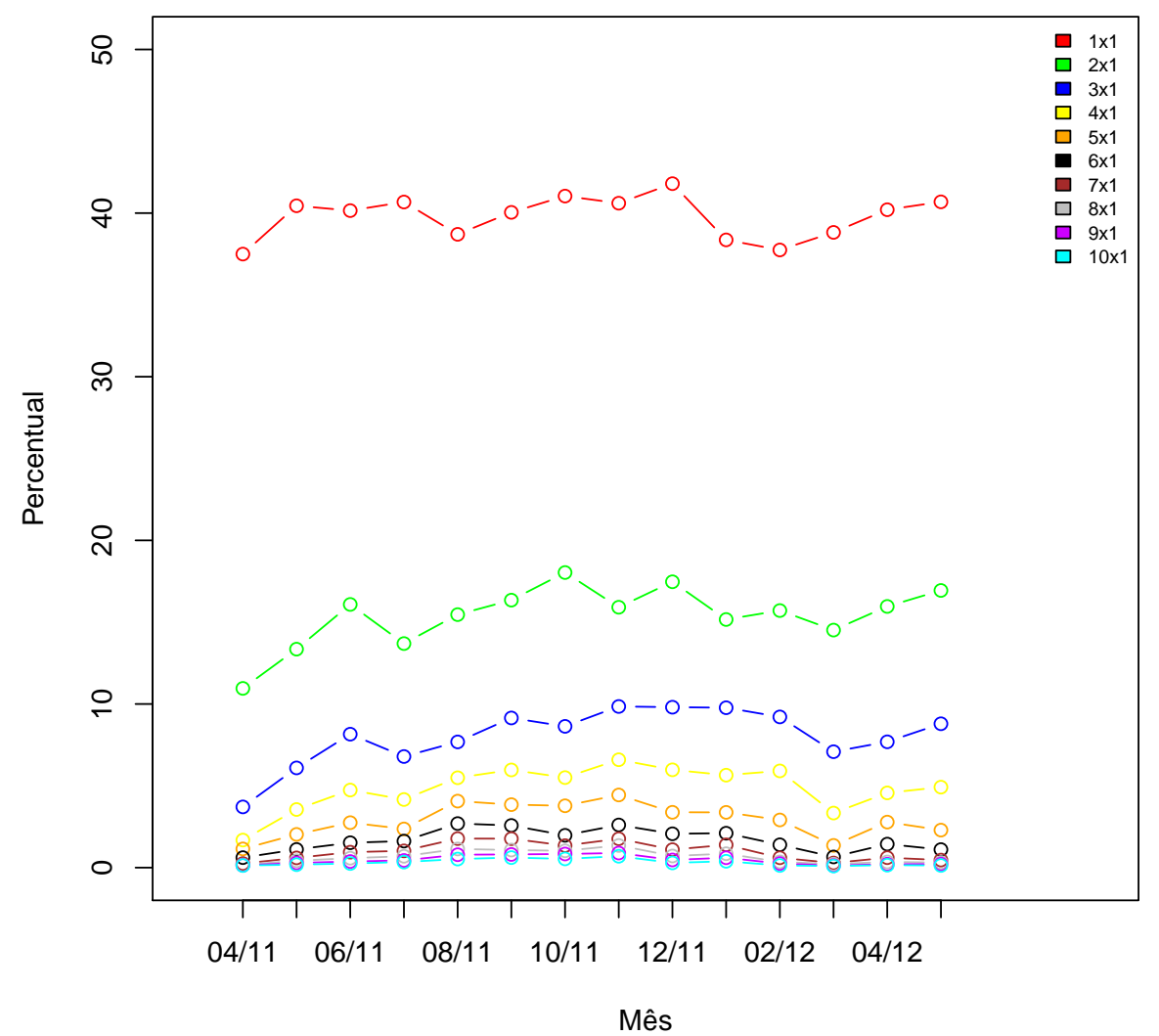

Figura 6.5: Percentual de falsos alarmes por mês para cada nível de balanceamento da amostra de treinamento.

Os resultados da Figura 6.5 também são apresentados nas Tabelas 6.3 e 6.4, nas quais também mostramos o desvio padrão ao lado de cada um dos valores médios:

\begin{tabular}{|c|c|c|c|c|c|c|c|}
\hline Balanceamento & $04 / 11$ & $05 / 11$ & $06 / 11$ & $07 / 11$ & $08 / 11$ & $09 / 11$ & $10 / 11$ \\
\hline $1 \times 1$ & $37,5 / 3,2$ & $40,4 / 2$ & $40,2 / 1,8$ & $40,7 / 1,7$ & $38,7 / 1,3$ & $40 / 2,3$ & $41 / 1,3$ \\
$2 \times 1$ & $11 / 1,7$ & $13,4 / 1,6$ & $16,1 / 1$ & $13,7 / 2,5$ & $15,5 / 2,4$ & $16,3 / 1,6$ & $18 / 3,8$ \\
$3 \times 1$ & $3,7 / 0,8$ & $6,1 / 1$ & $8,2 / 1$ & $6,8 / 0,8$ & $7,7 / 0,9$ & $9,1 / 1,4$ & $8,6 / 0,8$ \\
$4 \times 1$ & $1,7 / 0,5$ & $3,6 / 0,6$ & $4,7 / 0,7$ & $4,2 / 0,9$ & $5,5 / 0,6$ & $6 / 1,1$ & $5,5 / 0,7$ \\
$5 \times 1$ & $1,1 / 0,3$ & $2 / 0,7$ & $2,7 / 0,8$ & $2,4 / 0,5$ & $4,1 / 0,7$ & $3,9 / 0,9$ & $3,8 / 1$ \\
$6 \times 1$ & $0,6 / 0,3$ & $1,1 / 0,5$ & $1,5 / 0,4$ & $1,6 / 0,4$ & $2,7 / 0,9$ & $2,6 / 0,6$ & $2 / 0,6$ \\
$7 \times 1$ & $0,3 / 0,2$ & $0,6 / 0,2$ & $0,9 / 0,3$ & $1 / 0,3$ & $1,8 / 0,7$ & $1,8 / 0,5$ & $1,3 / 0,4$ \\
$8 \times 1$ & $0,2 / 0$ & $0,4 / 0,2$ & $0,6 / 0,2$ & $0,7 / 0,2$ & $1,1 / 0,4$ & $1,1 / 0,3$ & $1 / 0,3$ \\
$9 \times 1$ & $0,1 / 0$ & $0,3 / 0,1$ & $0,4 / 0,1$ & $0,4 / 0,2$ & $0,8 / 0,3$ & $0,8 / 0,2$ & $0,8 / 0,3$ \\
$10 \times 1$ & $0,1 / 0$ & $0,2 / 0,1$ & $0,3 / 0,1$ & $0,3 / 0,1$ & $0,5 / 0,2$ & $0,6 / 0,2$ & $0,5 / 0,2$ \\
\hline
\end{tabular}

Tabela 6.3: Percentual de falsos alarmes por mês para cada nível de balanceamento da amostra de treinamento. Os dados estão no formato média/desvio padrão. 


\begin{tabular}{|c|c|c|c|c|c|c|c|}
\hline Balanceamento & $11 / 11$ & $12 / 11$ & $01 / 12$ & $02 / 12$ & $03 / 12$ & $04 / 12$ & $05 / 12$ \\
\hline $1 \times 1$ & $40,6 / 1,3$ & $41,8 / 1,6$ & $38,4 / 1,5$ & $37,7 / 1,4$ & $38,8 / 1,6$ & $40,2 / 1,5$ & $40,7 / 1,9$ \\
$2 \times 1$ & $15,9 / 1,9$ & $17,5 / 1,5$ & $15,2 / 1$ & $15,7 / 1,4$ & $14,5 / 1$ & $16 / 1,2$ & $16,9 / 2,1$ \\
$3 \times 1$ & $9,9 / 0,8$ & $9,8 / 1,2$ & $9,8 / 1,2$ & $9,2 / 0,8$ & $7,1 / 1,2$ & $7,7 / 1,4$ & $8,8 / 1$ \\
$4 \times 1$ & $6,6 / 0,9$ & $6 / 1,2$ & $5,7 / 0,9$ & $5,9 / 0,9$ & $3,3 / 0,9$ & $4,6 / 0,6$ & $4,9 / 1,1$ \\
$5 \times 1$ & $4,4 / 1,1$ & $3,4 / 1$ & $3,4 / 0,8$ & $2,9 / 0,8$ & $1,4 / 0,7$ & $2,8 / 0,8$ & $2,3 / 0,9$ \\
$6 \times 1$ & $2,6 / 0,6$ & $2,1 / 0,7$ & $2,1 / 0,6$ & $1,4 / 0,6$ & $0,7 / 0,4$ & $1,4 / 0,8$ & $1,1 / 0,7$ \\
$7 \times 1$ & $1,8 / 0,6$ & $1,1 / 0,4$ & $1,4 / 0,5$ & $0,6 / 0,3$ & $0,3 / 0,1$ & $0,6 / 0,4$ & $0,5 / 0,2$ \\
$8 \times 1$ & $1,4 / 0,5$ & $0,7 / 0,3$ & $0,9 / 0,3$ & $0,4 / 0,2$ & $0,2 / 0,1$ & $0,3 / 0,1$ & $0,3 / 0,2$ \\
$9 \times 1$ & $0,9 / 0,3$ & $0,5 / 0,2$ & $0,6 / 0,2$ & $0,2 / 0,1$ & $0,1 / 0,1$ & $0,2 / 0,1$ & $0,2 / 0,1$ \\
$10 \times 1$ & $0,7 / 0,2$ & $0,3 / 0,2$ & $0,4 / 0,1$ & $0,1 / 0,1$ & $0,1 / 0,1$ & $0,2 / 0,1$ & $0,1 / 0,1$ \\
\hline
\end{tabular}

Tabela 6.4: Percentual de falsos alarmes por mês para cada nivel de balanceamento da amostra de treinamento. Os dados estão no formato média/desvio padrão.

Fica claro pela Figura 6.5 e pelas Tabelas 6.3 e 6.4 que a taxa de falsos alarmes aumenta conforme diminuímos a quantidade de transações legítimas da amostra. Ou seja, ao mesmo tempo que uma amostra de treinamento mais similar em relação à quantidade de transações em cada classe aumenta a taxa de detecção de chargebacks, ela também aumenta a taxa de falsos alarmes.

\subsection{Eficiência Econômica}

Até então, utilizamos somente métricas tradicionais de avaliação de classificadores para avaliar os resultados obtidos. A métrica de avaliação da taxa de detecção de fraudes é bastante utilizada em sistemas de detecção de fraudes em cartão de crédito (Bhatla et al., 2003), porém, para o problema em questão, a melhor solução não é necessariamente aquela que detecta muitas fraudes, mas sim aquela que detecta fraudes possivelmente em quantidade menor, mas com um prejuízo em potencial maior (Duman e Ozcelik, 2011).

Cada transação tem um valor financeiro específico e portanto possui um prejuízo em potencial diferente. Assim, o custo da falha na detecção de uma fraude varia para cada transação (Chan et al., 1999). Além disso, conforme já vimos no Capítulo 2, quando uma transação é identificada como suspeita, uma análise individual deve ser realizada por uma equipe de especialistas, o que implica em custos. Uma solução de gerenciamento de risco eficiente é aquela que minimiza o custo total da fraude, o que inclui as perdas financeiras devido às fraudes assim como o custo geral do sistema. Para minimizar o custo total da fraude, um balanço ótimo precisa ser alcançado entre a redução do número de fraudes e o custo do processo de análise manual (Bhatla et al., 2003). Além disso, quando uma transação é identificada como suspeita e necessita de uma revisão manual de especialistas, isso gera um atraso na efetivação da transação, proporcionando ao cliente uma visão de mau serviço prestado. Esse tipo de custo é extremamente difícil de ser mensurado.

No presente trabalho não temos a informação do custo do processo de análise manual por transação, e portanto não conseguimos considerar esse custo na nossa avaliação. Também não conseguimos considerar o custo da visão de mau serviço prestado no caso de transações legítimas identificadas como fraude. Portanto, faremos uma simplificação do custo do processo para tentar estimar a eficiência econômica do processo aqui apresentado: consideraremos que nenhuma transação passaria por análise manual. Se o classificador decidir que a transação é legítima, ela é aprovada imediatamente e, de forma análoga, se o classificador decidir que a transação é uma fraude, ela é reprovada imediatamente.

Apresentamos agora o conceito de eficiência econômica adaptado de Caldeira et al. (2012a,b). Chamemos de $G$ a taxa de lucro da empresa em cada transação e de $V$ o valor de uma determinada transação. Temos 4 situações possíveis:

1. A transação é legítima e o sistema de detecção de fraude a identificou como legítima: temos um lucro de $G * V$ com a transação; 
2. A transação é legítima e o sistema a identificou como fraude: deixamos de realizar o lucro da transação e portanto temos uma perda de $G * V$;

3. A transação é fraudulenta e o sistema a identificou como fraude: não tivemos lucro nem prejuízo; e

4. A transação é fraudulenta e o sistema a identificou como legítima: temos um prejuízo de $(1-G) * V$.

Vamos utilizar como exemplo uma situação em que temos uma transação de valor $V=\mathrm{R} \$ 100,00$ e uma taxa de lucro $G=10 \%$. Nessa situação, para cada uma das 4 situações recém-enumeradas, teríamos os seguintes resultados, respectivamente:

1. Lucro de $\mathrm{R} \$ 10,00$;

2. Perda de $\mathrm{R} \$ 10,00$;

3. Lucro de $\mathrm{R} \$ 0,00$ e prejuízo de $\mathrm{R} \$ 0,00$; e

4. Prejuízo de $\mathrm{R} \$ 90,00$. Aqui é importante notar que, incialmente teríamos um lucro de $\mathrm{R} \$ 10,00$ com a transação e, após o chargeback, recebemos um prejuízo de $\mathrm{R} \$ 100,00$, o que nos dá como saldo final um prejuízo de $\mathrm{R} \$ 90,00$.

Executamos essa análise para cada transação, obtendo-se o lucro ou prejuízo para cada uma delas, e somamos os resultados de todas as transações. Por fim, comparamos esses resultados com aqueles obtidos atualmente pela empresa e chegamos ao que chamamos de medida de eficiência econômica: sendo $E E_{t}$ o resultado econômico obtido através dos experimentos com o procedimento aqui apresentado, e $E E_{e}$ o resultado econômico obtido atualmente pela empresa, a medida de eficiência econômica é definida por:

$$
E E=\left(E E_{t}-E E_{e}\right) / E E_{e}
$$

Ou seja, de acordo com a equação 6.1, a medida de eficiência econômica aqui definida representa o ganho financeiro que obtivemos com o processo descrito nesse trabalho, relativo ao resultado econômico atual da empresa.

Analisemos agora a eficiência econômica recém-descrita para cada um dos níveis de balanceamento da amostra de treinamento, descritos na Seção 6.3, seguindo o processo de classificação descrito na Seção 6.2. Além disso, consideraremos somente as transações efetivadas na nossa análise (ou seja, desconsideraremos as transações negadas pela empresa ou pelo adquirente).

A Figura 6.6 mostra a eficiência econômica para cada um dos níveis de balanceamento da amostra de treinamento. 


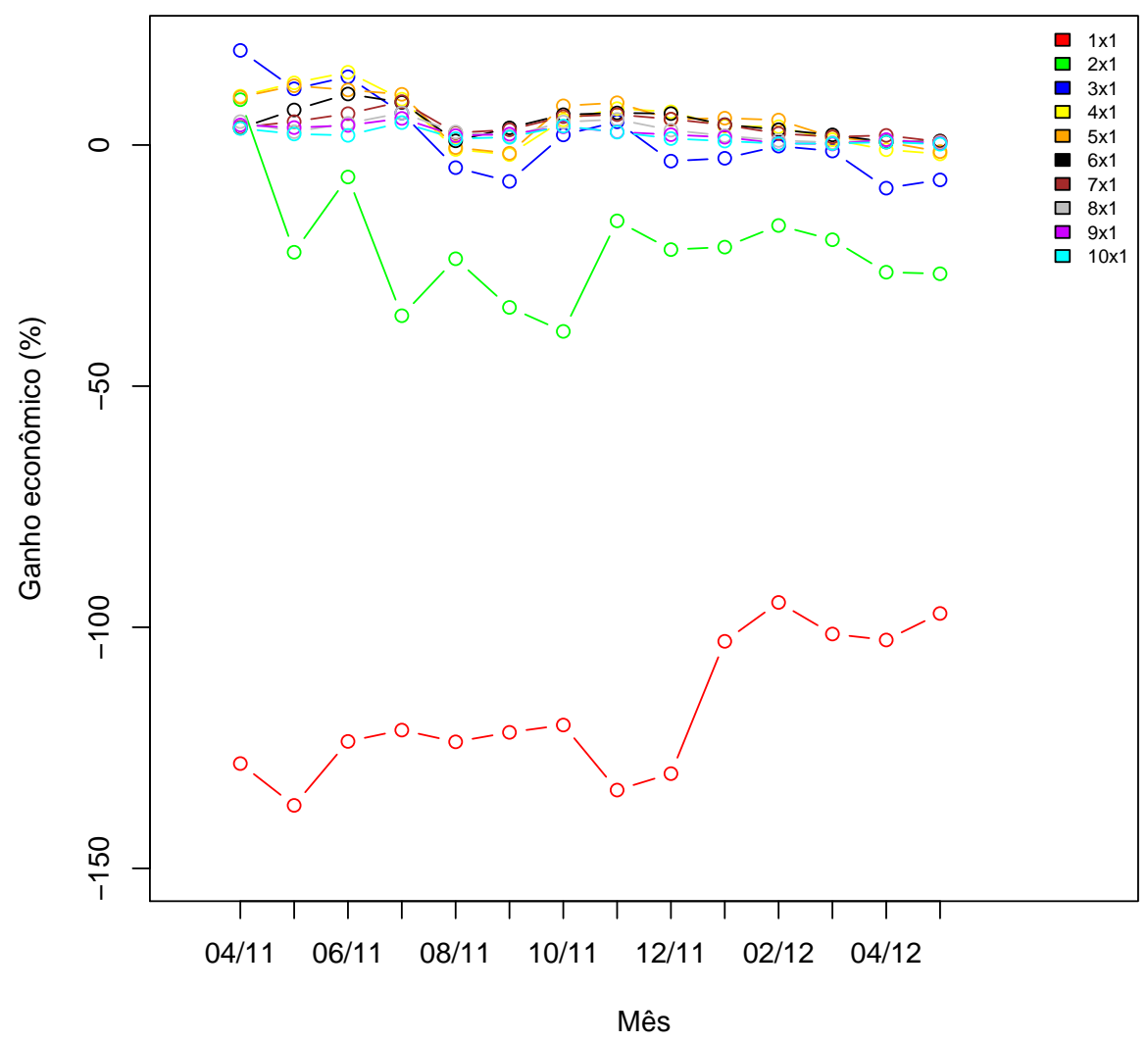

Figura 6.6: Eficiência econômica para os diferentes niveis de balanceamento artificial da amostra de treinamento.

Percebe-se pela Figura 6.6 que há muita variação nos resultados de acordo com o nível de balanceamento da amostra de treinamento. O nível $1 x 1$ particularmente apresenta resultados muitos ruins. Consideremos agora somente os melhores níveis, ou seja, aqueles que geraram resultados positivos para a grande maioria dos meses. Os resultados são apresentados na Figura 6.7. 


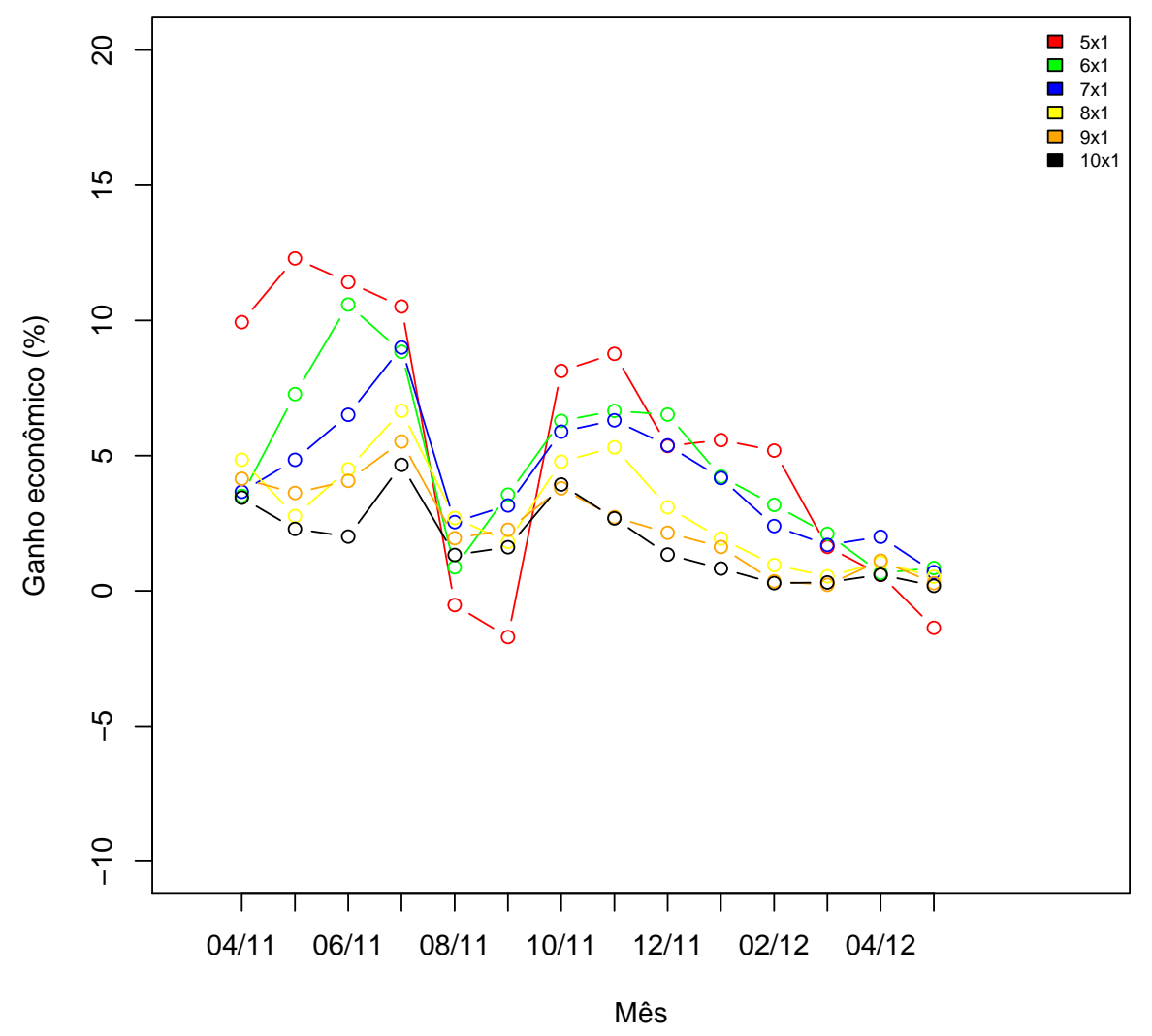

Figura 6.7: Eficiência econômica considerando somente os melhores níveis de balanceamento.

Note que para os níveis de balanceamento onde a proporção de transações legítimas é menor (ex: 5x1) há mais variação nos resultados. O nível 10x1, por exemplo, apresenta resultados em geral piores que os outros, porém mais constantes, sempre próximo a $2 \%$.

É importante comparar os resultados aqui apresentados com aqueles da Seção 6.3. Na Seção 6.3 vimos que a taxa de deteç̧ão de chargebacks piora conforme aumentamos a quantidade de transações legítimas na amostra de treinamento, ao mesmo tempo que a taxa de falsos alarmes diminui conforme adicionamos transações legítimas à amostra de treinamento. Pelas figuras $6.6 \mathrm{e}$ 6.7 vemos que a eficiência econômica melhora para níveis de balanceamento com uma quantidade maior de transações legítimas. Isso fica ainda mais claro ao verificarmos os resultados do nível 1x1 na Figura 6.6: percebe-se que, a alta taxa de falsos alarmes para o nível 1x1, que foi observado na Figura 6.5, tem um profundo impacto negativo do ponto de vista econômico. Logo, podemos dizer que, do ponto de vista econômico, manter uma taxa de falsos alarmes baixa em um sistema de detecção de fraude é tão ou mais importante quanto ter uma alta taxa de detecção de chargebacks, pelo menos na hipótese aqui assumida de não termos um processo de análise manual pós-classificação.

É importante ressaltar que temos uma região de incerteza nos nossos dados que são as transações não aprovadas pelo processo de análise da empresa. O fato da transação não ter sido aprovada não significa necessariamente que ela é uma fraude e que consequentemente geraria um chargeback, o que nos impede de fazer qualquer afirmação concreta a respeito das transações desse conjunto. Nos resultados das figuras 6.6 e 6.7 estamos ignorando completamente as transações não aprovadas, ou seja, não estamos classificando essas transações. Executaremos novamente nossa análise supondo que todas as transações não aprovadas realmente são fraudes. Os resultados considerando todos os níveis estão na Figura 6.8 . 


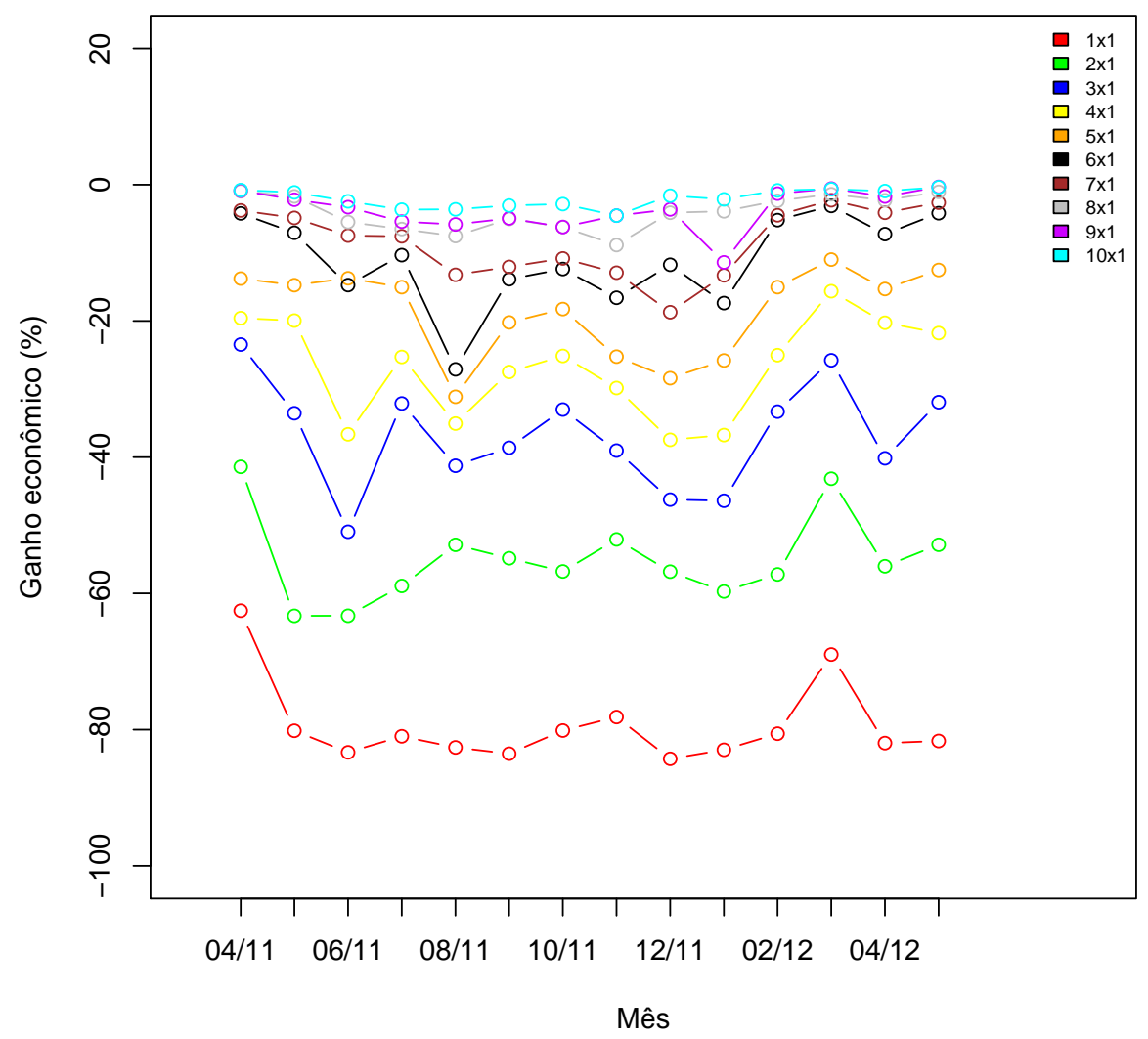

Figura 6.8: Eficiência econômica considerando que toda transação não aprovada pela empresa é fraude.

De forma análoga ao que fizemos para a Figura 6.7, visualizemos a Figura 6.8 considerando somente os melhores níveis. O resultado está na Figura 6.9. 


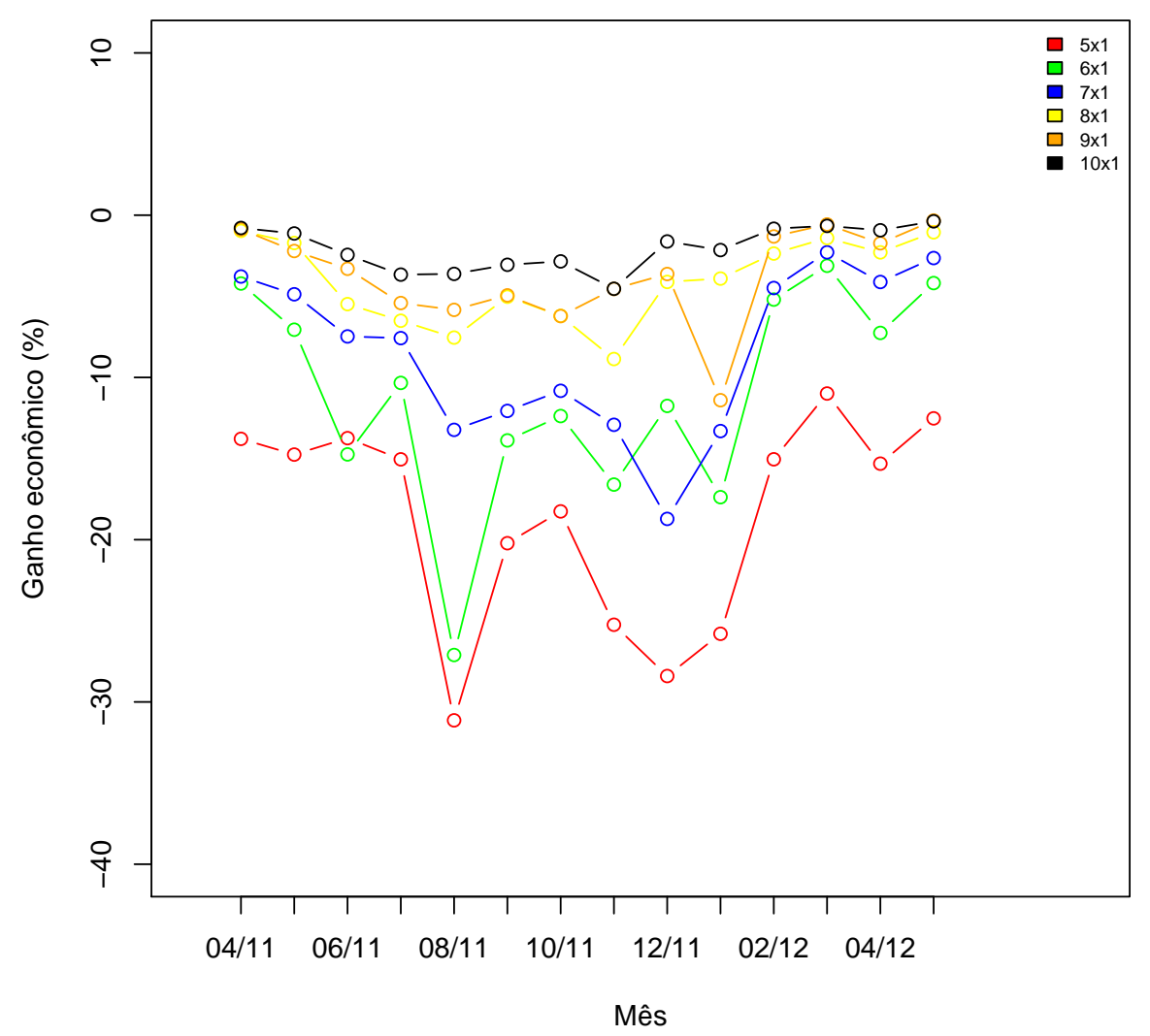

Figura 6.9: Eficiência econômica somente para os melhores niveis de balanceamento e considerando que toda transação não aprovada pela empresa é fraude.

Percebe-se pelas figuras 6.8 e 6.9 que, ao assumir que toda transação não autorizada pela empresa é fraude, temos uma queda significativa na eficiência econômica. Faremos agora o oposto e consideraremos que toda transação não autorizada é legítima. Os resultados considerando todos os níveis e somente os melhores níveis estão respectivamente nas figuras 6.10 e 6.11 . 


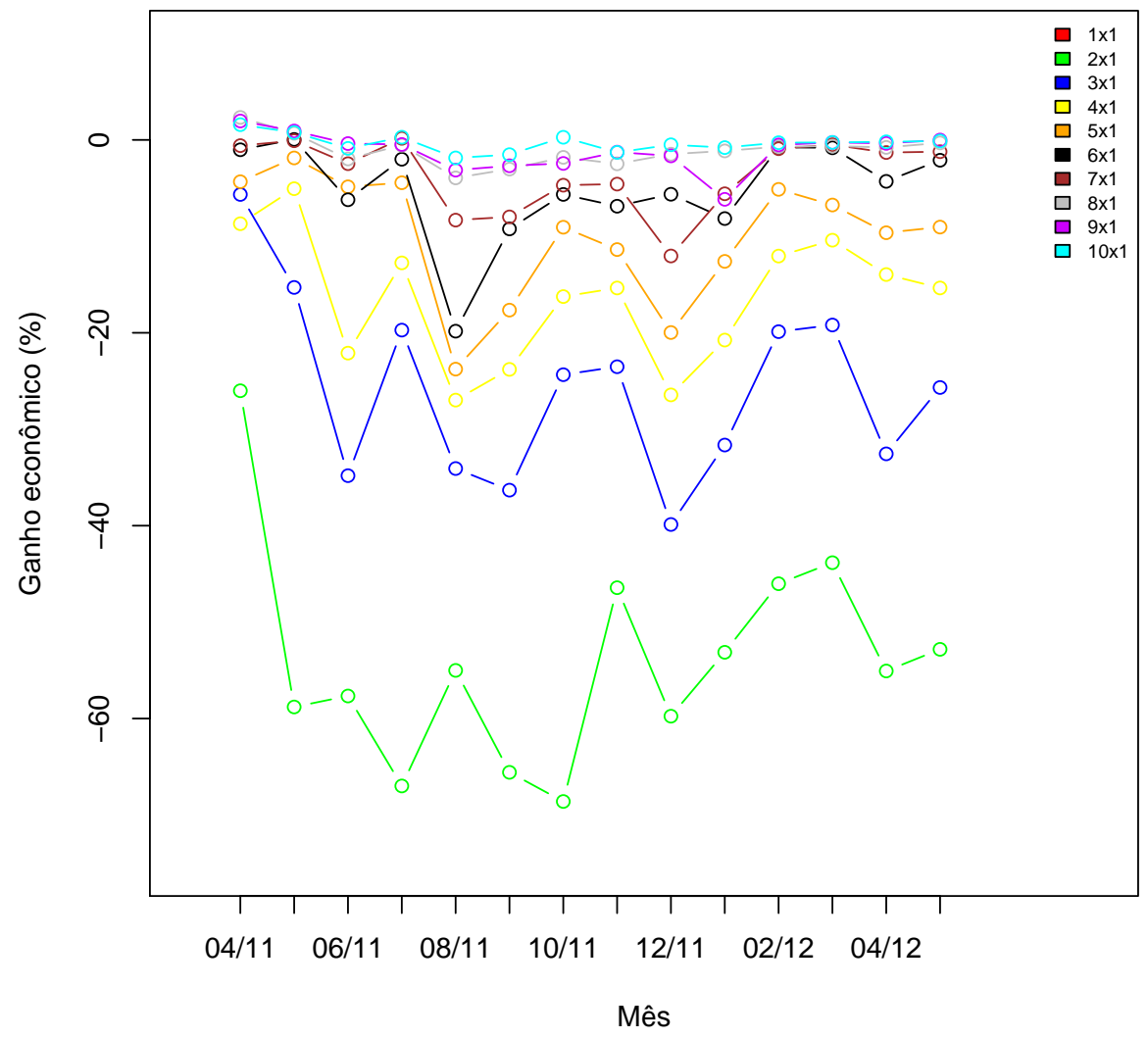

Figura 6.10: Eficiência econômica considerando que toda transação não aprovada pela empresa é legítima. 


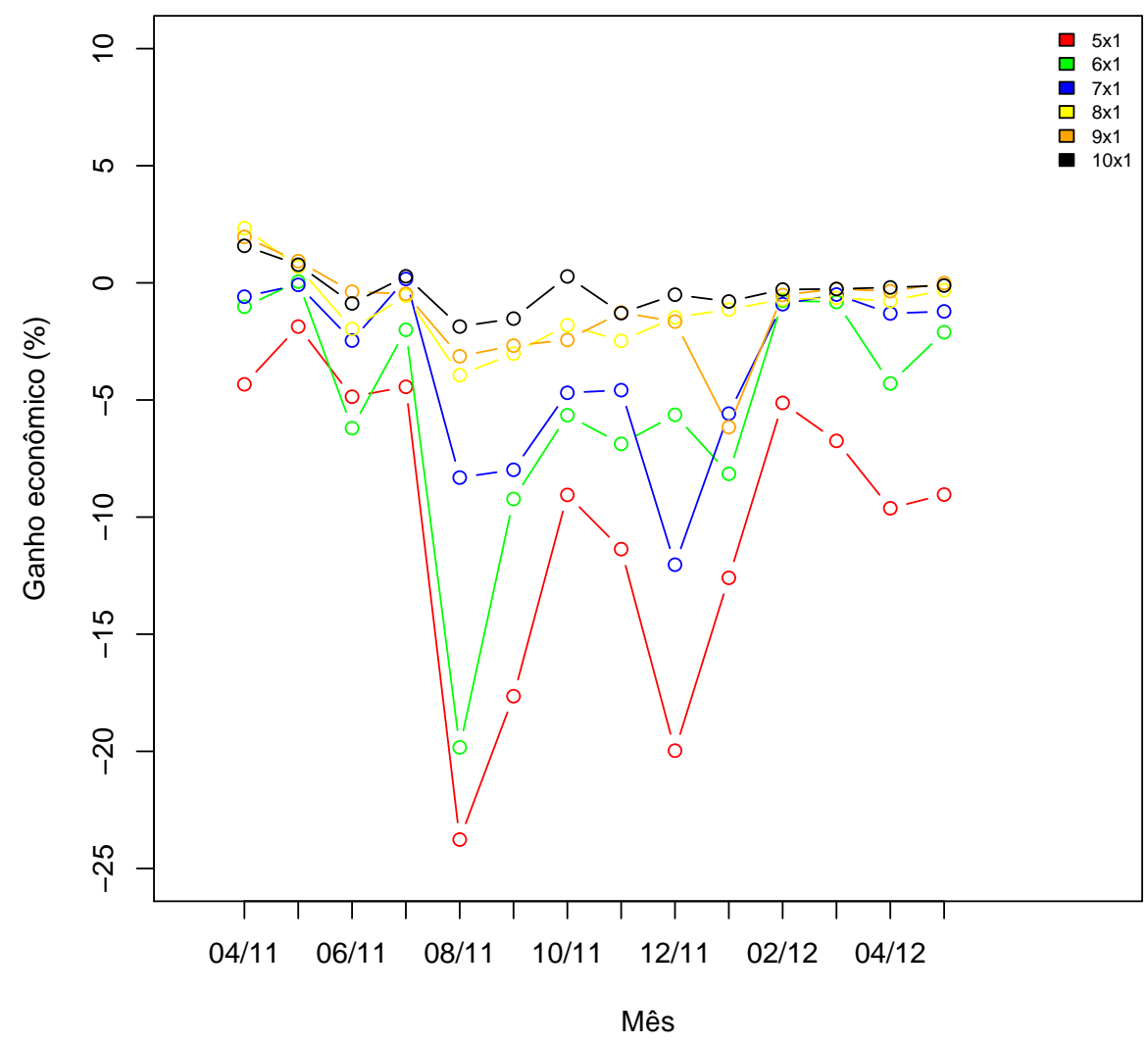

Figura 6.11: Eficiência econômica somente para os melhores níveis de balanceamento e considerando que toda transação não aprovada pela empresa é legítima. 
Novamente percebemos uma queda significativa na eficiência econômica. Utilizaremos agora uma estimativa feita pela empresa do percentual de transações não aprovadas que realmente são fraudes. Re-executamos nossa avaliação considerando que esse mesmo percentual de transações não aprovadas, selecionadas aleatoriamente, é realmente fraude. Estamos aqui introduzindo mais um componente aleatório, e devido a isso esse experimento foi executado 200 vezes e o valor apresentado aqui é a média aritmética simples dos resultados de todas as execuções. A Figura 6.12 apresenta os resultados.

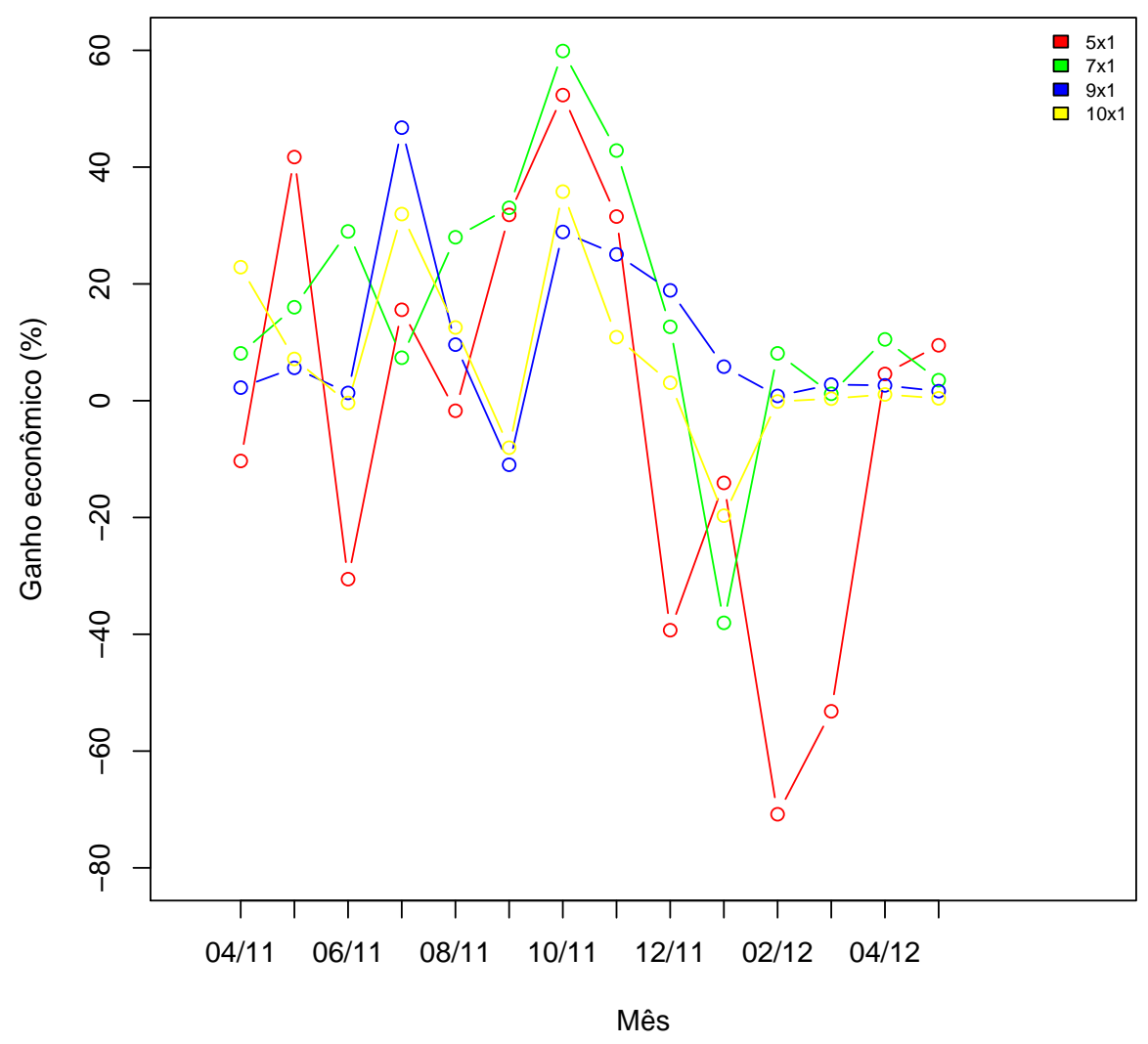

Figura 6.12: Eficiência econômica considerando uma estimativa da taxa de transações não aprovadas que realmente são fraudes.

Os resultados da Figura 6.12 também estão apresentados nas tabelas 6.5 e 6.6, nas quais também são apresentados o desvio padrão para cada valor médio.

\begin{tabular}{|c|c|c|c|c|c|c|c|}
\hline Balanceamento & $04 / 11$ & $05 / 11$ & $06 / 11$ & $07 / 11$ & $08 / 11$ & $09 / 11$ & $10 / 11$ \\
\hline $5 \times 1$ & $-10,31 / 41,01$ & $41,73 / 61,83$ & $-30,55 / 1302,08$ & $15,57 / 663,02$ & $-1,72 / 194,61$ & $31,83 / 374,3$ & $52,34 / 685,67$ \\
$7 \times 1$ & $8,11 / 152,86$ & $16,01 / 24,98$ & $28,99 / 209,25$ & $7,36 / 1336,66$ & $27,99 / 35,62$ & $33,04 / 283,12$ & $59,89 / 582,4$ \\
$9 \times 1$ & $2,24 / 136,69$ & $5,63 / 8,39$ & $1,34 / 128,63$ & $46,76 / 218,97$ & $9,61 / 101,82$ & $-10,97 / 273,71$ & $28,9 / 295,24$ \\
$10 \times 1$ & $22,87 / 113,13$ & $7,16 / 14,54$ & $-0,38 / 319,39$ & $31,97 / 140,17$ & $12,54 / 15,49$ & $-8,05 / 180,88$ & $35,81 / 272,45$ \\
\hline
\end{tabular}

Tabela 6.5: Eficiência econômica considerando uma estimativa da taxa de transações não aprovadas que realmente são fraudes. Os resultados estão no formato média/desvio padrão. 


\begin{tabular}{|c|c|c|c|c|c|c|c|}
\hline Balanceamento & $11 / 11$ & $12 / 11$ & $01 / 12$ & $02 / 12$ & $03 / 12$ & $04 / 12$ & $05 / 12$ \\
\hline $5 \times 1$ & $31,54 / 259,26$ & $-39,29 / 695,16$ & $-14,07 / 134,76$ & $-70,81 / 1108,2$ & $-53,19 / 775,81$ & $4,58 / 66,95$ & $9,49 / 42,25$ \\
$7 \times 1$ & $42,84 / 201,29$ & $12,66 / 262,25$ & $-38,04 / 203,18$ & $8,11 / 24,14$ & $1,19 / 40,4$ & $10,5 / 12,01$ & $3,51 / 2,77$ \\
$9 \times 1$ & $25,06 / 87,68$ & $18,9 / 82,97$ & $5,83 / 10,94$ & $0,82 / 3,69$ & $2,76 / 23,43$ & $2,63 / 3,35$ & $1,64 / 1,21$ \\
$10 \times 1$ & $10,88 / 86,76$ & $3,07 / 61,99$ & $-19,69 / 146,88$ & $-0,14 / 0,94$ & $0,35 / 3,16$ & $1,07 / 1,47$ & $0,41 / 0,5$ \\
\hline
\end{tabular}

Tabela 6.6: Eficiência econômica considerando uma estimativa da taxa de transações não aprovadas que realmente são fraudes. Os resultados estão no formato média/desvio padrão.

Não apresentamos os resultados de todos níveis pois há uma variação muito grande nos resultados, o que dificulta a visualização do gráfico com todos os níveis. Percebe-se aqui que há uma variação muito grande, provavelmente devido à escolha aleatória do conjunto de transações considerada fraude. Além disso, observando o desvio padrão apresentado nas tabelas 6.5 e 6.6 , percebemos que os dados estão bastante dispersos, o que não nos permite tirar conclusões assertivas. Os dados obtidos com as estimativas feitas pela empresa nos dizem somente qual o percentual de transações que seria fraude, mas não nos diz quais seriam essas transações ou ao menos quais as características dessas transações, logo a única forma que encontramos de simular a situação foi escolher as transações aleatoriamente, mas isso certamente não é uma estimativa muito confiável. Outra coisa que se percebe é que os melhores níveis não são exatamente os mesmos apresentados nas figuras 6.7, 6.9 e 6.11.

\subsection{Considerações Finais}

Neste capítulo, descrevemos o processo de classificação utilizando um classificador $S V M$ aplicado à abordagem de modelagem proposta no Capítulo 5. Executamos alguns experimentos iniciais, nos quais avaliamos a importância de tratar o problema do alto nível de desbalanceamento entre as classes de uma forma adequada, assim como mostramos resultados gerais que nos forneceram uma visão da eficiência da abordagem proposta em termos econômicos.

Ao analisarmos o impacto do nível de balanceamento da amostra de treinamento nos resultados da classificação, ficou claro que, uma quantidade maior de transações legítimas diminui a taxa de falsos alarmes geradas pelo classificador, da mesma forma que uma quantidade maior de chargebacks aumenta a eficácia do classificador na detecção das fraudes. Por outro lado, percebemos ao analisar a eficiência econômica do processo que, uma alta taxa de falsos alarmes pode ter um impacto negativo significativo nos resultados do ponto de vista econômico, sendo então fundamental uma seleção cuidadosa do nível de balanceamento a ser aplicado na amostra de treinamento do classificador.

Uma limitação da abordagem proposta é a necessidade da existência de histórico de utilização do sistema por parte das entidades envolvidas na transação. Existe um conjunto de transações que não possuem histórico relacionado às suas entidades, e portanto não podem ser tratadas pela etapa do processo que estamos aplicando. Porém, é importante notar que descrevemos aqui um processo mais amplo para a detecção automatizada de transações fraudulentas e detalhamos somente a última etapa desse processo. Logo, as transações que não são contempladas pelo escopo da etapa do processo aqui detalhada poderiam ser contempladas em uma etapa anterior. 


\section{Capítulo 7}

\section{Resultados da Classificação para Cada Subconjunto de Transação}

Neste capítulo iremos apresentar resultados mais específicos obtidos com o procedimento de classificação descrito previamente no Capítulo 6.

\subsection{Resultados da Classificação das Transações}

Conforme visto na Seção 6.3, a preparação da amostra de treinamento do classificador no que se refere ao nível de desbalanceamento entre as duas classes envolvidas tem um grande impacto nos resultados. A Seção 6.3 mostrou alguns resultados gerais para todos os níveis de balanceamento da amostra de treinamento avaliados e a Seção 6.4 nos mostrou um comparativo em termos de eficiência econômica para os diferentes níveis de balanceamento. Olhemos agora para os resultados mais detalhados para dois diferentes níveis de balanceamento: 2x1 e 10x1. Os resultados para os demais níveis estão no Apêndice A.

A Figura 7.1 mostra a taxa de detecção de chargebacks para cada subconjunto utilizando o balanceamento $2 x 1$ na amostra de treinamento. 


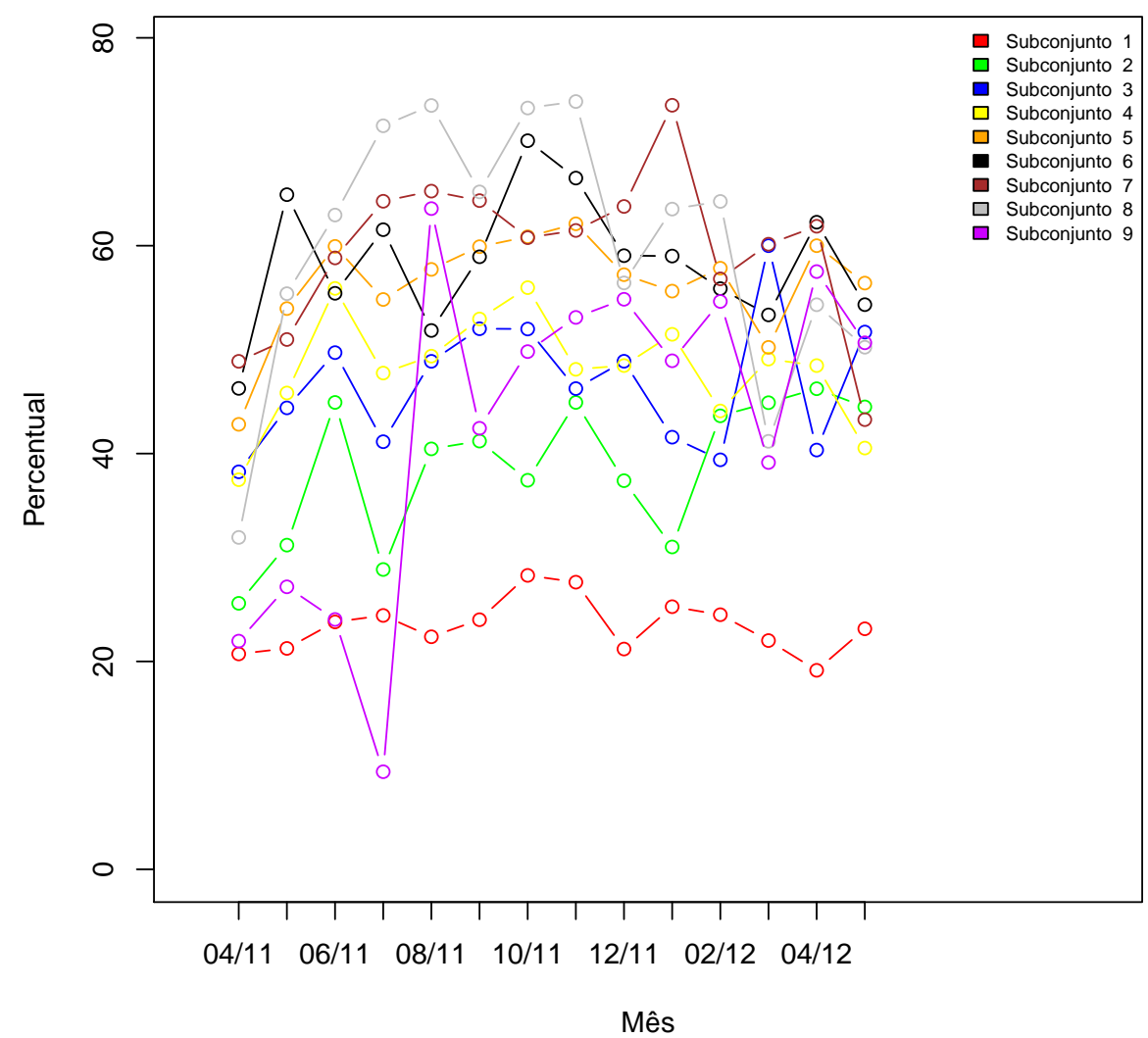

Figura 7.1: Taxa de detecção de chargebacks por mês para cada subconjunto utilizando um balanceamento $2 \times 1$ na amostra de treinamento do classificador.

Os dados da Figura 7.1 estão representados nas Tabelas 7.1 e 7.2, nas quais também mostramos os respectivos desvio padrão.

\begin{tabular}{|c|c|c|c|c|c|c|c|}
\hline Subconjunto & $04 / 11$ & $05 / 11$ & $06 / 11$ & $07 / 11$ & $08 / 11$ & $09 / 11$ & $10 / 11$ \\
\hline 1 & $20,72 / 1,42$ & $21,26 / 1,69$ & $23,8 / 1,16$ & $24,43 / 5,8$ & $22,37 / 1,27$ & $24,02 / 0,78$ & $28,28 / 8,58$ \\
2 & $25,59 / 3,33$ & $31,19 / 2,87$ & $44,92 / 4,94$ & $28,85 / 3,56$ & $40,45 / 5,05$ & $41,2 / 3,1$ & $37,43 / 5,02$ \\
3 & $38,24 / 7,79$ & $44,4 / 5,14$ & $49,71 / 3,53$ & $41,14 / 3,82$ & $48,88 / 2,43$ & $52,01 / 4,91$ & $51,99 / 4,77$ \\
4 & $37,49 / 3,11$ & $45,83 / 2,61$ & $55,89 / 1,77$ & $47,75 / 4,4$ & $49,38 / 2,47$ & $52,95 / 4,29$ & $55,96 / 4,14$ \\
5 & $42,81 / 4,2$ & $53,95 / 3$ & $59,94 / 1,36$ & $54,83 / 1,31$ & $57,72 / 1,57$ & $59,91 / 1,75$ & $60,86 / 1,52$ \\
6 & $46,27 / 4,59$ & $64,91 / 3,04$ & $55,42 / 1,98$ & $61,54 / 1,73$ & $51,84 / 2,37$ & $58,93 / 2,25$ & $70,1 / 3,01$ \\
7 & $48,88 / 3,97$ & $50,98 / 5,43$ & $58,82 / 2,91$ & $64,28 / 1,64$ & $65,25 / 2,62$ & $64,34 / 2,58$ & $60,77 / 4,33$ \\
8 & $31,93 / 4,69$ & $55,38 / 2,85$ & $62,95 / 2,51$ & $71,54 / 2,24$ & $73,49 / 1,24$ & $65,18 / 3,12$ & $73,25 / 2,99$ \\
9 & $21,96 / 2,34$ & $27,18 / 1,19$ & $24,04 / 5,6$ & $9,39 / 6,47$ & $63,57 / 3,06$ & $42,44 / 1,59$ & $49,81 / 2,84$ \\
\hline
\end{tabular}

Tabela 7.1: Percentual de chargebacks detectados por mês para cada subconjunto utilizando um balanceamento $2 x 1$ na amostra de treinamento do classificador, com o respectivo desvio padrão. Os dados estão no formato média/desvio padrão. 


\begin{tabular}{|c|c|c|c|c|c|c|c|}
\hline Subconjunto & $11 / 11$ & $12 / 11$ & $01 / 12$ & $02 / 12$ & $03 / 12$ & $04 / 12$ & $05 / 12$ \\
\hline 1 & $27,63 / 3,76$ & $21,19 / 1,2$ & $25,27 / 1,03$ & $24,5 / 0,78$ & $22,01 / 0,95$ & $19,15 / 2,98$ & $23,14 / 3,03$ \\
2 & $44,92 / 8,41$ & $37,39 / 5,56$ & $31,02 / 5,48$ & $43,63 / 2,61$ & $44,9 / 1,69$ & $46,24 / 3$ & $44,49 / 2,09$ \\
3 & $46,25 / 3,08$ & $48,88 / 3,02$ & $41,58 / 2,64$ & $39,4 / 3,56$ & $60 / 2,28$ & $40,34 / 4,96$ & $51,69 / 2,59$ \\
4 & $48,11 / 4,23$ & $48,47 / 3,47$ & $51,48 / 3,72$ & $44,1 / 3,03$ & $49,09 / 6,66$ & $48,46 / 3,31$ & $40,53 / 8,86$ \\
5 & $62,11 / 1,14$ & $57,21 / 1,75$ & $55,63 / 1,71$ & $57,84 / 2,16$ & $50,22 / 0,98$ & $60 / 1,6$ & $56,4 / 2,09$ \\
6 & $66,51 / 3,17$ & $59,04 / 1,9$ & $59,01 / 1,86$ & $55,87 / 1,68$ & $53,34 / 2,58$ & $62,26 / 1,99$ & $54,33 / 1,95$ \\
7 & $61,47 / 2,54$ & $63,78 / 2,89$ & $73,51 / 4,14$ & $56,81 / 2,6$ & $60,15 / 2,42$ & $61,87 / 2,92$ & $43,27 / 1,54$ \\
8 & $73,87 / 2,28$ & $56,42 / 2,51$ & $63,52 / 3,45$ & $64,26 / 1,32$ & $41,18 / 2,38$ & $54,32 / 4,98$ & $50,23 / 3,18$ \\
9 & $53,1 / 2,55$ & $54,85 / 2,56$ & $48,93 / 1,76$ & $54,64 / 2,92$ & $39,14 / 3,2$ & $57,51 / 4,63$ & $50,66 / 4,55$ \\
\hline
\end{tabular}

Tabela 7.2: Percentual de chargebacks detectados por mês para cada subconjunto utilizando um balanceamento $2 \times 1$ na amostra de treinamento do classificador, com o respectivo desvio padrão. Os dados estão no formato média/desvio padrão.

A Figura 7.2 mostra a taxa de detecção de chargebacks para cada subconjunto utilizando o balanceamento $10 x 1$ na amostra de treinamento.

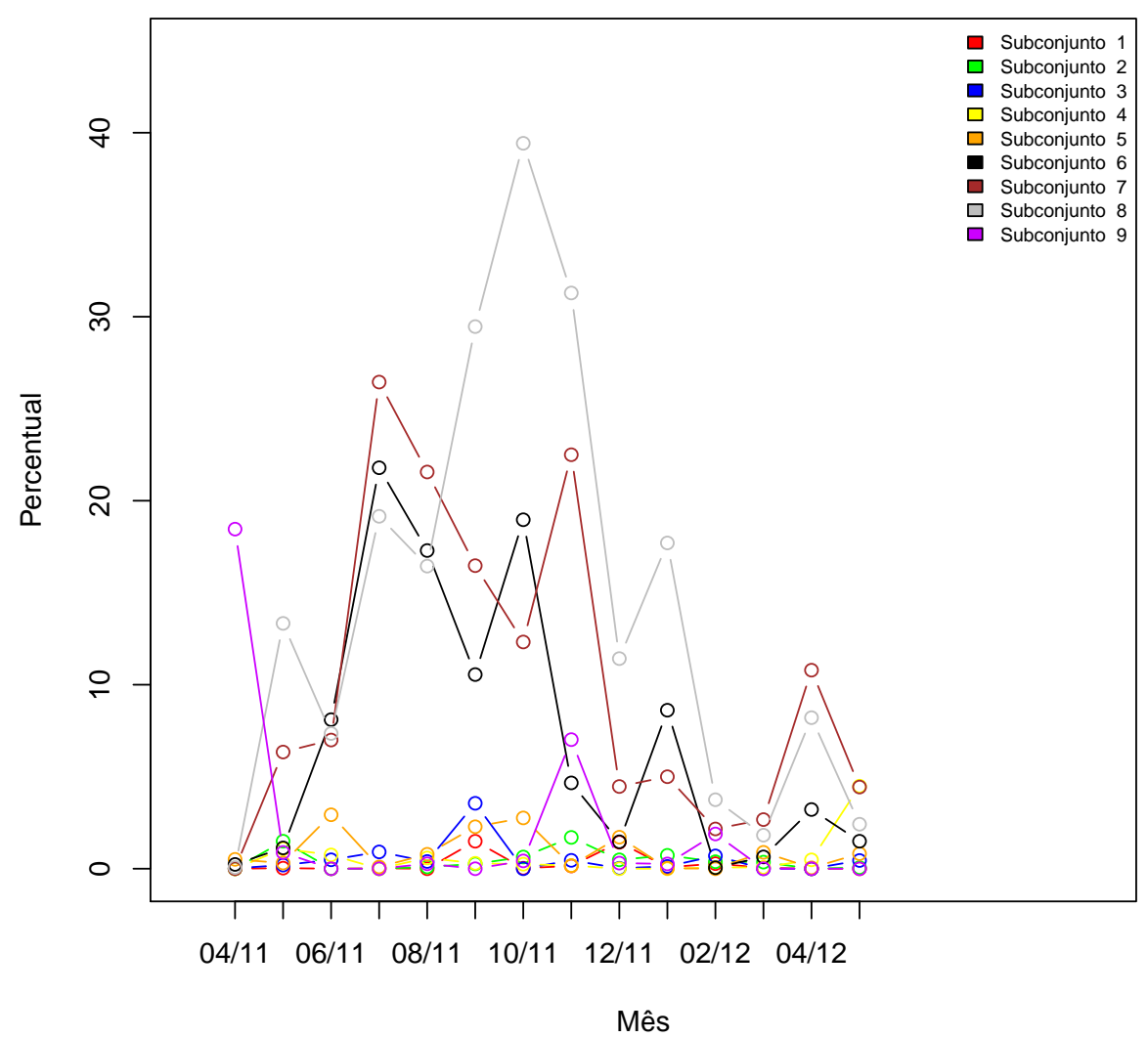

Figura 7.2: Percentual de chargebacks detectados por mês para cada subconjunto utilizando um balanceamento 10x1 na amostra de treinamento do classificador.

Os dados da Figura 7.2 estão representados nas Tabelas 7.3 e 7.4, nas quais também mostramos os respectivos desvio padrão. 


\begin{tabular}{|c|c|c|c|c|c|c|c|}
\hline Subconjunto & $04 / 11$ & $05 / 11$ & $06 / 11$ & $07 / 11$ & $08 / 11$ & $09 / 11$ & $10 / 11$ \\
\hline 1 & $0 / 0$ & $0,03 / 0,1$ & $0 / 0$ & $0,02 / 0,06$ & $0 / 0$ & $1,49 / 1,12$ & $0,03 / 0,09$ \\
2 & $0 / 0$ & $1,49 / 1,63$ & $0 / 0$ & $0 / 0$ & $0,1 / 0,26$ & $0,26 / 0,4$ & $0,64 / 0,3$ \\
3 & $0,02 / 0,07$ & $0,2 / 0,55$ & $0,48 / 0,29$ & $0,91 / 0,8$ & $0,39 / 0,72$ & $3,56 / 1,87$ & $0 / 0$ \\
4 & $0 / 0$ & $1,08 / 2,34$ & $0,75 / 0,64$ & $0 / 0$ & $0,59 / 1,11$ & $0,3 / 0,53$ & $0,25 / 0,66$ \\
5 & $0,51 / 0,29$ & $0,31 / 0,25$ & $2,93 / 0,54$ & $0,1 / 0,15$ & $0,78 / 1,03$ & $2,28 / 0,77$ & $2,76 / 1,25$ \\
6 & $0,23 / 0,22$ & $1,13 / 0,48$ & $8,1 / 1,9$ & $21,79 / 2,21$ & $17,29 / 2,06$ & $10,55 / 1,98$ & $18,97 / 1,58$ \\
7 & $0 / 0$ & $6,34 / 2,76$ & $6,99 / 2,65$ & $26,45 / 4,09$ & $21,56 / 2,72$ & $16,47 / 2,43$ & $12,32 / 3,5$ \\
8 & $0,07 / 0,14$ & $13,33 / 3,14$ & $7,35 / 4,84$ & $19,15 / 4,2$ & $16,45 / 3,19$ & $29,46 / 1,93$ & $39,43 / 6,19$ \\
9 & $18,46 / 0$ & $0,88 / 0$ & $0 / 0$ & $0 / 0$ & $0,27 / 0,85$ & $0 / 0$ & $0,42 / 0,27$ \\
\hline
\end{tabular}

Tabela 7.3: Percentual de chargebacks detectados por mês para cada subconjunto utilizando um balanceamento 10x1 na amostra de treinamento do classificador, com o respectivo desvio padrão. Os dados estão no formato média/desvio padrão.

\begin{tabular}{|c|c|c|c|c|c|c|c|}
\hline Subconjunto & $11 / 11$ & $12 / 11$ & $01 / 12$ & $02 / 12$ & $03 / 12$ & $04 / 12$ & $05 / 12$ \\
\hline 1 & $0,15 / 0,26$ & $1,44 / 0,67$ & $0,08 / 0,18$ & $0,28 / 0,15$ & $0,05 / 0,15$ & $0 / 0$ & $0 / 0$ \\
2 & $1,7 / 1,06$ & $0,48 / 0,67$ & $0,73 / 0,38$ & $0,38 / 0,18$ & $0,36 / 0,1$ & $0 / 0$ & $0,06 / 0,19$ \\
3 & $0,46 / 0,79$ & $0,02 / 0,08$ & $0,13 / 0,24$ & $0,7 / 0,71$ & $0 / 0$ & $0 / 0$ & $0,45 / 0,27$ \\
4 & $0,17 / 0,2$ & $0 / 0$ & $0 / 0$ & $0,07 / 0,14$ & $0,07 / 0,23$ & $0,48 / 1,53$ & $4,49 / 1,79$ \\
5 & $0,17 / 0,11$ & $1,71 / 1,12$ & $0,03 / 0,05$ & $0 / 0$ & $0,89 / 0,28$ & $0,05 / 0,08$ & $0,82 / 0,45$ \\
6 & $4,66 / 4,68$ & $1,46 / 1,77$ & $8,61 / 2,47$ & $0,06 / 0,12$ & $0,64 / 0,31$ & $3,22 / 1,6$ & $1,49 / 1,26$ \\
7 & $22,5 / 4,23$ & $4,47 / 4,72$ & $5 / 4,02$ & $2,16 / 1,69$ & $2,67 / 1,7$ & $10,79 / 3,01$ & $4,44 / 2,28$ \\
8 & $3,29 / 11,88$ & $11,42 / 2,76$ & $17,7 / 1,76$ & $3,75 / 2,94$ & $1,82 / 2,2$ & $8,21 / 1,72$ & $2,42 / 2,02$ \\
9 & $7,02 / 3,9$ & $0,31 / 0,16$ & $0,26 / 0,26$ & $1,89 / 1,2$ & $0 / 0$ & $0 / 0$ & $0 / 0$ \\
\hline
\end{tabular}

Tabela 7.4: Percentual de chargebacks detectados por mês para cada subconjunto utilizando um balanceamento 10x1 na amostra de treinamento do classificador, com o respectivo desvio padrão. Os dados estão no formato média/desvio padrão.

Fica claro na Figura 7.1, onde utilizamos o balanceamento $2 x 1$ na amostra de treinamento, uma taxa de deteç̧ão de chargebacks maior para todos os subconjuntos em relação aos resultados apresentados na Figura 7.2, na qual utilizamos a taxa de 10x1, o que é coerente com o apresentado na Seção 6.3. Além disso, percebe-se que a taxa de detecção de chargebacks tende a melhorar a medida que aumentamos o peso geral definido na Seção 5.3.1 (e consequentemente o tamanho do histórico) nos subconjuntos. Isso vai de encontro à nossa hipótese de que o classificador tende a ficar mais eficiente com o aumento do tamanho do histórico das entidades.

Os resultados das Figuras 7.1 e 7.2 são interessantes para percebermos a importância do tamanho do histórico das entidades para a tarefa de classificação, porém eles não são os mais adequados para a visualização da performance em termos de deteç̧ão de chargebacks para o classificador como um todo. Para isso, apresentamos a seguir os resultados dos subconjuntos de forma incremental: os resultados do Subconjunto 1 representam a quantidade de chargebacks detectados no Subconjunto 1 em relação ao total de chargebacks de todos todos os subconjuntos avaliados; os resultados do Subconjunto 2 representam a quantidade de chargebacks presentes nos Subconjuntos 1 e 2 que foram detectados em relação ao total de chargebacks de todos os subconjuntos, e assim por adiante. Dessa forma, os resultados do Subconjunto 9 representam o resultado completo da classificação, porém os demais subconjuntos são interessantes de serem visualizados para acompanharmos a evolução dos resultados em relação ao aumento no valor do peso geral da transação. A Figura 7.3 mostra os resultados incrementais utilizando o balanceamento $2 x 1$ na amostra de treinamento. 


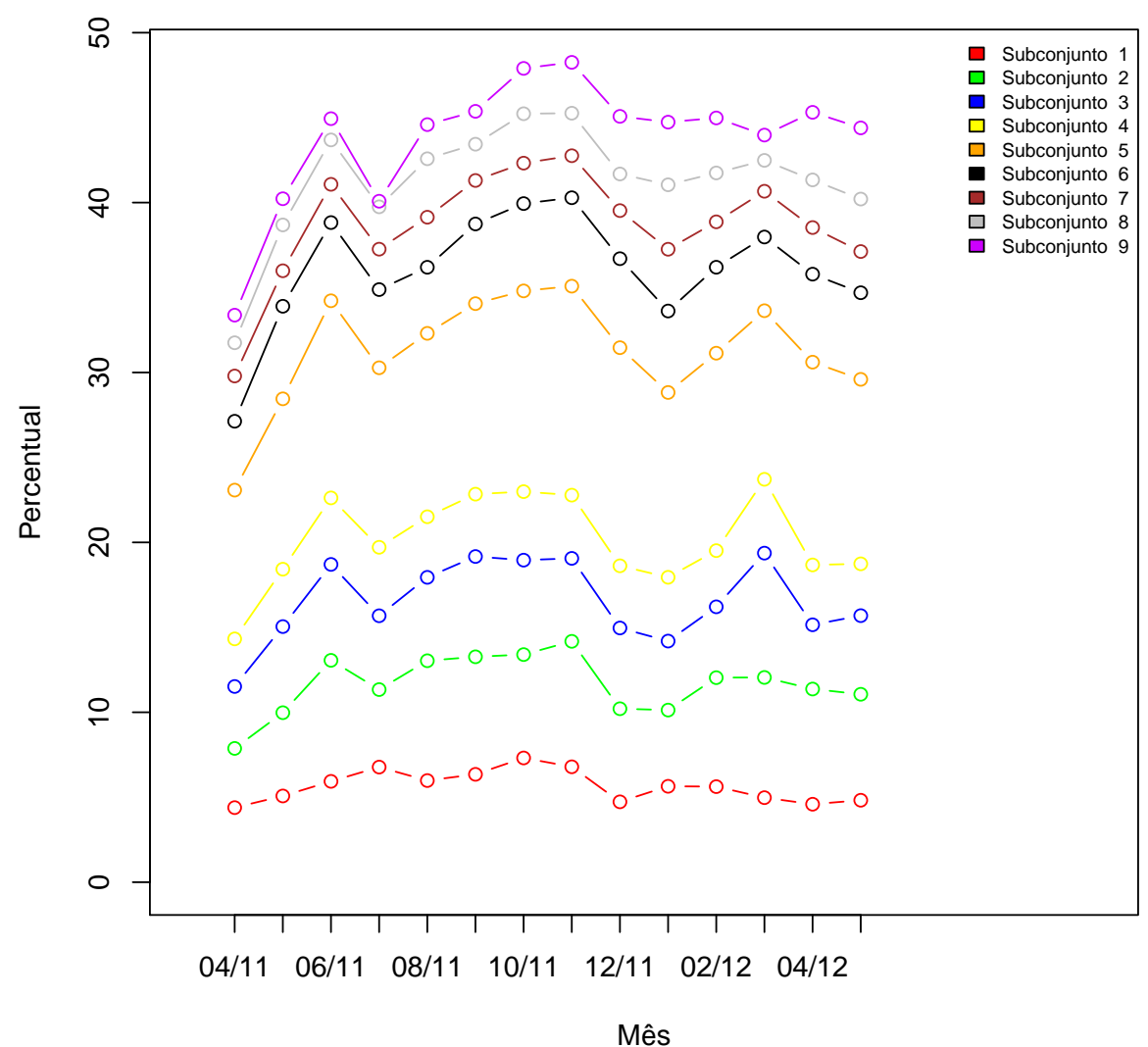

Figura 7.3: Taxa de detecção de chargebacks por mês para cada subconjunto utilizando um balanceamento $2 \times 1$ na amostra de treinamento do classificador. Os resultados para cada subconjunto são incrementais para que se perceba a evolução dos resultados em relação ao peso geral da transação.

A Figura 7.4 mostra os resultados incrementais utilizando o balanceamento $10 x 1$ na amostra de treinamento. 


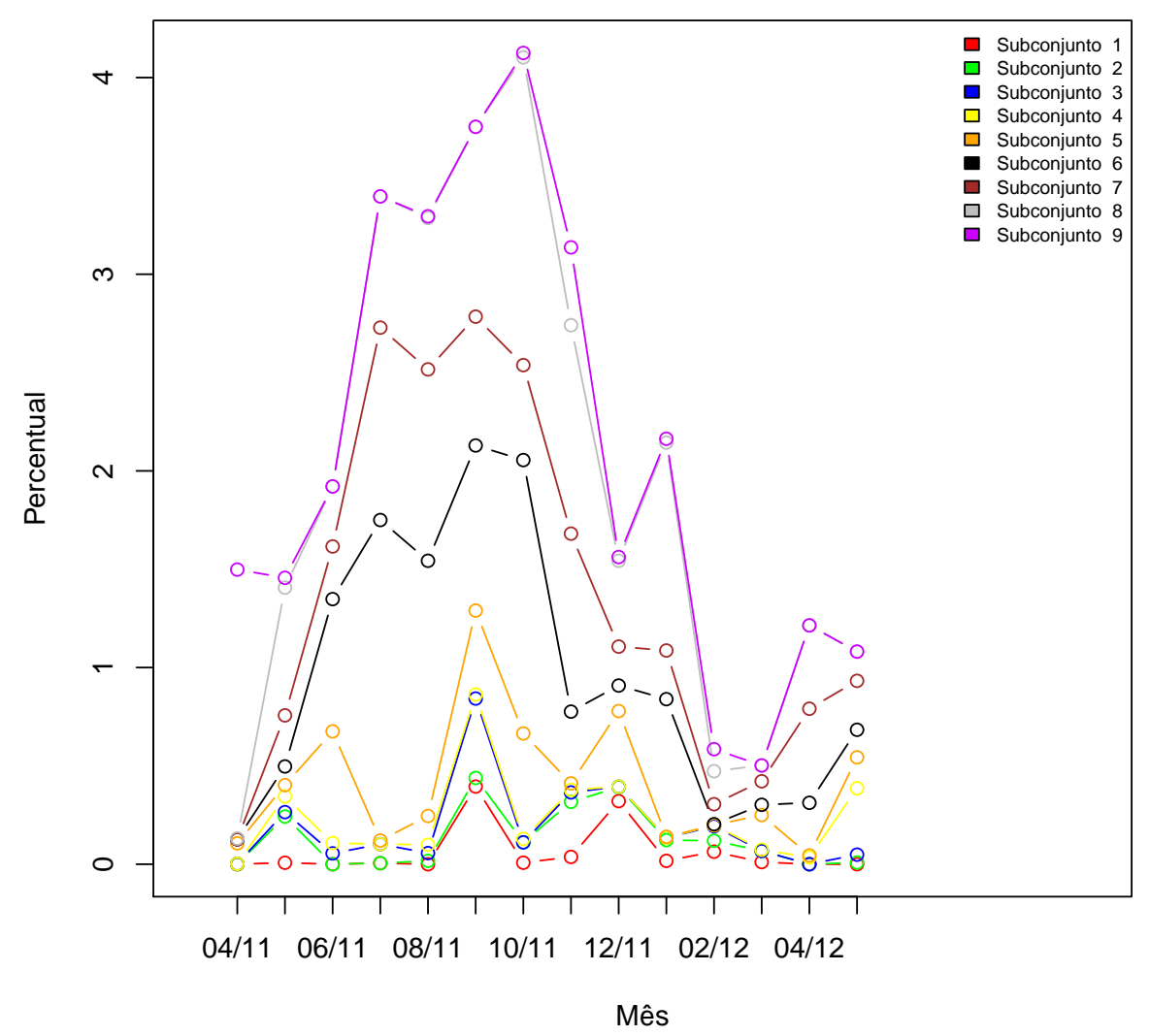

Figura 7.4: Taxa de detecção de chargebacks por mês para cada subconjunto utilizando um balanceamento 10x1 na amostra de treinamento do classificador. Os resultados para cada subconjunto são incrementais para que se perceba a evolução dos resultados em relação ao peso geral da transação.

Percebe-se em ambos os casos, mas principalmente na Figura 7.3, que aumentamos a cobertura de chargebacks detectados conforme avançamos nos subconjuntos. Isso era de se esperar visto que conforme avançamos nos subconjuntos nós também estamos aumentando o universo de transações avaliadas. Outra coisa que fica clara é uma melhora significativa nos resultados utilizando o balanceamento 2x1, da Figura 7.3, em relação ao resultado utilizando balanceamento $10 x 1$ da Figura 7.4: enquanto que para o balanceamento $2 x 1$ temos uma taxa de final deteç̧ão que fica entre $40 \%$ e $50 \%$ para a maioria dos meses, essa taxa cai para menos de $4 \%$ quando utilizamos o balanceamento $10 x 1$.

Olhemos agora para os falsos alarmes gerados pelo classificador, ou seja, transações que não geraram chargeback mas que foram identificadas como fraude. A Figura 7.5 mostra a taxa de falsos alarmes obtida para cada subconjunto utilizando o balanceamento $2 x 1$ na amostra de treinamento. 


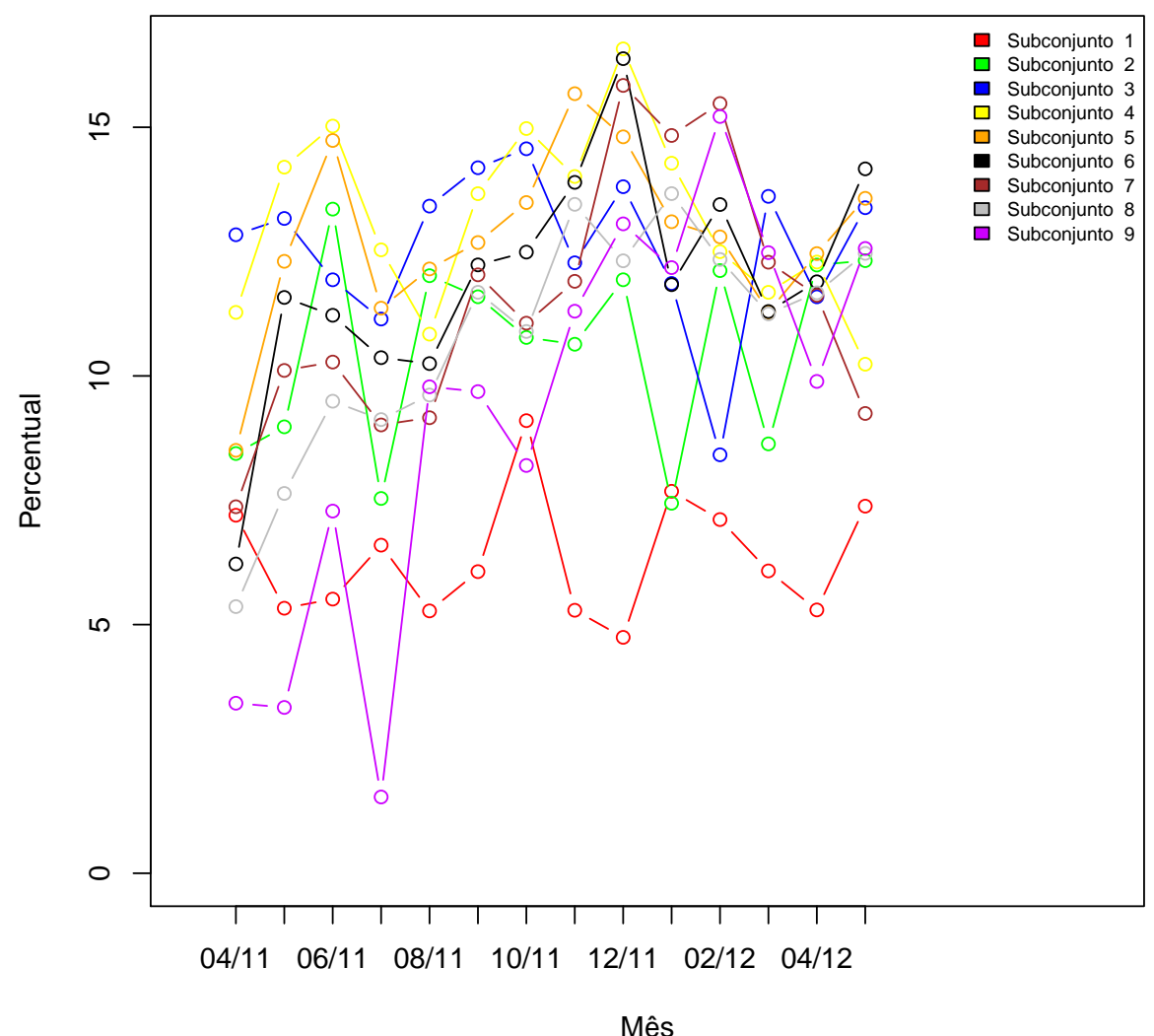

Figura 7.5: Taxa de transações legítimas classificadas como fraude para cada subconjunto utilizando balanceamento 2x1 na amostra de treinamento do classificador.

Os dados da Figura 7.5 estão representados nas Tabelas 7.5 e 7.6, nas quais também mostramos os respectivos desvio padrão.

\begin{tabular}{|c|c|c|c|c|c|c|c|}
\hline Subconjunto & $04 / 11$ & $05 / 11$ & $06 / 11$ & $07 / 11$ & $08 / 11$ & $09 / 11$ & $10 / 11$ \\
\hline 1 & $7,2 / 0,92$ & $5,33 / 0,98$ & $5,51 / 0,6$ & $6,6 / 2,5$ & $5,28 / 0,52$ & $6,07 / 0,43$ & $9,1 / 5,12$ \\
2 & $8,44 / 1,6$ & $8,98 / 1,5$ & $13,35 / 2,78$ & $7,54 / 2,12$ & $12,02 / 2,5$ & $11,59 / 1,8$ & $10,77 / 3,05$ \\
3 & $12,84 / 3,28$ & $13,17 / 2,34$ & $11,93 / 1,55$ & $11,14 / 1,57$ & $13,41 / 0,78$ & $14,19 / 2,07$ & $14,57 / 2,42$ \\
4 & $11,28 / 1,55$ & $14,2 / 1,4$ & $15,02 / 0,99$ & $12,54 / 2,25$ & $10,84 / 1,14$ & $13,66 / 1,39$ & $14,97 / 2,08$ \\
5 & $8,5 / 1,02$ & $12,3 / 0,74$ & $14,73 / 0,41$ & $11,36 / 0,41$ & $12,15 / 0,82$ & $12,68 / 0,5$ & $13,49 / 0,48$ \\
6 & $6,22 / 1,12$ & $11,58 / 0,76$ & $11,22 / 0,81$ & $10,37 / 0,47$ & $10,25 / 0,93$ & $12,23 / 1,07$ & $12,49 / 1,32$ \\
7 & $7,37 / 1,34$ & $10,11 / 1,25$ & $10,28 / 0,74$ & $9,01 / 0,76$ & $9,16 / 1,52$ & $12,03 / 1,32$ & $11,06 / 1,44$ \\
8 & $5,36 / 0,97$ & $7,64 / 1,01$ & $9,49 / 0,72$ & $9,12 / 0,67$ & $9,62 / 0,67$ & $11,68 / 0,72$ & $10,89 / 1,29$ \\
9 & $3,42 / 0,26$ & $3,33 / 0,3$ & $7,28 / 0,83$ & $1,53 / 1,47$ & $9,78 / 0,59$ & $9,69 / 0,81$ & $8,2 / 0,81$ \\
\hline
\end{tabular}

Tabela 7.5: Taxa de transações legítimas classificadas como fraude para cada subconjunto utilizando balanceamento 2x1 na amostra de treinamento do classificador. Os dados estão no formato média/desvio padrão.

\begin{tabular}{|c|c|c|c|c|c|c|c|}
\hline Subconjunto & $11 / 11$ & $12 / 11$ & $01 / 12$ & $02 / 12$ & $03 / 12$ & $04 / 12$ & $05 / 12$ \\
\hline 1 & $5,29 / 0,98$ & $4,74 / 0,45$ & $7,68 / 0,56$ & $7,11 / 0,3$ & $6,08 / 0,48$ & $5,3 / 0,98$ & $7,38 / 1,35$ \\
2 & $10,64 / 3,72$ & $11,93 / 3,71$ & $7,44 / 1,9$ & $12,12 / 2,31$ & $8,63 / 1,04$ & $12,23 / 0,84$ & $12,32 / 0,7$ \\
3 & $12,27 / 1,38$ & $13,8 / 1$ & $11,86 / 1,27$ & $8,41 / 1,38$ & $13,61 / 1,11$ & $11,59 / 1,52$ & $13,38 / 1,49$ \\
4 & $14,01 / 1,61$ & $16,58 / 1,97$ & $14,28 / 1,6$ & $12,5 / 1,06$ & $11,68 / 1,01$ & $12,29 / 0,84$ & $10,24 / 2,27$ \\
5 & $15,68 / 0,8$ & $14,81 / 1,11$ & $13,1 / 0,55$ & $12,8 / 0,43$ & $11,29 / 0,52$ & $12,46 / 0,71$ & $13,57 / 0,82$ \\
6 & $13,89 / 0,96$ & $16,38 / 0,91$ & $11,84 / 1,05$ & $13,45 / 0,49$ & $11,29 / 0,98$ & $11,89 / 0,46$ & $14,16 / 1,2$ \\
7 & $11,9 / 1,25$ & $15,84 / 1,08$ & $14,84 / 1,71$ & $15,48 / 1,04$ & $12,29 / 1,23$ & $11,62 / 0,76$ & $9,25 / 0,88$ \\
8 & $13,45 / 0,65$ & $12,32 / 1,26$ & $13,67 / 1,6$ & $12,34 / 0,83$ & $11,25 / 0,98$ & $11,67 / 1,01$ & $12,46 / 1,23$ \\
9 & $11,3 / 1,26$ & $13,06 / 1,27$ & $12,18 / 0,69$ & $15,22 / 0,92$ & $12,48 / 1,04$ & $9,89 / 0,9$ & $12,56 / 1,05$ \\
\hline
\end{tabular}

Tabela 7.6: Taxa de transações legítimas classificadas como fraude para cada subconjunto utilizando balanceamento $2 \mathrm{x} 1$ na amostra de treinamento do classificador. Os dados estão no formato média/desvio padrão. 
A Figura 7.6 mostra a taxa de falsos alarmes obtida para cada subconjunto utilizando o balanceamento $10 x 1$ na amostra de treinamento.

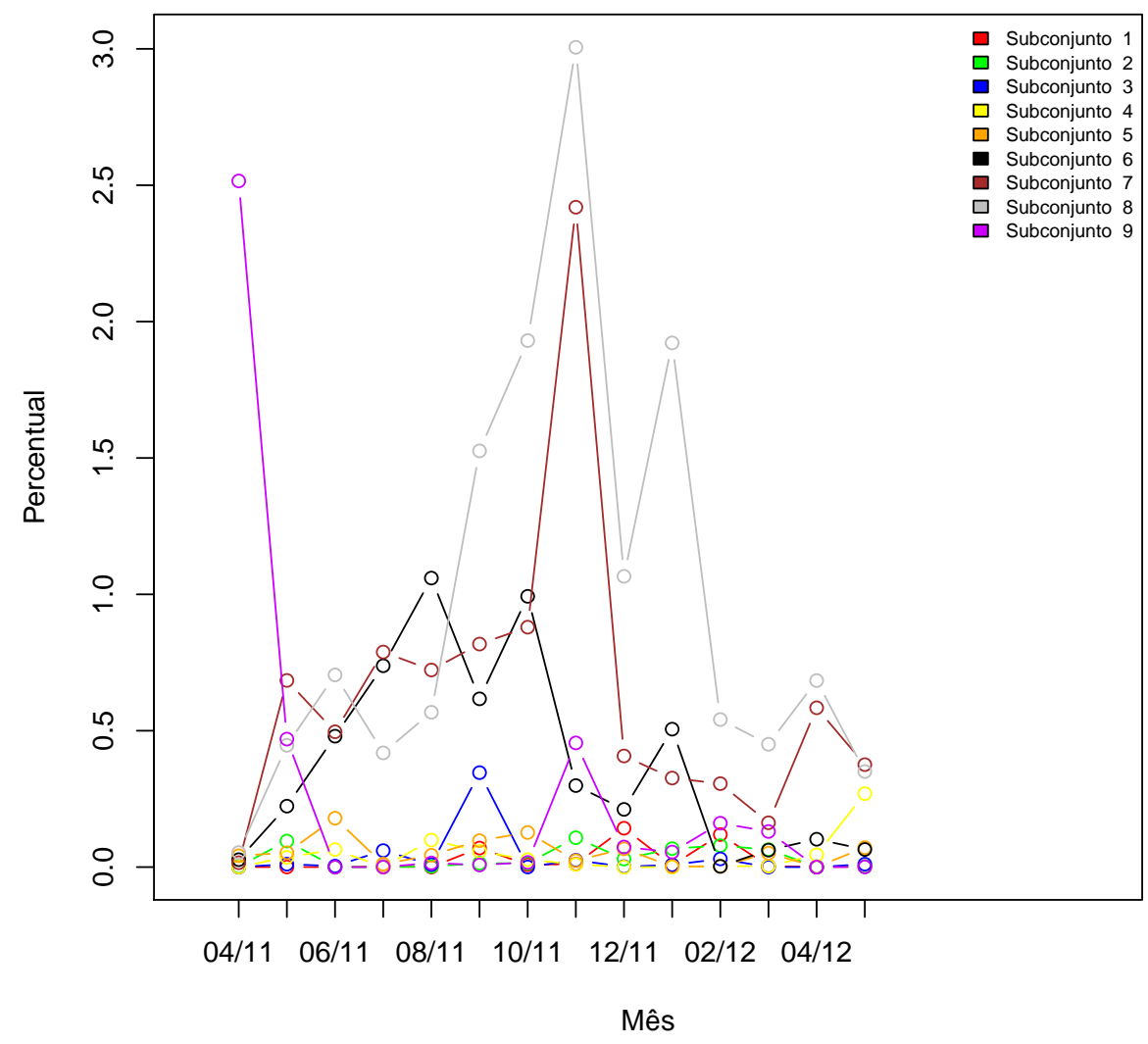

Figura 7.6: Taxa de transações legítimas classificadas como fraude para cada subconjunto utilizando balanceamento 10x1 na amostra de treinamento do classificador.

Os dados da Figura 7.6 estão representados nas Tabelas 7.7 e 7.8, nas quais também mostramos os respectivos desvio padrão.

\begin{tabular}{|c|c|c|c|c|c|c|c|}
\hline Subconjunto & $04 / 11$ & $05 / 11$ & $06 / 11$ & $07 / 11$ & $08 / 11$ & $09 / 11$ & $10 / 11$ \\
\hline 1 & $0 / 0$ & $0 / 0$ & $0 / 0$ & $0 / 0$ & $0 / 0$ & $0,07 / 0,05$ & $0,01 / 0,01$ \\
2 & $0 / 0,01$ & $0,1 / 0,14$ & $0 / 0$ & $0 / 0$ & $0 / 0,01$ & $0,01 / 0,02$ & $0,01 / 0,01$ \\
3 & $0 / 0$ & $0,01 / 0,02$ & $0 / 0,01$ & $0,06 / 0,04$ & $0,01 / 0,02$ & $0,35 / 0,14$ & $0 / 0$ \\
4 & $0 / 0$ & $0,04 / 0,08$ & $0,06 / 0,04$ & $0 / 0$ & $0,1 / 0,11$ & $0,06 / 0,07$ & $0,03 / 0,07$ \\
5 & $0,04 / 0,02$ & $0,05 / 0,02$ & $0,18 / 0,04$ & $0,01 / 0,01$ & $0,04 / 0,04$ & $0,1 / 0,03$ & $0,13 / 0,08$ \\
6 & $0,03 / 0,02$ & $0,22 / 0,04$ & $0,48 / 0,1$ & $0,74 / 0,14$ & $1,06 / 0,13$ & $0,62 / 0,15$ & $0,99 / 0,16$ \\
7 & $0,02 / 0,01$ & $0,68 / 0,12$ & $0,5 / 0,15$ & $0,79 / 0,27$ & $0,72 / 0,23$ & $0,82 / 0,15$ & $0,88 / 0,29$ \\
8 & $0,05 / 0,01$ & $0,45 / 0,15$ & $0,7 / 0,23$ & $0,42 / 0,07$ & $0,57 / 0,14$ & $1,53 / 0,2$ & $1,93 / 0,46$ \\
9 & $2,52 / 0$ & $0,47 / 0,04$ & $0 / 0$ & $0 / 0$ & $0,02 / 0,03$ & $0,01 / 0$ & $0,02 / 0,01$ \\
\hline
\end{tabular}

Tabela 7.7: Taxa de transações legítimas classificadas como fraude para cada subconjunto utilizando balanceamento 10x1 na amostra de treinamento do classificador. Os dados estão no formato média/desvio padrão. 


\begin{tabular}{|c|c|c|c|c|c|c|c|}
\hline Subconjunto & $11 / 11$ & $12 / 11$ & $01 / 12$ & $02 / 12$ & $03 / 12$ & $04 / 12$ & $05 / 12$ \\
\hline 1 & $0,01 / 0,02$ & $0,14 / 0,07$ & $0,01 / 0,01$ & $0,12 / 0,05$ & $0 / 0,01$ & $0 / 0$ & $0 / 0,01$ \\
2 & $0,11 / 0,06$ & $0,03 / 0,05$ & $0,07 / 0,03$ & $0,08 / 0,02$ & $0,06 / 0,02$ & $0 / 0$ & $0 / 0,01$ \\
3 & $0,03 / 0,03$ & $0 / 0$ & $0,01 / 0,01$ & $0,03 / 0,03$ & $0 / 0$ & $0 / 0$ & $0,01 / 0,01$ \\
4 & $0,01 / 0,01$ & $0 / 0$ & $0 / 0$ & $0 / 0$ & $0 / 0,01$ & $0,05 / 0,14$ & $0,27 / 0,09$ \\
5 & $0,02 / 0,01$ & $0,07 / 0,05$ & $0 / 0$ & $0 / 0$ & $0,05 / 0,03$ & $0 / 0$ & $0,07 / 0,03$ \\
6 & $0,3 / 0,36$ & $0,21 / 0,22$ & $0,51 / 0,19$ & $0 / 0$ & $0,06 / 0,03$ & $0,1 / 0,07$ & $0,06 / 0,08$ \\
7 & $2,42 / 0,36$ & $0,41 / 0,38$ & $0,33 / 0,25$ & $0,31 / 0,09$ & $0,16 / 0,11$ & $0,58 / 0,17$ & $0,38 / 0,22$ \\
8 & $3,01 / 1,34$ & $1,07 / 0,44$ & $1,92 / 0,19$ & $0,54 / 0,34$ & $0,45 / 0,27$ & $0,68 / 0,15$ & $0,35 / 0,28$ \\
9 & $0,460 /, 27$ & $0,07 / 0,06$ & $0,06 / 0,04$ & $0,16 / 0,11$ & $0,13 / 0,04$ & $0 / 0$ & $0 / 0$ \\
\hline
\end{tabular}

Tabela 7.8: Taxa de transações legítimas classificadas como fraude para cada subconjunto utilizando balanceamento 10x1 na amostra de treinamento do classificador. Os dados estão no formato média/desvio padrão.

Tanto na Figura 7.5 como na Figura 7.6 não fica claro o comportamento de melhora nos resultados, ou seja, uma taxa de falsos alarmes menor, para os subconjuntos com maior histórico. Isso sugere que que uma maior histórico das entidades tende a gerar melhores resultados em termos de detecção de chargeback, mas não necessariamente do ponto de vista de falsos alarmes.

A Figura 7.7 mostra os resultados incrementais para cada subconjunto utilizando o balanceamento $2 x 1$ na amostra de treino do classificador.

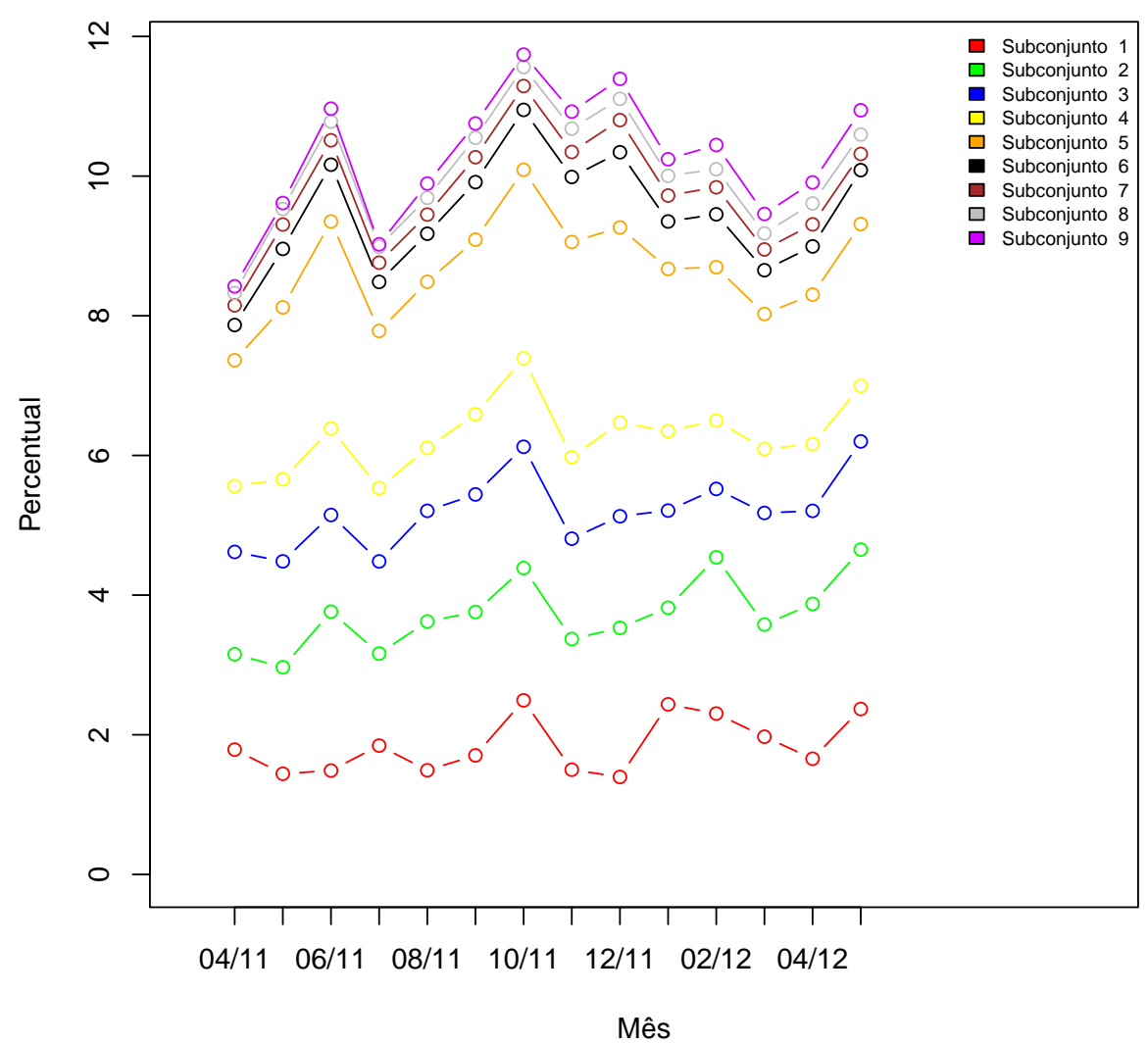

Figura 7.7: Taxa de transações legítimas classificadas como fraude para cada subconjunto utilizando balanceamento $2 \times 1$ na amostra de treinamento do classificador. Os resultados para cada subconjunto são incrementais para que se perceba a evolução dos resultados em relação ao peso geral da transação.

A Figura 7.8 mostra os resultados incrementais para cada subconjunto utilizando o balanceamento $10 x 1$ na amostra de treino do classificador. 


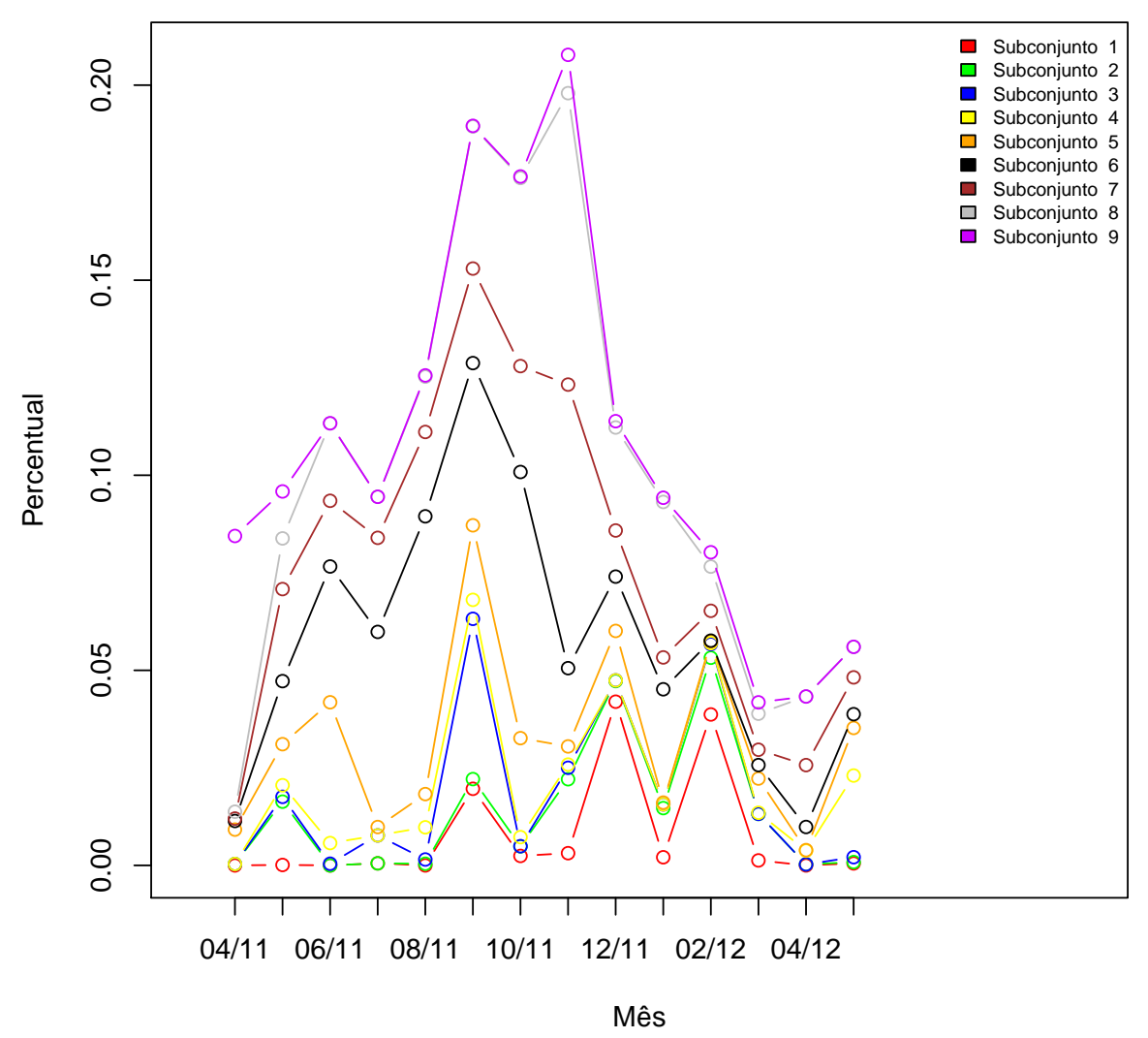

Figura 7.8: Taxa de transações legítimas classificadas como fraude para cada subconjunto utilizando balanceamento 10x1 na amostra de treinamento do classificador. Os resultados para cada subconjunto são incrementais para que se perceba a evolução dos resultados em relação ao peso geral da transação.

Fica claro aqui uma melhora significativa nos resultados, ou seja, uma redução na taxa de falsos alarmes, quando utilizamos o balanceamento $10 x 1$ da Figura 7.8 em comparação com o balanceamento 2x1 da Figura 7.7. Ou seja, ao aumentarmos a quantidade de transações legítimas na amostra de treinamento do classificador, notamos uma melhora na taxa de detecção de transações legítimas. Isso vai de encontro aos resultados apresentados na Seção 6.3.

Conforme dito na Seção 6.4, temos uma região de incerteza nos nossos dados que são as transações que não foram aprovadas pelo processo de análise na empresa: não temos como saber se essas transações são ou não fraudes. Devido a isso, até o momento não estamos considerando as transações não efetivadas nos nossos resultados. Vamos agora analisar qual é o comportamento do nosso classificador para esse conjunto de transações: continuamos considerando somente transações que sofreram chargeback e transações efetivadas para a amostra de treinamento, mas classificamos somente as transações que não foram aprovadas pela empresa. A Figura 7.9 mostra o percentual de transações não aprovadas que foram classificadas como fraude, utilizando a abordagem de visualização incremental dos resultados em relação aos subconjuntos, com um balanceamento $2 x 1$ na amostra de treinamento. 


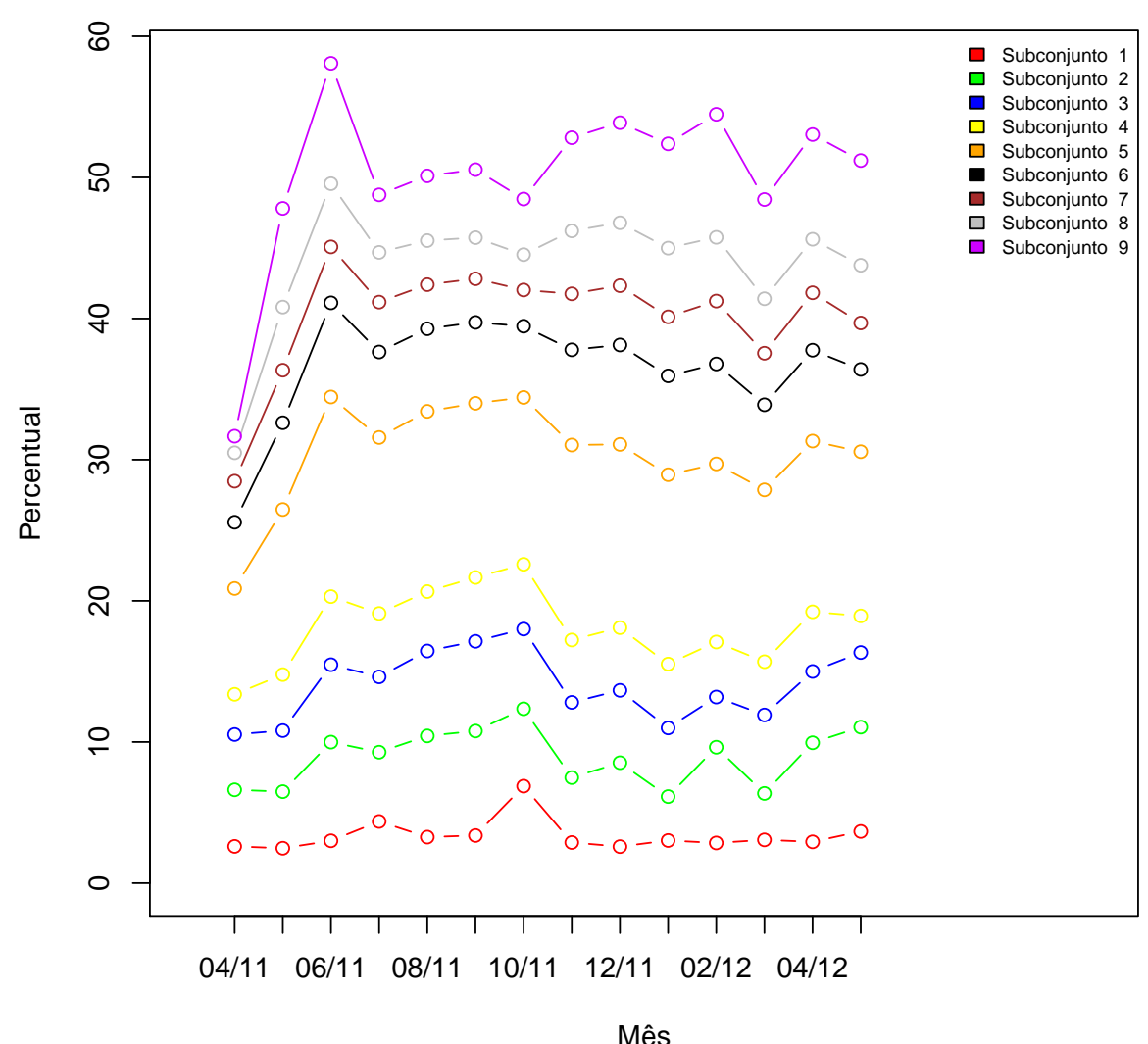

Figura 7.9: Percentual de transações não aprovadas pela empresa classificadas como fraude pelo classificador, utilizando balanceamento $2 \mathrm{x} 1$ na amostra de treino. Os resultados para cada subconjunto são incrementais para que se perceba a evolução dos resultados em relação ao peso geral da transação.

A Figura 7.10 mostra o percentual de transações não aprovadas que foram classificadas como fraude pelo classificador, utilizando a abordagem de visualização incremental dos resultados em relação aos subconjuntos, com um balanceamento $10 x 1$ na amostra de treinamento. 


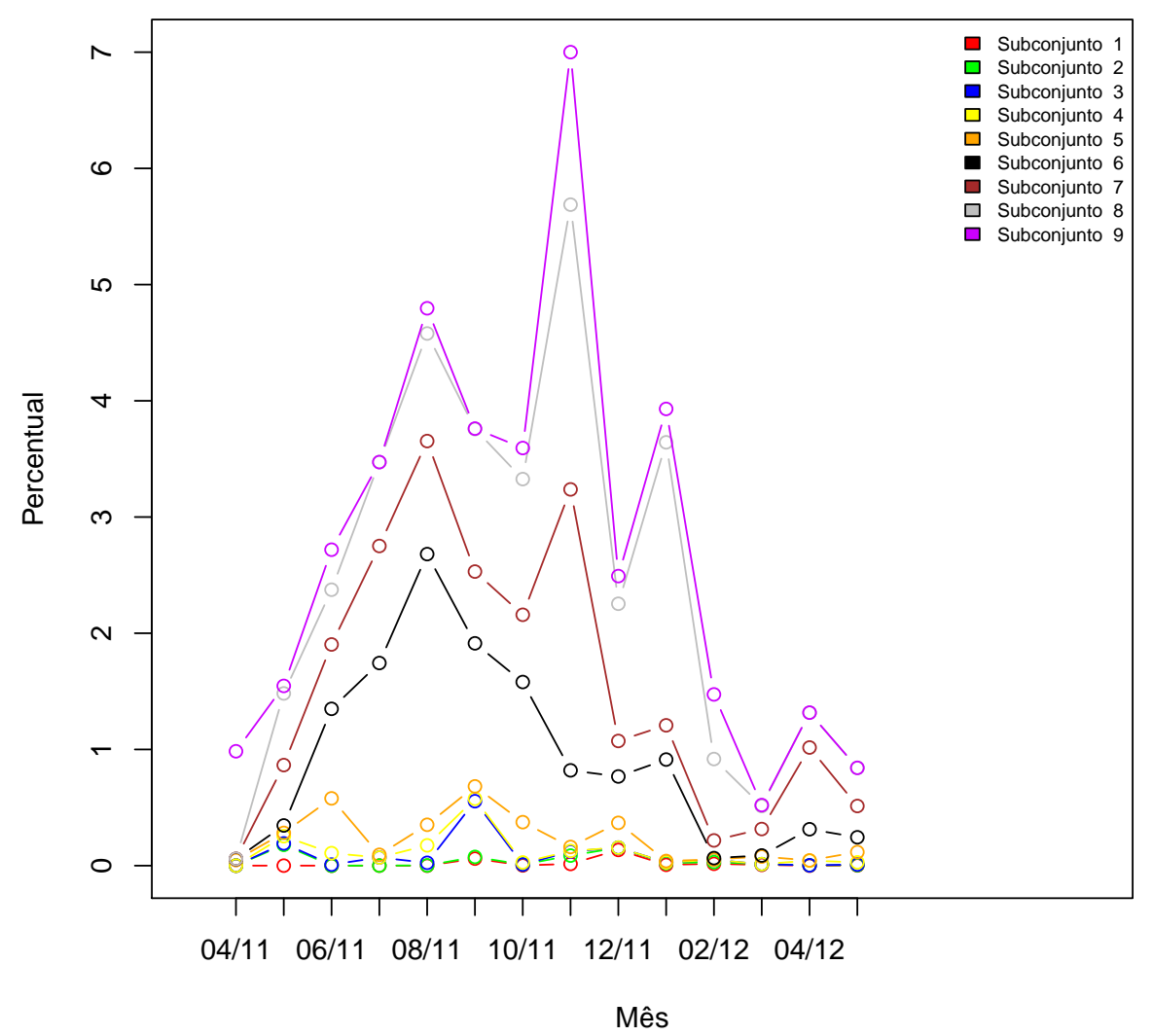

Figura 7.10: Percentual de transações não aprovadas pela empresa classificadas como fraude pelo classificador, utilizando balanceamento 10x1 na amostra de treino. Os resultados para cada subconjunto são incrementais para que se perceba a evolução dos resultados em relação ao peso geral da transação.

Comparando os resultados das Figuras 7.9 e 7.10 com os das Figuras 7.3 e 7.4 respectivamente, percebe-se que a taxa de classificação de transações não aprovadas como fraudes está um pouco acima da taxa de detecção de chargebacks. Isso nos sugere que pode haver certa semelhança entre o conjunto de transações não aprovadas e o conjunto de transações que sofreram chargeback. 


\section{Capítulo 8}

\section{Conclusões e Trabalhos Futuros}

Frente ao forte crescimento do e-commerce que temos observado nos últimos anos com a consequente ascensão do mercado de intermediadores de pagamento online, associado aos prejuízos financeiros causados pelas fraudes nesse mercado, este trabalho propôs um sub-processo a ser aplicado na etapa de triagem automatizada do já bem estabelecido processo de gestão de risco utilizado por grandes empresas que precisam lidar com pagamentos eletrônicos. Utilizamos como estudo de caso dados reais disponibilizados por uma grande empresa do mercado de intermediação de pagamentos online brasileiro. Para isso, começamos com um estudo do funcionamento do mercado de cartões de crédito, procuramos entender onde se situam os intermediadores de pagamento online na cadeia de processamento do cartão, para então desenvolvermos uma abordagem para a fase de triagem automatizada da análise de transações dessas empresas.

Fizemos uma análise preliminar de caracterização dos dados do nosso estudo de caso para ganhar um entendimento profundo desses dados. Essa análise foi fundamental para começarmos a entender o comportamento de algumas características básicas das transações que iríamos analisar. Por exemplo, através dessa análise percebemos que os vendedores possuem um comportamento bastante diferenciado em relação ao comprador, ao portador e ao cartão de crédito de uma transação, e essa conclusão foi de suma importância na fase posterior de modelagem do problema.

Vimos também que, dada a heterogeneidade do problema, é muito difícil ter um único sistema capaz de lidar com todos os tipos de fraude. Face a isso, a abordagem proposta para tratar de forma automatizada o problema consiste de várias etapas que vão desde simples estratégias de prevenção a fraude até uma modelagem mais complexa baseada nas 4 principais entidades envolvidas para a realização de uma transação: o Comprador, o Vendedor, o Cartão e o Portador. Vimos que esse modelo pode ser utilizado para uma análise histórica baseada tanto nas transações legítimas como nas transações fraudulentas do sistema. Por fim, apesar da abordagem proposta envolver várias etapas, abordamos somente a última etapa do processo, por uma questão de limitação do escopo da pesquisa e também por considerarmos que essa é a etapa mais adequada de se validar com os dados que temos disponíveis.

Podemos considerar atingidos os seguintes objetivos específicos enumerados no Capítulo 1:

1. Definimos no Capítulo 5 um processo de análise automatizada de transações eletrônicas, que se encaixa em um processo maior apresentado no Capítulo 2;

2. Apresentamos ainda no Capítulo 5 uma aplicação prática de uma das etapas do processo proposto, onde detalhamos a modelagem baseada nas 4 entidades principais da transação assim como o processo de cálculo dos scores da transação; e

3. Validamos, nos capítulos 6 e 7, nossa proposta utilizando dados reais que nos foram disponibilizados.

Ao validarmos experimentalmente nossa abordagem, vimos a importância de tratar adequadamente a questão do grande desbalanceamento entre as classes ao utilizarmos técnicas de aprendizado computacional para a tarefa de classificação. Ficou evidente nos resultados dos experimentos que, 
ao adicionar uma proporção maior de transações fraudulentas à amostra de treinamento, temos uma assertividade maior na identificação das fraudes, porém também classificamos erroneamente uma quantidade maior de transações legítimas como fraude. A proporção exata entre transações fraudulentas e legítimas na amostra de treinamento do classificador vai depender da estratégia do negócio: em geral, as transações classificadas como fraude passam por uma análise manual posterior de uma equipe de especialistas e, a quantidade aceitável de falsos alarmes de fraude vai depender da capacidade de análise da equipe disponível. Posteriormente, ao fazermos uma análise dos resultados da classificação em termos de eficiência econômica em um cenário simplificado, vimos que manter um nível baixo de falsos alarmes pode ser tão ou mais importante do que uma alta taxa de detecção de transações fraudulentas.

Vimos que a entidade Vendedor não foi considerada nos experimentos aqui descritos, e dissemos no Seção 5.2.4 que experimentos preliminares mostraram uma piora significativa nos resultados quando utilizamos essa entidade. Vimos também, na Seção 4.1, que um chargeback pode ter três causas possíveis, sendo elas uma fraude com origem no comprador, uma fraude com origem no vendedor ou um desacordo comercial entre as partes. Assim, uma hipótese é que a grande maioria das fraudes presentes nos nossos dados possuem origem no comprador, porém essa hipótese não foi testada.

Consideramos as demais etapas do processo proposto, que não foram aplicadas nesse trabalho, uma fonte promissora para pesquisas futuras. Vimos que, apesar de o processo aqui proposto consistir de várias etapas, nós aplicamos somente a última etapa e portanto não conseguimos avaliar o efeito que a execução das etapas anteriores teriam no resultado final do sistema. Em particular, vimos que essa etapa não é adequada para lidar com aquele subconjunto das transações cujas entidades não possuem nenhum histórico. Assim, as etapas anteriores do processo seriam de grande importância, pois elas poderiam tratar esse subconjunto de transações, sendo então interessantes de serem também abordadas com mais detalhes.

Outro ponto passível de ser abordado em futuras pesquisas seria a validação dos resultados aqui obtidos com transações mais recentes, visto que isso não foi possível com o conjunto de dados que temos disponível. Além disso, um ponto importante a ser considerado é que, nos experimentos de classificação que realizamos, estamos tentando identificar o conjunto de fraudes mais difícil existente no conjunto de dados. Para entender isso, é importante relembrar a existência de transações não aprovadas pelo processo de análise da empresa. Muitas fraudes já foram identificadas e consequentemente tais transações foram canceladas pela empresa, e as transações que utilizamos como fraude nos nossos experimentos de classificação são aquelas que conseguiram passar por esse processo de análise, ou seja, são fraudes que podemos considerar como sendo mais difíceis de serem identificadas.

As variações nos resultados de acordo com o nível de balanceamento da amostra de treinamento somente foram avaliadas em relação a um classificador SVM com um kernel radial. Outras técnicas de classificação, como Redes Neurais, por exemplo, podem apresentar um comportamento diferente em relação à essa variação, e essa análise constitui um interessante fonte de pesquisa futura.

Ao separarmos o universo de transações em subconjuntos de acordo com o respectivo peso geral de cada transação, percebemos que a quantidade de transações diminui a medida que aumentamos o peso geral da transação, e que os Subconjuntos 7, 8 e 9 possuem uma quantidade pequena de transações em relação aos demais. Assim, um ponto passível de se abordar em pesquisas futuras seria o agrupamento dos Subconjuntos 7, 8 e 9 em um único subconjunto.

Nos dados que temos disponíveis não conseguimos identificar se a transação cancelada pela empresa realmente era uma fraude ou não, e portanto não podemos considerar essas transações como fraudulentas no nosso classificador. Na maioria das vezes, ignoramos completamente essas transações e em alguns casos chegamos a fazer algumas suposições genéricas a respeito desse conjunto de transações, mas certamente essa é uma limitação importante do trabalho que não conseguimos superar completamente, mas que merece ser abordada em futuros trabalhos. Apesar disso, vimos que, mesmo classificando somente o conjunto mais difícil de transações, conseguimos chegar em um determinado cenário a uma taxa de detecção de chargebacks entre $40 \%$ e $50 \%$ para a maioria dos meses analisados, mantendo ao mesmo um tempo uma taxa de falsos alarmes entre $10 \%$ e $12 \%$. 


\section{Apêndice A}

\section{Resultados da Classificação para Todos os Níveis de Balanceamento}

Apresentamos na Seção 7.1 resultados detalhados do procedimento de classificação para os níveis de balanceamento 2x1 e 10x1, descritos na Seção 6.3. Apresentamos agora resultados para os demais níveis de balanceamento da amostra de treino do classificador. Para cada nível de balanceamento, apresentaremos os seguintes resultados:

- Taxa de detecção de chargebacks por mês para cada subconjunto, semelhante ao que foi apresentado nas Figuras 7.1 e 7.2;

- Taxa de detecção de chargebacks por mês para cada subconjunto, de forma incremental, semelhante ao que foi apresentado nas Figuras 7.3 e 7.4;

- Taxa de falsos alarmes, ou seja, transações legítimas classificadas como fraude, por mês para cada subconjunto, semelhante ao que foi apresentado nas Figuras 7.5 e 7.6; e

- Taxa de falsos alarmes por mês para cada subconjunto e de forma incremental, semelhante ao que foi apresentado nas Figuras 7.7 e 7.8.

Os resultados apresentados nas seções seguintes não nos trazem novas conclusões, apenas reforçam aquilo que foi apresentado no Capítulo 7. A maior taxa de deteç̧ão de chargebacks é obtida utilizando a amostra de treinamento com uma distribuição mais similar entre as classes (1x1 no nosso caso) e essa taxa vai diminuindo a medida que aumentos a proporção de transações legítimas em relação às transações fraudulentas na amostra de treinamento, chegando ao menor valor para o nível de balanceamento 10x1. Por outro lado, a menor taxa de falsos alarmes é obtida utilizando a amostra de treinamento com a maior proporção de transações legítimas em relação a fraudes (10x1, no nosso caso), e vai aumentando a medida que retiramos transações legítimas da amostra de treinamento, chegando ao seu maior nível para o balanceamento $1 x 1$.

\section{A.1 Balanceamento $1 x 1$}

Nesta Seção apresentamos os resultados obtidos utilizando um balanceamento $1 x 1$ na amostra de treinamento.

A Figura A.1 mostra a taxa de deteç̧ão de chargebacks por mês para cada subconjunto. 


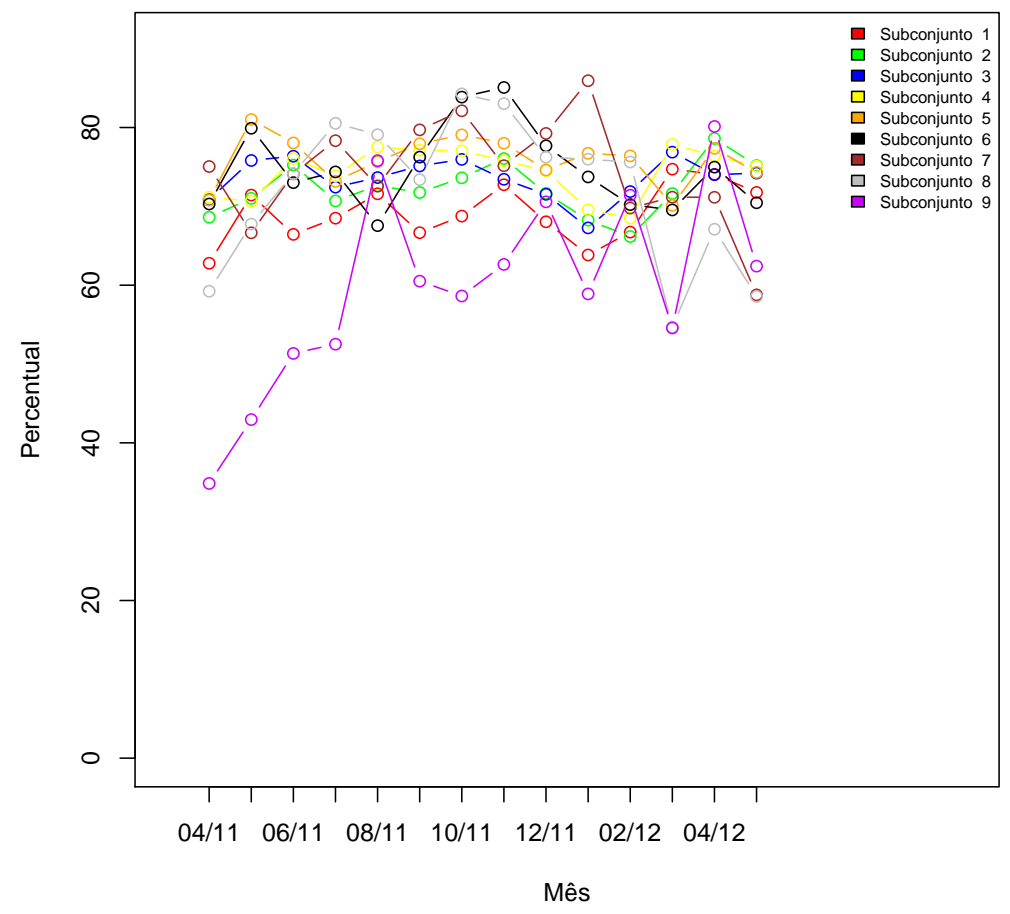

Figura A.1: Taxa de detecção de chargebacks por mês para cada subconjunto utilizando um balanceamento $1 \mathrm{x} 1$ na amostra de treinamento do classificador.

A Figura A.2 mostra a taxa de detecção de chargebacks por mês, para cada subconjunto, de forma incremental e acumulativa. 


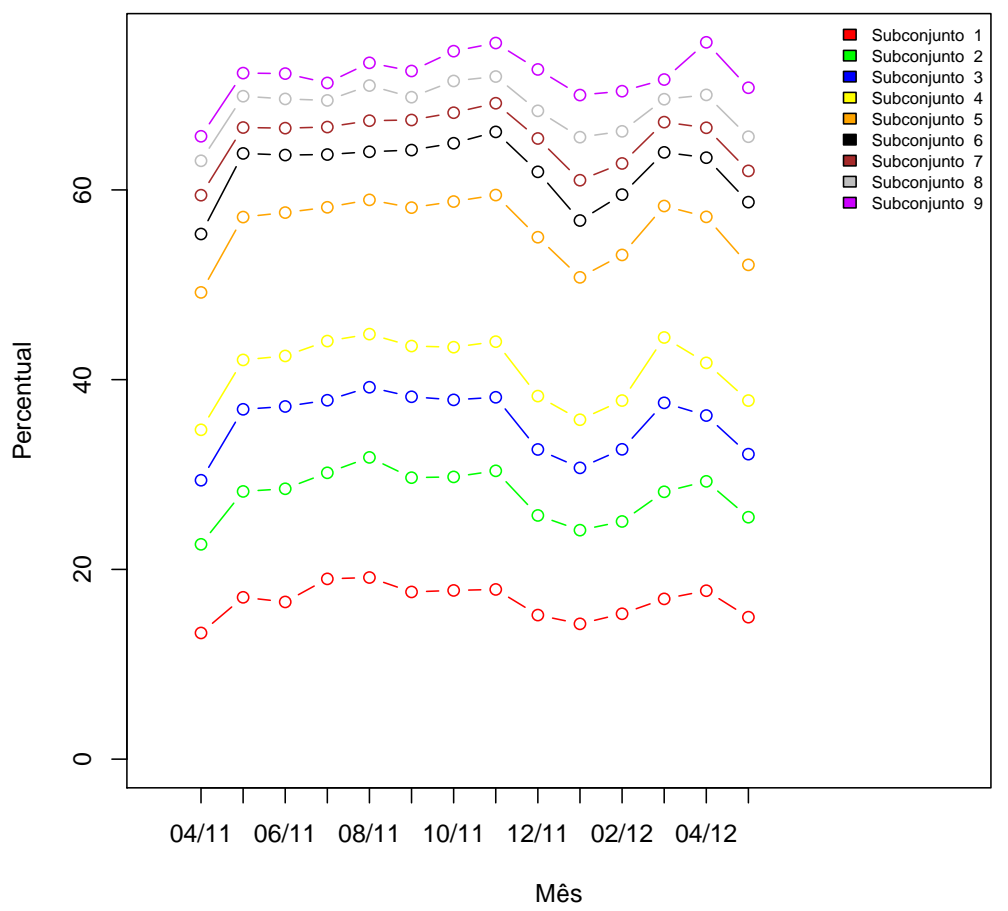

Figura A.2: Taxa de detecção de chargebacks por mês para cada subconjunto utilizando um balanceamento $1 \times 1$ na amostra de treinamento do classificador. Os resultados para cada subconjunto são incrementais para que se perceba a evolução dos resultados em relação ao peso geral da transação.

A Figura A.3 mostra a taxa de falsos alarmes por mês para cada subconjunto. 


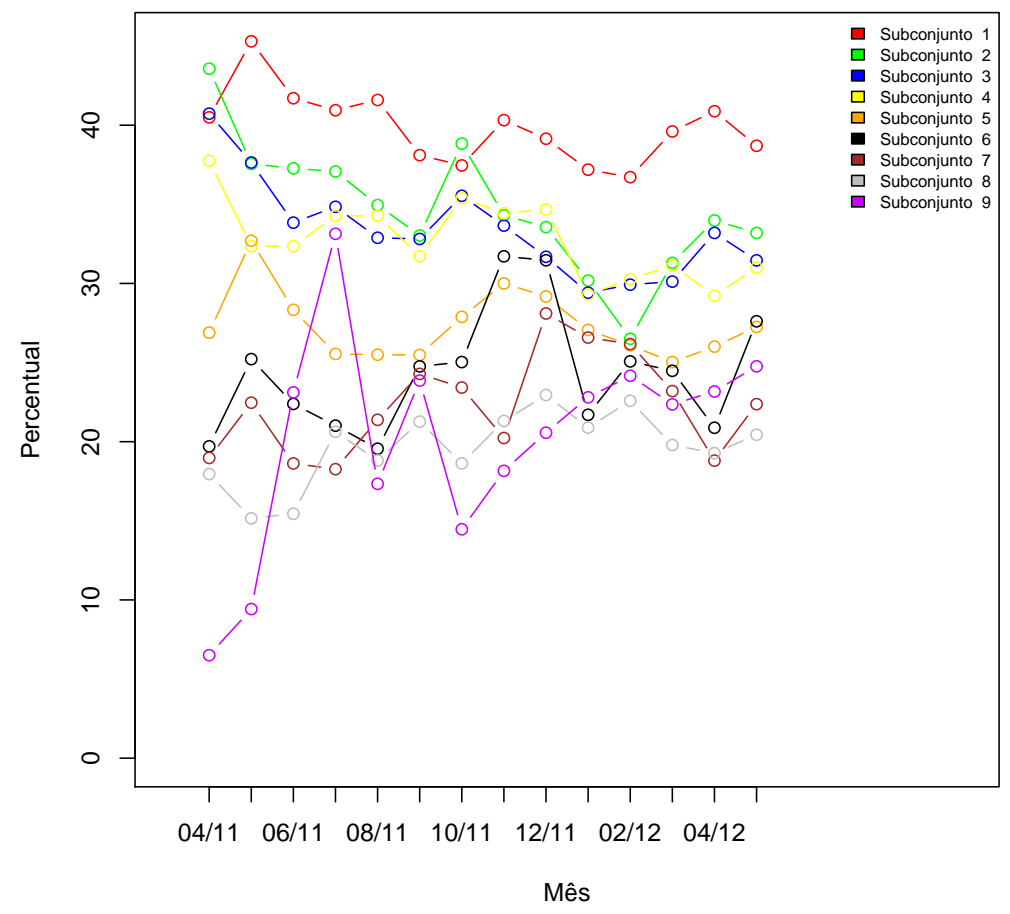

Figura A.3: Taxa de transações legítimas classificadas como fraude para cada subconjunto utilizando balanceamento $1 \mathrm{x} 1$ na amostra de treinamento do classificador.

A Figura A.4 mostra a taxa de falsos alarmes por mês para cada subconjunto, de forma incremental e acumulativa. 


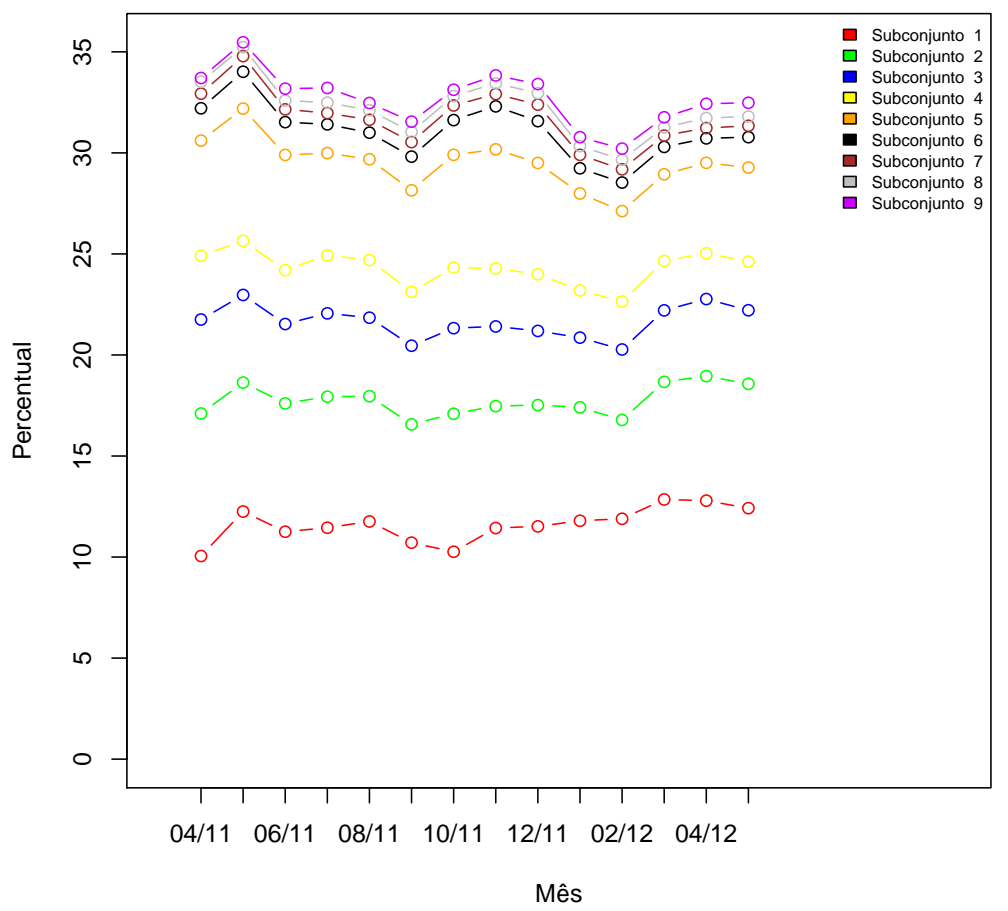

Figura A.4: Taxa de transaçôes legítimas classificadas como fraude para cada subconjunto utilizando balanceamento $1 \mathrm{x} 1$ na amostra de treinamento do classificador. Os resultados para cada subconjunto são incrementais para que se perceba a evolução dos resultados em relação ao peso geral da transação.

\section{A.2 Balanceamento $3 x 1$}

Nesta Seção apresentamos os resultados obtidos utilizando um balanceamento $3 x 1$ na amostra de treinamento.

A Figura A.5 mostra a taxa de detecção de chargebacks por mês para cada subconjunto. 


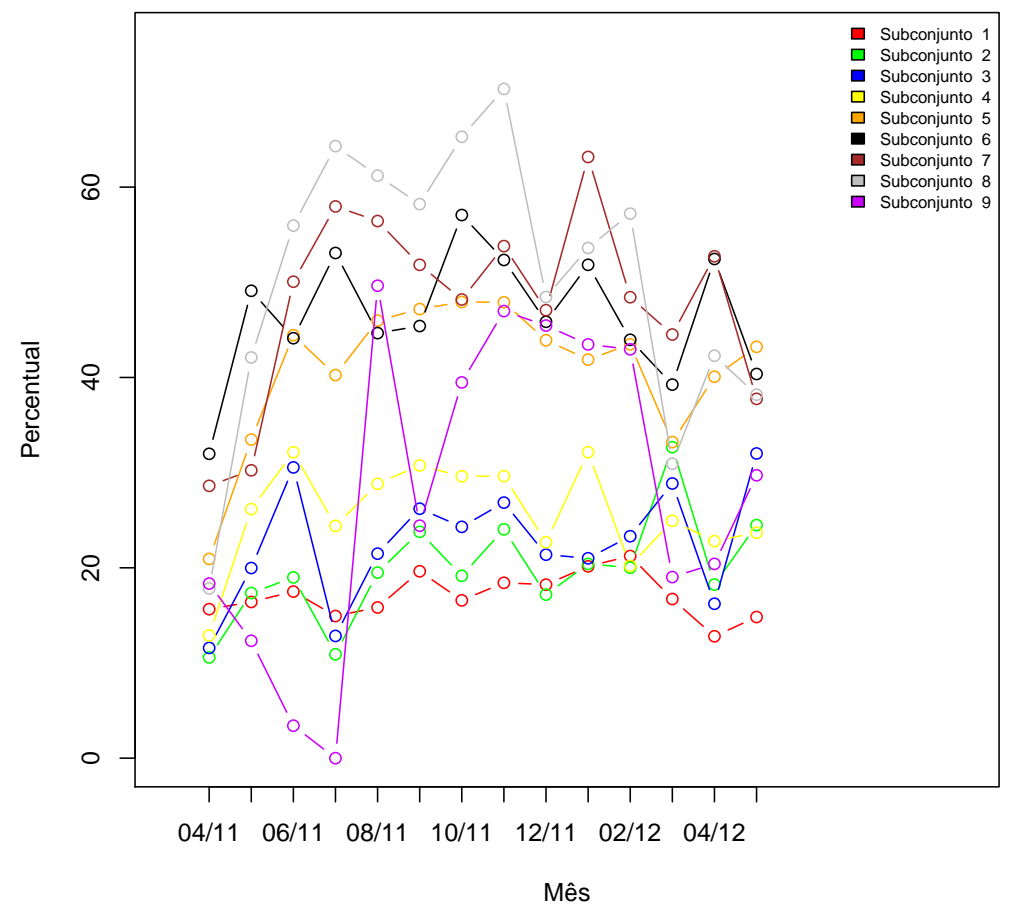

Figura A.5: Taxa de detecção de chargebacks por mês para cada subconjunto utilizando um balanceamento $3 \times 1$ na amostra de treinamento do classificador.

A Figura A.6 mostra a taxa de detecção de chargebacks por mês, para cada subconjunto, de forma incremental e acumulativa. 


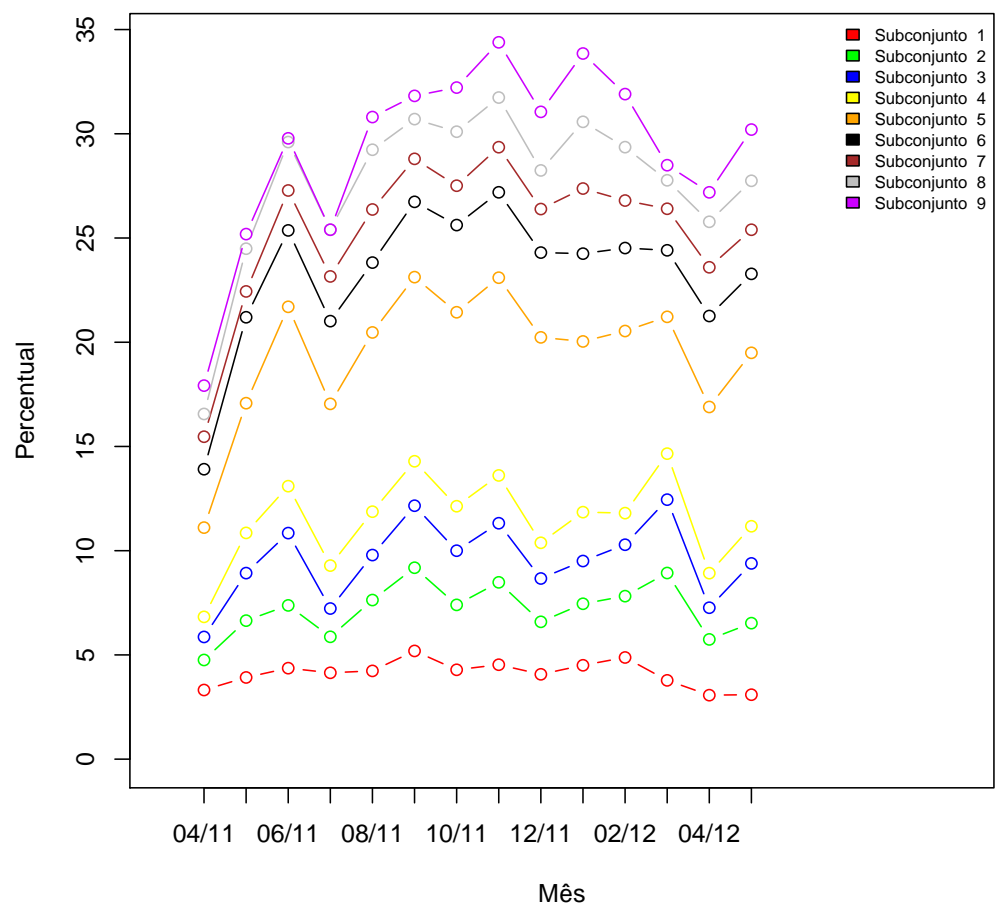

Figura A.6: Taxa de detecção de chargebacks por mês para cada subconjunto utilizando um balanceamento $3 \times 1$ na amostra de treinamento do classificador. Os resultados para cada subconjunto são incrementais para que se perceba a evolução dos resultados em relação ao peso geral da transação.

A Figura A.7 mostra a taxa de falsos alarmes por mês para cada subconjunto. 


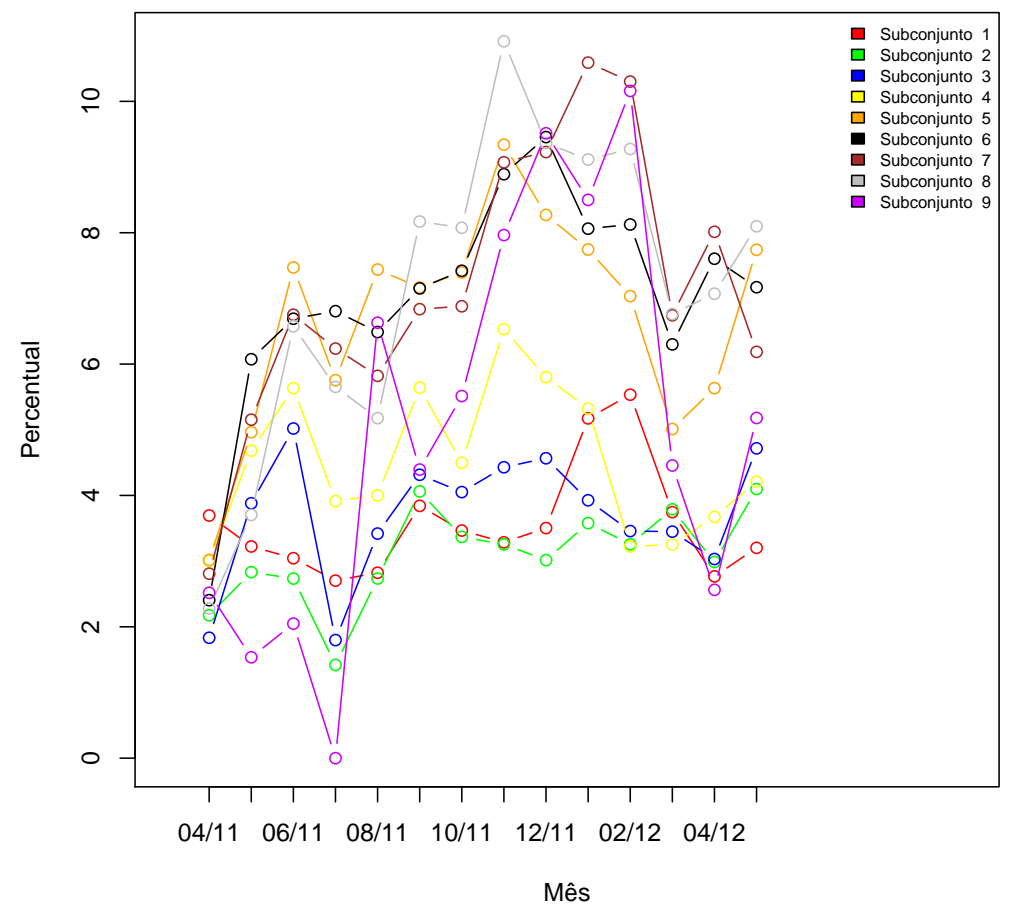

Figura A.7: Taxa de transações legítimas classificadas como fraude para cada subconjunto utilizando balanceamento $3 \mathrm{x} 1$ na amostra de treinamento do classificador.

A Figura A.8 mostra a taxa de falsos alarmes por mês para cada subconjunto, de forma incremental e acumulativa. 


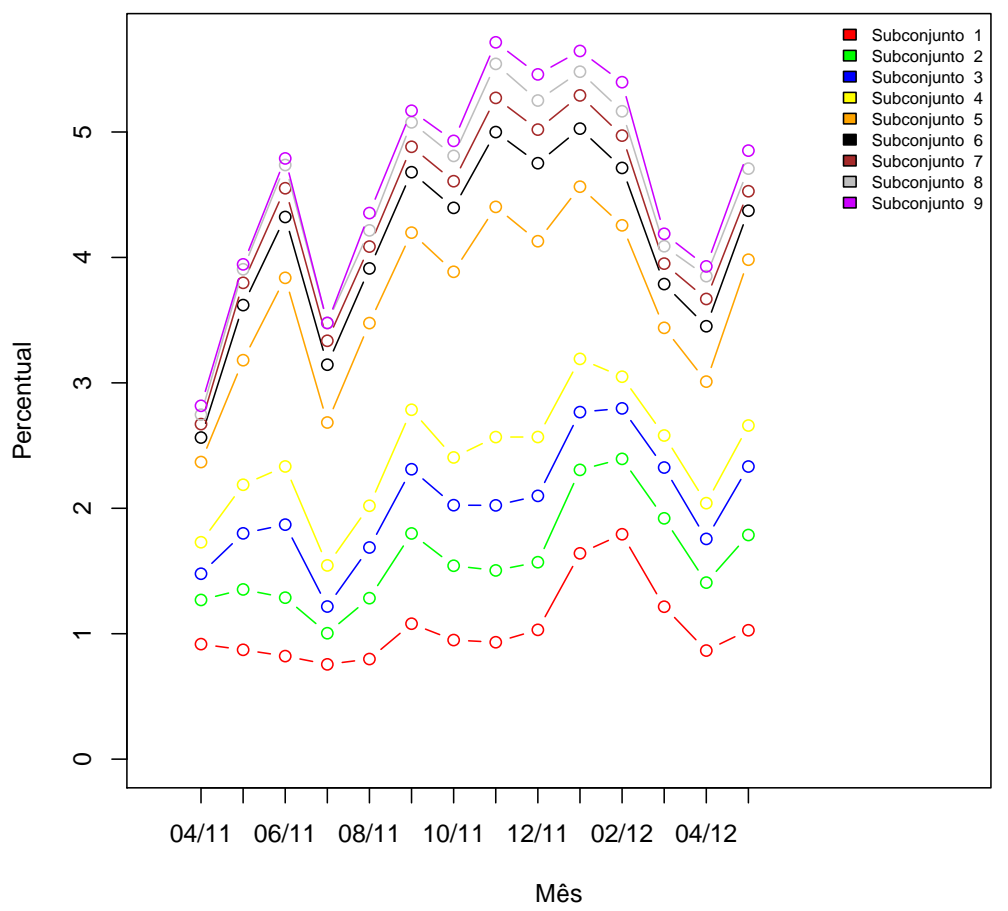

Figura A.8: Taxa de transações legítimas classificadas como fraude para cada subconjunto utilizando balanceamento $3 \times 1$ na amostra de treinamento do classificador. Os resultados para cada subconjunto são incrementais para que se perceba a evolução dos resultados em relação ao peso geral da transação.

\section{A.3 Balanceamento $4 x 1$}

Nesta Seção apresentamos os resultados obtidos utilizando um balanceamento $4 x 1$ na amostra de treinamento.

A Figura A.9 mostra a taxa de detecção de chargebacks por mês para cada subconjunto. 


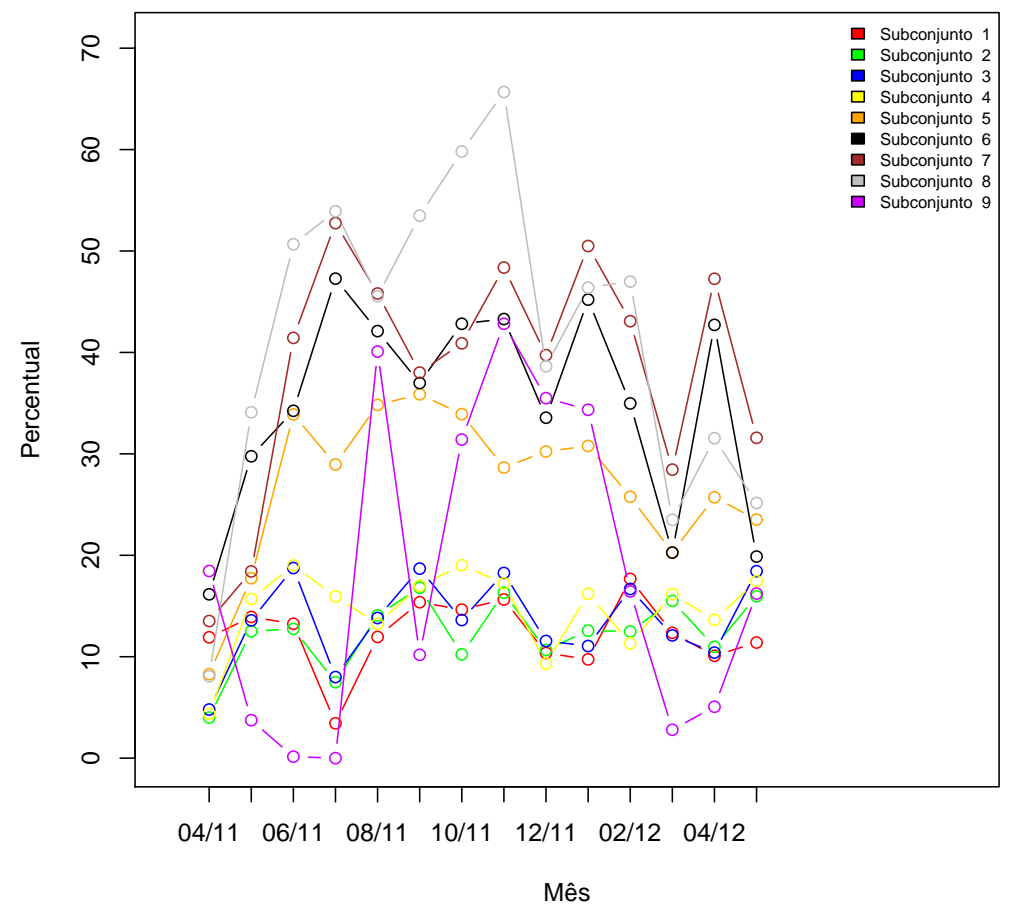

Figura A.9: Taxa de detecção de chargebacks por mês para cada subconjunto utilizando um balanceamento $4 \mathrm{x} 1$ na amostra de treinamento do classificador.

A Figura A.10 mostra a taxa de detecção de chargebacks por mês, para cada subconjunto, de forma incremental e acumulativa. 


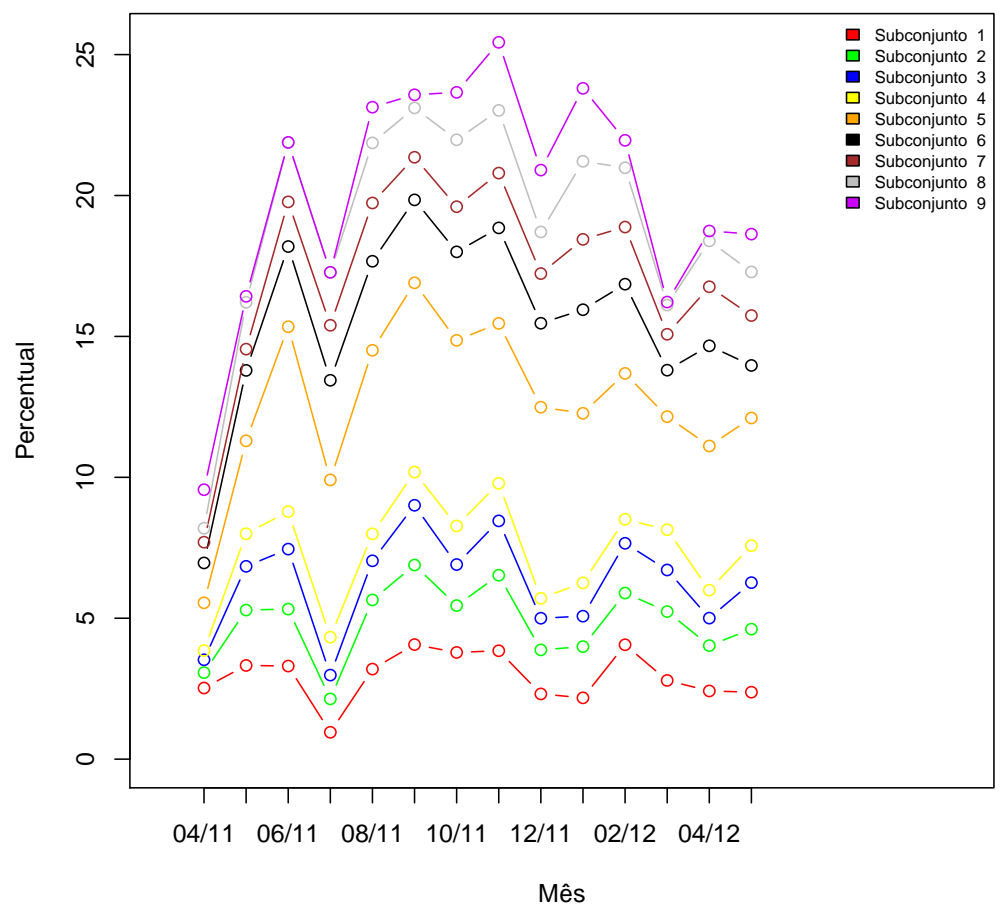

Figura A.10: Taxa de detecção de chargebacks por mês para cada subconjunto utilizando um balanceamento $4 \times 1$ na amostra de treinamento do classificador. Os resultados para cada subconjunto são incrementais para que se perceba a evolução dos resultados em relação ao peso geral da transação.

A Figura A.11 mostra a taxa de falsos alarmes por mês para cada subconjunto. 


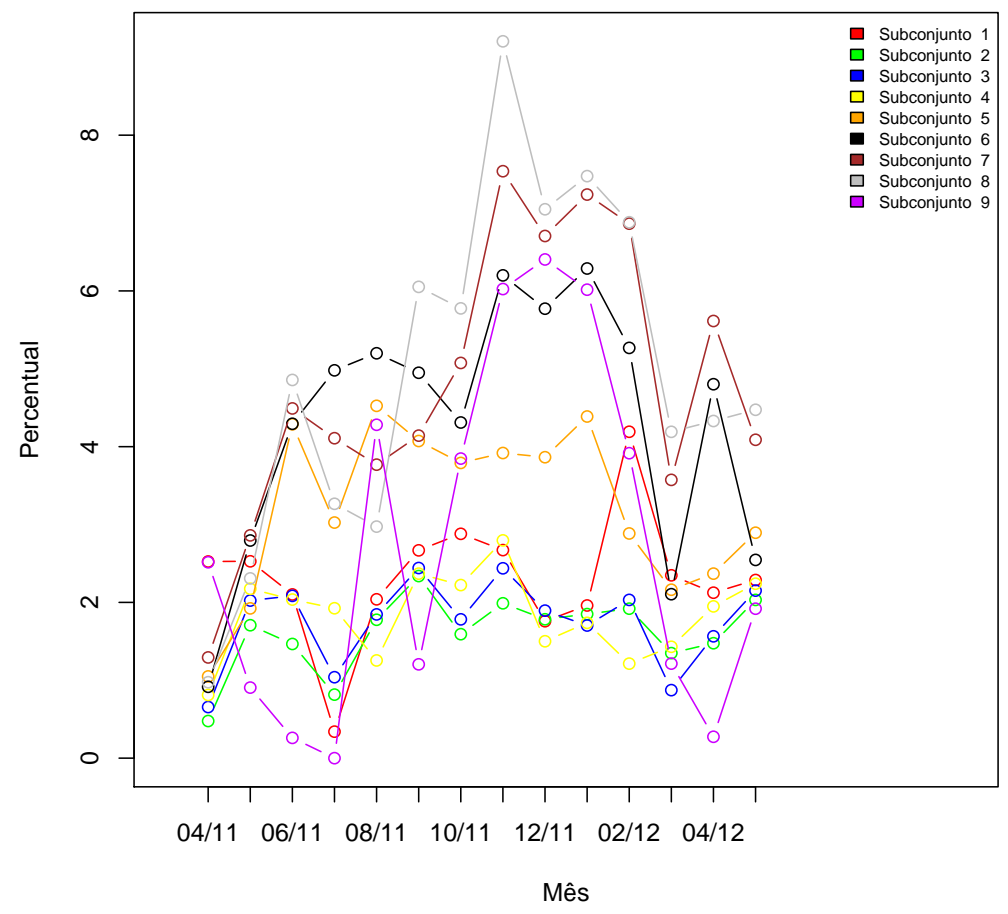

Figura A.11: Taxa de transações legítimas classificadas como fraude para cada subconjunto utilizando balanceamento $4 \times 1$ na amostra de treinamento do classificador.

A Figura A.12 mostra a taxa de falsos alarmes por mês para cada subconjunto, de forma incremental e acumulativa. 


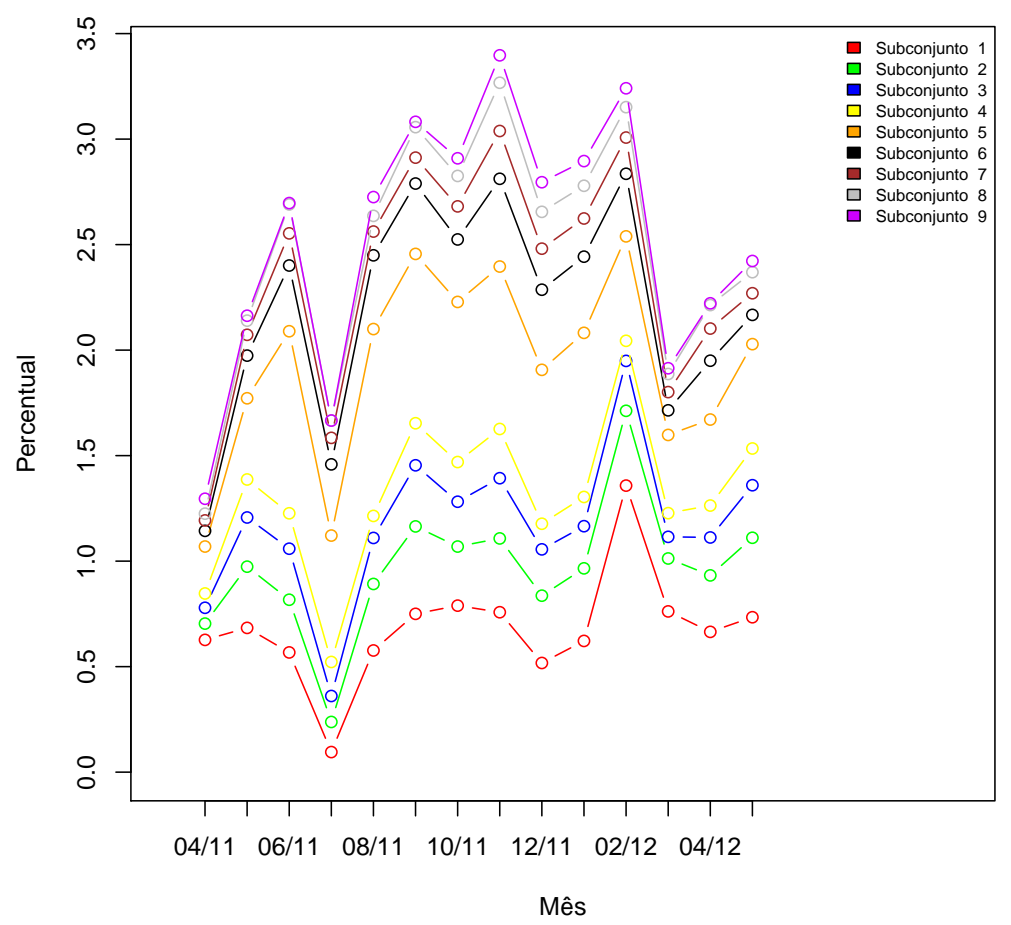

Figura A.12: Taxa de transações legítimas classificadas como fraude para cada subconjunto utilizando balanceamento $4 \mathrm{x} 1$ na amostra de treinamento do classificador. Os resultados para cada subconjunto são incrementais para que se perceba a evolução dos resultados em relação ao peso geral da transação.

\section{A.4 Balanceamento $5 x 1$}

Nesta Seção apresentamos os resultados obtidos utilizando um balanceamento $5 x 1$ na amostra de treinamento.

A Figura A.13 mostra a taxa de detecção de chargebacks por mês para cada subconjunto. 


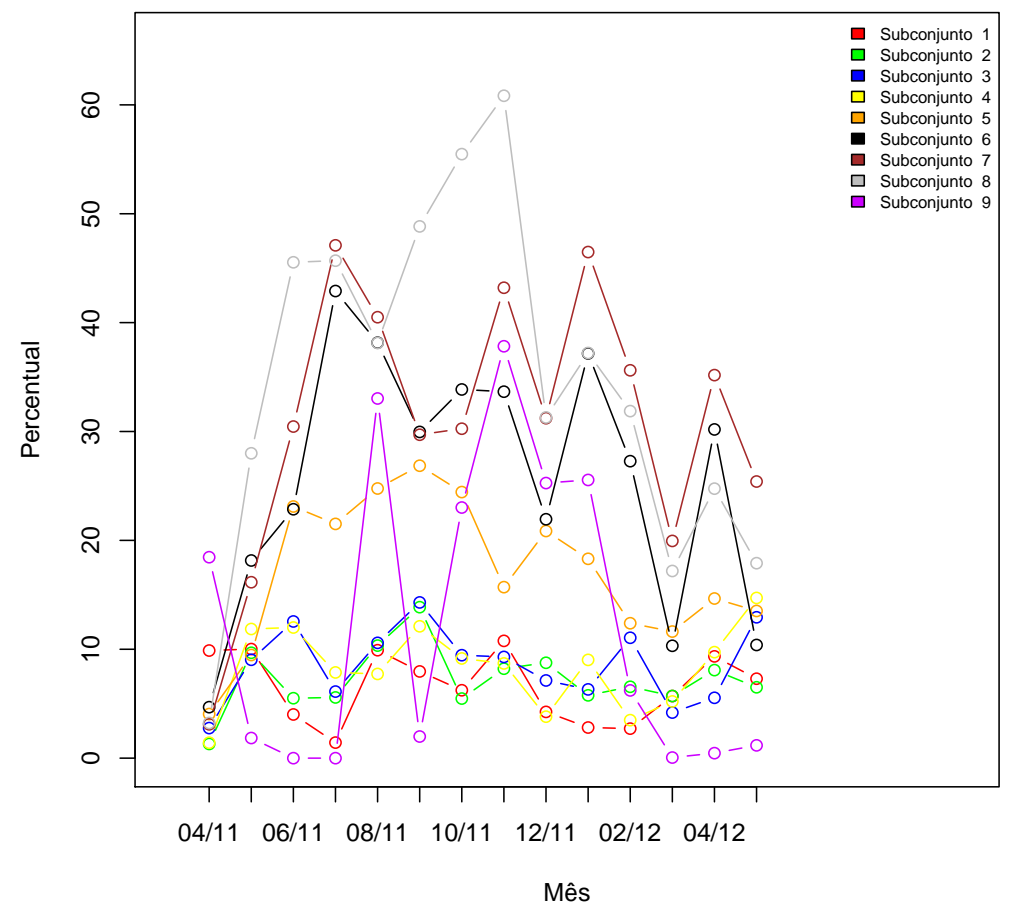

Figura A.13: Taxa de detecção de chargebacks por mês para cada subconjunto utilizando um balanceamento $5 \times 1$ na amostra de treinamento do classificador.

A Figura A.14 mostra a taxa de detecção de chargebacks por mês, para cada subconjunto, de forma incremental e acumulativa. 


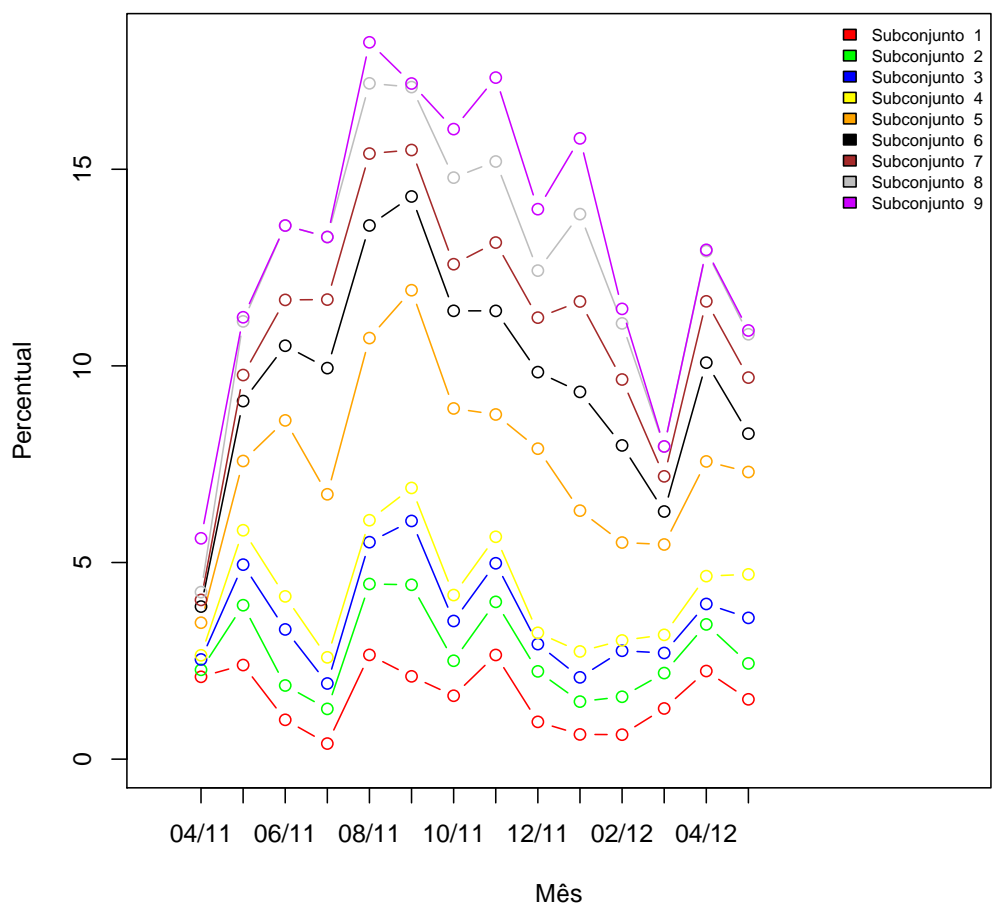

Figura A.14: Taxa de detecção de chargebacks por mês para cada subconjunto utilizando um balanceamento $5 \mathrm{x} 1$ na amostra de treinamento do classificador. Os resultados para cada subconjunto são incrementais para que se perceba a evolução dos resultados em relação ao peso geral da transação.

A Figura A.15 mostra a taxa de falsos alarmes por mês para cada subconjunto. 


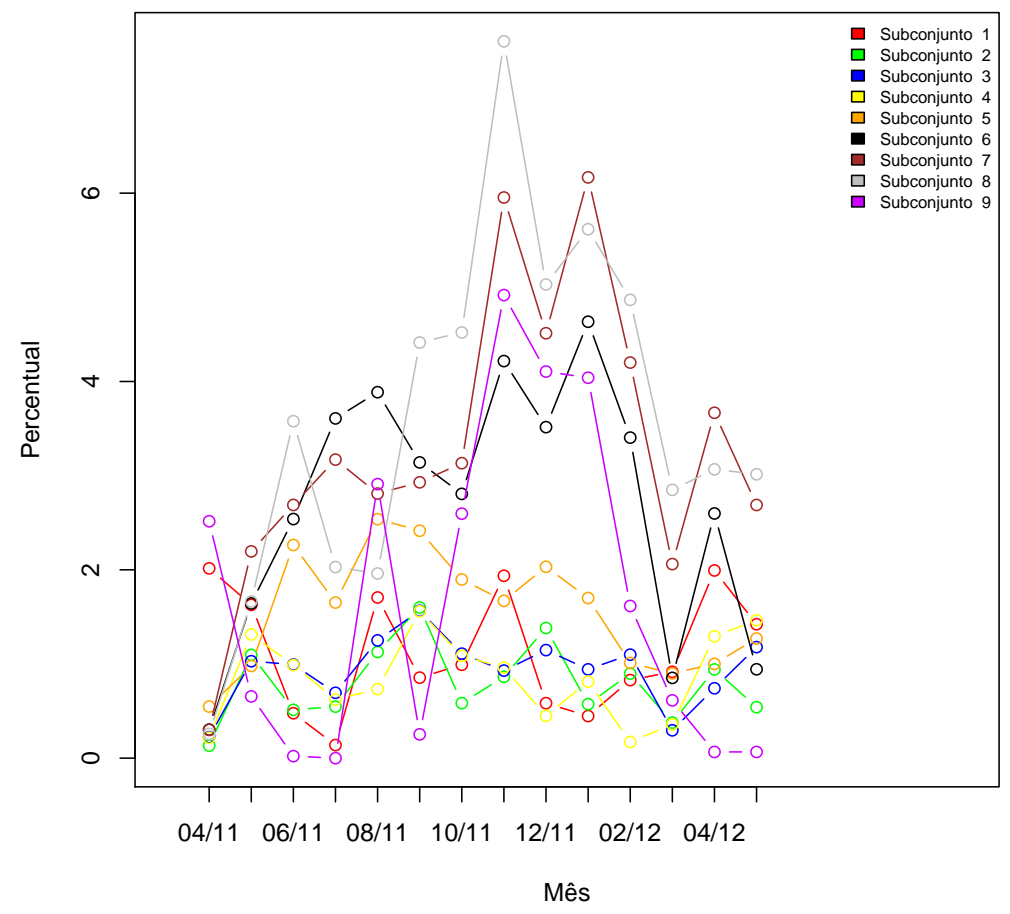

Figura A.15: Taxa de transações legítimas classificadas como fraude para cada subconjunto utilizando balanceamento 5x1 na amostra de treinamento do classificador.

A Figura A.16 mostra a taxa de falsos alarmes por mês para cada subconjunto, de forma incremental e acumulativa. 


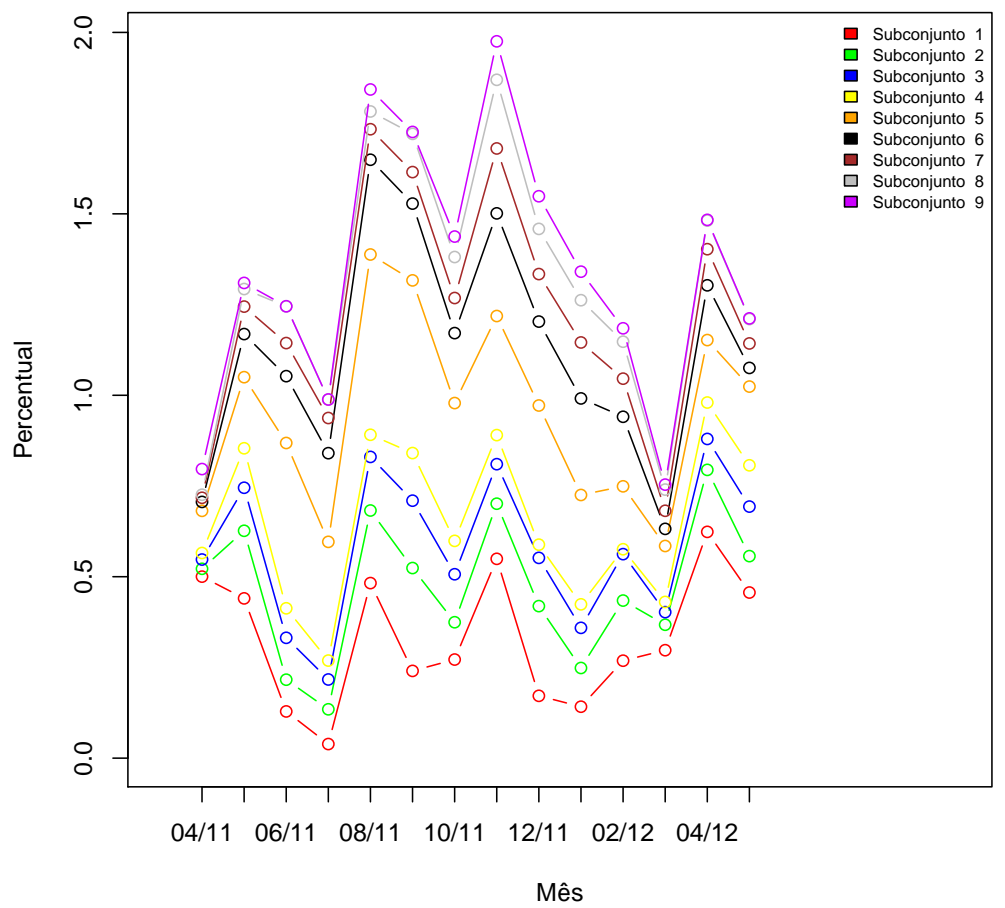

Figura A.16: Taxa de transações legítimas classificadas como fraude para cada subconjunto utilizando balanceamento $5 \times 1$ na amostra de treinamento do classificador. Os resultados para cada subconjunto são incrementais para que se perceba a evolução dos resultados em relação ao peso geral da transação.

\section{A.5 Balanceamento $6 x 1$}

Nesta Seção apresentamos os resultados obtidos utilizando um balanceamento $6 x 1$ na amostra de treinamento.

A Figura A.17 mostra a taxa de deteç̧ão de chargebacks por mês para cada subconjunto. 


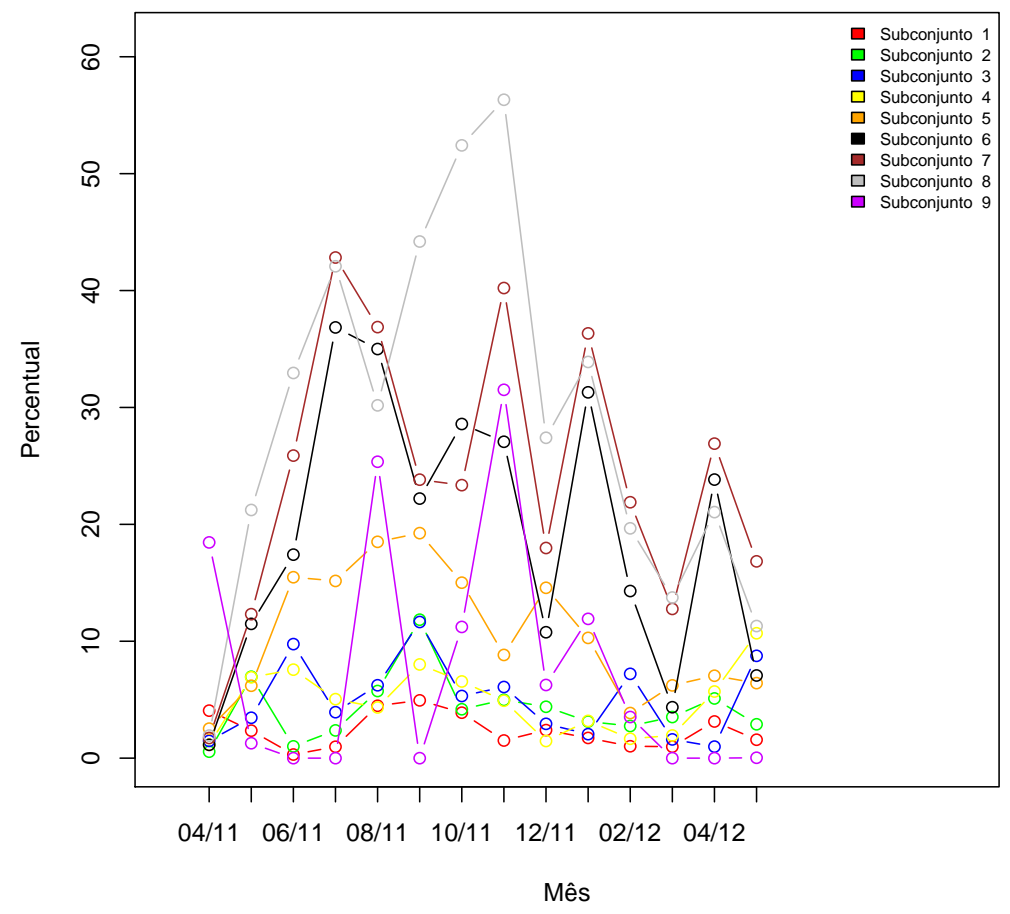

Figura A.17: Taxa de detecção de chargebacks por mês para cada subconjunto utilizando um balanceamento $6 \times 1$ na amostra de treinamento do classificador.

A Figura A.18 mostra a taxa de detecção de chargebacks por mês, para cada subconjunto, de forma incremental e acumulativa. 


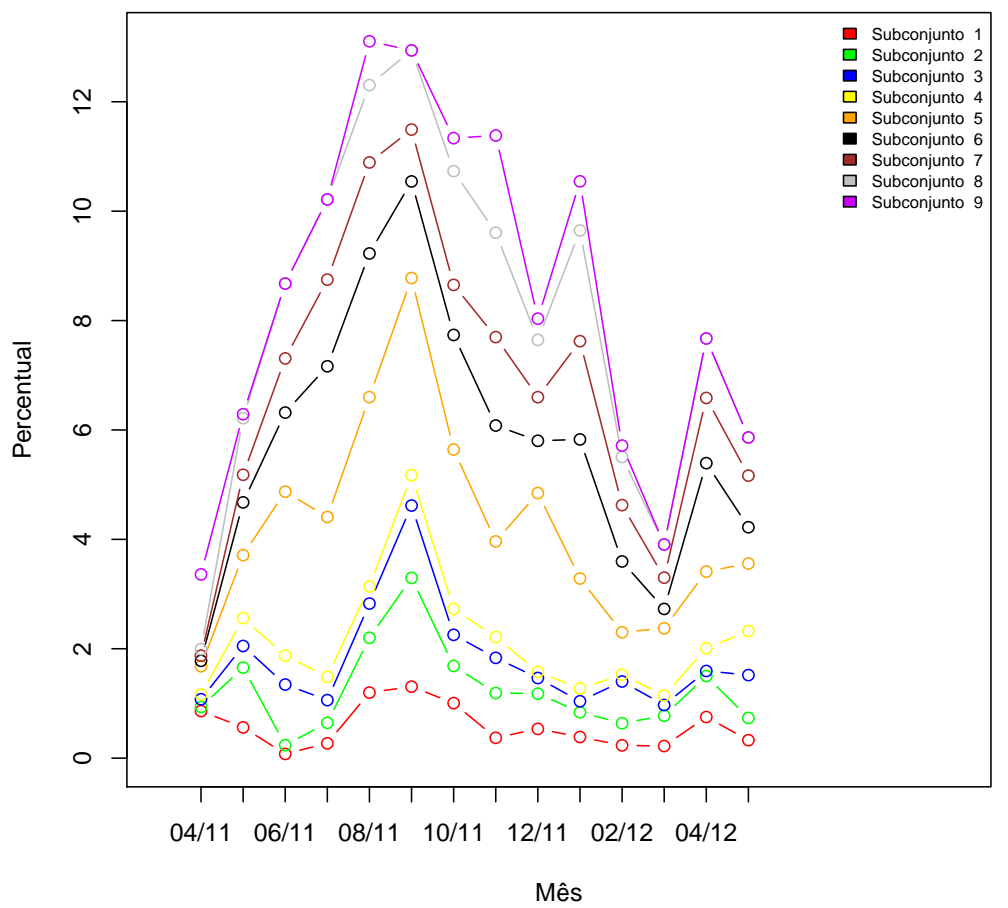

Figura A.18: Taxa de detecção de chargebacks por mês para cada subconjunto utilizando um balanceamento 6x1 na amostra de treinamento do classificador. Os resultados para cada subconjunto são incrementais para que se perceba a evolução dos resultados em relação ao peso geral da transação.

A Figura A.19 mostra a taxa de falsos alarmes por mês para cada subconjunto. 


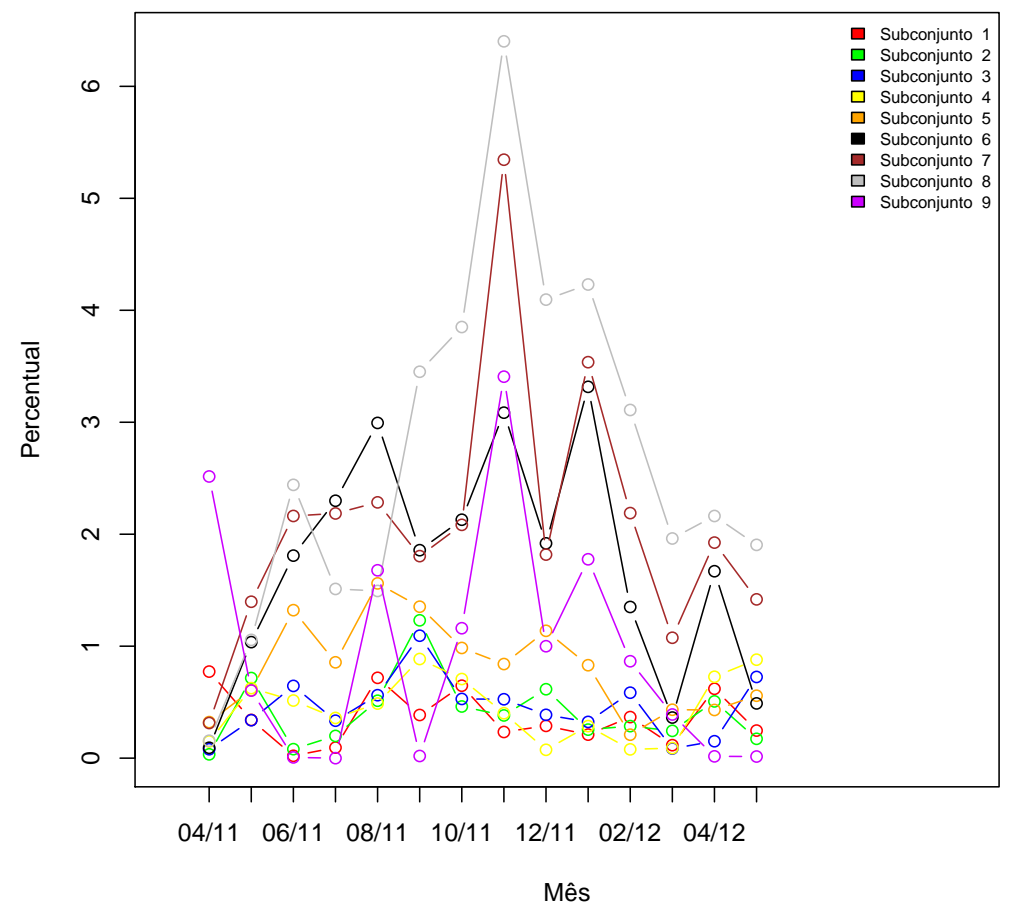

Figura A.19: Taxa de transações legítimas classificadas como fraude para cada subconjunto utilizando balanceamento $6 \times 1$ na amostra de treinamento do classificador.

A Figura A.20 mostra a taxa de falsos alarmes por mês para cada subconjunto, de forma incremental e acumulativa. 


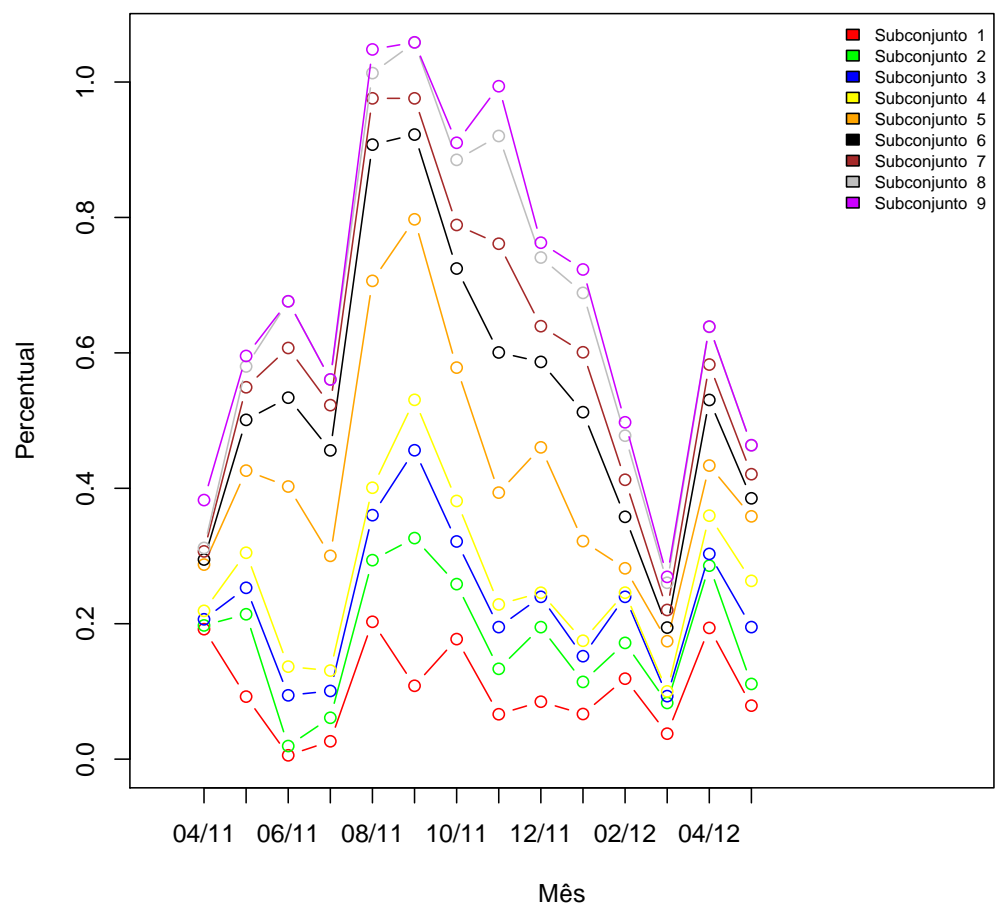

Figura A.20: Taxa de transações legítimas classificadas como fraude para cada subconjunto utilizando balanceamento $6 \times 1$ na amostra de treinamento do classificador. Os resultados para cada subconjunto são incrementais para que se perceba a evolução dos resultados em relação ao peso geral da transação.

\section{A.6 Balanceamento $7 x 1$}

Nesta Seção apresentamos os resultados obtidos utilizando um balanceamento $7 x 1$ na amostra de treinamento.

A Figura A.21 mostra a taxa de deteç̧ão de chargebacks por mês para cada subconjunto. 


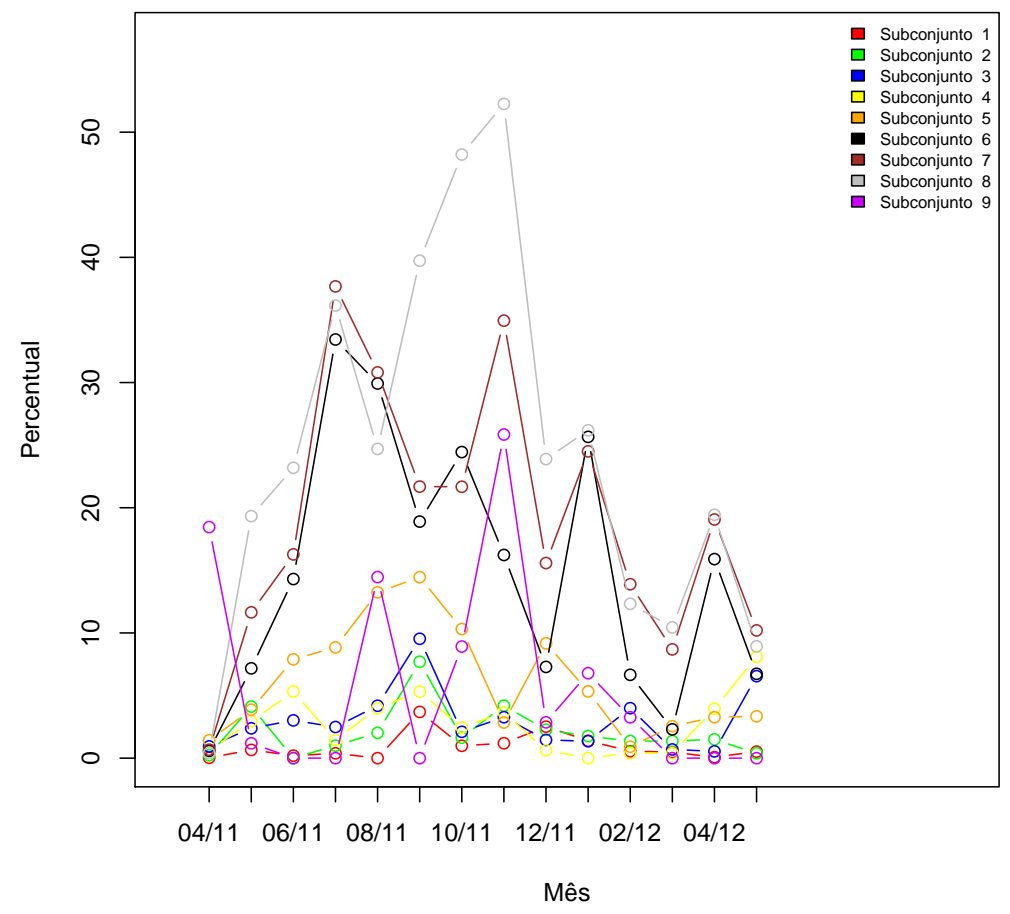

Figura A.21: Taxa de detecção de chargebacks por mês para cada subconjunto utilizando um balanceamento $7 \times 1$ na amostra de treinamento do classificador.

A Figura A.22 mostra a taxa de detecção de chargebacks por mês, para cada subconjunto, de forma incremental e acumulativa. 


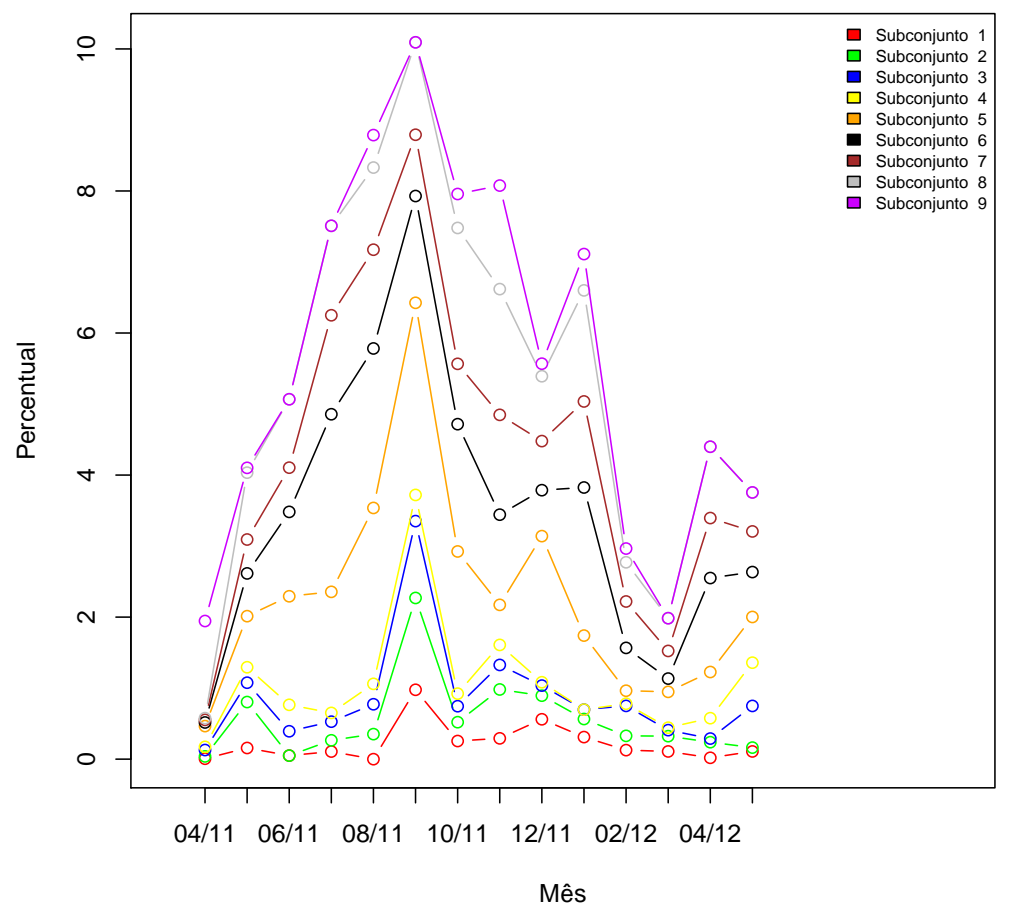

Figura A.22: Taxa de detecção de chargebacks por mês para cada subconjunto utilizando um balanceamento $7 \times 1$ na amostra de treinamento do classificador. Os resultados para cada subconjunto são incrementais para que se perceba a evolução dos resultados em relação ao peso geral da transação.

A Figura A.23 mostra a taxa de falsos alarmes por mês para cada subconjunto. 


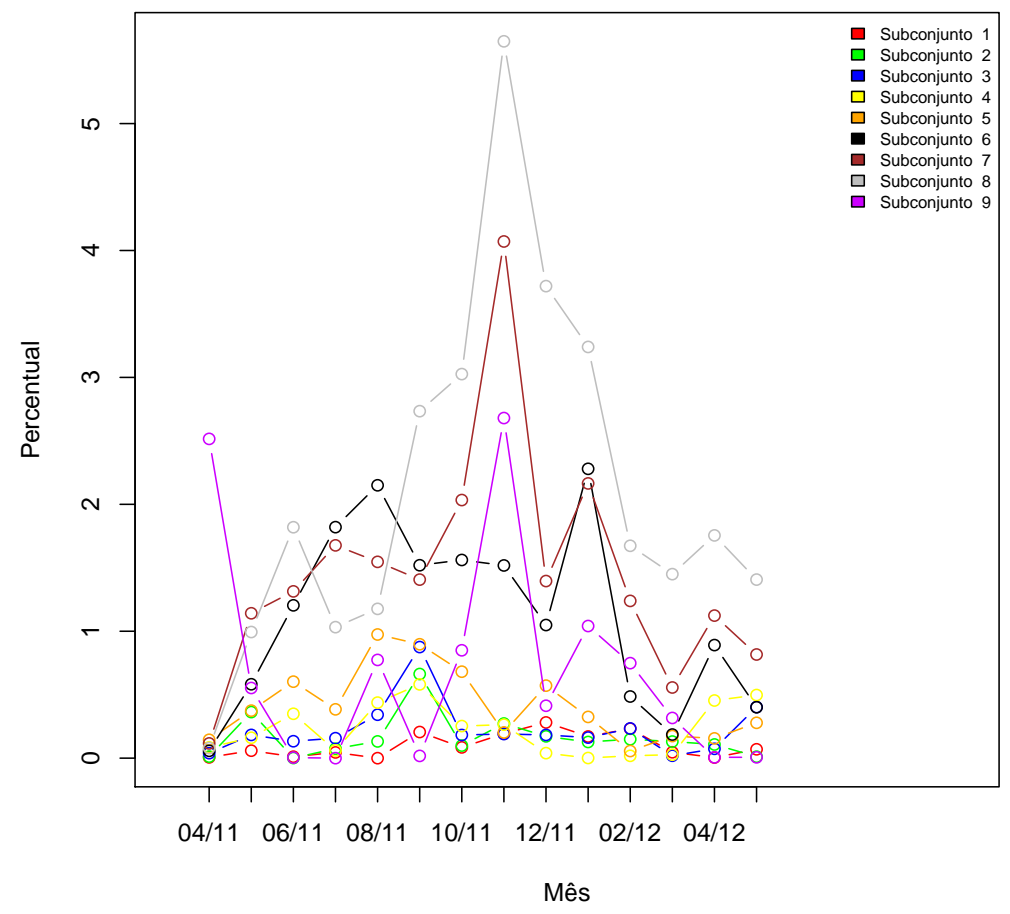

Figura A.23: Taxa de transações legítimas classificadas como fraude para cada subconjunto utilizando balanceamento $7 \times 1$ na amostra de treinamento do classificador.

A Figura A.24 mostra a taxa de falsos alarmes por mês para cada subconjunto, de forma incremental e acumulativa. 


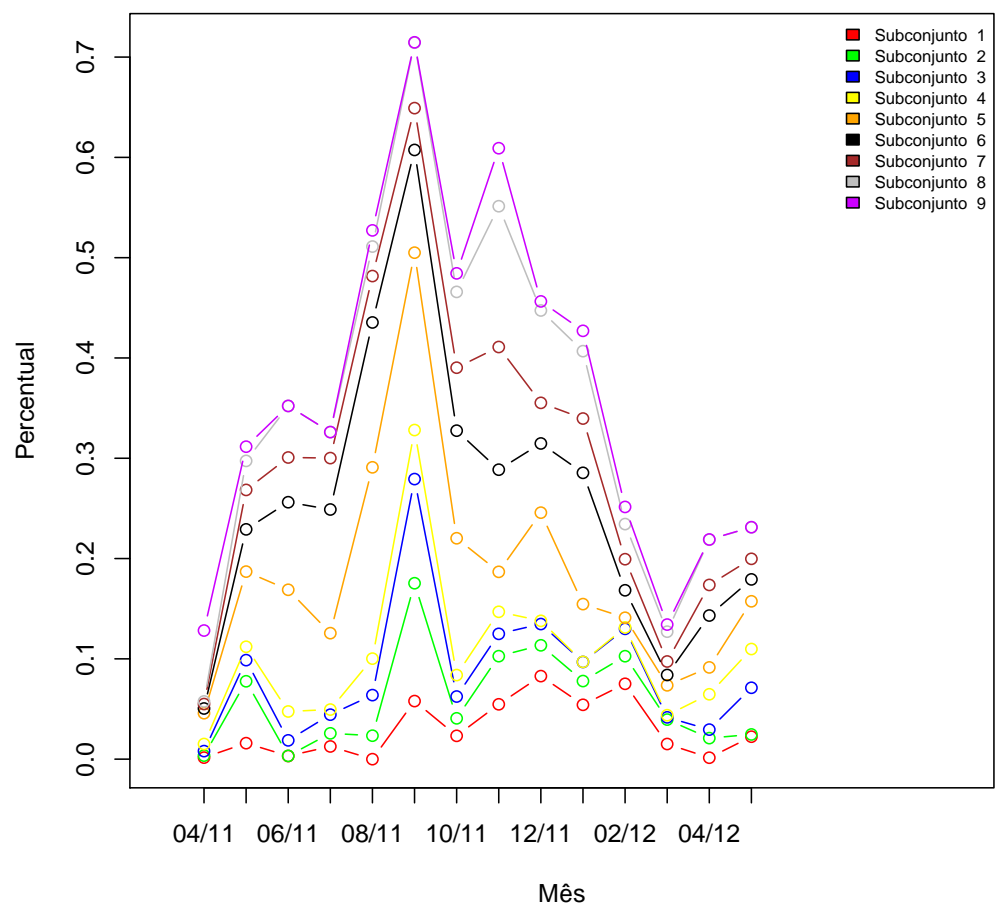

Figura A.24: Taxa de transações legítimas classificadas como fraude para cada subconjunto utilizando balanceamento $7 \times 1$ na amostra de treinamento do classificador. Os resultados para cada subconjunto são incrementais para que se perceba a evolução dos resultados em relação ao peso geral da transação.

\section{A.7 Balanceamento $8 x 1$}

Nesta Seção apresentamos os resultados obtidos utilizando um balanceamento $8 x 1$ na amostra de treinamento.

A Figura A.25 mostra a taxa de deteç̧ão de chargebacks por mês para cada subconjunto. 


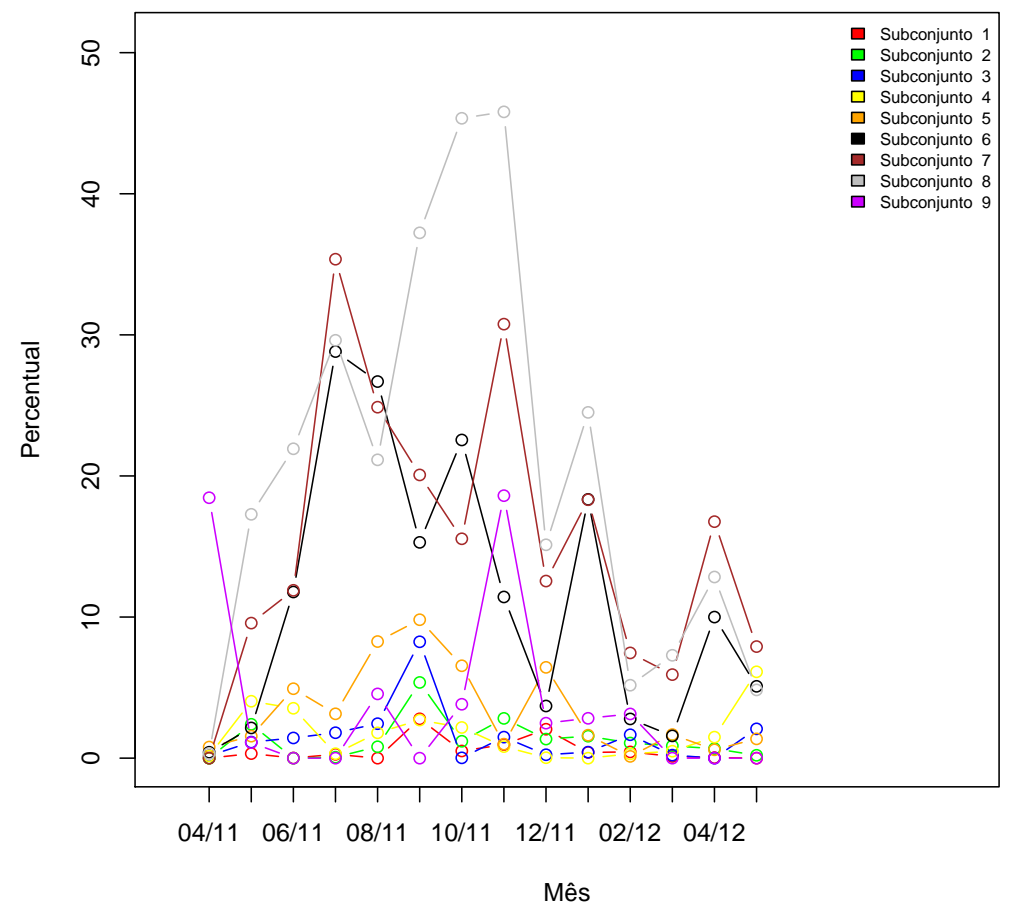

Figura A.25: Taxa de detecção de chargebacks por mês para cada subconjunto utilizando um balanceamento $8 \times 1$ na amostra de treinamento do classificador.

A Figura A.26 mostra a taxa de detecção de chargebacks por mês, para cada subconjunto, de forma incremental e acumulativa. 


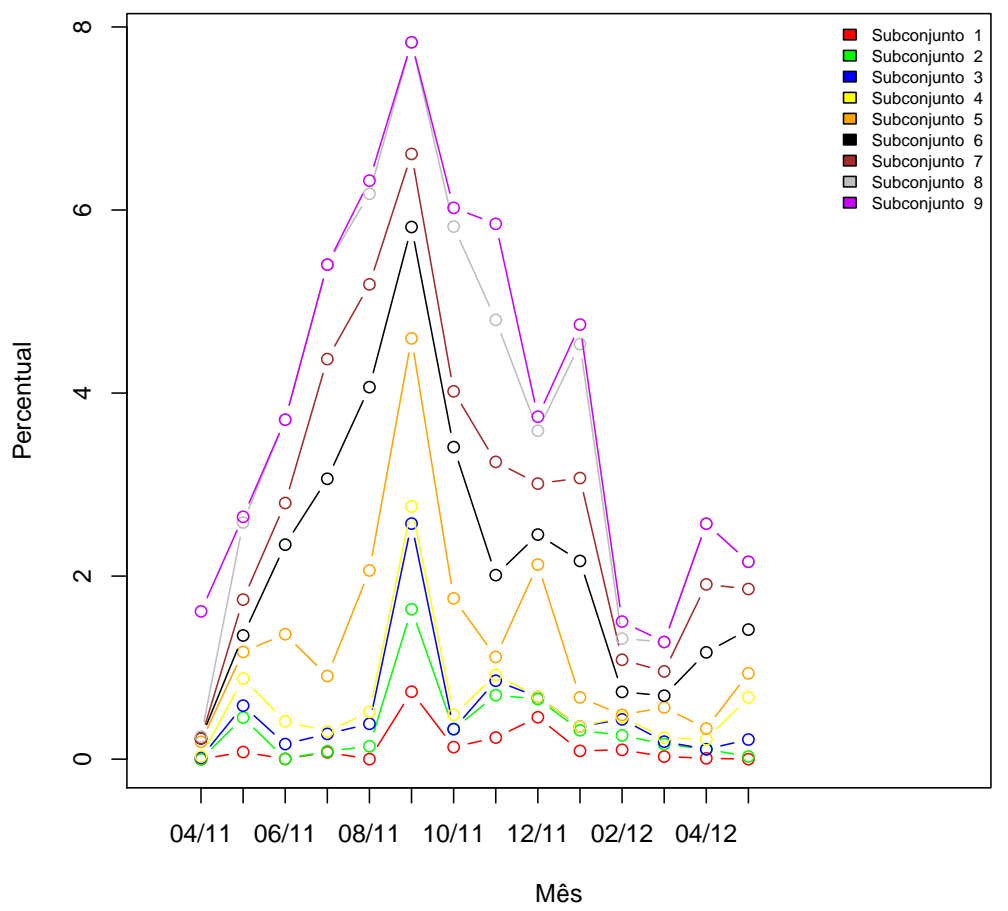

Figura A.26: Taxa de detecção de chargebacks por mês para cada subconjunto utilizando um balanceamento 8x1 na amostra de treinamento do classificador. Os resultados para cada subconjunto são incrementais para que se perceba a evolução dos resultados em relação ao peso geral da transação.

A Figura A.27 mostra a taxa de falsos alarmes por mês para cada subconjunto. 


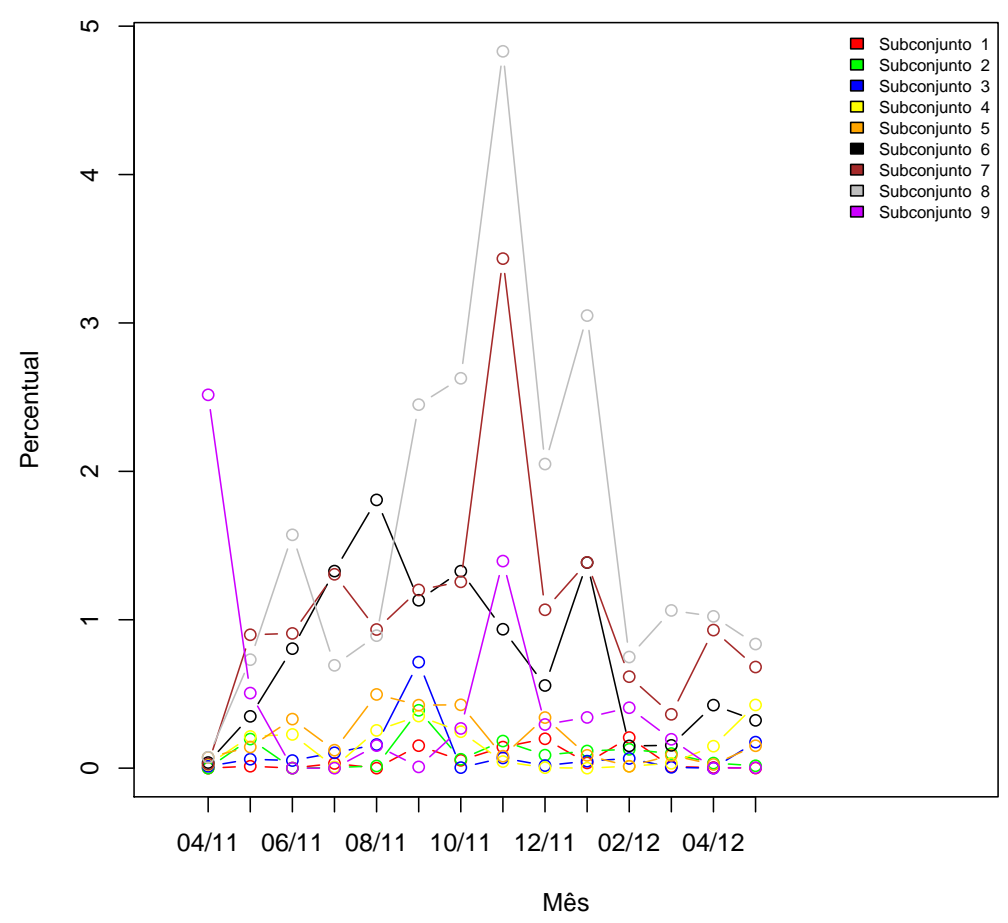

Figura A.27: Taxa de transaçôes legítimas classificadas como fraude para cada subconjunto utilizando balanceamento 8x1 na amostra de treinamento do classificador.

A Figura A.28 mostra a taxa de falsos alarmes por mês para cada subconjunto, de forma incremental e acumulativa. 


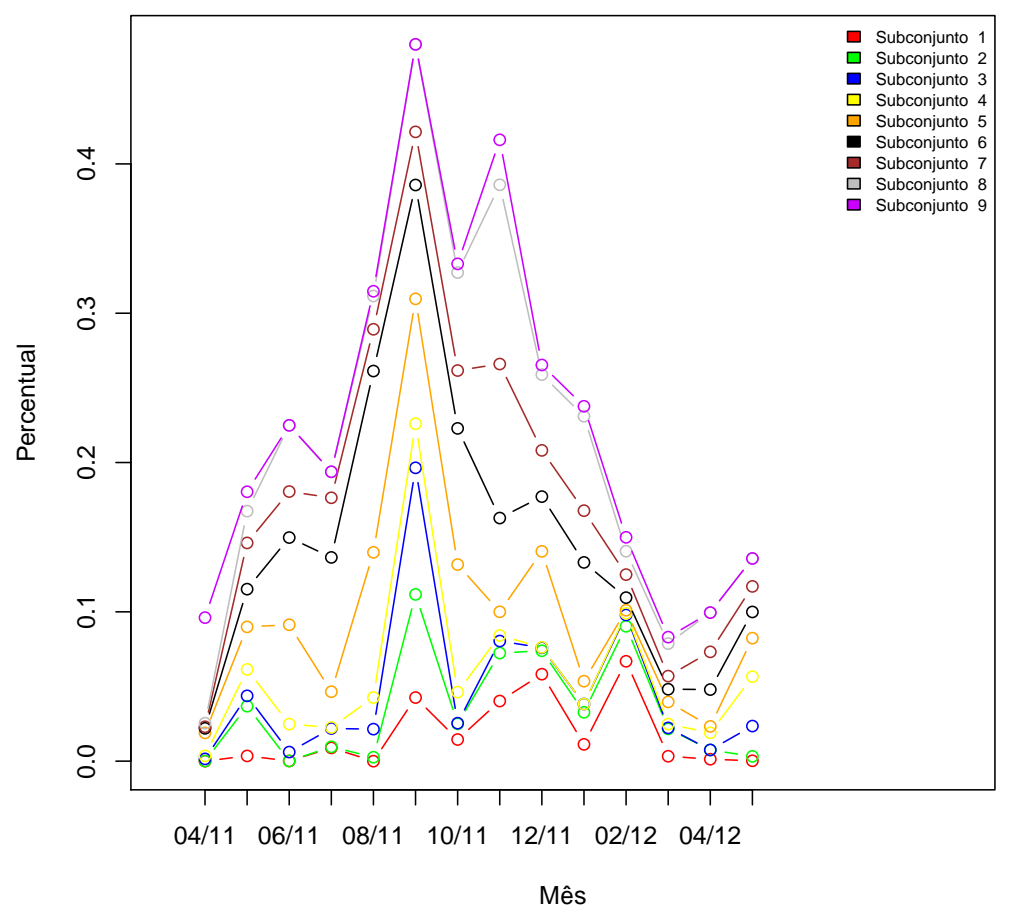

Figura A.28: Taxa de transações legítimas classificadas como fraude para cada subconjunto utilizando balanceamento 8x1 na amostra de treinamento do classificador. Os resultados para cada subconjunto são incrementais para que se perceba a evolução dos resultados em relação ao peso geral da transação.

\section{A.8 Balanceamento $9 x 1$}

Nesta Seção apresentamos os resultados obtidos utilizando um balanceamento $9 x 1$ na amostra de treinamento.

A Figura A.29 mostra a taxa de detecção de chargebacks por mês para cada subconjunto. 


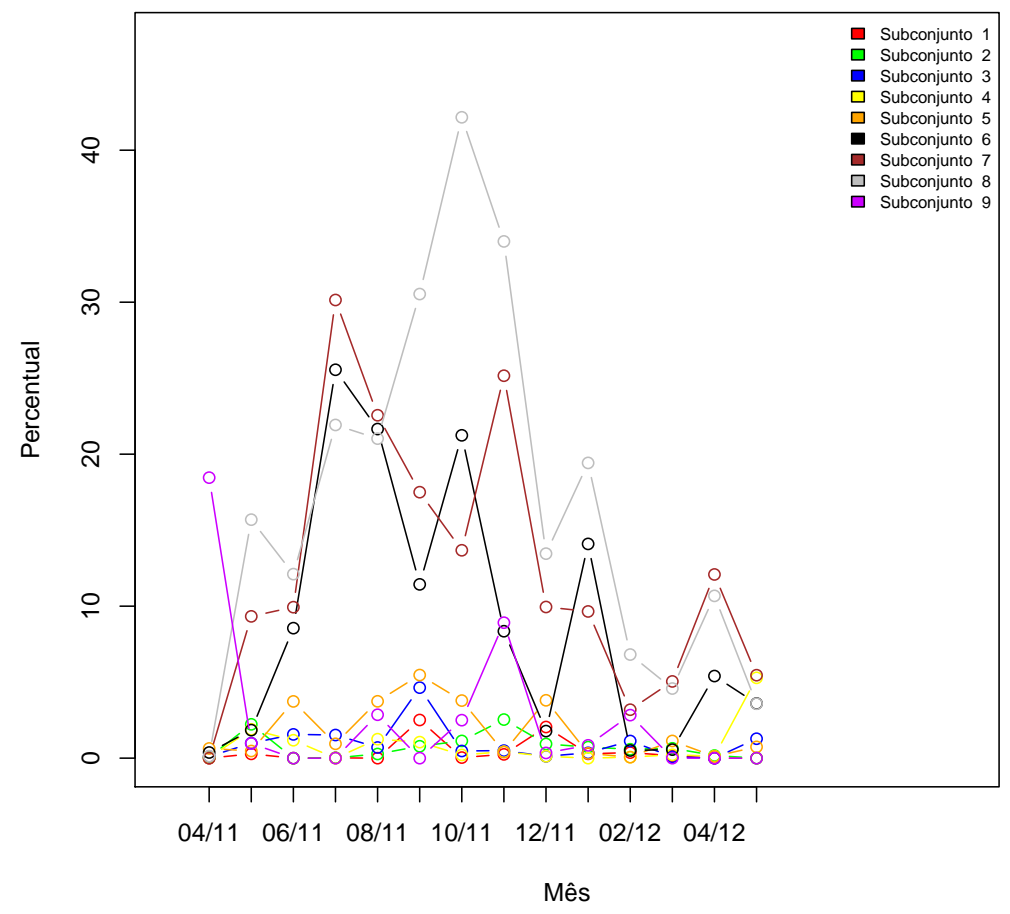

Figura A.29: Taxa de detecção de chargebacks por mês para cada subconjunto utilizando um balanceamento $9 \mathrm{x} 1$ na amostra de treinamento do classificador.

A Figura A.30 mostra a taxa de detecção de chargebacks por mês, para cada subconjunto, de forma incremental e acumulativa. 


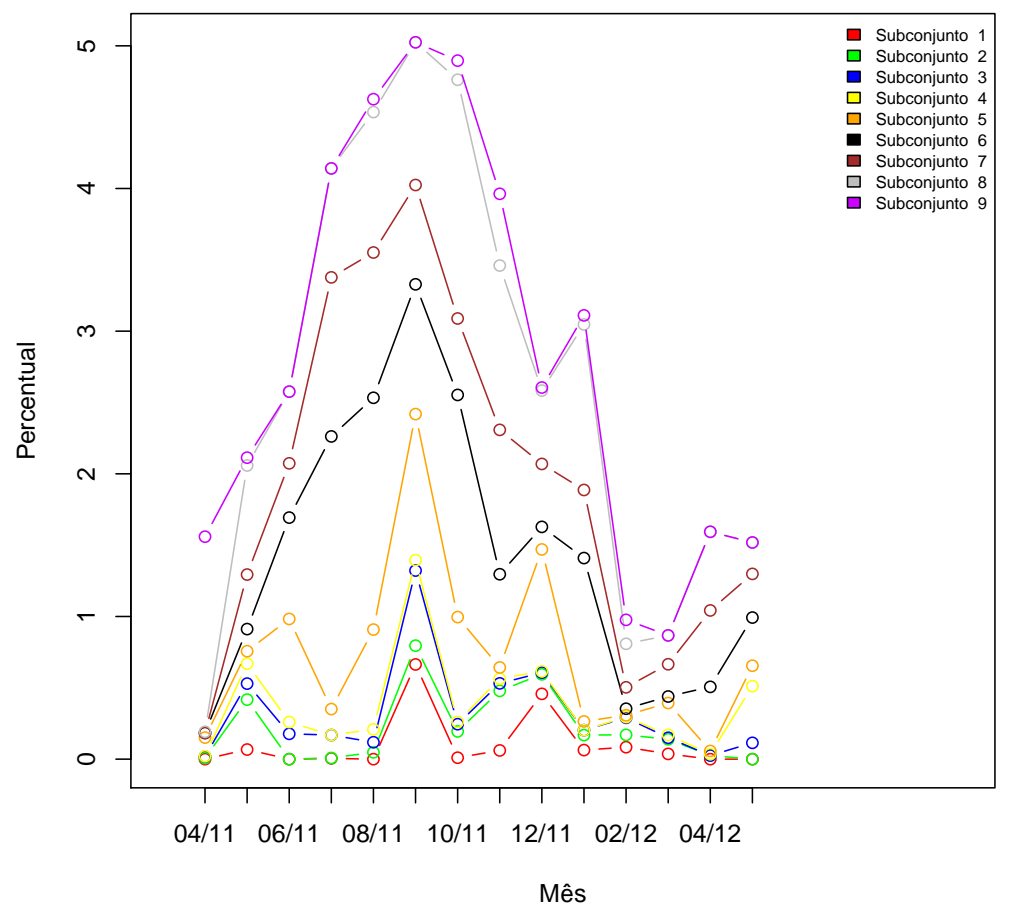

Figura A.30: Taxa de deteç̧ão de chargebacks por mês para cada subconjunto utilizando um balanceamento 9x1 na amostra de treinamento do classificador. Os resultados para cada subconjunto são incrementais para que se perceba a evolução dos resultados em relação ao peso geral da transação.

A Figura A.31 mostra a taxa de falsos alarmes por mês para cada subconjunto. 


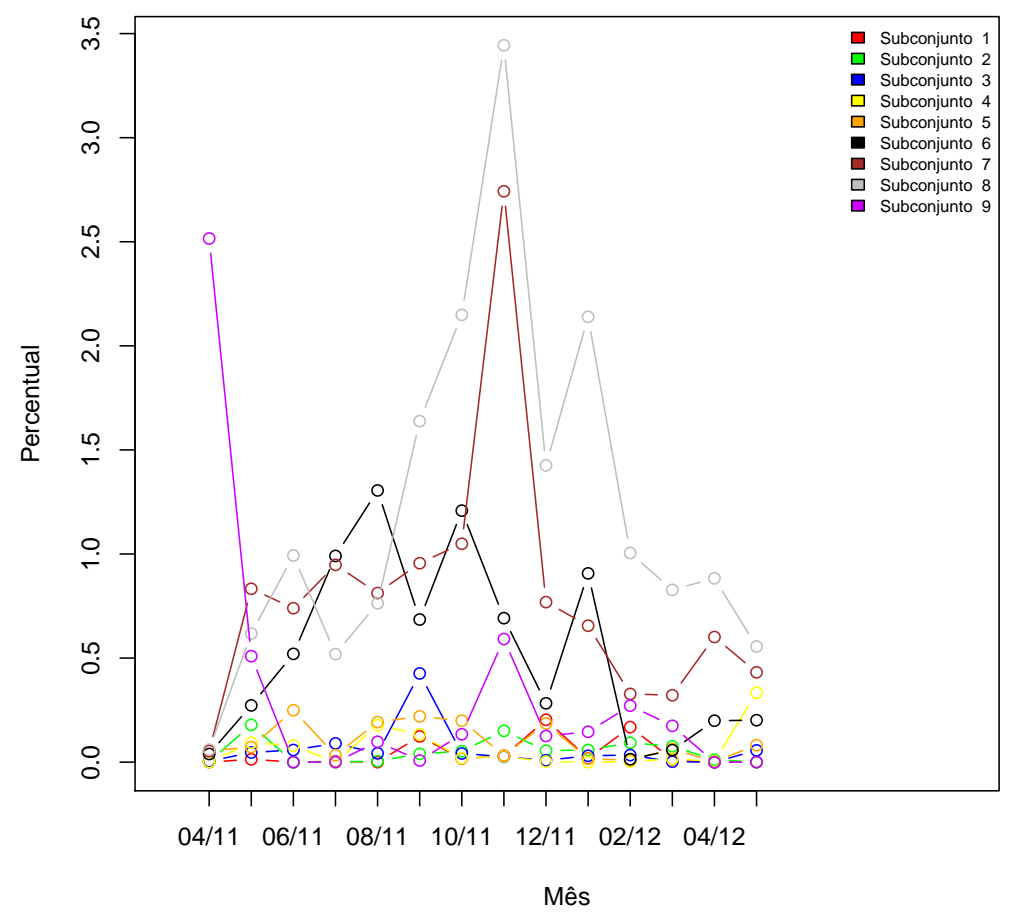

Figura A.31: Taxa de transaçôes legítimas classificadas como fraude para cada subconjunto utilizando balanceamento 9x1 na amostra de treinamento do classificador.

A Figura A.32 mostra a taxa de falsos alarmes por mês para cada subconjunto, de forma incremental e acumulativa. 


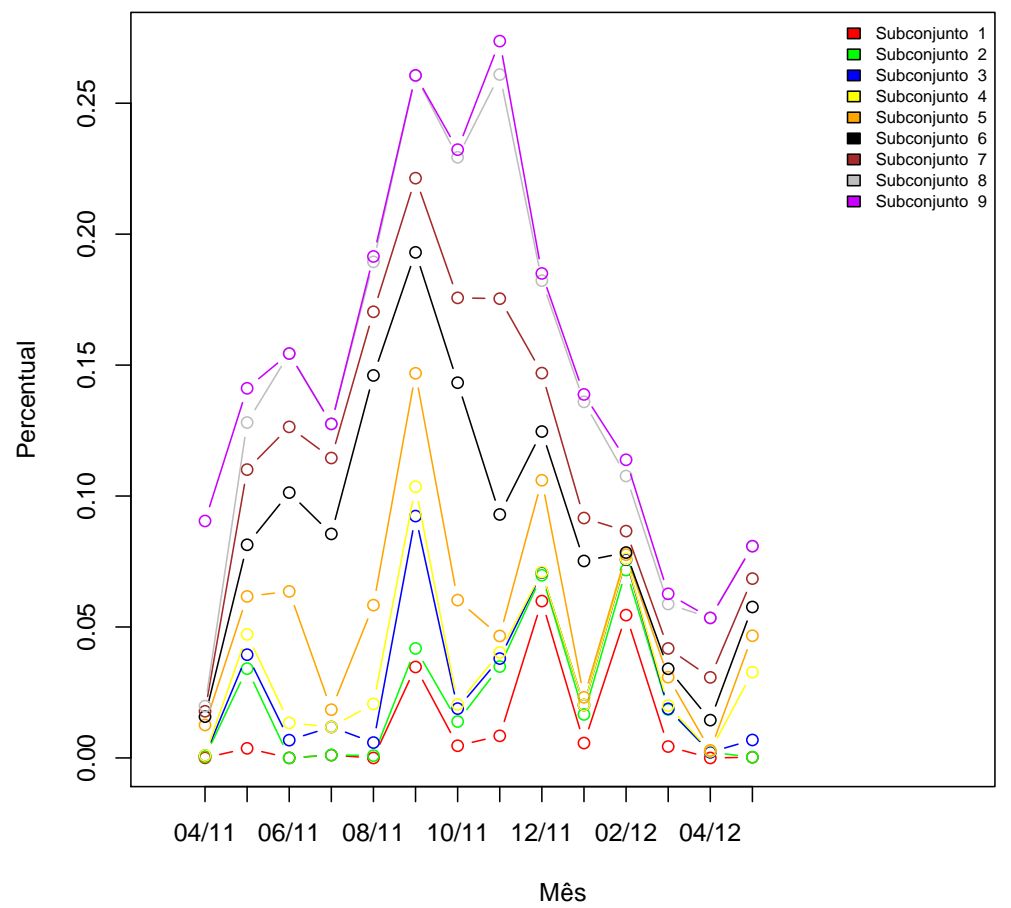

Figura A.32: Taxa de transações legítimas classificadas como fraude para cada subconjunto utilizando balanceamento 9x1 na amostra de treinamento do classificador. Os resultados para cada subconjunto são incrementais para que se perceba a evolução dos resultados em relação ao peso geral da transação. 
APÊNDICE A 


\section{Referências Bibliográficas}

Bhatla et al. (2003) Tej Paul Bhatla, Vikram Prabhu e Amit Dua. Understanding credit card frauds. Relatório técnico. Citado na pág. 4, 5, 8, 9, 12, 14, 19, 21, 27, 49

Bhattacharyya et al. (2011) Siddhartha Bhattacharyya, Sanjeev Jha, Kurian Tharakunnel e J. Christopher Westland. Data mining for credit card fraud: A comparative study. Decision Support Systems, 50(3):602-613. URL http://linkinghub.elsevier.com/retrieve/pii/ S0167923610001326. Citado na pág. 2, 4, 5, 8, 17, 18, 19

Bifet e Gavaldà (2006) Albert Bifet e Ricard Gavaldà. Learning from time-changing data with adaptive windowing, 2006. URL http://www.lsi.upc.edu/ abifet/TimevaryingE.pdf. Citado na pág. 4

Bolton e Hand (2001) Richard J. Bolton e David J. Hand. Unsupervised profiling methods for fraud detection. Credit Scoring and Credit Control VII. URL http://citeseerx.ist.psu.edu/ viewdoc/download?doi $=10 \cdot 1 \cdot 1.24 .5743 \&$ rep $=$ rep1\&type $=$ pdf. Citado na pág. 4, 5, 8, 18, 20, 33

Burges (1998) Christopher J. C. Burges. A tutorial on support vector machines for pattern recognition. Knowledge Discovery and Data Mining, 2:1-43. Citado na pág. 22, 23

Caldeira et al. (2012a) Evandro Caldeira, Gabriel Brandão, H. Campos e Adriano Pereira. Characterizing and evaluating fraud in electronic transactions. Eighth Latin America Web Congress. Citado na pág. $4,5,49$

Caldeira et al. (2012b) Evandro Caldeira, Gabriel Brandão e Adriano Pereira. Characterizing and preventing chargebacks in next generation web payment services. CASoN. Citado na pág. 4, 5, 49

Cao (2003) Lijuan Cao. Support vector machines experts for time series forecasting. Neurocomputing. Citado na pág. 23, 41

Chan e Stolfo (1998) Philip K. Chan e Salvatore J. Stolfo. Toward scalable learning with nonuniform class and cost distributions: A case study in credit card fraud detection. Proceedings of the Fourth International Conference on Knowledge Discovery and Data Mining, páginas 164-168. Citado na pág. 2, 4, 5, 14, 18, 33

Chan et al. (1999) Philip K. Chan, Wei Fan, Andreas L. Prodromidis e Salvatore J. Stolfo. Distributed data mining in credit card fraud detection. IEEE Intelligent Systems, páginas 67-74. Citado na pág. $4,5,14,17,18,21,33,49$

Chiu e Tsai (2004) Chuang-Cheng Chiu e Chieh-Yuan Tsai. A web services-based collaborative scheme for credit card fraud detection. Em IEEE International Conference on e-Technology, eCommerce and e-Service, páginas 177-181. Ieee. URL http://ieeexplore.ieee.org/lpdocs/epic03/ wrapper.htm?arnumber $=1287306$. Citado na pág. 4

CyberSource (2011) CyberSource. Online fraud report. Relatório técnico. Citado na pág. xiii, 2, 13,15 
CyberSource (2013) CyberSource. Online fraud report. Relatório técnico. Citado na pág. 1

Delamaire et al. (2009) Linda Delamaire, Hussein Abdou e John Pointon. Credit card fraud and detection techniques: a review. Banks and Bank Systems, 4(2):57-68. Citado na pág. 1, 4, 5, 8, 17, 18,33

Duman e Ozcelik (2011) Ekrem Duman e M. Hamdi Ozcelik. Detecting credit card fraud by genetic algorithm and scatter search. Expert Systems with Applications: An International Journal, 38(10):13057-13063. URL http://linkinghub.elsevier.com/retrieve/pii/S0957417411006373. Citado na pág. $4,5,17,20,21,49$

Ferdousi e Maeda (2006) Zakia Ferdousi e Akira Maeda. Unsupervised outlier detection in time series data. Em Proceedings of the 22nd International Conference on Data Engineering Workshops, páginas 51-56. ISBN 0769525717. URL http://www.inf.ufrgs.br/ alvares/ CMP259DCBD/outlier_detection_PGA.pdf. Citado na pág. 4

Gadi (2008) Manoel Fernando Alonso Gadi. Uma comparação de métodos de classificação aplicados a detecção de fraudes em cartão de crédito. Dissertação de Mestrado. Citado na pág. 4

Gadi et al. (2010) Manoel Fernando Alonso Gadi, Alair Pereira do Lago e Jorn Mehnen. Data mining with skewed data. InTech, páginas 173-188. URL http://cdn.intechweb.org/pdfs/10691. pdf. Citado na pág. xiii, $4,5,7,8$

Ganji e Mannem () Venkata Ratnam Ganji e Siva Naga Prasad Mannem. International Journal on Computer Science and Engineering. Citado na pág. 4, 5

Gutierrez-Osuna () Ricardo Gutierrez-Osuna. Intelligent sensor systems. URL http://research. cs.tamu.edu/prism/lectures/iss/iss_113.pdf. Citado na pág. 20

Guyon e Elisseeff (2003) Isabelle Guyon e André Elisseeff. An introduction to variable and feature selection. Journal ofMachine Learning Research, páginas 1157-1182. Citado na pág. 4, 5

Hand et al. (2006) David Hand, Heikki Mannila e Padhraic Smyth. Principles of Data Mining. Citado na pág. 23, 41

Hejazi e Singh (2012) Maryamsadat Hejazi e Yashwant Prasad Singh. Credit data fraud detection using kernel methods with support vector machine. Journal Of Advanced Computer Science and Technology Research, 2:35-49. Citado na pág. 4, 23

Hirata (2011) Nina S. T. Hirata. Aprendizagem computacional: Modelos, algoritmos e aplicações - avaliação de classificadores. Notas de aula, 2011. URL http://paca.ime.usp.br/mod/resource/ view.php?id $=13819$. Citado na pág. 20

Hodge e Austin (2004) Victoria J. Hodge e Jim Austin. A survey of outlier detection methodologies. Artificial Intelligence Review, 22(2):85-126. URL http://www.springerlink.com/openurl. asp?id=doi:10.1023/B:AIRE.0000045502.10941.a9. Citado na pág. 5, 19, 20, 21

Jha et al. (2012) Sanjeev Jha, Montserrat Guillen e J. Christopher Westland. Employing transaction aggregation strategy to detect credit card fraud. Expert Systems with Applications, 39:1265012657. ISSN 09574174. URL http://linkinghub.elsevier.com/retrieve/pii/S0957417412007166. Citado na pág. 4,5

Júnior et al. (2012) José Felipe Júnior, Wagner Meira Júnior e Adriano César Machado Pereira. Mineração de dados para detecção de fraudes em transações eletrônicas. Dissertação de Mestrado. Citado na pág. $1,4,5,7,8,9,12,13,14,21$

Kifer et al. (2004) Daniel Kifer, Shai Ben-david e Johannes Gehrke. Detecting change in data streams. Citado na pág. 4 
Kou et al. (2004) Yufeng Kou, Chang-Tien Lu, Sirirat Sinvongwattana e Yo-Ping Huang. Survey of fraud detection techniques. International Conference on Networking, Sensing $\& 3$ Control, páginas 749-754. Citado na pág. 5

Kumar et al. (2006) V. Kumar, M. Steinbach e P. Tan. Introduction to Data Mining. Citado na pág. 2,21

Lee e Shamoun (2013) Don Lee e Dhakwan Shamoun. Credit card fraud frau detection using hidden markov model (hmm). European Journal of Industrial and System Engineering, páginas 15-18. Citado na pág. 4,5

Lorena e Carvalho (2007) Ana Carolina Lorena e André C. P. L. F. Carvalho. Uma introdução às support vector machines. Revista de Informática Teórica e Aplicada, XIV(2). Citado na pág. xiii, 22,23

Maranzato et al. (2010a) Rafael Maranzato, Adriano Pereira e Alair Pereira Lago. Fraud detection in reputation systems in e-markets using logistic regression. Citado na pág. 5

Maranzato et al. (2010b) Rafael Maranzato, Adriano Pereira, Marden Neubert e Alair Pereira Lago. Fraud detection in reputation systems in e-markets using logistic regression and stepwise optimization. 11. Citado na pág. 5

Mishra et al. (2013) Jaba Suman Mishra, Souyashree Panda e Ashis Kumar Mishra. A novel approach for credit card fraud detection targeting the indian market. International Journal of Computer Science Issues. Citado na pág. 4, 5

Molina et al. (2002) Luis Carlos Molina, Lluís Belanche, Àngela Nebot e Jordi Girona. Feature selection algorithms: A survey and experimental evaluation. IEEE International Conference on Data Mining, páginas 306-313. URL http://ieeexplore.ieee.org/xpls/abs_all.jsp?arnumber= 1183917. Citado na pág. 5

Ngai et al. (2011) E.W.T. Ngai, Yong Hu, Y.H. Wong, Yijun Chen e Xin Sun. The application of data mining techniques in financial fraud detection: A classification framework and an academic review of literature. Decision Support Systems, páginas 559-569. URL http://linkinghub.elsevier. com/retrieve/pii/S0167923610001302. Citado na pág. 4, 5, 17

Nguyen (2008) Quang Nhat Nguyen. Machine learning: Algorithms and applications. Notas de aula, 2008. URL http://www.inf.unibz.it/〜qnhatnguyen/mlearning/slides/Evaluation.pdf. Citado na pág. 20

Panigrahi et al. (2009) Suvasini Panigrahi, Amlan Kundu, Shamik Sural e A.K. Majumdar. Credit card fraud detection: A fusion approach using dempster-shafer theory and bayesian learning. Information Fusion, páginas 354-363. URL http://linkinghub.elsevier.com/retrieve/pii/ S1566253509000141http://www.sciencedirect.com/science/article/pii/S1566253509000141. Citado na pág. 5

Phua et al. (2010) Clifton Phua, Vincent Lee, Kate Smith e Ross Gayler. A comprehensive survey of data mining-based fraud detection research. Em International Conference on Intelligent Computation Technology and Automation (ICICTA), volume 1, páginas 50-53. URL http://arxiv. org/abs/1009.6119. Citado na pág. 4, 5, 8, 17, 18, 20, 33

Raj e Portie (2011) S. Benson Edwin Raj e A. Annie Portie. Analysis on credit card fraud detection methods. International Conference on Computer, Communication and Electrical Technology, páginas 152-156. URL http://academypublisher.com/ijrte/vol02/no03/ijrte0203126128.pdf. Citado na pág. 4,5 
Sahin et al. (2013) Yusuf Sahin, Serol Bulkan e Ekrem Duman. A cost-sensitive decision tree approach for fraud detection. Expert Systems with Applications, 40:5916-5923. ISSN 09574174. URL http://linkinghub.elsevier.com/retrieve/pii/S0957417413003072. Citado na pág. 4, 5

Sebastião e Gama (2009) Raquel Sebastião e João Gama. A study on change detection methods. 14th Portuguese Conference on Artificial Intelligence. URL http://epia2009.web.ua. pt/onlineEdition/353.pdf. Citado na pág. 4

Simic (2005) Dejan Simic. Reducing fraud in electronic payment systems. The 7th Balkan Conference on Operational Research. URL http://fmi.unibuc.ro/balkan-conf/CD/Section5/ SimicDejan.pdf. Citado na pág. 4, 5

Singh et al. (2012) Gajendra Singh, Ravindra Gupta, Ashish Rastogi, Mahiraj D. S. Chandel e A. Riyaz. A machine learning approach for detection of fraud based on svm. International Journal of Scientific Engineering and Technology, 1(3):194-198. Citado na pág. 22, 23

Travaille et al. (2011) Peter Travaille, Roland M. Müller, Dallas Thornton e Jos van Hillegersberg. Electronic fraud detection in the us medicaid healthcare program: Lessons learned from other industries. Em Proceedings of the Seventeenth Americas Conference on Information Systems, páginas 1-10. URL http://doc.utwente.nl/78000/. Citado na pág. 4, 8

Vapnik (1995) Vladimir Vapnik. The Natural of Statistical Learning Theory. Springer-Verlag. Citado na pág. 21

Vapnik et al. (1997) Vladimir Vapnik, Steven E. Golowich e Alex Smola. Support vector method for function approximation, regression estimation, and signal processing. Advances in Neural Information Processin Systems. Citado na pág. 21

Weiss (2004) Gary M. Weiss. Mining with rarity: a unifying framework. ACM SIGKDD Explorations Newsletter, 6(1):7-19. URL http://dl.acm.org/ft_gateway.cfm?id=1007734\&type=pdf. Citado na pág. $4,5,17,18,36$

Wheeler e Aitken (2000) R. Wheeler e S. Aitken. Multiple algorithms for fraud detection. Knowledge-Based Systems, 13(2-3):93-99. URL http://linkinghub.elsevier.com/retrieve/ pii/S0950705100000502. Citado na pág. 4, 18

Whitrow et al. (2008) C. Whitrow, D. J. Hand, P. Juszczak, D.Weston e N. M. Adams. Transaction aggregation as a strategy for credit card fraud detection. Data Mining and Knowledge Discovery, páginas 30-55. URL http://www.springerlink.com/index/10.1007/s10618-008-0116-z. Citado na pág. $4,5,14$

Wong et al. (2012) Nicholas Wong, Pradeep Ray, Greg Stephens e Lundy Lewis. Artificial immune systems for the detection of credit card fraud: an architecture, prototype and preliminary results. Information Systems Journal, 22:53-76. ISSN 13501917. URL http://doi.wiley.com/10.1111/j. 1365-2575.2011.00369.x. Citado na pág. 4 